Utah State University

DigitalCommons@USU

$12-2008$

\title{
A Three-Dimensional, Time-Dependent Circulation Model of Utah Lake
}

Eric V. Callister

Utah State University

Follow this and additional works at: https://digitalcommons.usu.edu/etd

Part of the Environmental Sciences Commons, and the Mechanical Engineering Commons

\section{Recommended Citation}

Callister, Eric V., "A Three-Dimensional, Time-Dependent Circulation Model of Utah Lake" (2008). All

Graduate Theses and Dissertations. 86.

https://digitalcommons.usu.edu/etd/86

This Thesis is brought to you for free and open access by the Graduate Studies at DigitalCommons@USU. It has been accepted for inclusion in All Graduate Theses and Dissertations by an authorized administrator of DigitalCommons@USU. For more information, please contact digitalcommons@usu.edu.

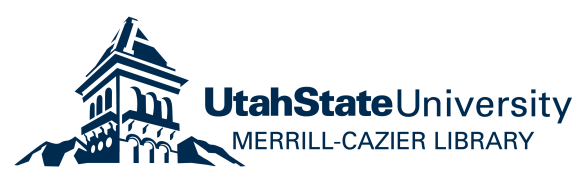




\section{A THREE-DIMENSIONAL, TIME-DEPENDENT CIRCULATION MODEL OF UTAH LAKE}

by

Eric V Callister

A thesis submitted in partial fulfillment

of the requirements for the degree

of

MASTER OF SCIENCE

in

Mechanical Engineering

Approved:

Dr. Robert E. Spall

Dr. Thomas H. Fronk

Major Professor

Committee Member

Dr. Barton L. Smith

Dr. Byron R. Burnham

Committee Member

Dean of Graduate Studies

UTAH STATE UNIVERSITY

Logan, Utah 
Copyright @ Eric V Callister 2008

All Rights Reserved 


\author{
ABSTRACT \\ by \\ Eric V Callister, Master of Science \\ Utah State University, 2008 \\ Department: Mechanical and Aerospace Engineering
}

A Three-Dimensional, Time-Dependent Circulation Model of Utah Lake

Major Professor: Dr. Robert E. Spall

Spatial and temporal variations of Utah Lake's flow field were modeled using the Estuary Lake and Computer Model from the Centre for Water Research (CWR-ELCOM) at the University of Western Australia as part of an effort to increase understanding of the lake's natural processes in order to restore the lake to its pristine, clear-water state and preserve the habitat of the June sucker, an endangered species. The model was validated using temperature measurements taken by sensors in 2007 . The water temperature was a strong function of air temperature and incident short wave radiation, and was influenced to a lesser degree by wind speed, wind direction, relative humidity, and cloud cover. The water currents were affected most strongly by wind speed and wind direction. The model also predicted the free drifting paths of June sucker larvae entering Utah Lake through the Provo and Spanish Fork Rivers between mid-April and July. 


\section{ACKNOWLEDGMENTS}

I would like to thank Dr. Robert E. Spall for his help and support in this effort. Without his invaluable advice and the time he spent answering my questions and helping me debug my simulations, this would not have been possible.

I would also like to thank my family and friends for their unwavering support and endless patience as I worked on my models and analysis. I would especially like to thank my new wife and sweetheart, Katie, for her tireless devotion and her words of motivation as I worked on this research even as we made wedding preparations, married, and settled into our new home together.

I would also like to thank the June Sucker Recovery Implementation Program and its members for their support, and wish them good fortune in their endeavors to improve the water quality of Utah Lake.

Eric V Callister 


\section{CONTENTS}

Page

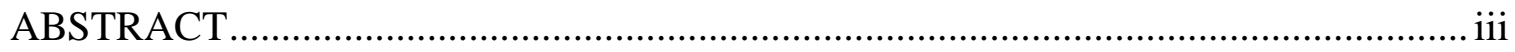

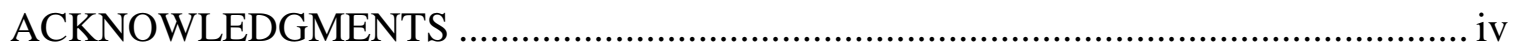

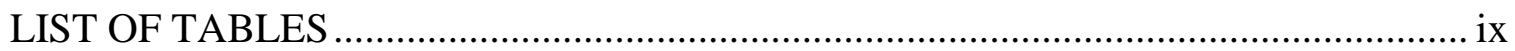

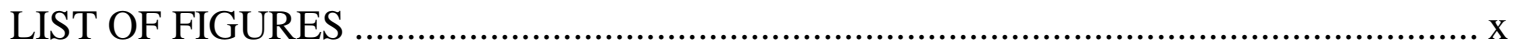

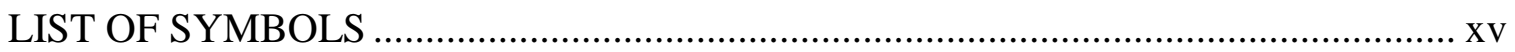

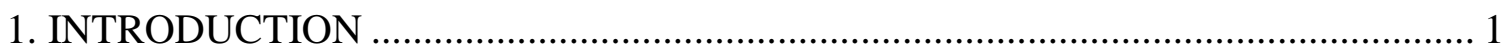

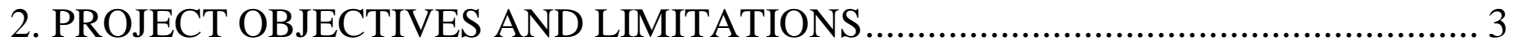

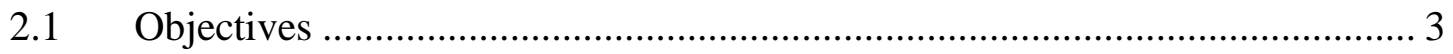

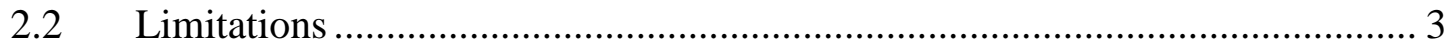

3. BACKGROUND INFORMATION ….................................................................. 5

3.1 History of Water Diversion from Utah Lake Tributaries................................ 5

3.2 History of Fish Species in Utah Lake ....................................................... 7

4. CWR-ELCOM HISTORY AND PREVIOUS APPLICATIONS ............................. 9

4.1 Modeling of Lakes Using Computational Fluid Dynamics ........................... 9

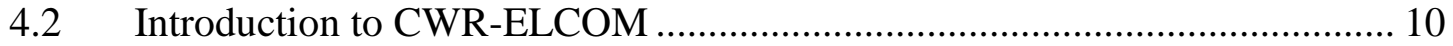

4.3 Case Studies of CWR-ELCOM Usage ..................................................... 11

4.3.1 Case Study 1: Lake Kinneret ........................................................ 11

4.3.2 Case Study 2: Lake Constance ...................................................... 13

4.3.3 Case Study 3: Great Slave Lake....................................................... 14

4.4 Justification for CWR-ELCOM Usage on Utah Lake Model........................ 16

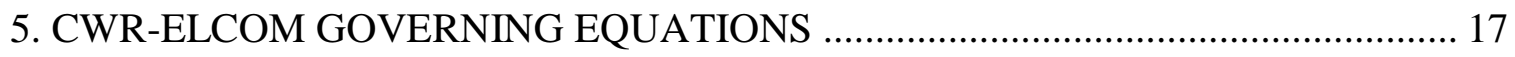

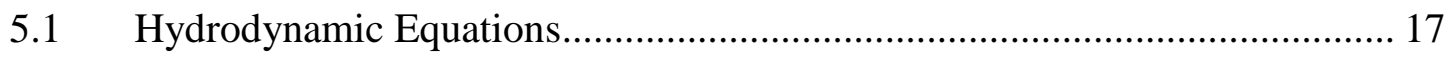

5.1.1 Reynolds-Averaged Navier-Stokes Equations.............................. 17 


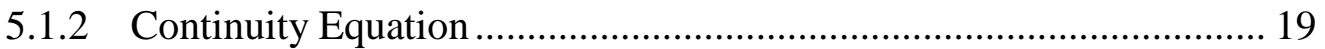

5.1.3 Scalar Transport Equation......................................................... 19

5.1.4 Free-Surface Wind Shear ........................................................ 19

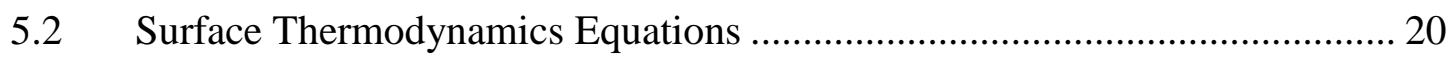

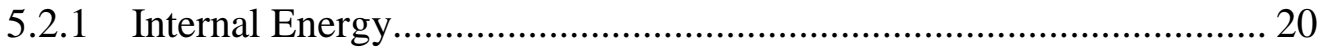

5.2.2 Non-Penetrative Long Wave Radiation ......................................... 21

5.2.3 Penetrative Short Wave Radiation ................................................... 21

5.2.4 Sensible Heat Transfer .................................................................... 22

5.2.5 Evaporative Heat Loss .................................................................. 22

6. CWR-ELCOM NUMERICAL APPROACH .......................................................... 24

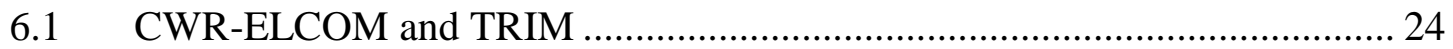

6.2 Numerical Implementation of Governing Equations ................................... 24

6.2.1 Grid Characteristics and Grid Stencil ........................................ 25

6.2.2 Surface Heating/Cooling ....................................................... 25

6.2.3 Mixing of Scalar Concentrations and Momentum........................... 27

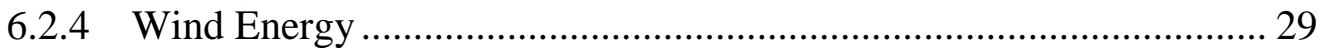

6.2.5 Free-Surface Evolution and Velocity Field .................................. 30

6.2.6 Horizontal Diffusion of Momentum ................................................. 30

6.2.7 Hybrid Advective Scheme for Momentum .................................... 30

6.2.8 Advection and Horizontal Diffusion of Scalars ............................... 32

6.3 Time Step Limitations Imposed by the Numerical Methods ........................ 33

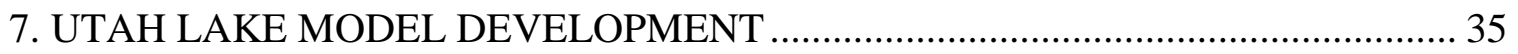

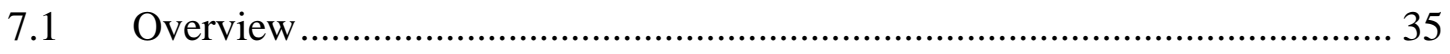

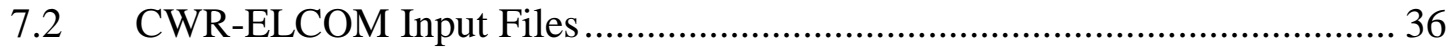

7.2.1 Components of CWR-ELCOM Program .......................................... 36

7.2.2 Input Files Required for a Typical Simulation ................................. 37

7.2.3 Matlab ${ }^{\circledR}$ Usage in the Utah Lake Model ......................................... 39

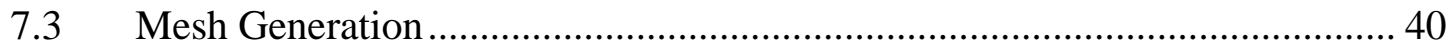

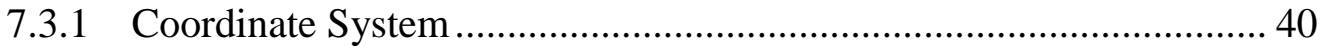

7.3.2 Digitizing Lake Boundaries and Contours...................................... 41

7.3.3 Meshing Through Interpolation ..................................................... 44

7.3.4 Creating the Bathymetry File ................................................... 45

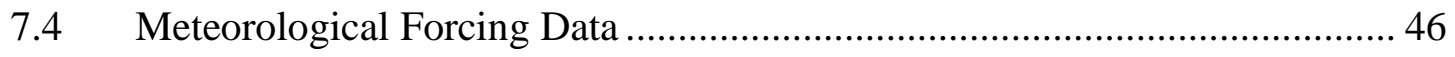




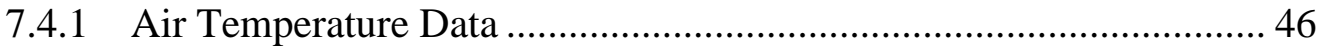

7.4.2 Atmospheric Pressure ............................................................... 50

7.4.3 Relative Humidity ................................................................. 50

7.4.4 Cloud Cover ............................................................................... 54

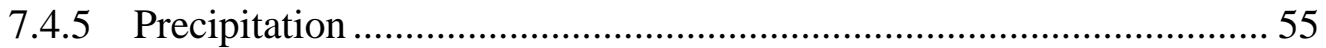

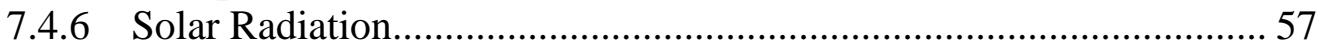

7.4.7 Wind Speed and Direction ............................................................ 59

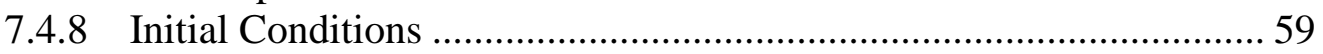

7.4.9 Creating the Meteorological Data File ........................................... 60

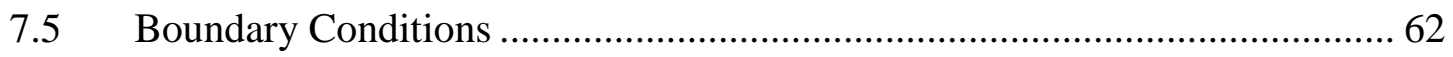

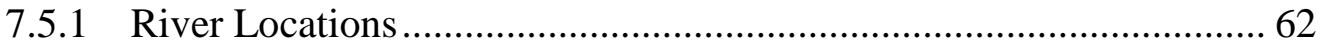

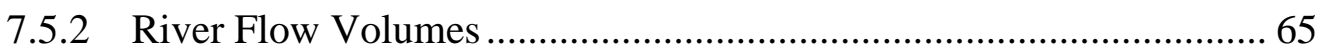

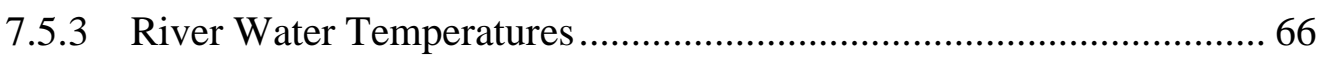

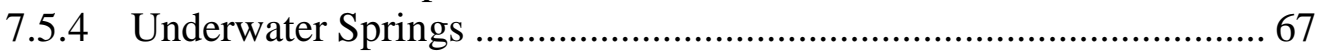

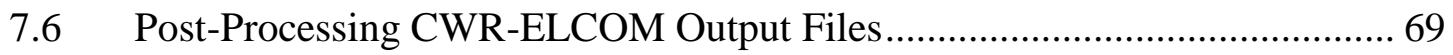

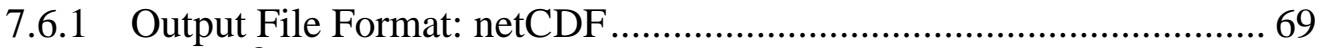

7.6.2 Matlab ${ }^{\circledR}$ Scripts ...................................................................... 70

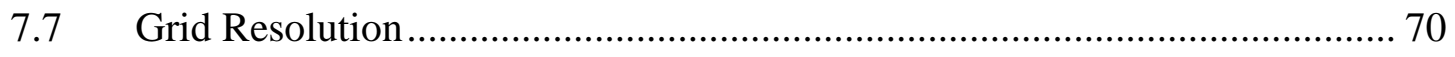

7.7.1 Mesh Size and Temperature Resolution ........................................ 71

7.7.2 Mesh Size and Velocity Component Resolution ............................. 73

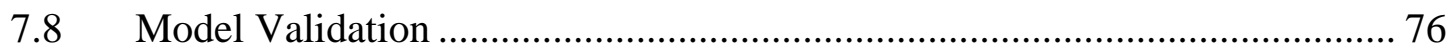

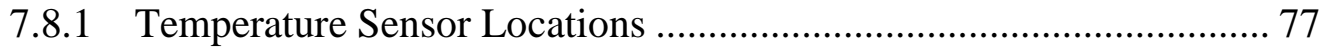

7.8.2 Plots of Actual vs. Simulated Temperatures .................................. 77

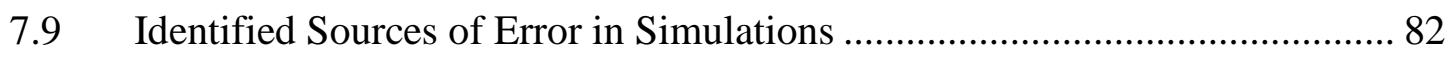

8. UTAH LAKE FLOW FIELD AND TEMPERATURE PATTERNS ........................ 85

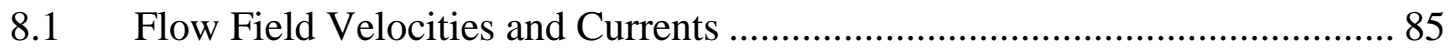

8.1.1 Graphical Analysis Tools for Velocities and Currents ..................... 85

8.1.2 Visible Features in Flow Field .................................................... 86

8.2 Flow Field Temperature Variations and Distribution ................................ 90

8.2.1 Graphical Analysis Tools for Water Temperature............................. 90

8.2.1 Notable Temperature Characteristics............................................... 91 


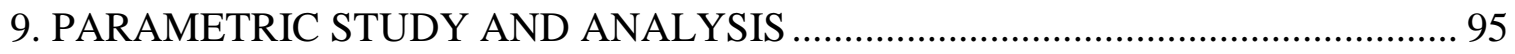

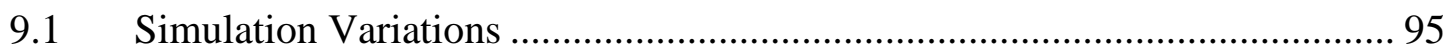

9.1.1 Model Parameters ...................................................................... 96

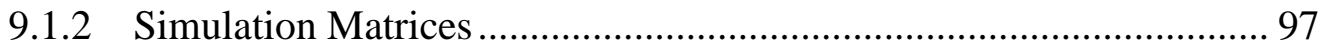

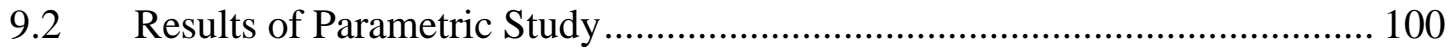

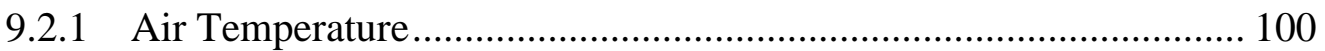

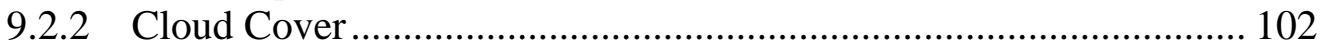

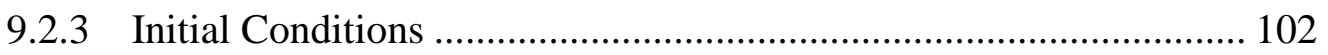

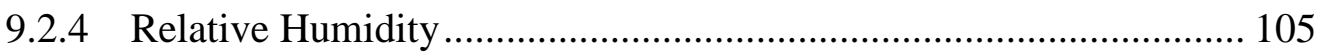

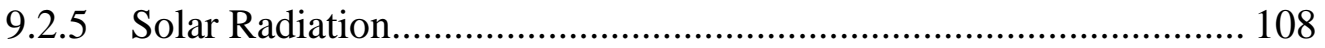

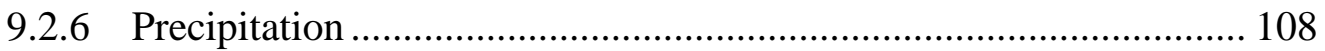

9.2.7 River Inflow Rates ................................................................... 110

9.2.8 River Outflow Rates ................................................................. 110

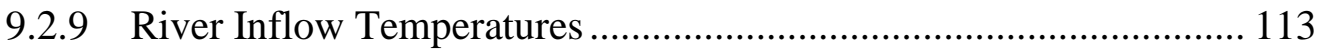

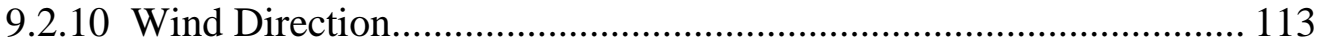

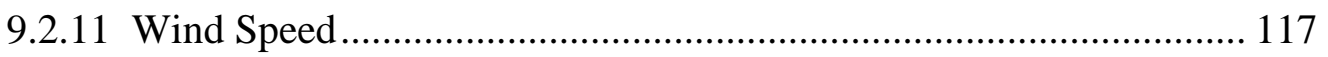

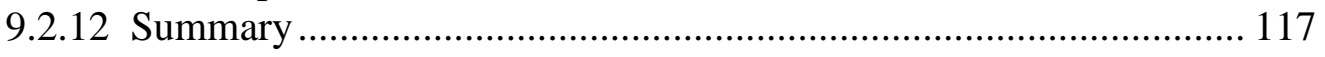

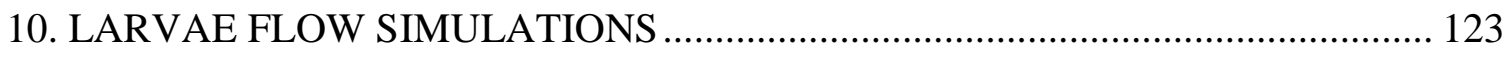

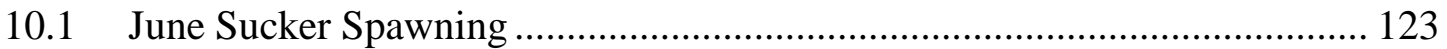

10.2 Larvae Flow Inclusion in CWR-ELCOM.............................................. 123

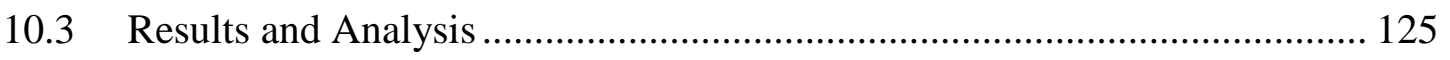

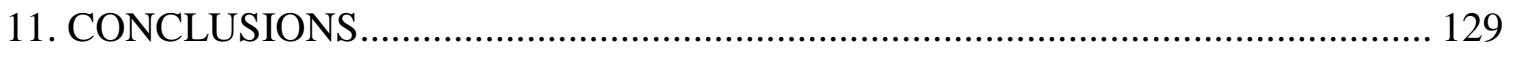

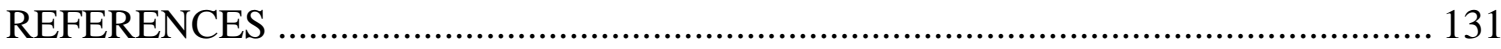

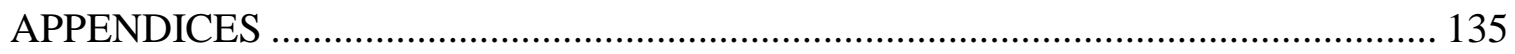

Appendix A: Provo River Larvae Drifting Paths................................................. 136

Appendix B: Spanish Fork River Larvae Drifting Paths ...................................... 140 


\section{LIST OF TABLES}

Table

7.1 Utah Lake Regional Air Temperatures (in ${ }^{\circ} \mathrm{C}$ ) .................................................. 47

7.2 Monthly Precipitation for Utah Lake Region (in $\mathrm{cm}$ ) ................................... 56

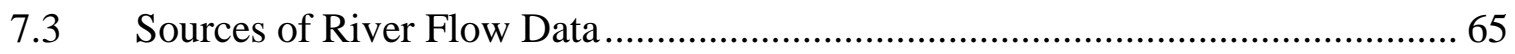

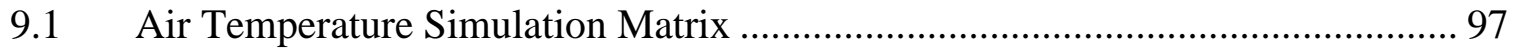

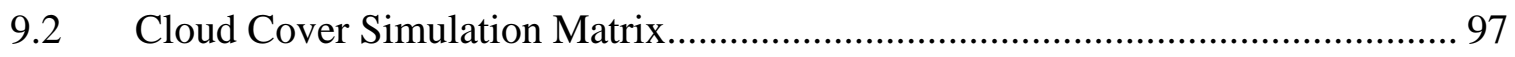

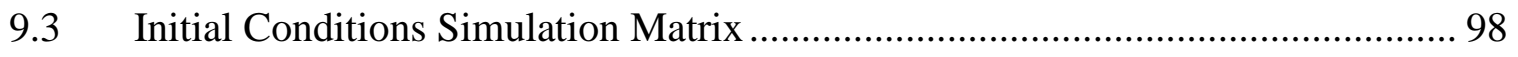

9.4 Relative Humidity Simulation Matrix ......................................................... 99

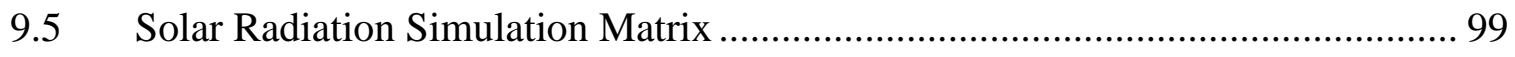

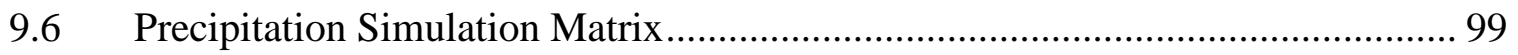

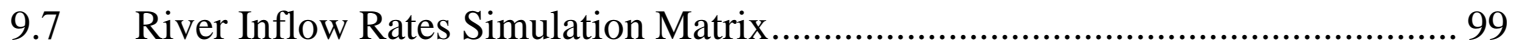

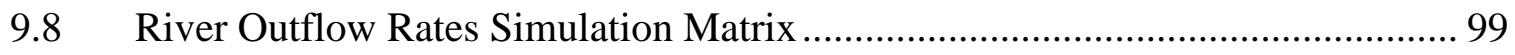

9.9 River Inflow Temperatures Simulation Matrix.............................................. 99

9.10 Wind Direction Simulation Matrix .......................................................... 100

9.11 Wind Speed Simulation Matrix ........................................................... 100

10.1 Larvae Drift Simulation Matrix ................................................................ 124 


\section{LIST OF FIGURES}

Figure

Page

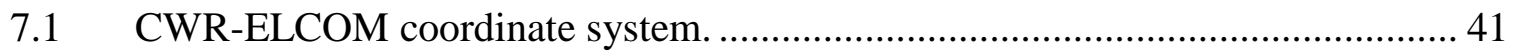

7.2 Utah Lake map from Heckmann [3] .................................................... 42

Fish-n-Map Company's map of Utah Lake. .................................................... 43

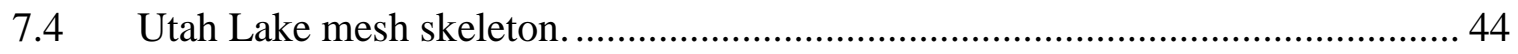

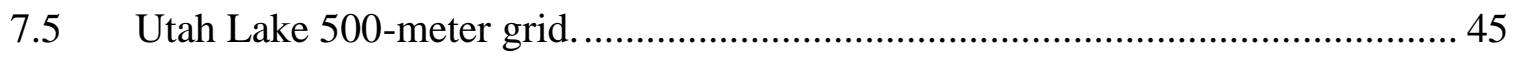

7.6 Sinusoidal approximation for daily air temperatures.................................... 48

7.7 Interpolated daily temperatures for the entire year.................................... 51

7.8 Interpolated daily temperatures for the summer months. ............................. 52

7.9 Magnified view of interpolated daily temperatures..................................... 53

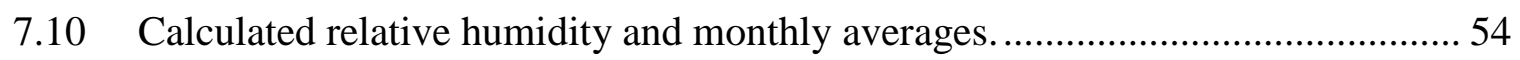

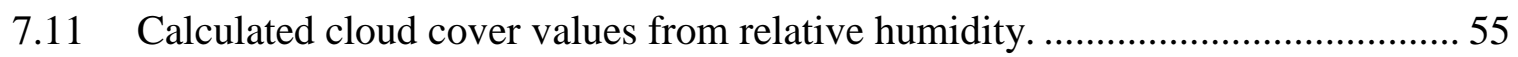

7.12 Interpolated rainfall values and average monthly values................................ 57

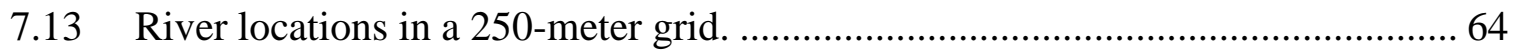

7.14 Interpolated volumetric flow rates for Utah Lake tributaries. ........................... 66

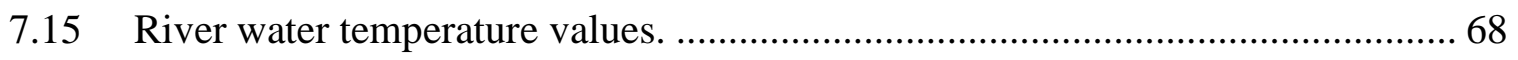

7.16 Simulation temperature results at Jordan sensor location: entire simulation grid

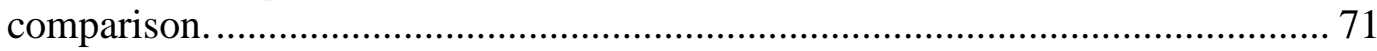

7.18 Simulation temperature results at Jordan sensor location: magnified view 2...... 72

7.17 Simulation temperature results at Jordan sensor location: magnified view $1 \ldots \ldots . .72$

7.19 $U$-velocity components at Bird Island sensor location. ................................. 73

7.21 $U$-velocity components at South American Fork sensor location. ...................... 74

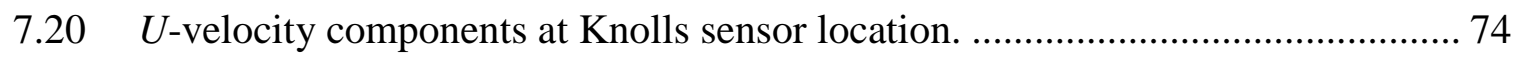


7.22 $V$-velocity components at Lincoln sensor location. ......................................... 75

7.23 $V$-velocity components at Provo Bay sensor location...................................... 75

$7.24 V$-velocity components at Saratoga sensor location.......................................... 76

7.25 Temperature sensor locations in a 500-meter grid...................................... 78

7.26 Actual vs. simulation temperatures at Bird Island sensor location..................... 79

7.28 Actual vs. simulation temperatures at Saratoga sensor location......................... 80

7.27 Actual vs. simulation temperatures at Goshen sensor location............................ 80

7.29 Complete data set for temperature sensor at Saratoga location. ......................... 81

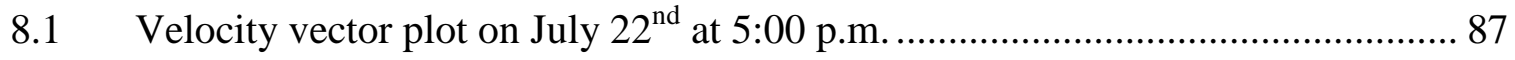

8.2 $U$-velocity component at South Spring sensor location.................................. 87

8.3 $\quad V$-velocity component at South Spring sensor socation.................................. 88

8.4 Primarily horizontal flow in southern horn of Utah Lake................................ 89

8.5 Independence of Provo Bay currents from lake currents................................ 89

8.6 Diverging currents on east side of Utah Lake............................................. 90

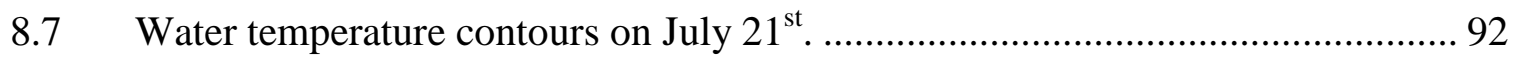

8.8 Representative plot of temperature vs. time. ........................................... 92

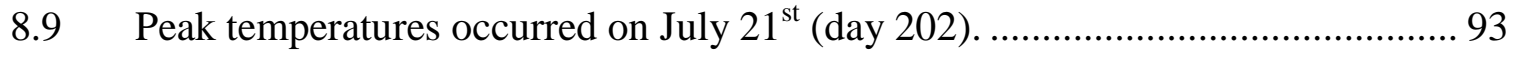

8.10 Plot of temperature vs. time at Bird Island sensor location. ................................. 94

8.11 Plot of temperature vs. time at Provo Bay sensor location............................... 94

9.1 Effect of air temperature variations on water temperature. ............................ 101

9.2 Effect of air temperature variations on $u$-velocity component. ...................... 101

9.3 Effect of air temperature variations on $v$-velocity component............................ 102

9.4 Effect of cloud cover on water temperature.............................................. 103

9.5 Effect of cloud cover on $u$-velocity component........................................ 103 


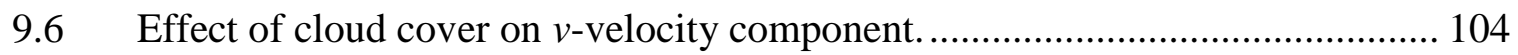

9.7 Effect of initial conditions on temperature. …............................................. 104

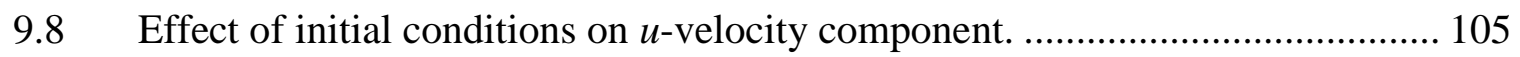

9.9 Effect of initial conditions on $v$-velocity component.................................. 106

9.10 Effect of relative humidity on water temperature....................................... 106

9.11 Effect of relative humidity on $u$-velocity component................................. 107

9.12 Effect of relative humidity on $v$-velocity component. .................................. 107

9.13 Effect of solar radiation on water temperature. ............................................ 108

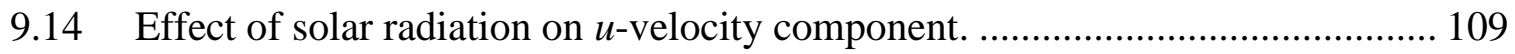

9.15 Effect of solar radiation on $v$-velocity component..................................... 109

9.16 Effect of precipitation on water temperature. ........................................... 110

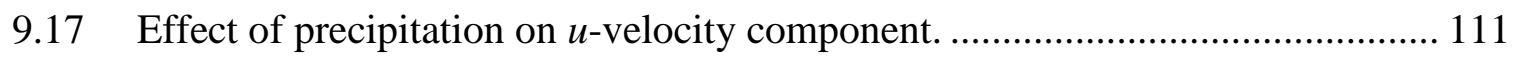

9.18 Effect of precipitation on $v$-velocity component. ....................................... 111

9.19 Effect of river inflow rate on water temperature. ....................................... 112

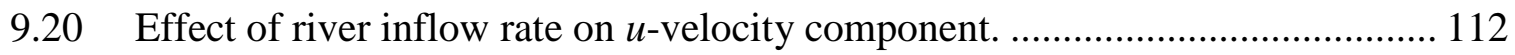

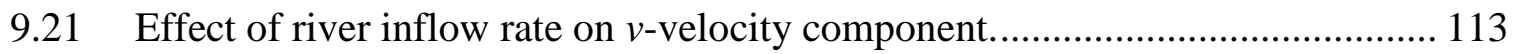

9.22 Effect of river outflow rate on water temperature. ...................................... 114

9.23 Effect of river outflow rate on $u$-velocity component. .................................. 114

9.24 Effect of river outflow rate on $v$-velocity component................................. 115

9.25 Effect of river inflow temperature on water temperature. .............................. 115

9.26 Effect of river inflow temperature on $u$-velocity component. ......................... 116

9.27 Effect of river inflow temperature on $v$-velocity component........................... 116

9.28 Effect of wind direction on water temperature: west shore. ............................ 118

9.29 Effect of wind direction on water temperature: east shore. ........................... 118 
9.30 Effect of wind direction on $u$-velocity component: west shore. ...................... 119

9.31 Effect of wind direction on $u$-velocity component: east shore. ....................... 119

9.32 Effect of wind direction on $v$-velocity component: west shore. ....................... 120

9.33 Effect of wind direction on $v$-velocity component: east shore. ....................... 120

9.34 Effect of wind speed on water temperature. ............................................. 121

9.35 Effect of wind speed on $u$-velocity component. ....................................... 121

9.36 Effect of wind speed on $v$-velocity component........................................... 122

10.1 Free drifting path of a June sucker larvae entering Utah Lake through the Provo River on May 13................................................................................. 126

10.2 Plot of depth vs. time for a June sucker larvae entering Utah Lake through the Provo River on May 13.................................................................... 126

10.3 Free drifting path of a June sucker larvae entering Utah Lake through the Spanish

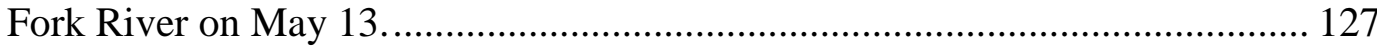

10.4 Plot of depth vs. time for a June sucker larvae entering Utah Lake through the Spanish Fork River on May 13............................................................. 127

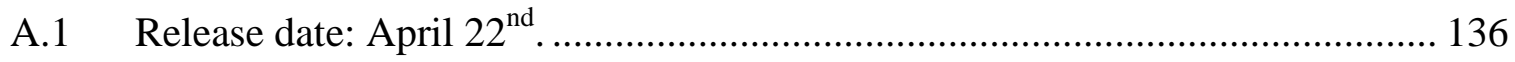

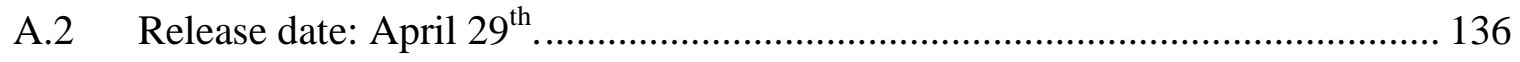

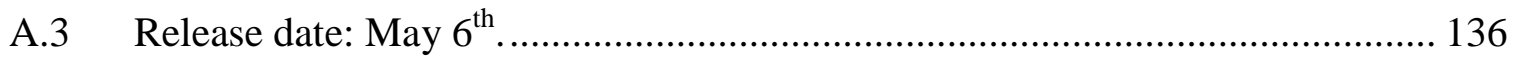

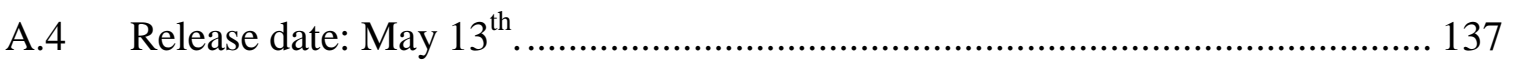

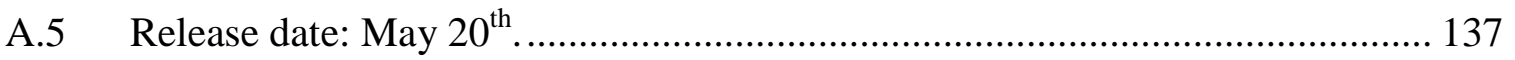

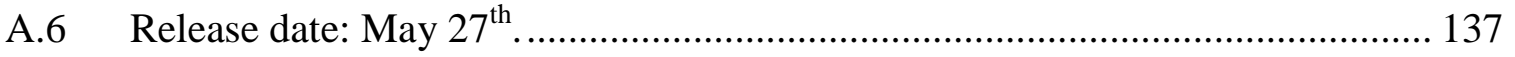

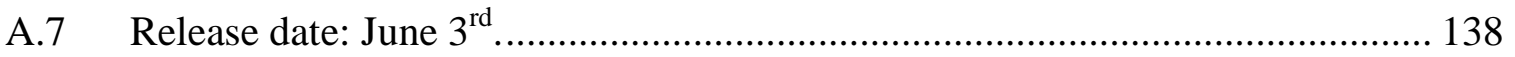

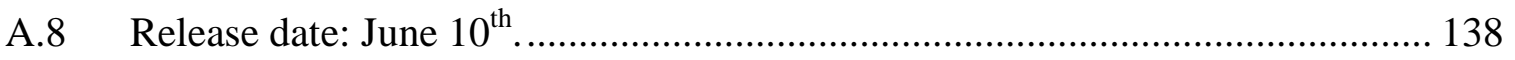

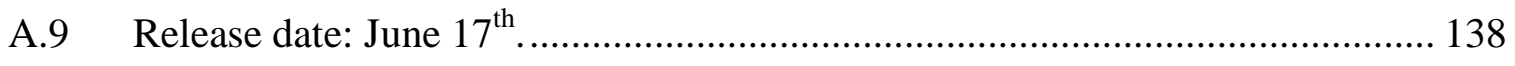

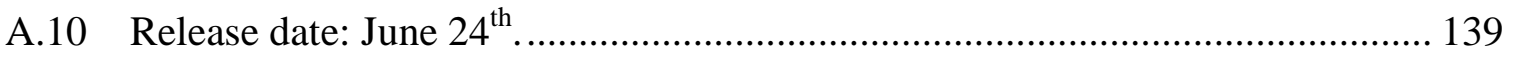

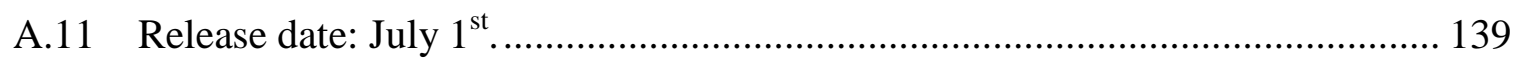




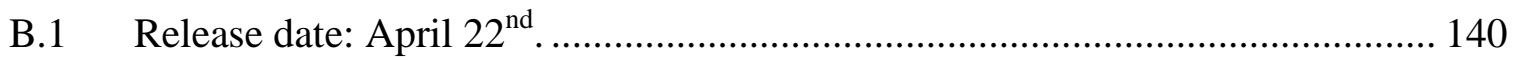

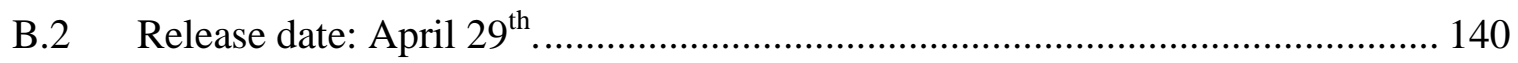

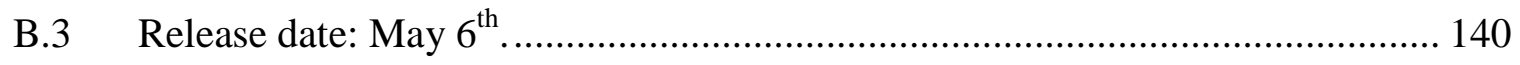

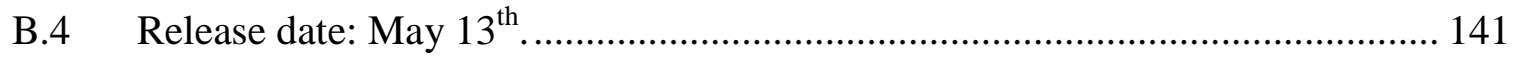

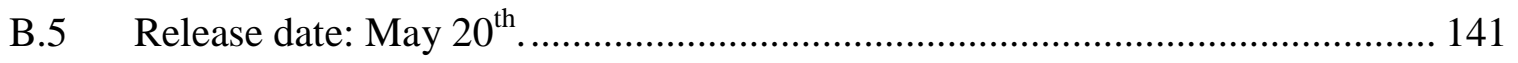

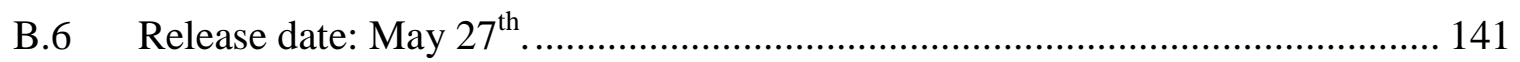

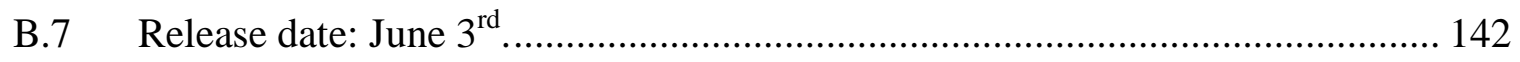

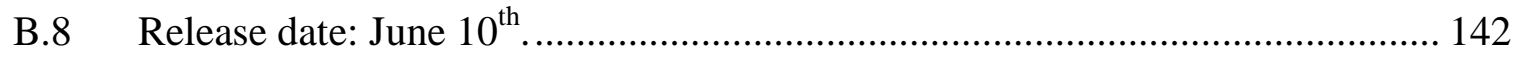

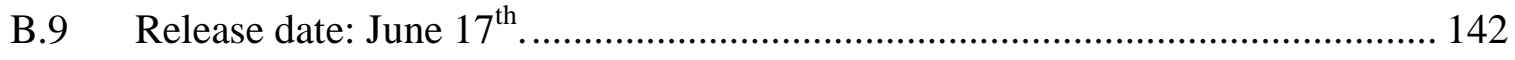

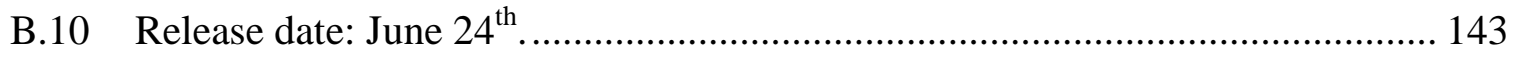

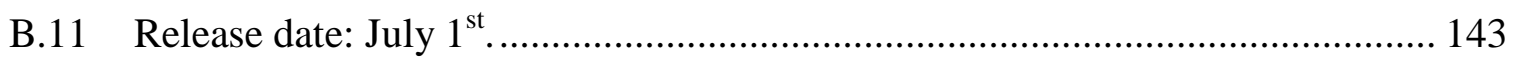




\section{LIST OF SYMBOLS}

$\begin{array}{ll}a_{t} & \text { atmospheric transmission term } \\ b & \text { water column depth } \\ C & \text { scalar concentration } \\ C_{a} & \text { fraction of solar radiation not absorbed by clouds } \\ C_{\text {cloud }} & \text { fractional cloud cover } \\ C F L_{a} & \text { advective Courant-Friedrichs-Lewy condition } \\ C F L_{b} & \text { baroclinic Courant-Friedrichs-Lewy condition } \\ c_{p} & \text { specific heat of the water at constant pressure } \\ C_{H} & \text { bulk transfer coefficient for sensible heat } \\ C_{W} & \text { bulk transfer coefficient for evaporative heat } \\ C_{1} & \text { annual mean temperature of Utah Lake region } \\ C_{10} & \text { bulk wind stress coefficient for wind values at 10 meters } \\ d & \text { depth below free surface } \\ D & \text { effective depth } \\ D(t) & \text { average daily temperature as a function of time (continuous } \\ D_{\text {av }}(t) & \text { function) } \\ E_{\text {drag }} & \text { average daily temperature (from discrete data) } \\ E_{r e q} & \text { bottom energy input } \\ e_{\text {sat }} & \text { energy required to mix adjacent layers in a water column } \\ E_{\text {shear }} & \text { saturated vapor pressure } \\ E_{\text {wind }} & \text { coriolis constant } \\ f & \end{array}$




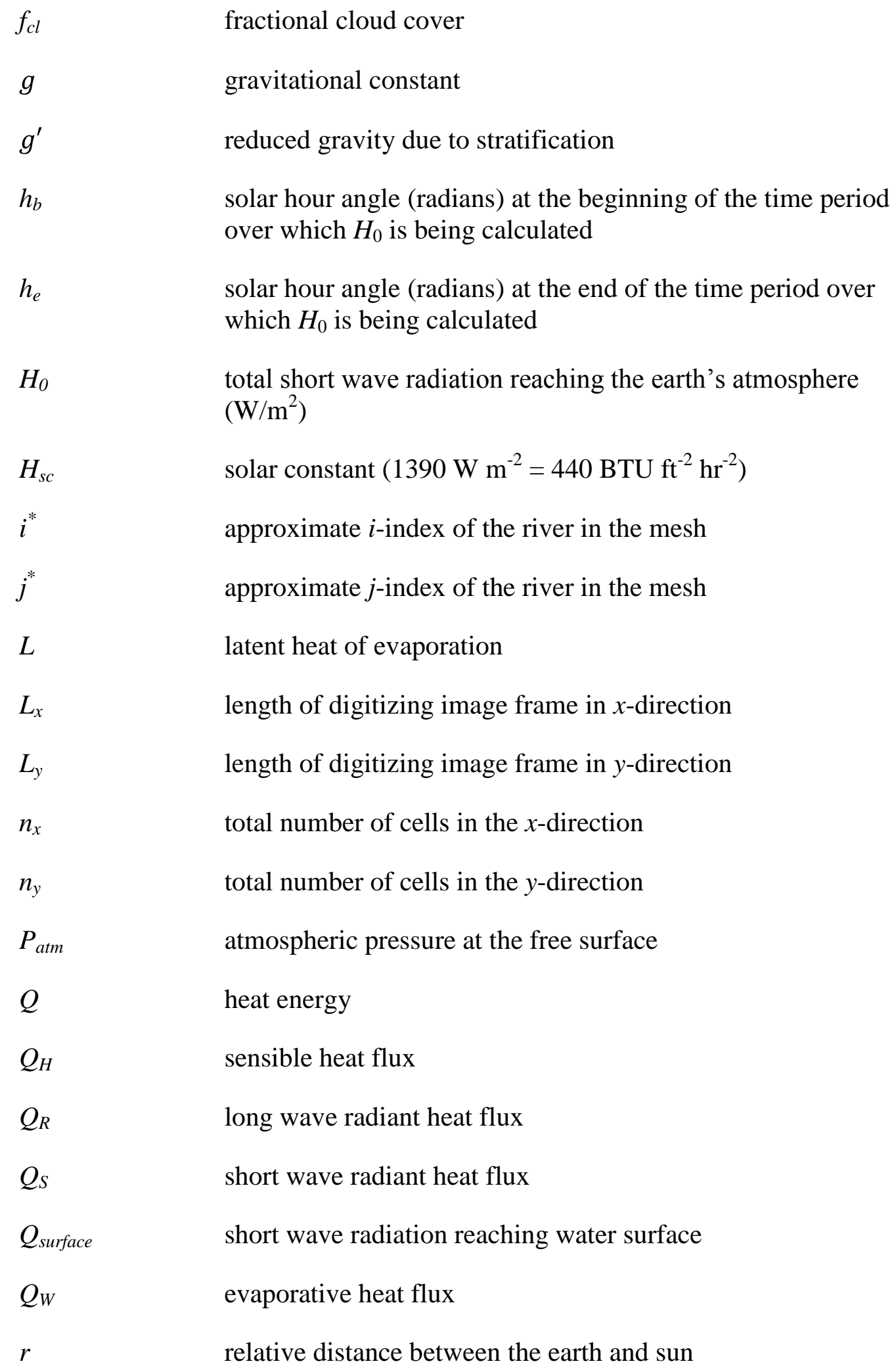




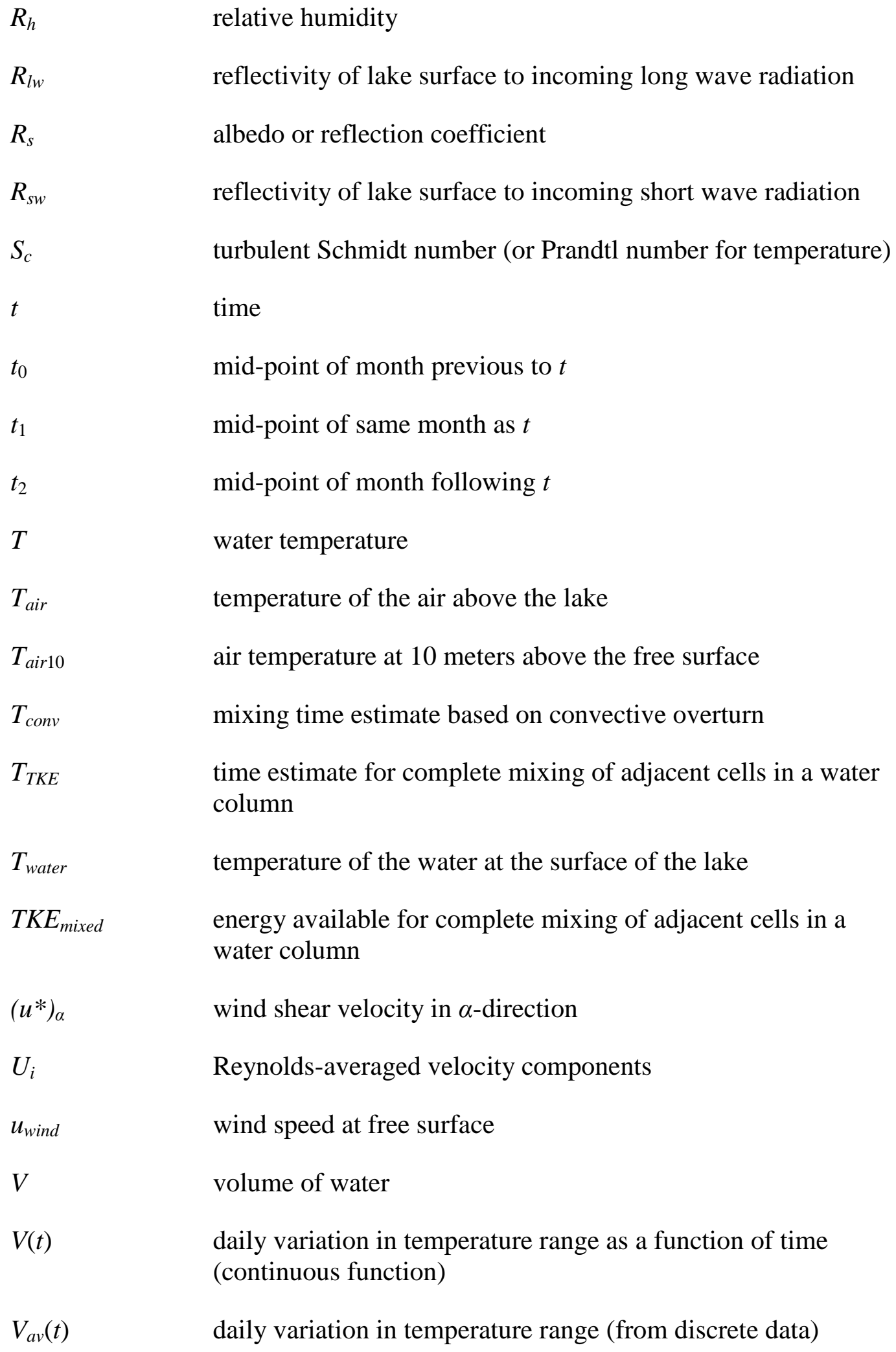


vertical velocity of air

vector wind speed in $\beta$-direction

spacial dimensions

$x$-coordinate of river found using digitizing software

$y$-coordinate of river found using digitizing software

depth variable

depth of density anomaly

depth of individual grid layers

annual temperature variation phase angle

variable for calculating cloud cover

daily temperature variation phase angle

correction factor for diurnal exposure to the radiation flux

extinction coefficient

declination

emissivity of the air above the lake

emissivity of the water at the surface of the lake

two-component permutation tensor

Reynolds-averaged free surface height

mixing fraction

latitude (degrees)

diffusion components

molecular viscosity components

density anomaly (i.e. the difference between the in situ density and the reference density 
$\rho_{\text {air }}$

$\rho_{\text {water }}$

$\rho_{0}$

$\sigma$

$\sigma_{c l}$ air density at free surface

water density

reference density

Stefan-Boltzmann constant

air pressure relative to the surface pressure 


\section{CHAPTER 1}

\section{INTRODUCTION}

Utah Lake is the largest freshwater lake in the state of Utah and plays a vital role in the region's ecosystem. The lake strongly influences the temperature and moisture content of the air in the region, acts as a storage basin for agricultural irrigation water, provides wetlands that are an important stopover and nesting area for over 200 species of migratory birds, and is used for recreational purposes by those living in Utah Valley. However, the ecology of Utah Lake has transformed over time as a result of a growing human population in the region and the introduction of non-native fish. As a result, some native species are now extinct while the survival of others, like the June Sucker, are now at risk.

Utah Lake has a surface area of approximately 391 square kilometers (151 square miles) and contains about $1073 \times 10^{6} \mathrm{~m}^{3}$ (870,000 acre-feet) of water. Despite its large size, however, it is classified as a shallow lake. Its maximum depth is 4.3 meters (14 feet), and its average depth is 2.74 meters (9.6 feet) [1]. Shallow lakes such as Utah Lake are typically found in one of two possible, stable ecological states. The first, a clear water state, is characterized by an abundance of aquatic plants along the lakebed and a water condition that allows sunlight to reach the bottom of the lake. The second, a turbid state, is characterized by large amounts of phytoplankton and suspended sediment that prevent the sun's rays from reaching the lakebed. The clear water state is considered to be the pristine state for shallow lakes. While originally in a clear water state, Utah Lake has gradually transitioned to a turbid state. 
As a result of this change in the water condition and plant life in Utah Lake, several native fish species have struggled to survive. The June sucker, which once had populations numbering in the millions in the early 1800 's, is now on the endangered species list and has a natural population of less than 1000 today [2]. The Bonneville cutthroat trout, the original predator fish in the ecosystem of Utah Lake, and the Utah Lake sculpin, a bottom-dwelling species, both became extinct in the 1930's. The last collected specimens of each were taken in 1932 and 1928, respectively [2].

In response to the threat of extinction of the June sucker, organizations have been formed to determine ways to improve the ecology of Utah Lake and restore it, if possible, to its pristine, clear-water state. One of these groups, the June Sucker Recovery Implementation Program (JSRIP), combines members of multiple agencies and with a variety of backgrounds into one cohesive group.

It was proposed that, as part of the JSRIP's efforts to understand the ecology of Utah Lake, a virtual model of the lake be created to predict circulation patterns and temperature distributions over time. This document contains details of the development of the model, including background information on the software package used, information on the data sources for the model inputs, model validation using actual temperature data, and identification of the primary forcing parameters. 
CHAPTER 2

PROJECT OBJECTIVES AND LIMITATIONS

\subsection{Objectives}

The Utah Lake modeling effort had the following objectives:

1) Predict water circulation patterns over time.

2) Predict temperature distributions in the lake over time.

3) Predict the free drifting path that June Sucker larvae follow as they flow into the lake through the Provo and Spanish Fork Rivers tributaries.

4) Determine the influence and effect of key controlling parameters such as wind speed, air temperature, etc., on the water circulation patterns and temperature distributions.

In order to accomplish the above stated objectives and accurately reflect possible variations in physical conditions, different values were used for the relevant forcing functions. These variations are listed and discussed in further detail in Section 9.1.1. Multiple grid sizes were also used to show solution convergence.

\subsection{Limitations}

It should be noted, however, that while the model does generally predict the circulation patterns and water temperatures over time, it should not be expected to give exact conditions at any given time in the solution interval. Small variations between the model and actual water flow conditions will exist. This is due to the highly nonlinear nature of the Navier-Stokes equations upon which the model is based (see Section 5.1.1) and the impact of unpredictable extreme natural events such as storms, forest fires, etc. In 
addition, annual variations in precipitation, regional temperatures, and river flow volume and temperatures will affect the state of Utah Lake.

Instead of making exact predictions of lake conditions at a specific time, the model is useful in generally characterizing the direction and velocity of water currents in Utah Lake. It also provides a way to predict general temperature distributions over time. In addition, the model identifies and determines the relative importance and influence of the external forcing functions. Finally, it is useful in determining the general impact of changes in other key parameters on the circulation patterns, temperature distributions, and larvae drift paths. 


\section{CHAPTER 3}

\section{BACKGROUND INFORMATION}

A summary of significant events that have affected the current state of Utah Lake will be presented here. For further details on these events and others, please see Great Basin Naturalist Memoirs Number 5, Utah Lake Monograph [3].

\subsection{History of Water Diversion from Utah Lake Tributaries}

Mormon pioneers came to the region in the mid 1800's and began diverting water from Utah Lake's tributaries for agricultural purposes. As the population increased over time, larger amounts of water were required to sustain the additional acres of cultivated land. By 1869, five major ditches had been built by the Provo River Company, and the American Fork River had four additional major canals [1].

In addition to the diversion for agricultural purposes, several dams on the main tributaries of Utah Lake were built to create reservoirs. By 1910, a total of 14 small reservoirs had been built along the Provo River. Larger reservoirs were built in later years. For example, the Deer Creek Reservoir, finished in 1941, provided hydroelectric power generation and irrigation water storage in the mountains above Provo [1]. In 1992, the Jordanelle Reservoir, located several miles above the Deer Creek Reservoir, was finished, further diverting and storing water that otherwise would have flowed down the Provo River to Utah Lake.

In 1872 a dam was constructed on the north end of Utah Lake at the Jordan River, the lake's principal outlet, to increase the lake's storage capacity and try to maintain its water at a fairly constant level from year to year [1]. However, due to annual fluctuations 
in precipitation, evaporation rates, and the amount of water diverted to reservoirs along Provo River and for irrigation, Utah Lake's water level varied considerably from year to year.

These variations in inflow, combined with periods of drought, have drastically impacted the plant and animal species that live in Utah Lake. In the 1890's, low precipitation levels combined with irrigation of crops dramatically lowered the lake level, and thousands of tons of native fish were trapped in shallower areas. These fish eventually died once the remaining water in those areas dried up, leaving them on dry ground. Another drought struck the area in the 1930's, and the average water depth in Utah Lake was reduced to only one foot. During both droughts, vegetation that had previously been covered with water withered and dried in the summer sun [2]. Because of the low water levels, the sun heated the remaining water to much higher temperatures, stimulating the growth of undesirable phytoplankton and bacteria. Once Utah Lake eventually refilled, the lack of vegetation and low water levels allowed the incoming water to stir up sediment, providing further impetus in the lake's transition from a clear water to a turbid water state.

In addition to the impact that the construction of the reservoirs, canals, and ditches had on Utah Lake's water levels, the ability of the fish species to reproduce was diminished. Those fish that traveled upriver to spawn every year, like the June Sucker, found that the dams and irrigation diversions constricted their passage and limited the length of river available to them for spawning. Many of these fish wandered into canals and ditches and were swept onto farmers' fields [1]. Those fish larvae that did hatch still 
had to successfully navigate the river downstream to find their way safely down to Utah Lake.

\subsection{History of Fish Species in Utah Lake}

Before the mid 1800's, Utah Lake was largely unaffected by human interaction.

Various nomadic cultures in the region had used the lake and its tributaries as a source of food, but the impact of these cultures on the fish populations was small. Early descriptions of Utah Lake were of a beautiful lake full of a variety of fish species, including the June sucker, Utah sucker, mountain sucker, Utah Lake sculpin, mottled sculpin, cutthroat trout, Utah chub, leatherside chub, least chub, and mountain whitefish [3]. Over time, permanent settlers arriving in the area introduced several non-native fish species that now make up more than $90 \%$ of the total fish biomass of Utah Lake [4].

By 1949, 25 non-native species had been intentionally introduced into Utah Lake, thirteen of which were successful [5]. The most successful introduced species were the common carp, white bass, black bullhead, channel catfish, and walleyed pike. These continue to be the most abundant game fish in Utah Lake [6]. The introduction of these fish species provided competition for the native fish for resources such as food and habitat. In 1906, E.A. Tillian, superintendent of the United States Fish Commission, said:

We found the lake trout [Bonneville cutthroat trout] had done poorly, because of low and consequently muddy water; and the carp, which have thriven immensely, have eaten off the mosses and similar growth along the bottom of the lake, so that the trout have not had enough to eat. Carp are a good deal like the English sparrow-once they get into a place they are there to stay. [2]

The increase in competition proved to be too much for some of the native fish.

The last specimens of the Utah Lake sculpin and Bonneville cutthroat trout were 
collected in 1928 and 1932, respectively. It is believed that both of these fish went extinct during the drought and low water levels of the 1930's. The June sucker was federally listed as an endangered species on April 30, 1986, and fewer than 1000 June suckers are believed to exist in Utah Lake today [2]. 
CHAPTER 4

CWR-ELCOM HISTORY AND PREVIOUS APPLICATIONS

\subsection{Modeling of Lakes Using Computational Fluid Dynamics}

Computational fluid dynamics (CFD) is the branch of fluid mechanics dealing with the simulation of physical fluid flows through the use of numerical methods and computational algorithms. These methods are based on the governing equations of fluid mechanics, and are used to obtain detailed results about the flow field, such as velocities, pressures, temperatures, etc. A CFD simulation requires that the physical geometry, fluid properties, initial conditions, and forcing boundary conditions for the scenario be defined. The advent of computers and the increasing availability of powerful processors has allowed for extensive use of CFD modeling for many industrial and commercial purposes. In recent years, detailed codes have been written specifically for CFD simulations of lakes and other large bodies of water.

CFD models of lakes and other naturally occurring bodies of water require an additional degree of complexity beyond a typical industrial CFD simulation, however, in order to account for all of the natural processes that drive the system. Both the fundamental simulation codes and the forcing functions must be adapted to handle variations over time in air temperature, solar radiation, wind speed, precipitation, cloud cover, and other vital external functions. Appropriate methods for calculating heat transfer through the water's surface, evaporation rates, effects of Coriolis forces, and the amount of solar radiation incident upon the lake as a function of time of year and position on the earth's surface must also be incorporated. In addition, variations in water 
composition (i.e. salinity, total dissolved solids (TDS), density, etc.) and the possibility of a stratified system may need to be accounted for. All of these complexities introduce approximations and consequent sources of modeling error into the CFD codes.

Despite these difficulties, several programs for modeling ocean and lake currents have been developed. By 2004, over 45 different CFD codes had been written for specific modeling projects [7]. While all of them were based on the governing equations of fluid mechanics, each had variations in their solution algorithms; some models produced detailed results at enormous computational costs, others were developed for specialized modeling scenarios, while still others took advantage of unique assumptions that made them computationally more efficient. Many programs combined various advantageous adaptations of other, older codes to enhance their accuracy and efficiency.

As a result of the gradual evolution in modeling programs and the advances in computing technology, many CFD models of oceans and lakes can now be run on standard desktop computers rather than on supercomputers or processor clusters.

\subsection{Introduction to CWR-ELCOM}

The Centre for Water Research (CWR) was established at the University of Western Australia (UWA) in 1981 as a joint UWA and Western Australia State Government initiative. The Centre for Environmental Fluid Mechanics, an important research and applied science department within CWR, was established the following year. Its stated objective is to focus on "the interaction between individual transport and mixing processes in stratified lakes, estuaries and coastal seas" [8]. To date, CWR has been involved with over $50 \%$ of Australia's water supply and has research partners in ten 
different countries representing every continent except Antarctica. Software developed at CWR to model physical, chemical, and biological dynamics within aquatic systems is currently in use in over 80 countries around the world [8].

The Estuary Lake and Computer Model (CWR-ELCOM) program was written and enhanced from 1997 to 2000 by Ben Hodges while he was working as a research fellow at CWR. Several graduate students have made significant improvements to CWRELCOM since that time [9]. It has been used to model lakes and other bodies of water in various locations around the world with great success. Further discussion of some of these applications of CWR-ELCOM is found in the case studies summarized in Section 4.3 .

\subsection{Case Studies of CWR-ELCOM Usage}

The first version of CWR-ELCOM was finished in 1999. Since that time, it has been used to model various bodies of water with great accuracy and success. The following examples are presented as validation of CWR-ELCOM's accuracy and usefulness.

\subsubsection{Case Study 1: Lake Kinneret}

Lake Kinneret, or the Sea of Galilee, is the largest freshwater lake in Israel. With an average water surface elevation of 209 meters (685.7 feet) below sea level, it is also the lowest freshwater lake in the world. Lake Kinneret is an ovoid-shaped body of water with a surface area of approximately 166 square kilometers (64 square miles) and an average depth of 25.6 meters (84.0 feet). Israel's National Water Carrier transports drinking water from Lake Kinneret to several major population centers. In addition to 
serving as a water source for these cities, the lake is also used for fishing and for agricultural water. Because of its importance to the region, Lake Kinneret has been extensively studied to determine how to maintain its water quality.

CWR-ELCOM was used to model Lake Kinneret in 2000. This was one of the first applications of the newly written code, and was important in validating CWRELCOM's methodology and accuracy. Ben Hodges, the principal author of CWRELCOM, was directly involved in the modeling work. He documented the approach to modeling Lake Kinneret and explained the results and their significance in Hodges et al. $[10]$.

Inputs for the CWR-ELCOM model were generated using field data collected in 1997. The details of the field investigation are found in Lemckhert and Imberger [11]. Eight temperature sensors were placed in various locations throughout the lake to provide temperature data for the initialization of the model. Meteorological data was also recorded at the sites for the temperature sensors and used as the forcing data for the model. The data included wind speed, wind direction, air temperature, relative humidity, cloud cover, and short wave solar radiation [10].

Prior to using CWR-ELCOM to model Lake Kinneret, the data collected in 1997 had been used to determine the periods of the primary modes of the Kelvin and Poincaré waves. The data was collected with sampling rates between 10 and 120 seconds while the CWR-ELCOM model used a time-step of 450 seconds and a grid size of 400 meters (1312 feet). As a result, some of the high frequency, low wavelength features from the data could not be accurately represented by the CWR-ELCOM model. 
Despite this shortcoming, however, the model accurately depicted the Kelvin and Poincaré waves with periods on the order of hours and it correctly captured the depth of the wind-mixed level, even with coarse vertical grid resolution. Hodges noted some programming issues that still needed to be addressed in future versions of CWRELCOM, including damping of the Kelvin wave, numerical diffusion of the metalimnion, and subgrid-scale modeling of internal wave effects.

\subsubsection{Case Study 2: Lake Constance}

Lake Constance, located on the Rhine River between Germany, Switzerland, and Austria, is used for commercial fishery, recreational purposes, and a drinking water supply for four million people [12]. Seasonal weather causes this large stratified lake to experience moderate and severe wind episodes during strong cooling. This nonuniform wind field and the lake's complicated geometry make accurate numerical modeling of the flow field very difficult. However, CRW-ELCOM was applied to this lake to gain a greater understanding of the behavior of large stratified lakes.

From October 15, 2001, to November 17, 2001 (33 days), eight Lake Diagnostic Systems (LDS) from CWR were used to gather data on the water temperature and wind speed and direction. Each LDS consisted of 51 temperature sensors s in a chain extending to 100 meters (328 feet) deep as well as an anemometer and wind direction sensor located 2.4 meters (7.9 feet) above the surface of the water. One station also recorded the relative humidity, air temperature, incident short wave radiation, and net radiation [12]. 
A uniform, coarse grid was applied to the lake without specific calibration of the model parameters to match the lake. The mesh had 400-meter spacing in both the horizontal directions and variable spacing from 2.5 meters ( 8.2 feet) to 34 meters (111.5 feet) in the vertical direction, with the finer mesh near the surface of the water [12].

Even without careful calibration of the model parameters, CWR-ELCOM successfully predicted the dominant internal oscillations that control mixing and transport by accurately capturing the period lengths of the Kelvin and Poincaré waves [12]. The recorded data was used to verify these waves and their period lengths. In addition, different seasonal air temperature profiles were used to discover that certain combinations of factors introduced additional features into the flow field for Lake Constance. For example, CWR-ELCOM simulations suggested that the phenomenon of the split surface layer may occur more frequently when strong westerly winds are present [12].

As a result of this study, there was an increased understanding of the processes controlling the flow field inside Lake Constance. This information could then be used to further understanding of processes inside other large stratified lakes. In addition, this study confirmed that, due to its relative robustness, CWR-ELCOM could be successfully applied to complex situations without careful calibration of each parameter.

\subsubsection{Case Study 3: Great Slave Lake}

Great Slave Lake, located in the Northwest Territories of Canada, is the ninthlargest lake in the world and the deepest lake in North America. As such a large body of water, it strongly impacts the regional weather patterns. CWR-ELCOM was used to 
model the lake for inclusion in the Canadian Regional Climate Model (CRCM) and accurately predicted results that correlated well with observed data (León et al., 2007).

Previous to this study, CRCM had no lake component; climate simulations for northern Canada had relied on historical or in situ observed data as the forcing functions for thermal models [13]. However, the complex interplay between lakes and the climate required that a sub-model for the lake be coupled with CRCM to increase the overall accuracy. Additionally, while the CRCM had previously assumed that Great Slave Lake had a constant surface temperature, the large size of the lake allowed for the existence of relatively large spatial and temporal temperature gradients that could only be simulated using a lake sub-model.

Input data for the CWR-ELCOM model was obtained empirically from July to mid-September 2003. The water currents were observed using a cross-lake transect [14]. Meteorological data such as wind speed and direction, air temperature, incident solar radiation, and relative humidity were obtained using sensors placed on buoys in the lake as well as on structures on the surrounding land. A series of five temperature sensors were use to collect temperature data over time at specified locations in the lake [13].

With this wealth of data, direct comparison to the results of the CWR-ELCOM model allowed extensive evaluation of its accuracy. CWR-ELCOM accurately predicted the temperatures within $\pm 5 \%$ when compared to the temperature sensors, and also correctly predicted the magnitude and direction of the currents in the lake [13]. Discrepancies in the results were attributed primarily to the fact that two major river sources were not included in the model. 


\subsection{Justification for CWR-ELCOM Usage on Utah Lake Model}

CWR-ELCOM was chosen as the modeling software for Utah Lake because of its proven accuracy, ability to run on a personal computer, and abundance of documentation. In addition, CWR-ELCOM can be coupled to the Computational Aquatic Ecosystem Dynamics Model (CAEDYM), a water-quality model for the major biogeomechanical processes in an aquatic environment that was also created by CWR. These processes include primary and secondary production, nutrient and metal cycling, oxygen dynamics, and the movement of sediment. CAEDYM is also flexible enough to allow the user to model other processes, such as the time-dependent relationship between nutrients, phytoplankton, and zooplankton [8]. The combined model formed by coupling CWRELCOM and CAEDYM is a powerful tool that can be used to predict the hydrostatic water conditions and the resulting biological processes inside Utah Lake. Armed with this valuable information, JSRIP and other organizations will be better equipped to make educated decisions about the management of Utah Lake as they continue their efforts to restore its pristine, clear water state and preserve endangered species such as the June sucker. 


\section{CHAPTER 5}

\section{CWR-ELCOM GOVERNING EQUATIONS}

\subsection{Hydrodynamic Equations}

CWR-ELCOM solves the unsteady, viscous Reynolds-averaged Navier-Stokes (RANS) and scalar transport equations by using the Boussinesq approximation and neglecting the non-hydrostatic pressure terms. Standard bulk transfer models are used to simulate heat transfer through the surface of the water [15]. Although an overview of these equations and their numerical implementation in CWR-ELCOM is given here, a more complete discussion of these equations can be found in Hodges [16].

\subsubsection{Reynolds-Averaged Navier-Stokes Equations}

The RANS equations are developed by averaging the Navier-Stokes equations over a specified time period that is long when compared to sub-grid scale processes but small relative to grid-scale processes [16]. For example, this method provides a way to include, in an averaged form, the effects of small length scale localized eddies while still accounting for the large lake circulation eddies that have a much larger length scale. The RANS equations are used primarily with turbulent flows. Quite often in numerical schemes the time step used in the iterative solving process is also the time scale used to average the Navier-Stokes equations [15]. In indicial notation, the RANS equations take the following form [16]:

$$
\begin{aligned}
\frac{\partial U_{\alpha}}{\partial t}+U_{j} \frac{\partial U_{\alpha}}{\partial x_{j}}=-g\left\{\frac{\partial \eta}{\partial x_{\alpha}}\right. & \left.+\frac{1}{\rho_{0}} \frac{\partial}{\partial x_{\alpha}} \int_{z^{\prime}}^{\eta} \rho^{\prime} d z\right\}+\frac{\partial}{\partial x_{1}}\left(v_{1} \frac{\partial U_{\alpha}}{\partial x_{1}}\right) \\
+ & \frac{\partial}{\partial x_{2}}\left(v_{2} \frac{\partial U_{\alpha}}{\partial x_{2}}\right)+\frac{\partial}{\partial x_{3}}\left(v_{3} \frac{\partial U_{\alpha}}{\partial x_{3}}\right)-\varepsilon_{\alpha \beta} f U_{\beta}
\end{aligned}
$$


where:

$$
\begin{array}{ll}
U_{i} & =\text { Reynolds-averaged velocity components } \\
t & =\text { time dimension } \\
g & =\text { gravitational constant } \\
x_{i} & =\text { spacial dimensions } \\
\eta & =\text { Reynolds-averaged free surface height } \\
\rho_{0} & =\text { reference density } \\
z & =\text { depth of density anomaly } \\
z & =\text { depth variable } \\
\rho^{\prime} & =\text { density anomaly (i.e. the difference between the in situ density and the } \\
\varepsilon_{\alpha \beta} & =\text { reference density) } \\
f & =\text { Coriolis constant } \\
v_{i} & =\text { molecular viscosity components } \\
&
\end{array}
$$

The boundary conditions for the momentum equation are as follows for the (i) free surface and (ii) bottom and sides of the lake [16]:

$$
\begin{gathered}
\frac{\partial U_{\alpha}}{\partial x_{3}}=0 \\
U_{i}=0
\end{gathered}
$$

There is no momentum flux through the free surface of the lake, as shown in Eq. 5.2. In addition, the no-slip condition requires that velocity components on the bottom and sides be zero. 


\subsubsection{Continuity Equation}

Closely associated with the RANS equations is the equation for conservation of mass, or continuity equation, shown here in indicial notation [16]:

$$
\frac{\partial U_{j}}{\partial x_{j}}=0
$$

Vertical integration of the continuity equation from the bottom of the water

column $b$ to the free surface $\eta[17]$ and application of the Reynolds-averaging filter to the kinematic boundary condition yields the equation for free-surface evolution [16]:

$$
\frac{\partial \eta}{\partial t}=-\frac{\partial}{\partial x_{\alpha}} \int_{b}^{\eta} U_{\alpha} d z
$$

\subsubsection{Scalar Transport Equation}

The scalar transport equation is [15]:

$$
\frac{\partial C}{\partial t}+\frac{\partial}{\partial x_{j}}\left(C U_{j}\right)=\frac{\partial}{\partial x_{1}}\left(\kappa_{1} \frac{\partial C}{\partial x_{1}}\right)+\frac{\partial}{\partial x_{2}}\left(\kappa_{2} \frac{\partial C}{\partial x_{2}}\right)+\frac{\partial}{\partial x_{3}}\left(\kappa_{3} \frac{\partial C}{\partial x_{3}}\right)+S_{C}
$$

where:

$C=$ scalar concentration

$\kappa_{i} \quad=$ diffusion components

$S_{c} \quad=$ turbulent Schmidt number (or Prandtl number for temperature)

The no-flux boundary conditions for scalar transport are:

$$
\frac{\partial C}{\partial x_{j}}=0
$$

\subsubsection{Free-Surface Wind Shear}

The free-surface wind shear has the following equation [16]:

$$
\left(u_{*}\right)_{\alpha}^{2}=C_{10} \frac{\rho_{\text {air }}}{\rho_{\text {water }}}\left(W_{\beta} W_{\beta}\right)^{1 / 2} W_{\alpha}
$$


where:

$$
\begin{aligned}
& \left(u^{*}\right)_{\alpha}=\text { wind shear velocity in } \alpha \text {-direction } \\
& C_{10}=\text { bulk wind stress coefficient for wind values at } 10 \text { meters } \\
& \rho_{\text {air }}=\text { air density at free surface } \\
& \rho_{\text {water }}=\text { water density at free surface } \\
& W_{\beta}=\text { vector wind speed in } \beta \text {-direction }
\end{aligned}
$$

The momentum input by the wind has the following equation [16]:

$$
\frac{\partial U_{\alpha}}{\partial t}=\frac{\left(U_{*}\right)_{\alpha}^{2}}{h}
$$

where $h$ is the height of the wind-mixed layer.

\subsection{Surface Thermodynamics Equations}

The heat energy transfer across the water surface is separated into non-penetrative components of long wave radiation, penetrative short wave radiation, sensible heat transfer, and evaporative heat loss.

\subsubsection{Internal Energy}

The general temperature and internal energy relation is [16]:

$$
\Delta T=\frac{\Delta Q}{\rho_{\text {water }} V c_{p(\text { water })}}
$$

where:

$$
\begin{array}{ll}
T & =\text { water temperature } \\
Q & =\text { heat energy } \\
\rho_{\text {water }} & =\text { water density } \\
V & =\text { volume of water }
\end{array}
$$


$c_{p}=$ specific heat of the water at constant pressure

\subsubsection{Non-Penetrative Long Wave Radiation}

The equation for long wave radiation absorbed by the water is [16]:

$$
Q_{R(\text { absorbed })}=\varepsilon_{\text {air }} \sigma\left(1+0.17 C_{\text {cloud }}^{2}\right)\left(273.2+T_{\text {air }}\right)^{4}\left(1-R_{l w}\right)
$$

where:

$$
\begin{aligned}
& Q_{R}=\text { long wave radiant heat flux } \\
& \varepsilon_{\text {air }}=\text { emissivity of the air above the lake } \\
& \sigma \quad=\text { Stefan-Boltzmann constant } \\
& C_{\text {cloud }}=\text { fractional cloud cover } \\
& T_{\text {air }}=\text { temperature of the air above the lake } \\
& R_{l w}=\text { reflectivity of lake surface to incoming long wave radiation }
\end{aligned}
$$

Long wave radiation emitted at the free surface by the water is governed by [16]:

$$
Q_{R(\text { emitted })}=-\varepsilon_{\text {water }} \sigma\left(273.2+T_{\text {water }}\right)^{4}
$$

where:

$$
\begin{aligned}
& \varepsilon_{\text {water }}=\text { emissivity of the water at the surface of the lake } \\
& T_{\text {water }}=\text { temperature of the water at the surface of the lake }
\end{aligned}
$$

\subsubsection{Penetrative Short Wave Radiation}

The amount of short wave radiation penetrating the free surface is given as [16]:

$$
Q_{S}(0)=Q_{\text {surface }}\left(1-0.65 C_{\text {cloud }}^{2}\right)\left(1-R_{\text {sw }}\right)
$$

where:

$Q_{S} \quad=$ short wave radiant heat flux 
$Q_{\text {surface }}=$ short wave radiation reaching water surface

$R_{s w}=$ reflectivity of surface to incoming short wave radiation

The amount of heat flux due to the penetrative short wave radiation decreases exponentially according to [16]:

$$
Q_{S}(d)=Q_{S}(0) \exp \left(-\Gamma_{e} d\right)
$$

where:

$$
\begin{aligned}
& \Gamma_{e} \quad=\text { extinction coefficient } \\
& d \quad=\text { depth below free surface }
\end{aligned}
$$

\subsubsection{Sensible Heat Transfer}

Sensible heat flux due to convective heat transfer at the free surface is controlled by [16]:

$$
Q_{H}=C_{H} c_{p(a i r)} \rho_{a i r}\left(T_{a i r 10}-T_{\text {water }}\right)
$$

where:

$Q_{H} \quad=$ sensible heat flux

$C_{H}=$ bulk transfer coefficient for sensible heat

$T_{\text {air } 10}=$ air temperature at 10 meters above the free surface

\subsubsection{Evaporative Heat Loss}

Evaporative heat loss through the surface of the lake has the following governing equation [16]:

$$
Q_{W}=L \frac{0.622}{P_{a t m}} C_{W} u_{w i n d} \rho_{a i r} e_{s a t}\left(R_{h}-1\right)
$$

where: 


$$
\begin{aligned}
& Q_{W}=\text { evaporative heat flux } \\
& L \quad=\text { latent heat of evaporation } \\
& P_{a t m}=\text { atmospheric pressure at the free surface } \\
& C_{W}=\text { bulk transfer coefficient for evaporative heat } \\
& u_{w i n d}=\text { wind speed at free surface } \\
& e_{s a t}=\text { saturated vapor pressure } \\
& R_{h}=\text { relative humidity }
\end{aligned}
$$

Section 6.2.2 discusses how CWR-ELCOM incorporates the governing equations listed above for non-penetrative long wave radiation, penetrative short wave radiation, sensible heat transfer, and evaporative heat transfer. 
CHAPTER 6

CWR-ELCOM NUMERICAL APPROACH

\subsection{CWR-ELCOM and TRIM}

The basic structure for CWR-ELCOM's numerical method was adapted from the TRIM scheme of Casulli and Cheng [18]. Later adaptations and modifications to TRIM can be found in Casulli and Cattani [19], Casulli [20], and Gross et al. [21, 22]. The original method and these subsequent modifications will be collectively referred to as the TRIM method hereafter.

Although CWR-ELCOM's numerical method was based on TRIM, it has been adapted to include: (1) a hybrid advection scheme for momentum, (2) an energy-based mixing model for vertical diffusion, and (3) conservative advection of scalars using a third-order explicit method [16].

\subsection{Numerical Implementation of Governing Equations}

The governing equations upon which CWR-ELCOM was based are found in Chapter 5. The numerical methods used to convert those equations to computational domains are discussed here, along with important limitations that are a result of the methods that were employed.

CWR-ELCOM advances the model solution a single time step in a staged approach consisting of the following [16]:

1) Introduction of surface heating/cooling in the surface layer.

2) Mixing of scalar concentrations and momentum using a mixed-layer model.

3) Introduction of wind energy as a momentum source in the wind-mixed layer. 
4) Solution of the free-surface evolution and velocity field.

5) Horizontal diffusion of momentum.

6) Advection of scalars.

7) Horizontal diffusion of scalars.

Each of these steps is discussed in the following sections.

\subsubsection{Grid Characteristics and Grid Stencil}

CWR-ELCOM uses a rectangular grid to permit the use of a simple, efficient finite-difference/finite-volume scheme on a staggered grid. Vertical grid spacing is allowed to vary so that grid layers are concentrated only where the greatest resolution is required. The grid stencil used in the solution procedure is the Arakawa C-grid, which has velocities defined on cell faces and scalar quantities such as free-surface height and temperature defined at the cell center [16].

\subsubsection{Surface Heating/Cooling}

CWR-ELCOM employs standard bulk transfer models to calculate the heat exchange through the water's surface. Examples of these models in the literature are Amorocho and DeVries [23], Imberger and Patterson [24], and Jacquet [25]. As stated in Section 5.2, the heat energy transfer across the water surface is separated into nonpenetrative components of long wave radiation, penetrative short wave radiation, sensible heat transfer due to convection, and evaporative heat loss. CWR-ELCOM allows the user to directly input the incident long wave radiation or, in the absence of user-input values, calculates the necessary values from the user-input values for cloud cover, air temperature, and relative humidity. The user is required to input values for the incident 
short-wave radiation. Additional information on CWR-ELCOM thermodynamic modeling can be found in a CWR technical report by Hodges [26] and in Hodges and Dallimore [15].

Non-penetrative surface heat transfer effects are introduced into the surfacemixed layer as heat sources, and include the fluxes due to long wave radiation, sensible heat, and evaporation. If it were assumed that surface heat transfer from these sources was completely absorbed in the uppermost grid layer, the overall thermal effect on the water below the free surface would change as a function of grid resolution. Grids with small vertical spacing would contain a smaller volume of water in the uppermost grid layer and would experience larger temperature fluctuations than a grid with large vertical spacing. In CWR-ELCOM, the surface heat transfer is modeled as occurring in the first meter below the free surface, independent of vertical grid spacing. Because of exponential decay, it is assumed that $98 \%$ of the surface heat transfer is absorbed in this region [16].

Penetrative heat transfer effects are introduced into one or more of the grid layers in the water column based on exponential decay of the source with increasing depth. In very clear or shallow water such as is found in Utah Lake, these effects may reach to the lake floor. Complete incorporation of the penetrative heat transfer into the model would greatly complicate the model by requiring: (1) knowledge of the aborptivity, reflectivity, and emissivity characteristics of the sediments along the lake bottom, (2) knowledge of the variations in sediment composition throughout the lakebed, and (3) conduction and convection models for the lake bottom. 
Rather than incorporate these complexities, CWR-ELCOM instead employs a simpler approach by treating any short wave radiation that does reach the lake floor using a model similar to that used at the free surface. It assumes that $90 \%$ of the radiation (in Version 2.2) is converted into non-penetrative, long wave radiation and/or sensible heat transfer and absorbed in the first meter of water above the lake floor [15]. Exponential decay is employed such that $98 \%$ of these effects are absorbed in this one meter region [16].

\subsubsection{Mixing of Scalar Concentrations and Momentum}

Before computing the addition of momentum as a result of wind moving across the surface of the water, it is important that the changes in the scalars in the first layer of grid cells due to the surface heat input be determined. These scalars, such as temperature and density, play a critical role in determining the depth of the mixed-layer.

Modeling the effects of small-scale mixing events on stratified flows that result from large-scale processes is a challenging venture. In many conventional mixing models, eddy diffusivity terms in vertical transport equations are used to determine the amount of mixing that occurs across stable density gradients. However, this is not the only method by which mixing can be modeled.

CWR-ELCOM expands the mixing energy budget approach used in 1D lake modeling to create a 3D mixed-layer model. The 1D approach is found in Imberger and Patterson [24], Spigel et al. [27], and Imberger and Patterson [28]. In the 1D approach, the total amount of available mixing energy due to convective overturn, shear production, and wind stirring is computed and compared to the amount of energy required to mix a 
lower layer into the well-mixed region above it. If the available mixing energy exceeds the required mixing energy, then the lower layer is completely mixed into the upper, well-mixed region.

In CWR-ELCOM, this 1D mixing model is applied independently to each cell in the water column, starting at the surface and descending to the bottom of the column. In Hodges and Dallimore [15], the following steps are listed as those that the program executes for each water column during each time step:

1) Calculate wind energy input, $E_{\text {wind }}$

2) If the TBBL boundary condition is being used, calculate bottom energy input, $E_{\text {drag }}$

3) For each column cycle from surface to bottom cell

4) Calculate generation of total kinetic energy (TKE) by shear, $E_{\text {shear }}$

5) Calculate energy required for mixing, $E_{r e q}$

6) Calculate total energy available if two cells were totally mixed, $T K E_{\text {mixed }}$

7) Calculate time estimate for total mixing, $T_{T K E}$

8) If unstable, calculate time estimate based on convective overturn, $T_{\text {conv }}$

9) Calculate mixing fraction, $\eta_{f}$

10) If there is enough energy then mix cells

11) End of cycle from surface cell to bottom cell

12) Dissipate excess mixing energy 
Detailed information on the implementation of this mixing model in CWRELCOM, including the equations used to calculate the above values, can be found in Hodges and Dallimore [15].

\subsubsection{Wind Energy}

The momentum input by the wind blowing across the surface of a body of water has typically been modeled using a stress boundary condition (e.g. Casulli and Cheng [18]), which requires a solution of the vertical viscosity $v$ and diffusivity $\kappa$ terms in place of the Reynolds stress terms in the momentum and scalar transport equations listed in Sections 5.1.1 and 5.1.3. However, when using this approach in a stratified system, the depth, downwind velocity, and velocity shear in the wind-mixed layer are functions of the values used for eddy viscosity and diffusivity above the thermocline [16]. For coarse vertical grids, the predicted mixed-layer depth is generally unsatisfactory. It has been demonstrated [29] that even fine vertical grid resolution may produce questionable results.

CWR-ELCOM avoided this difficulty by introducing a first-order accurate model for predicting the mixed-layer depth $h$ and the distribution of momentum over the depth [28]:

$$
\left.\frac{d u_{w i n d}}{d t}\right|_{i, j, k}=\frac{\left.u_{*}^{2}\right|_{i, j, k}}{\left.h\right|_{i, j, k}} \quad: \quad \eta-h<\sum_{m=1}^{k} \Delta z_{m}<\eta
$$

where $u_{\text {wind }}$ is the wind velocity at the free surface, $u_{*}$ is the wind shear, $\eta$ is the free surface height in the water column, and $z_{m}$ is the depth of individual grid layers. This is comparable to Eq. 5.8 in Section 5.1.4. 
Eq. 6.1 is appliedf separately in both the $x$ - and $y$-directions to provide an increase in the velocity field before application of the Navier-Stokes equations.

\subsubsection{Free-Surface Evolution and Velocity Field}

The free-surface height in each water column is calculated using the free surface evolution equation found in Section 5.1.2, and is allowed to move up and down the column through the grid layers, if necessary [16].

The velocity field at each time step is calculated using a semi-implicit formulation based on the RANS equations similar to that used in TRIM. The approximations used to implement this method are found in Hodges [16] and Hodges and Dallimore [15]. The scheme is a backwards-Euler discretization of the free surface evolution that is first-order accurate in time [15].

\subsubsection{Horizontal Diffusion of Momentum}

The original TRIM method [18] applied the discretization of the horizontal diffusive terms at the pathline origin, introducing additional numerical complexity. Because it had been found that these additions did not increase solution accuracy, CWRELCOM utilizes a second-order stencil to calculate the diffusivity terms that are used when solving the RANS equations for the velocity field.

\subsubsection{Hybrid Advective Scheme for Momentum}

Several advective schemes are commonly used in CFD solvers, some of which include the linear Euler-Lagrange, quadratic Euler-Lagrange, upwind QUICKEST, and centered finite difference schemes [16]. Each of these methods has inherent strengths and 
weaknesses when applied to models of varying geometry and flow. Different schemes are selected for a particular application by considering the type of results expected, the resolution and accuracy expected in those results, and the computational cost required to produce the results. Rather than limiting itself to a single scheme, CWR-ELCOM instead has the capacity to select one of two different schemes based upon flow conditions at a given location. Utilizing this hybrid scheme, CWR-ELCOM can produce accurate results across a broad range of flow conditions with a minimal increase in computational cost.

Using the local flow velocities, CWR-ELCOM calculates the advective CourantFriedrichs-Lewy $\left(C F L_{a}\right)$ condition according to the following equation [16]:

$$
C F L_{a}=U \frac{\Delta t}{\Delta x}
$$

For regions where $0<C F L_{a}<2$, a quadratic semi-Lagrangian discretization is used for the advection of momentum. For $C F L_{a}>2$, not only is the computational accuracy questionable, but the stencil region would also have to be adjusted, introducing additional computational expense to the program. Rather than continue to use the quadratic semiLagrangian discretization, CWR-ELCOM instead employs a linear semi-Lagrangian discretization for flow regimes where $C F L_{a}>2$ [15].

Semi-Lagrangian methods have several advantages over other advective schemes that make them more suitable for use in CWR-ELCOM. For stratified flows, semiLagrangian discretizations are both stable and accurate where $0.1<C F L_{a}<1$. For higher $C F L_{a}$ regimes, they continue to be stable, though their accuracy does suffer unless the flow streamlines are well resolved by the grid [16]. In addition, the quadratic semiLagrangian method, though computationally more expensive than some schemes, allows 
for the computation of source terms for flows in the range $1<C F L_{a}<2$ without repositioning the stencil [15]. These advantages help to increase the stability and accuracy of CWR-ELCOM, even for flow regimes with high $C F L_{a}$ conditions. For detailed information on semi-Lagrangian methods and techniques, see Staniforth and Côté [30].

\subsubsection{Advection and Horizontal Diffusion of Scalars}

Scalar transport is one of the most critical (if not the most critical) piece of a hydrodynamic model. Other critical components of the model, such as the density field and interval wave motions, are dependent upon accurate scalar transport modeling. To ensure accuracy of this important component, CWR-ELCOM utilizes a conservative third-order accurate scalar transport model. The use of a conservative scalar transport scheme is vital to the accuracy of the model; non-conservative methods allow for the artificial loss of mass and momentum, overly rapid dissipation of internal waves, and the incorrect elimination of the strong gradients that drive underflows [15].

Scalar transport in CWR-ELCOM is modeled using a three stage numerical algorithm [16]:

1) Scalar sources are introduced via the mixing model described in Section 6.2.3 according to the heat transfer schemes described in Section 6.2.2.

2) Advection of scalars by the resolved flow field.

3) Horizontal diffusion of scalars by turbulent motion.

To increase accuracy in flow regimes where the $C F L_{a}$ condition defined in Section 6.2.7 is greater than unity, the model-scale time step $\Delta t$ is broken into $m$ sub-time 
steps of sufficiently small size $\delta t$ that recalculating the $C F L_{a}$ condition using $\delta t$ instead of $\Delta t$ produces a value less than unity [16].

\subsection{Time Step Limitations Imposed by the Numerical Methods}

Due to the manner in which the governing equations were implemented, CWRELCOM has two time step limitations. The first arises because of the explicit discretization of the baroclinic terms in the RANS equations in Section 5.1.1, while the second limitation is a result of the semi-implicit momentum solver described in Section 6.2.5.

The discretization of the baroclinic terms in the RANS equations leads to a time constraint based on the baroclinic Courant-Friedrichs-Lewy condition, which is defined as [16]:

$$
C F L_{b}=\sqrt{g^{\prime} D} \frac{\Delta t}{\Delta x}
$$

where $g^{\prime}$ is the reduced gravity due to stratification $\left(g \Delta \rho / \rho_{0}\right), D$ is the effective depth,

and the quantity $\sqrt{g^{\prime} D}$ is an approximation for the wave speed of an internal wave. It can be seen that the baroclinic CFL condition is identical to the advective CFL condition defined in Eq. 6.2 of Section 6.2.7, with the speed of the internal wave substituting for the velocity term. This time constraint applies only to stratified flows; for purely barotropic flows, CWR-ELCOM is unconditionally stable.

In order for the model to be stable, it is necessary that $C F L_{b}<\sqrt{2}$. This is generally the most restrictive condition in a density-stratified flow. Because internal wave speeds are generally $O(1) m s^{-1}$ and horizontal grid sizes are typically $O\left(10^{2}\right) m$, the maximum allowable time step according to this condition is usually $O\left(10^{2}\right) s$. However, 
in the vertical direction grid sizes are typically $O\left(10^{-1}\right) m$ to $O(10) m$, which would result in an unacceptably small time step limitation of $O(10) s$. To sidestep this shortcoming, CWR-ELCOM calculates an advective CFL condition $C F L_{a}$ for scalar transport according to Eq. 6.2 of Section 6.2.7 and splits each model time step $\Delta t$ into $m$ sub-time steps $\delta t$ such that $m \delta t=\Delta t$, as described in Section 6.2.8. The scalar transport solution is calculated using the sub-time steps, while the momentum solution, which has the ability to handle $C F L_{a}$ numbers greater than 1 because of the hybrid advection scheme described in Section 6.2.7, is calculated using the model time step $\Delta t$.

The second time step limitation, which arises because of the implementation of the semi-implicit scheme with explicit horizontal diffusion as described in Section 6.2.5, is the viscous stability condition which was derived for homogeneous flows in Casulli and Cattani [19]:

$$
\Delta t=\frac{\Delta x^{2} \Delta y^{2}}{2 v\left(\Delta x^{2}+\Delta y^{2}\right)}
$$

This time step constraint is typically at least an order of magnitude less restrictive than the constraint due to the CFL condition. 


\section{CHAPTER 7}

\section{UTAH LAKE MODEL DEVELOPMENT}

\subsection{Overview}

Development of the model for Utah Lake required the following steps:

1) Generation of a mesh that accurately depicted the physical boundaries of Utah Lake.

2) Gathering of accurate data on the surface water boundary conditions as a function of time, including river locations, inflow and outflow rates, and water temperature values.

3) Collection of accurate meteorological forcing data as a function of time, including air temperature, atmospheric pressure, cloud cover, precipitation, relative humidity, solar radiation, and wind speed and direction.

4) Generation of input files formatted to CWR-ELCOM's specifications.

5) Execution of the code to run the simulations.

6) Post-processing and analysis of the results, including model validation. Several unique difficulties were encountered in the modeling process for Utah Lake and are sources of error in the results. Lakes are generally deep enough that the lakebed contours have little influence on the overall flow pattern in the lake; large rocks and rapid lakebed elevation changes are typically found far enough from the surface inputs that drive the flow that their effect is very small. However, in the shallow water of Utah Lake, lakebed variations have a stronger influence on the flow patterns due to their proximity to the surface. In addition, Utah Lake has several underwater springs through 
which groundwater enters the lake. Little data is available on the flow rates of these springs or on the temperature of the springs as a function of time. Further discussion on these underwater springs is found in Section 7.5.4.

\subsection{CWR-ELCOM Input Files}

Before CWR-ELCOM can be executed successfully, the user must create a series of required input files, taking care to format them exactly as required by CWR-ELCOM. The files typically required for a simulation run of Utah Lake are found in Section 7.2.2. Detailed information on the content and formatting of the input files can be found in the user manual for CWR-ELCOM by Hodges and Dallimore [31].

\subsubsection{Components of CWR-ELCOM Program}

Although CWR-ELCOM has been referred to as if it were a single program thus far, it is, in fact, three codes that must be executed successively. The three codes are:

1) Pre-processor. Uses the mesh information and river locations to create the required files for the simulation engine.

2) Simulation engine. Uses the files created by the pre-processor in conjunction with the meteorological, surface water volumetric flow, and surface water temperature input files prepared by the user to perform a simulation run. Outputs a series of files that contains the results of the simulation that the user requested.

3) Post-processor. Converts the files output by the simulation engine to a format which can be read by conventional data processing programs such as Matlab ${ }^{\circledR}$. 
A full simulation run consists of creating the necessary input files and successfully executing these three codes to obtain usable results.

\subsubsection{Input Files Required for a Typical Simulation}

The following input files are typically required for a simple Utah Lake simulation using CWR-ELCOM:

- bathymetry file containing the mesh information (see Section 7.3.4)

- boundary conditions file with the indices of river locations in mesh and the direction of flow through the corresponding cells

- river volumetric flow data as a function of time

- river temperature data as a function of time

- meteorological data file with the air temperature, atmospheric pressure, cloud cover, precipitation, relative humidity, solar radiation, and wind speed and direction data as a function of time

- file specifying the data to be output after the simulation terminates.

In addition to the input files listed above, a separate file must be created to control the execution of each of the three codes that compose CWR-ELCOM. The names of these three files are fixed; they are hard-coded into the CWR-ELCOM programs and cannot be changed without modifying the programs themselves.

The first file, run_pre.dat, controls the pre-processor component of CWRELCOM. It specifies the names and file paths of the bathymetry and boundary conditions files as described above. It also allows the user to specify the names and file paths of the files output by the pre-processor. 
The file that controls the simulation engine, the second CWR-ELCOM code, is named run_elcom.dat. It serves several important functions, including the following:

- $\quad$ sets simulation start and end dates

- $\quad$ sets the simulation time step size

- contains the names and file paths to the files output by the pre-processor

- contains the names and file paths to the meteorological, surface water volumetric flow, and surface water temperature input files prepared by the user

- $\quad$ sets the initial temperature either by specifying a file path to an initial conditions file or by applying a scalar value across the entire lake

- allows the user to turn on/off individual simulation modules such as salinity, density, surface thermodynamics, temperature, etc., to give the additional control over the simulation and turn off those modules which do not apply to the particular simulation, thus eliminating the unnecessary use of computational power

- allows the user to specify the treatment of the water/land boundaries (e.g. no slip, Neumann, turbulent benthic, etc.)

- if the user chooses to use a drag water/land boundary condition, allows the user to set the drag coefficient

- allows the user to set the parameters by which a simulation can be restarted at a specified point in the simulation run 
- $\quad$ sets the scalar maximum and minimum values for water temperature and salinity

- allows the user to set the interval between update messages to the screen

The file that controls the third and final CWR-ELCOM code is named dbconv.dat.

It allows the user to set the names and file paths to the data files output by the simulation engine. Once again, it is recommended that these filenames not be changed, but that the file path be adjusted, if necessary, to allow CWR-ELCOM to locate the correct files. In addition, it allows the user to set the name of the final simulation output file containing the simulation results and dictate whether or not the post-processor will overwrite any existing files with the same name.

\subsubsection{Matlab $^{\circledR}$ Usage in the Utah Lake Model}

As shown in Section 7.2.2, each simulation run of the Utah Lake model required that a series of input files be created. In order to conduct a full parametric study by varying key data values by a given percentage, it became obvious that a systematic method for creating the necessary input files should be created and implemented to reduce the time required to prepare each simulation and to decrease the errors introduced through manual manipulation of the data files.

The Matlab ${ }^{\circledR}$ software package, created by The Mathworks, Inc., proved to be ideal for the task because of its strong matrix manipulation features, powerful intrinsic functions, ability to read and write formatted files, and graphing capabilities. As a result, Matlab $^{\circledR}$ was used throughout the modeling process to create and visualize the mesh and 
river locations, create meteorological data files with the necessary variations for each portion of the parametric study, and create plots of the simulations results.

\subsection{Mesh Generation}

The first, critical step in developing an accurate model of Utah Lake is to successfully translate the physical domain of the lake into a numerical domain, or mesh, for use in performing simulations. The mesh must accurately represent the shape of the lake, including lakebed contours, if the simulation results are to be representative of the actual physical processes occurring in the lake.

\subsubsection{Coordinate System}

CWR-ELCOM uses a right hand coordinate system, with the $z$-axis positive in the upward direction (normal to the water surface) and $z=0$ corresponding to the surface of the water. The origin is located in the upper left-hand corner of the mesh, when viewed in the $x y$-plane. Keeping with this convention in the Utah Lake model, the $x$-axis was aligned to be positive in the southerly direction, with the $y$-axis positive in the easterly direction, as shown in Figure 7.1.

The coordinate system typically used in simulations positions the origin in the lower left-hand corner of the $x y$-space, with the z-axis positive in the upward direction (normal to the water surface) and the $x$ - and $y$-axes positive to the east and north, respectively. While the orientation and location of the coordinate system for CWRELCOM deviate from those of the conventional coordinate system, it has certain advantages that facilitate file examination and processing by users. When a file based on this coordinate system and having values at each cell center is viewed in a spreadsheet 


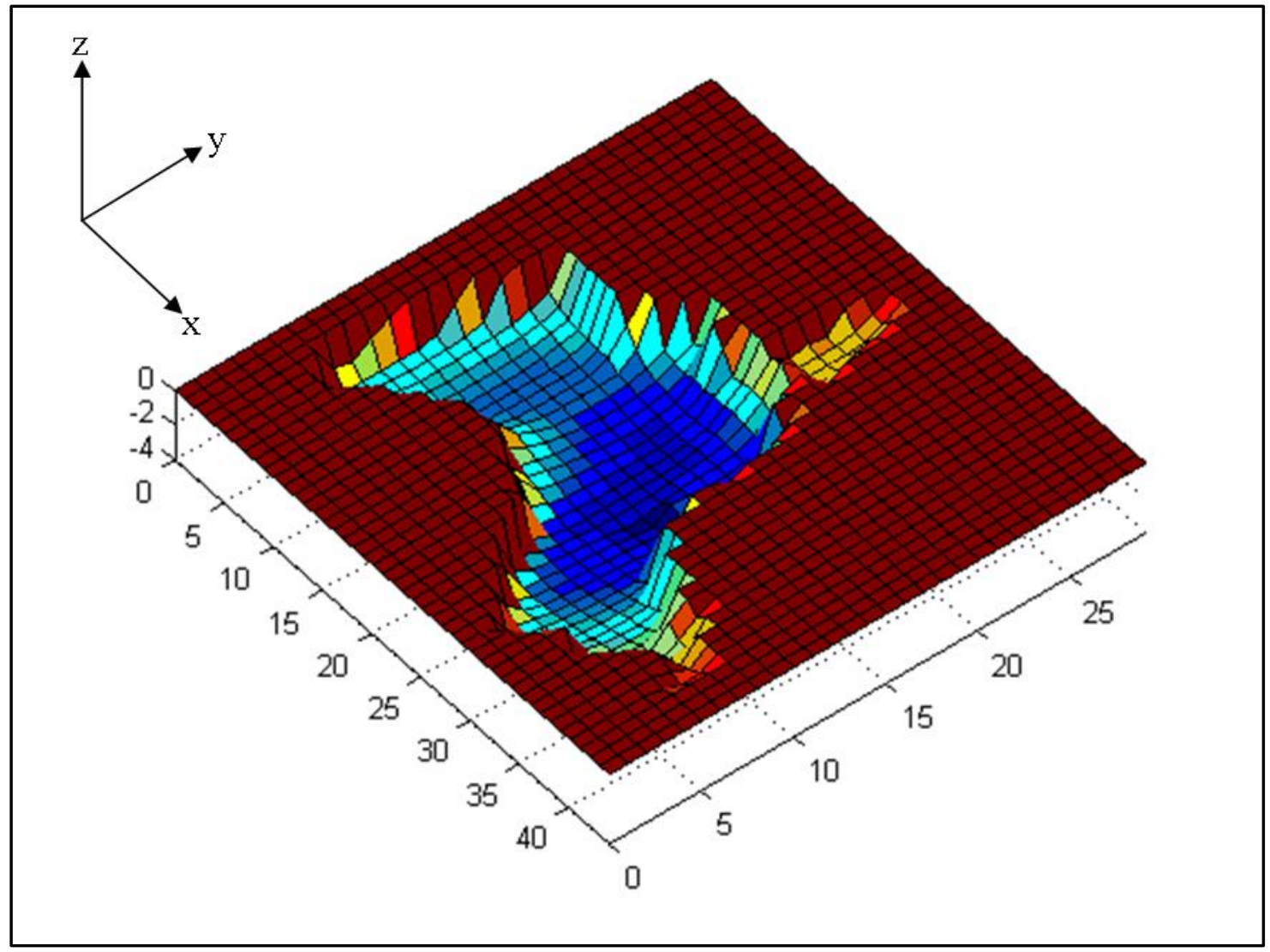

Figure 7.1 CWR-ELCOM coordinate system.

program, the user sees the values just as they would appear if the spreadsheet were laid over an image of the lake. This allows the user to more easily identify errors in input files and visually locate specific features within the mesh. The use of the conventional system would create files that are transposed in a spreadsheet program and would complicate viewing and manipulation of the mesh.

\subsubsection{Digitizing Lake Boundaries and Contours}

Digitization is a process by which the coordinates of data points can be extracted from an image. After the image is loaded into the digitizing software, the user defines a reference frame from which the program can interpolate to produce individual data 
points. Most digitizing programs automatically write these data points as a list in a file that can then be manipulated using other programs. Several digitizing software packages are commonly available.

Because the physical domain of Utah Lake has not been extensively studied in the recent past, few maps exist that have accurate and up-to-date information on its boundaries and lakebed contours. Initially, a map taken from Heckmann et al. [3], shown in Figure 7.2, was used as the source image for digitization using the XYit digitizing software. After tracing the boundary of the lake however, an intrinsic feature of XYit was used to calculate the enclosed area. The result was about 337 square kilometers (130 square miles), which was much less than the accepted value of 391 square kilometers (151 square miles). However, because the size of the map in the original work was

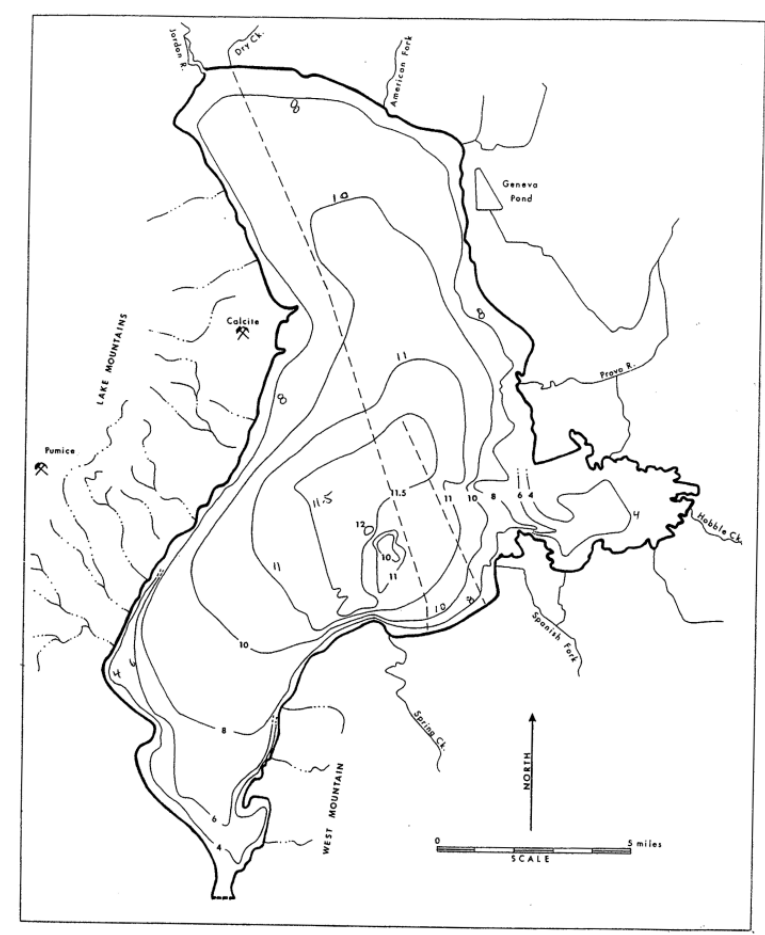

Figure 7.2 Utah Lake map from Heckmann [3]. 
limited to a single sheet of paper, small errors in creating the frame around the image in the digitizing software were magnified when trying to calculate the total area. In addition, Goshen Bay, a substantial area at the sound end of Utah Lake, was not present in the image, and contributed to the overall error.

Next, permission was obtained from Fish-n-Map Co. to produce a digital image of its Utah Lake map, shown in Figure 7.3. After digitizing the boundary of the lake in this image, the total calculated area was found to be 387.2 square kilometers (149.5 square

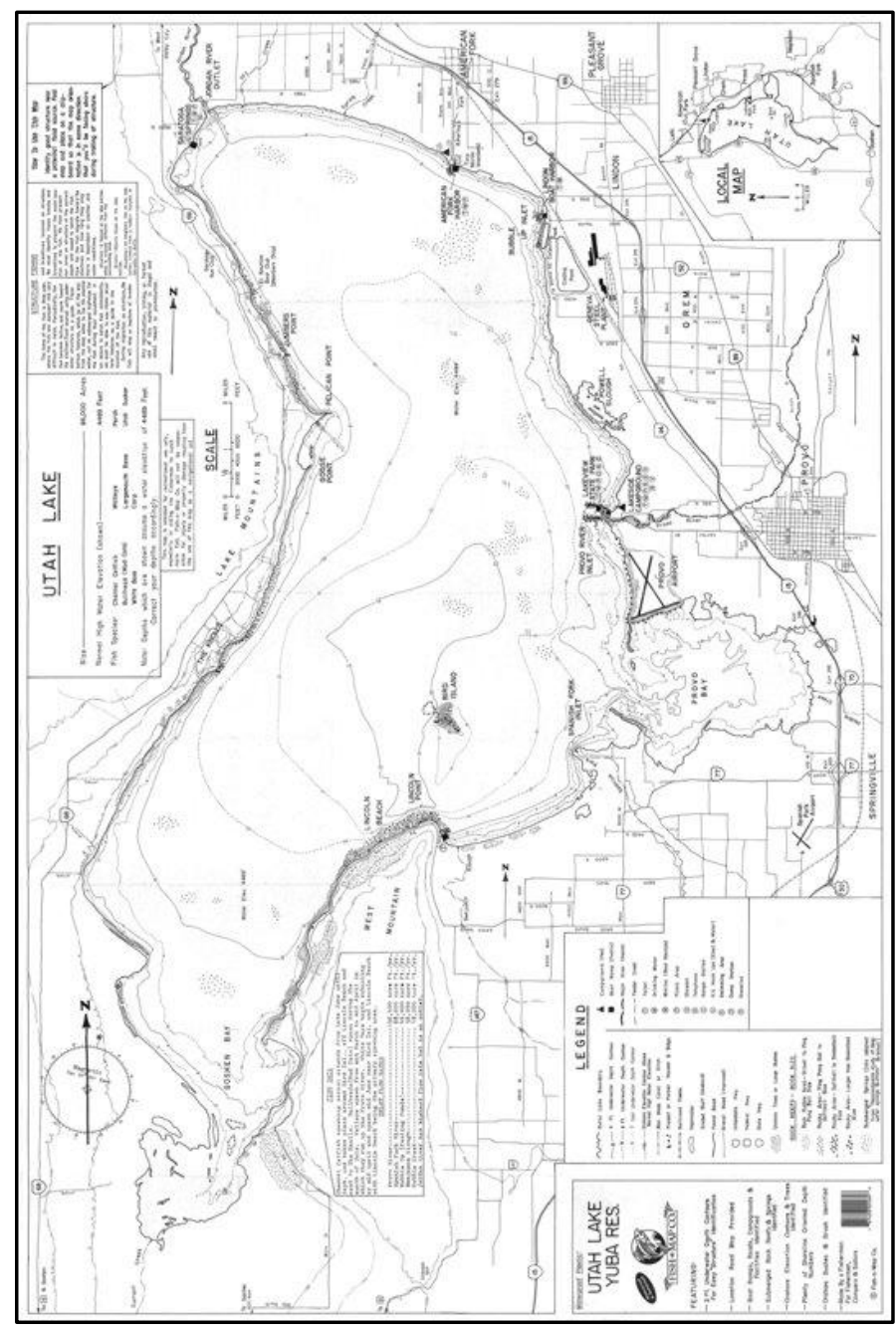

Figure 7.3 Fish-n-Map Company's map of Utah Lake. 
miles), an acceptable error of about $1 \%$. Having established the accuracy of the Utah Lake map from Fish-n-Map Co., the XYit digitizing software was used to trace the contour lines on the image of the map, resulting in a set of files, each of which contained a list of coordinates for points at a certain depth in the lake. These files were used to generate the mesh, as described in Section 7.3.3.

\subsubsection{Meshing Through Interpolation}

Once the Fish-n-Map Co.'s map of Utah Lake was successfully digitized, a threedimensional plot of the coordinates of each contour level of the lakebed was produced using Matlab ${ }^{\circledR}$, as shown in Figure 7.4. A systematic method for piecing together a mesh over this skeleton framework was necessary in order to create the input file for use in the simulations.

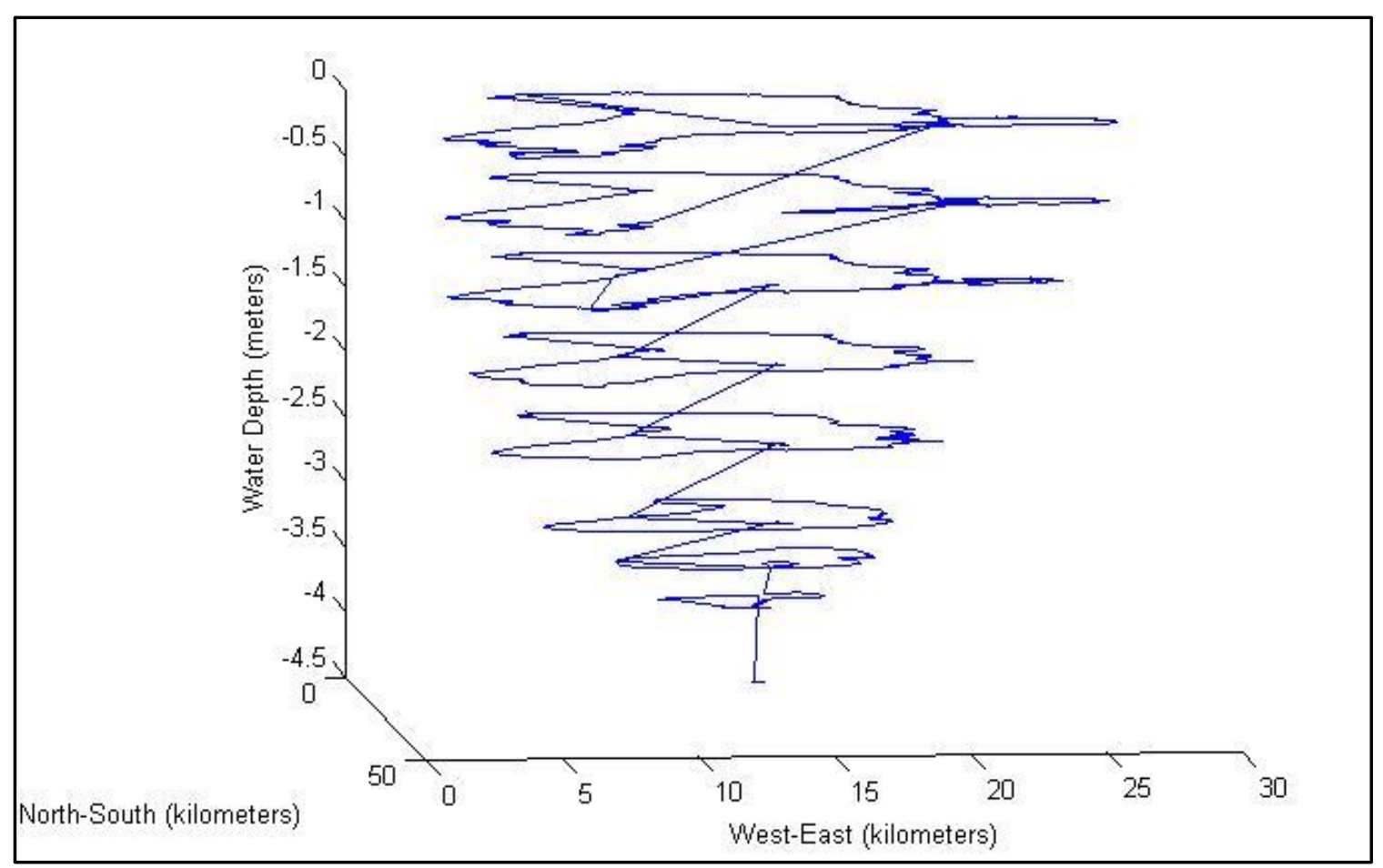

Figure 7.4 Utah Lake mesh skeleton. 
Matlab $^{\circledR}$ has an intrinsic function, griddata, which was written specifically for such applications. The function takes an array of data containing coordinates and their corresponding $z$-value, and creates a mesh over a region with user-defined spacing in each direction by interpolating between the values in the data array. The user has the option to use one of four different interpolation methods of different orders in creating the mesh. For Utah Lake, however, a simple linear interpolation proved to be sufficient.

A Matlab ${ }^{\circledR}$ script was created that used the digitized Utah Lake contour data to create a mesh. Controls were included in the code for creating the mesh to allow the user to control the grid size in the $x$ - and $y$-directions. A uniform mesh with 500-meter (1640foot) spacing in both the $x$ - and $y$-directions created using this method is shown in Figure 7.5 .

\subsubsection{Creating the Bathymetry File}

After the successful creation of the mesh using Matlab ${ }^{\circledR}$, the bathymetry file

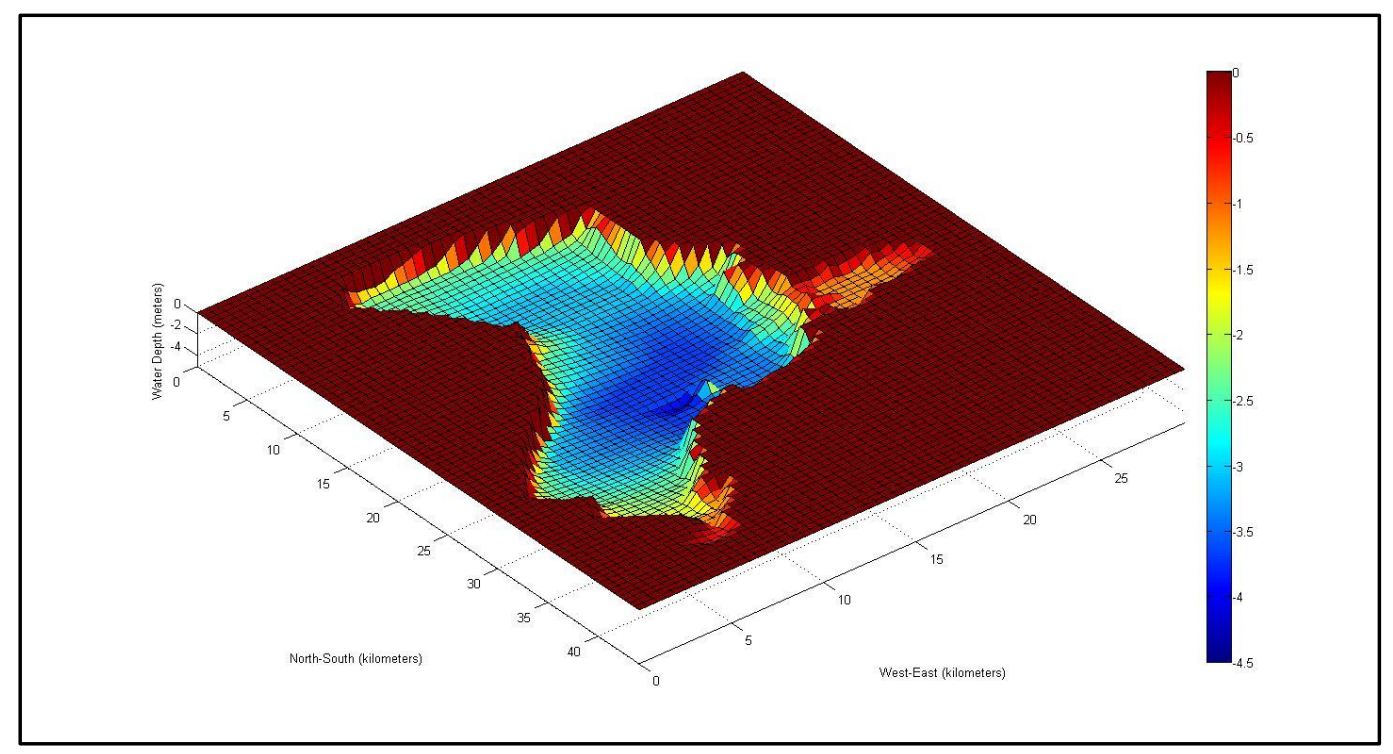

Figure 7.5 Utah Lake 500-meter grid. 
containing the mesh information required for CWR-ELCOM could be written in accordance with the required input file format.

For this task, Matlab ${ }^{\circledR}$ once again proved useful. The code that read in the digitization files and created the Utah Lake mesh was modified to include a section for writing out the bathymetry file. With this addition, after the user specified the grid dimensions and executed the code, the program automatically created the mesh and wrote the formatted bathymetry file. The bathymetry file could then be copied and pasted to the requisite directory for use in a simulation.

\subsection{Meteorological Forcing Data}

CWR-ELCOM requires that the user create one or more files containing information on how the air temperature, atmospheric pressure, cloud cover, precipitation, relative humidity, solar radiation, wind speed, and wind direction vary with time. The file is used by the second CWR-ELCOM code, the simulation engine, as it performs a simulation run.

All of the available meteorological data described below came from sources positioned adjacent to the lake, rather than on the lake itself. Because of the large impact the lake has on the atmosphere directly above it, data recorded from sources at the surface of the lake would vary somewhat from the data collected from the land-based sources. As a result, a small degree of inaccuracy is inherent in the meteorological forcing data.

\subsubsection{Air Temperature Data}

Average monthly temperatures for weather stations in the vicinity of Utah Lake were available in a report [32] issued by the National Climatic Data Center (NCDC), a 
division of the National Oceanic and Atmospheric Administration (NOAA). Three stations were chosen because of their proximity to Utah Lake, and their monthly mean high and low temperatures were averaged. The results can be found in Table 7.1.

Several difficulties arose when trying to create a meteorological file with the air temperatures as a function of time. Not only do the air temperatures vary cyclically over the course of a year, but they also vary cyclically from day to day. In addition, the daily variation in the range of temperatures (difference between maximum and minimum temperatures observed) changed from month to month.

Because of the annual and daily variations, initial attempts were made to fit a combination of sinusoidal curves of the following form to the data:

$$
T(t)=C_{1}-\cos \left[\frac{2 \pi}{365}(t-\alpha)\right]-\frac{V(t)}{2} \cos [2 \pi(t-\beta)]
$$

Table 7.1 Utah Lake Regional Air Temperatures (in ${ }^{\circ} \mathrm{C}$ )

\begin{tabular}{|c|c|c|c|c|c|c|c|c|c|c|}
\hline \multirow[t]{2}{*}{ Month } & \multicolumn{2}{|c|}{$\begin{array}{c}\text { Orem } \\
\text { Treatment } \\
\text { Plant }\end{array}$} & \multicolumn{2}{|c|}{$\begin{array}{c}\text { Brigham } \\
\text { Young } \\
\text { University }\end{array}$} & \multicolumn{2}{|c|}{$\begin{array}{c}\text { Utah Lake } \\
\text { Lehi }\end{array}$} & \multicolumn{4}{|c|}{ Average of NOAA Stations } \\
\hline & $\begin{array}{l}\text { Avg. } \\
\text { High }\end{array}$ & $\begin{array}{l}\text { Avg. } \\
\text { Low }\end{array}$ & $\begin{array}{l}\text { Avg. } \\
\text { High }\end{array}$ & $\begin{array}{l}\text { Avg. } \\
\text { Low }\end{array}$ & $\begin{array}{l}\text { Avg. } \\
\text { High }\end{array}$ & $\begin{array}{l}\text { Avg. } \\
\text { Low }\end{array}$ & $\begin{array}{l}\text { Avg. } \\
\text { High }\end{array}$ & $\begin{array}{l}\text { Avg. } \\
\text { Low }\end{array}$ & Mean & $\begin{array}{c}\text { Daily } \\
\text { Variation }\end{array}$ \\
\hline January & 2.67 & -6.50 & 4.00 & -5.28 & 2.56 & -9.06 & 3.07 & -6.94 & -1.94 & 10.02 \\
\hline February & 6.72 & -4.28 & 7.83 & -3.22 & 5.78 & -6.78 & 6.78 & -4.76 & 1.01 & 11.54 \\
\hline March & 13.17 & 0.50 & 13.28 & 0.94 & 10.61 & -2.17 & 12.35 & -0.24 & 6.06 & 12.59 \\
\hline April & 18.56 & 4.17 & 18.00 & 4.22 & 16.28 & 1.17 & 17.61 & 3.19 & 10.40 & 14.43 \\
\hline May & 24.17 & 8.11 & 23.50 & 8.28 & 21.50 & 5.17 & 23.06 & 7.19 & 15.12 & 15.87 \\
\hline June & 30.17 & 12.28 & 29.94 & 12.22 & 27.94 & 9.44 & 29.35 & 11.31 & 20.33 & 18.04 \\
\hline July & 33.50 & 15.89 & 34.11 & 15.78 & 32.11 & 13.17 & 33.24 & 14.94 & 24.09 & 18.30 \\
\hline August & 32.22 & 15.44 & 33.11 & 14.94 & 31.11 & 12.33 & 32.15 & 14.24 & 23.19 & 17.91 \\
\hline September & 26.22 & 10.61 & 27.39 & 10.17 & 25.67 & 7.06 & 26.43 & 9.28 & 17.85 & 17.15 \\
\hline October & 18.17 & 4.28 & 19.89 & 4.44 & 18.22 & 1.17 & 18.76 & 3.30 & 11.03 & 15.46 \\
\hline November & 9.06 & -1.11 & 10.72 & -0.56 & 9.06 & -3.89 & 9.61 & -1.85 & 3.88 & 11.46 \\
\hline December & 3.33 & -4.72 & 4.83 & -4.50 & 3.72 & -8.00 & 3.96 & -5.74 & -0.89 & 9.70 \\
\hline
\end{tabular}


where $\alpha$ and $\beta$ were the phase angles required to align the function with the minimum annual and daily temperatures, respectively, $V(t)$ was the daily variation in the range of observed temperatures as a function of the days elapsed since the beginning of the year $t$, and $C_{1}$ was a constant equal to the annual mean temperature for the region. The function in Eq. 7.1 assumed that the yearly and daily temperature variations were sinusoidal in nature with period lengths of one year and one day respectively. However, analysis showed that this was a poor approximation for the annual variation of the temperatures; a sinusoidal curve did not fit the monthly mean temperatures well, as shown in Figure 7.6. A different temperature approximation scheme was developed by modifying Eq. 7.1 as follows:

$$
T(t)=D(t)-\frac{V(t)}{2} \cos [2 \pi(t-\beta)]
$$

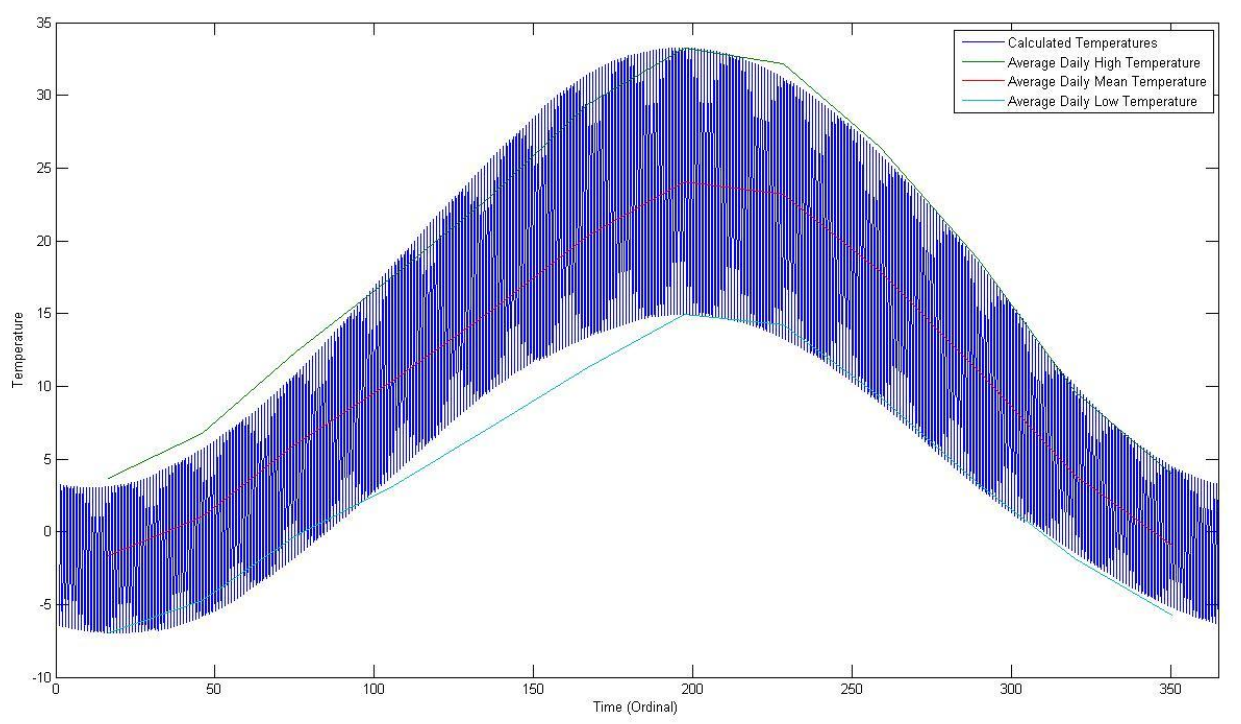

Figure 7.6 Sinusoidal approximation for daily air temperatures. 
where $D(t)$ was the average daily temperature as a function of time and all other variables were as defined above. Second-order Lagrange interpolating polynomials were used to determine both $D(t)$ and $V(t)$ as described below. The monthly average daily temperatures and variations were assumed to occur at the middle of each month, e.g. January $16^{\text {th }}$ at noon, Februaray $15^{\text {th }}$ at midnight, etc. It was also assumed that the coldest temperature occurred each day at 3 a.m. and that the hottest temperature occurred at 3 p.m. As a result, the value for the phase angle was $\beta=3 / 24=0.125$.

To calculate a value for any given time $t$, the polynomials used the data points from the previous, current, and following months, denoted as $t_{0}, t_{1}$, and $t_{2}$, respectively. Let $D_{a v}(t)$ and $V_{a v}(t)$ represent the average daily temperatures and variations for each month, which are discrete data points in Table 7.2. The functions $D(t)$ and $V(t)$ were then defined according to the following equations:

$$
\begin{gathered}
D(t)=\frac{\left(t-t_{1}\right)\left(t-t_{2}\right)}{\left(t_{0}-t_{1}\right)\left(t_{0}-t_{2}\right)} D_{a v}\left(t_{0}\right)+\frac{\left(t-t_{0}\right)\left(t-t_{2}\right)}{\left(t_{1}-t_{0}\right)\left(t_{1}-t_{2}\right)} D_{a v}\left(t_{1}\right) \\
\quad+\frac{\left(t-t_{0}\right)\left(t-t_{1}\right)}{\left(t_{2}-t_{0}\right)\left(t_{2}-t_{1}\right)} D_{a v}\left(t_{2}\right) \\
V(t)=\frac{\left(t-t_{1}\right)\left(t-t_{2}\right)}{\left(t_{0}-t_{1}\right)\left(t_{0}-t_{2}\right)} V_{a v}\left(t_{0}\right)+\frac{\left(t-t_{0}\right)\left(t-t_{2}\right)}{\left(t_{1}-t_{0}\right)\left(t_{1}-t_{2}\right)} V_{a v}\left(t_{1}\right) \\
+\frac{\left(t-t_{0}\right)\left(t-t_{1}\right)}{\left(t_{2}-t_{0}\right)\left(t_{2}-t_{1}\right)} V_{a v}\left(t_{2}\right)
\end{gathered}
$$

For example, on July $4^{\text {th }}$ (the $185^{\text {th }}$ day of the year) at 3 p.m. (0.625 days past midnight):

$$
\begin{array}{ll}
t=185.625 & \left.t_{0}=167.0 \text { (June } 16^{\text {th }} \text { at midnight }\right) \\
t_{1}=197.5\left(\text { July } 16^{\text {th }}\right. \text { at noon) } & t_{2}=228.5 \text { (August } 16^{\text {th }} \text { at noon) }
\end{array}
$$

The following values are obtained from Table 7.2: 


$$
\begin{array}{ll}
D_{a v}\left(t_{0}\right)=20.33 & V_{a v}\left(t_{0}\right)=18.04 \\
D_{a v}\left(t_{1}\right)=24.09 & V_{a v}\left(t_{1}\right)=18.30 \\
D_{a v}\left(t_{2}\right)=23.19 & V_{a v}\left(t_{2}\right)=17.91
\end{array}
$$

Using these numbers in Eq. 7.3 and 7.4 gives the following interpolated values:

$$
D(185.625)=23.17 \quad V(185.625)=18.28
$$

Finally, insertion of these values into Eq. 7.2 gives the air temperature at that time:

$$
\mathrm{T}(185.625)=32.31^{\circ} \mathrm{C}
$$

Temperatures were calculated for each hour of the year using a Matlab ${ }^{\circledR}$ code based on the data in Table 7.2 and Eq. 7.2 to 7.4. The resulting values fit the actual data from the NCDC report very well over the course of the entire year, as shown in Figures 7.7, 7.8, and 7.9.

\subsubsection{Atmospheric Pressure}

Rather than trying to account for the small variations in atmospheric pressure throughout the year, it was assumed that these variations would have little influence on the flow patterns and temperature distributions in the lake. The pressure was calculated as a function of the elevation using Kroo [33]. As a result, the pressure was assumed to be a constant $85.937 \mathrm{kPa}(12.464 \mathrm{psi})$ for all of the simulations.

\subsubsection{Relative Humidity}

Data for the monthly average relative humidity of the region around Utah Lake was taken from the MesoWest system maintained by the University of Utah in Salt Lake City [34]. A second-order interpolation scheme like those shown in Eq. 7.3 and 7.4 was used to convert the monthly data into a discrete data set with individual values taken at 


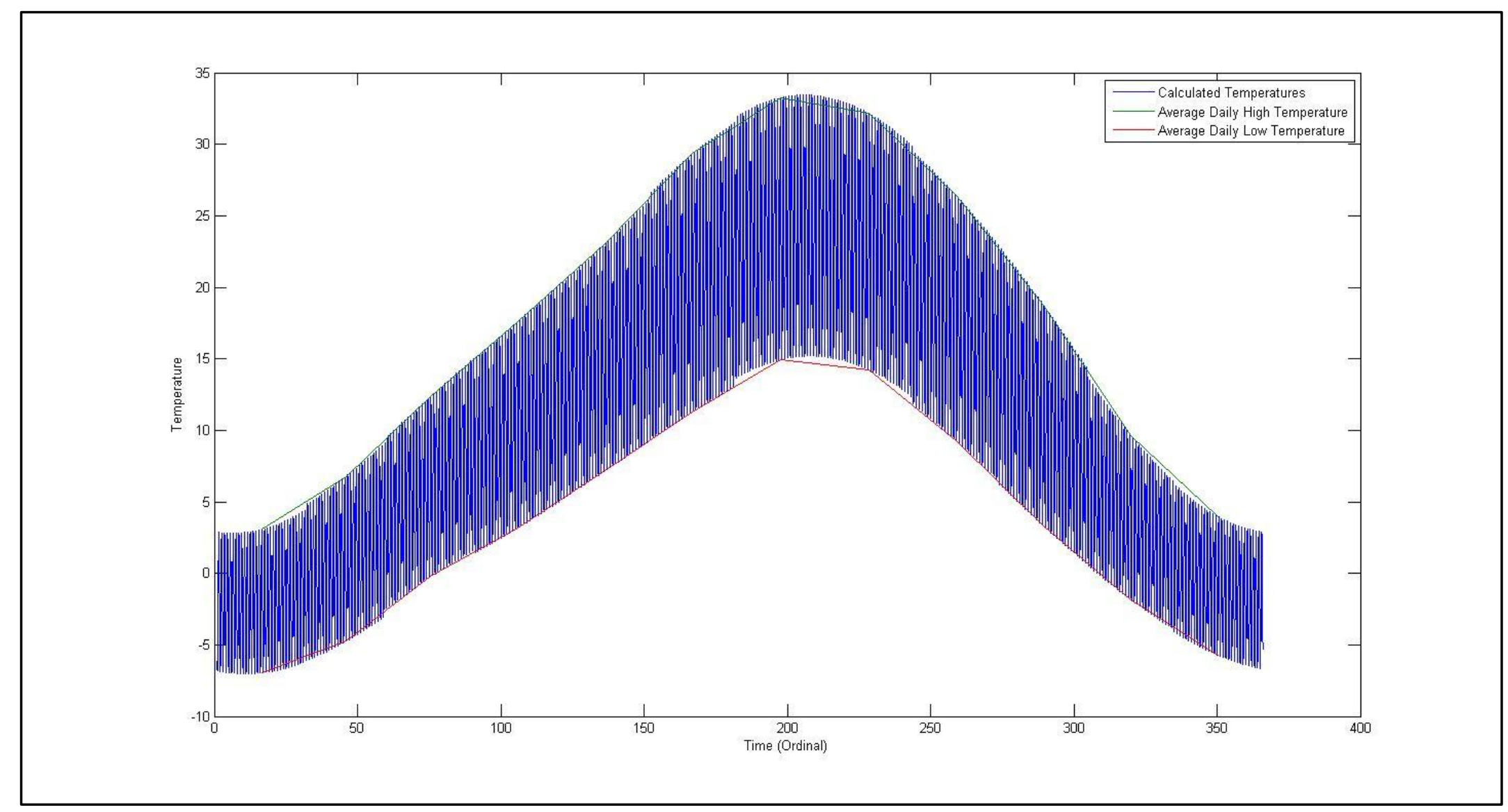

Figure 7.7 Interpolated daily temperatures for the entire year. 


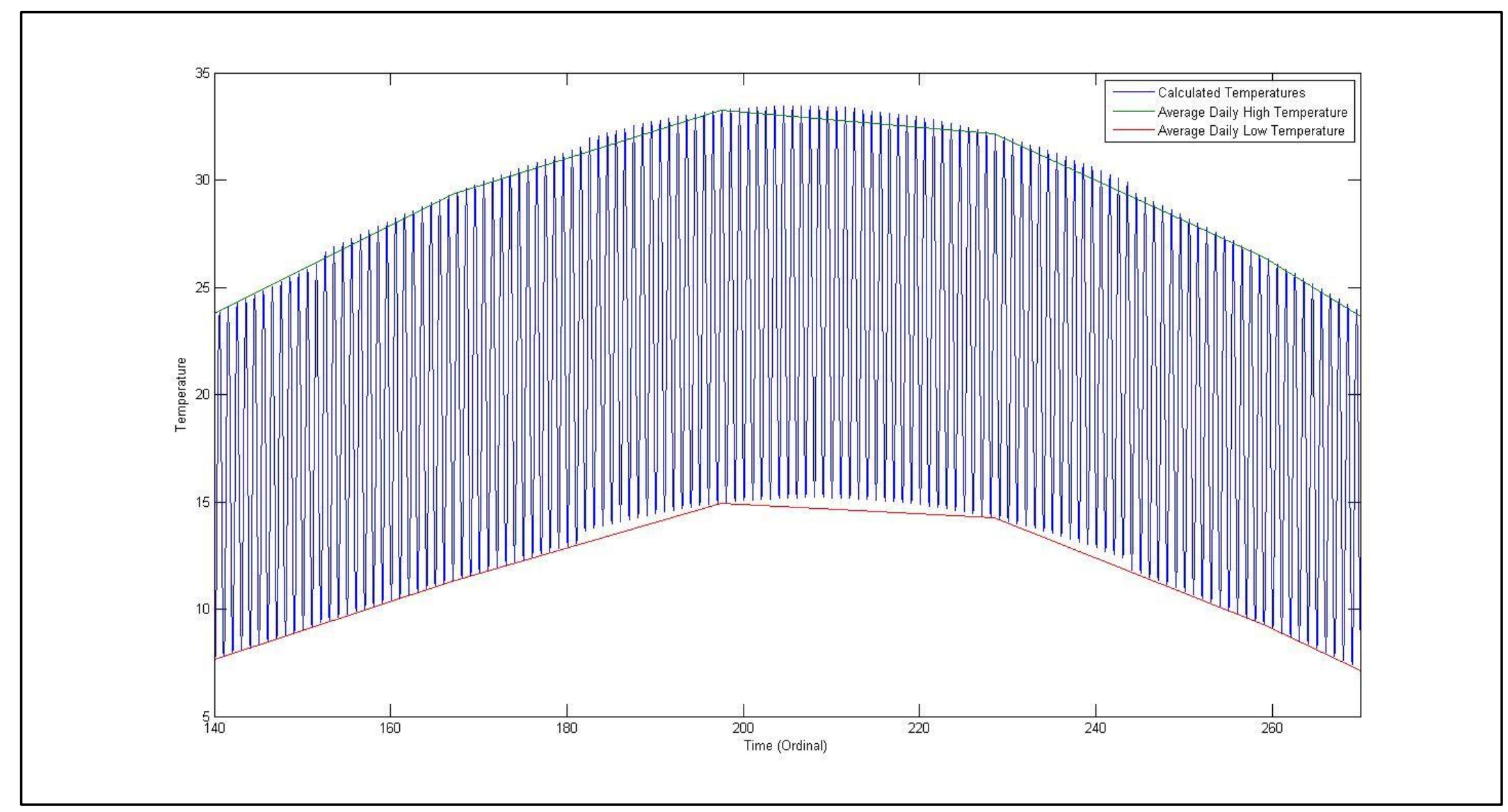

Figure 7.8 Interpolated daily temperatures for the summer months. 


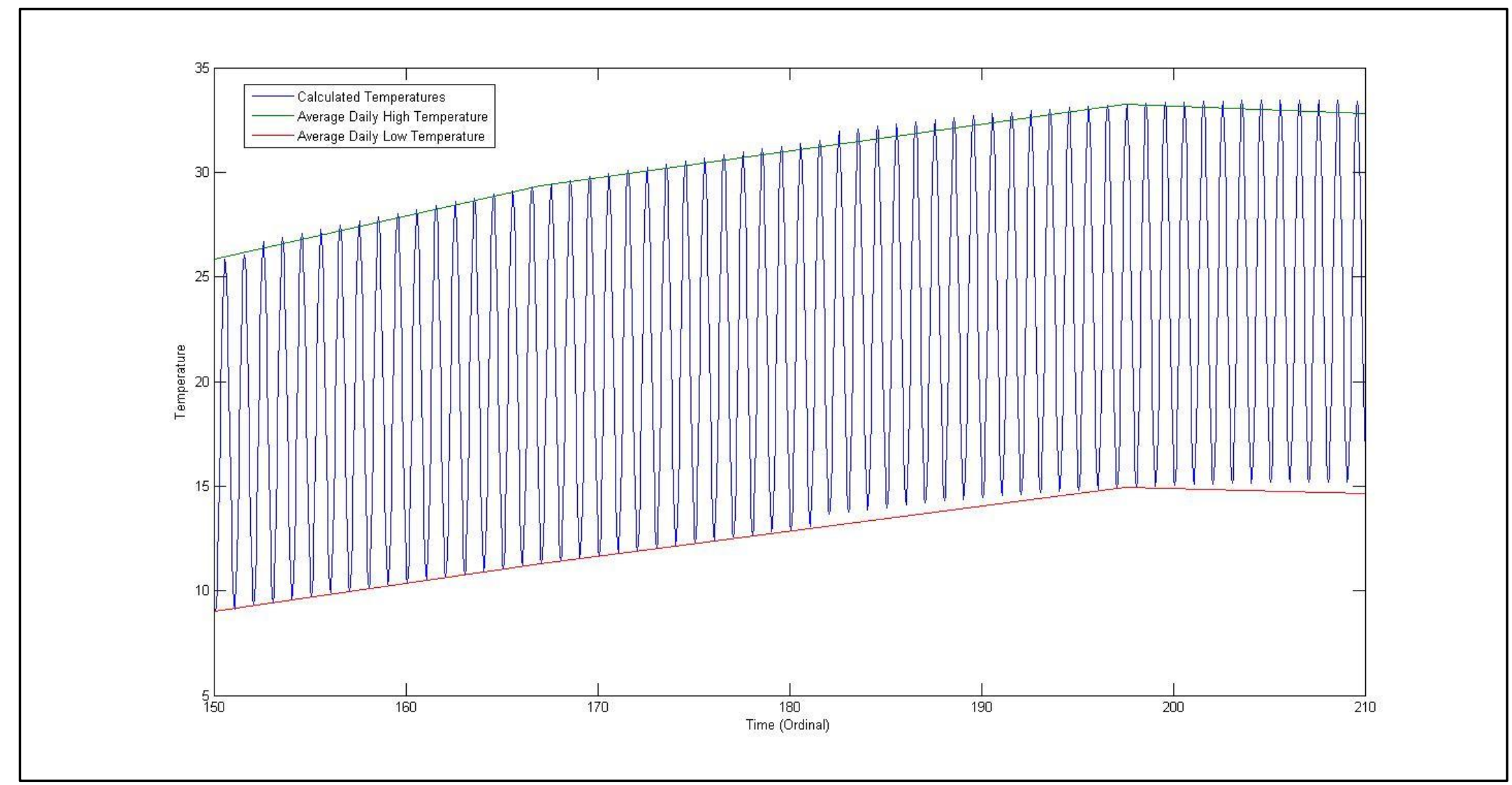

Figure 7.9 Magnified view of interpolated daily temperatures. 
user-defined intervals. The chart in Figure 7.10 was created using interpolated values at 20-minute intervals. For more information on the implementation of this scheme to produce the data values, see Section 7.4.8. The effects of varying the calculated relative humidity values by a user-defined percentage formed part of the parametric study. The results are presented and discussed in Section 9.2.4.

\subsubsection{Cloud Cover}

CWR-ELCOM allows the user to input the fractional amount of cloud cover, with 1.0 being a completely cloudy sky. A rough model for approximating the cloud cover was found in Walcek [35], which suggested that an exponential relationship exists between relative humidity and cloud cover of the form:

$$
f_{c l}\left(R_{h}\right)=\exp \left(\frac{R_{h}-1}{\alpha_{c l}-0.1 \sigma_{c l}^{2} w}\right)
$$

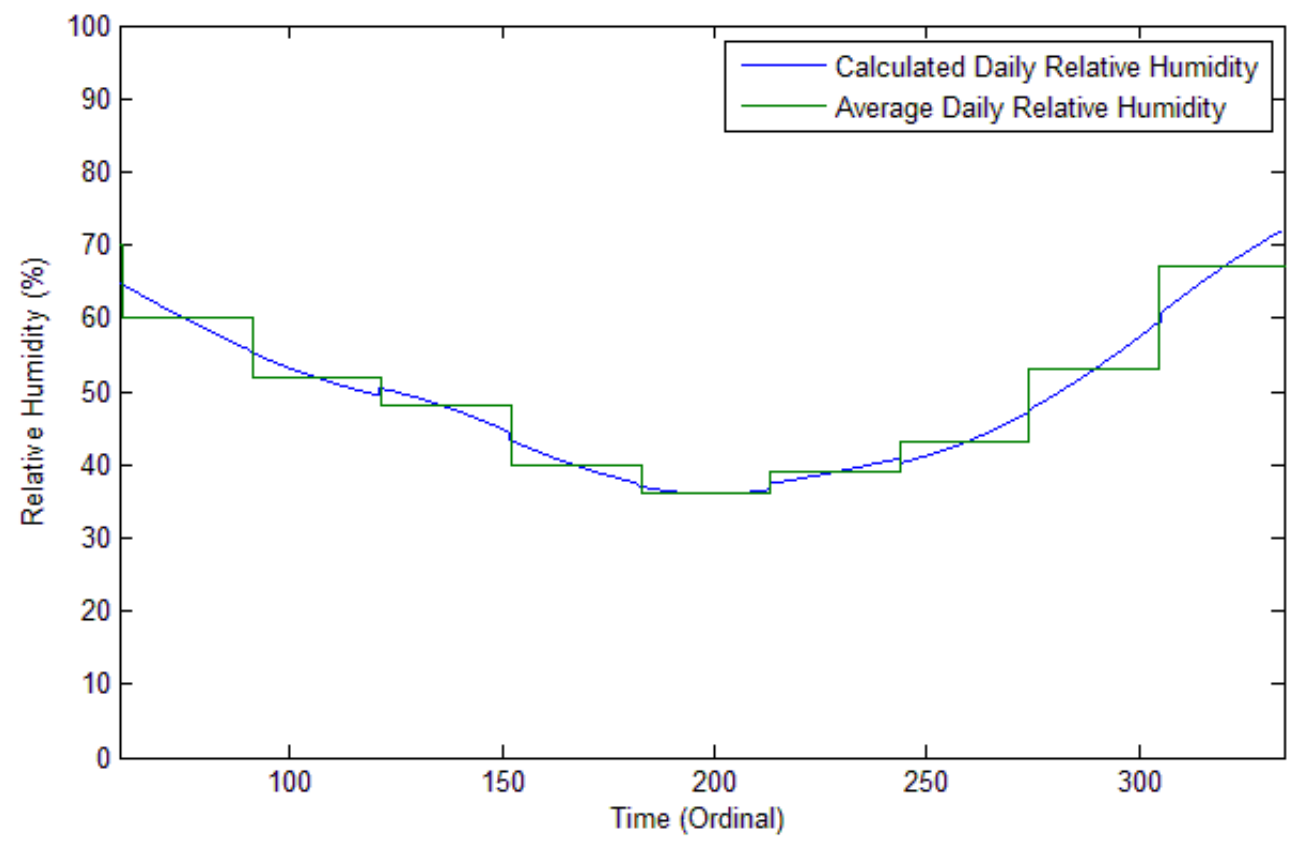

Figure 7.10 Calculated relative humidity and monthly averages. 
where $f_{c l}$ is the fractional cloud cover, $R_{h}$ is the relative humidity, $w$ is the vertical velocity, $\sigma_{c l}$ is the pressure relative to the surface pressure, and $\alpha_{c l}$ is given by:

$$
\alpha_{c l}= \begin{cases}0.2+\frac{\sigma_{c l}}{3}, & \sigma_{c l}<0.75 \\ 1.8\left(1-\sigma_{c l}\right), & \sigma_{c l} \geq 0.75\end{cases}
$$

Using Eq. 7.5 and 7.6, the cloud cover for each relative humidity value could be calculated. Fractional cloud cover for the relative humidity from Figure 7.10 is shown in Figure 7.11. The effects of varying the calculated cloud cover values by a user-defined percentage formed part of the parametric study. The results are presented and discussed in Section 9.2.2.

\section{$\underline{7.4 .5}$ Precipitation}

Average monthly precipitation for the region was taken from the NCDC report

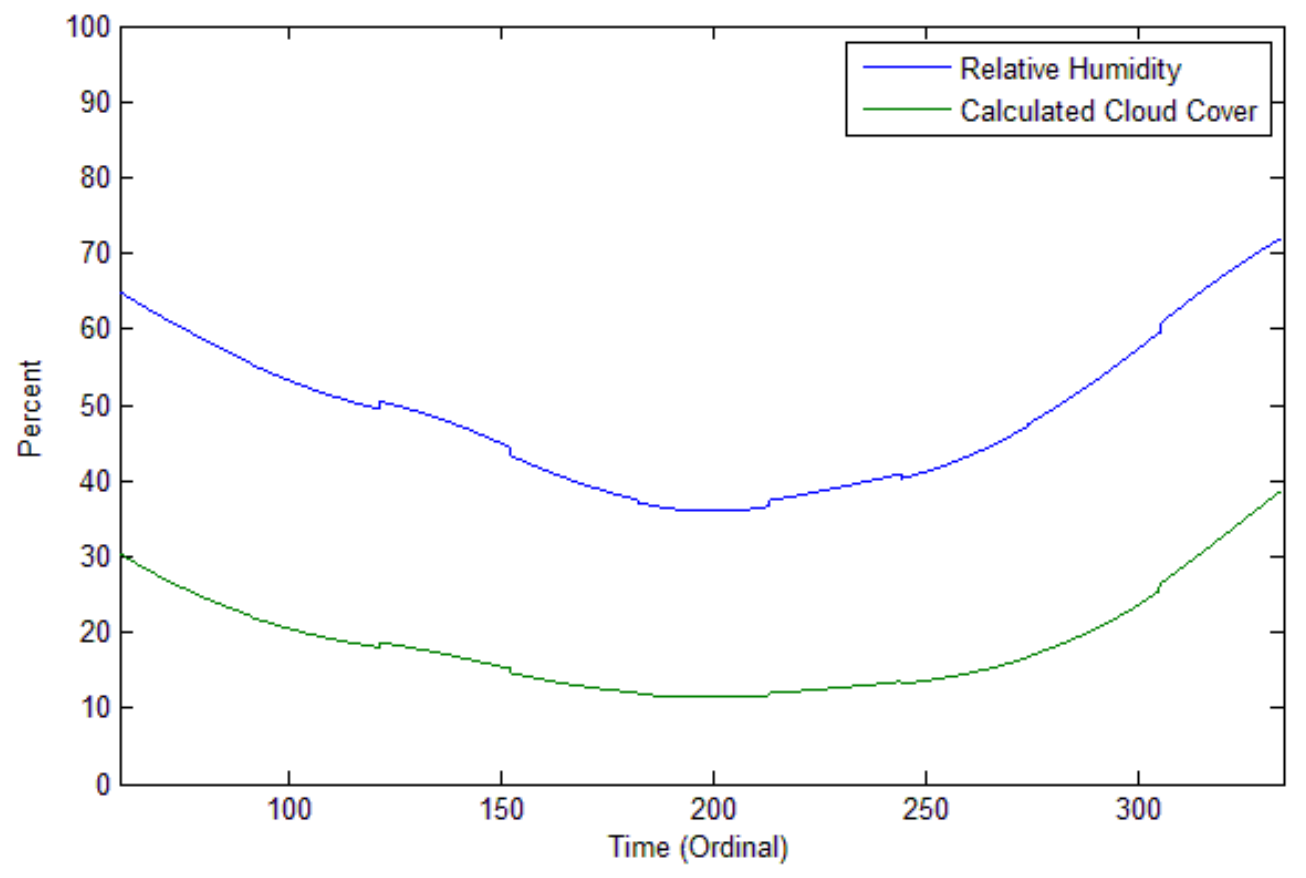

Figure 7.11 Calculated cloud cover values from relative humidity. 
[32]. The Utah Lake Lehi and Orem Treatment Plant weather stations were used as the basis for the determination. The average values recorded at these stations are shown in Table 7.2. The weather station at Brigham Young University (BYU) in Provo, Utah, recorded precipitation levels that were significantly higher than those recorded at the Utah Lake Lehi and Orem Treatment Plant weather stations. It was assumed that the mountains directly east of BYU had influenced the precipitation levels, so the data from the BYU station was excluded.

Second-order Lagrange polynomials like those in Eq. 7.3 and 7.4 were used to interpolate from these monthly averages to find individual data points at user-specified intervals. Rainfall values interpolated at 20 minute intervals are shown in Figure 7.12. The effects of varying the calculated cloud cover values by a user-defined percentage formed part of the parametric study. The results are presented and discussed in Section 9.2.6.

Table 7.2 Monthly Precipitation for Utah Lake Region (in cm)

\begin{tabular}{|l|c|c|c|}
\hline \multicolumn{1}{|c|}{ Month } & $\begin{array}{c}\text { Orem Treatment } \\
\text { Plant }\end{array}$ & Utah Lake Lehi & $\begin{array}{c}\text { Average } \\
\text { Precipitation }\end{array}$ \\
\hline January & 3.0988 & 2.4892 & 2.79 \\
\hline February & 2.8194 & 2.54 & 2.68 \\
\hline March & 2.921 & 2.8448 & 2.88 \\
\hline April & 3.302 & 3.302 & 3.30 \\
\hline May & 3.5052 & 3.556 & 3.53 \\
\hline June & 1.9812 & 1.6764 & 1.83 \\
\hline July & 1.7018 & 1.7018 & 1.70 \\
\hline August & 1.9558 & 2.4892 & 2.22 \\
\hline September & 2.921 & 2.921 & 2.92 \\
\hline October & 3.7846 & 3.3782 & 3.58 \\
\hline November & 2.6162 & 2.8702 & 2.74 \\
\hline December & 2.0066 & 1.7526 & 1.88 \\
\hline
\end{tabular}




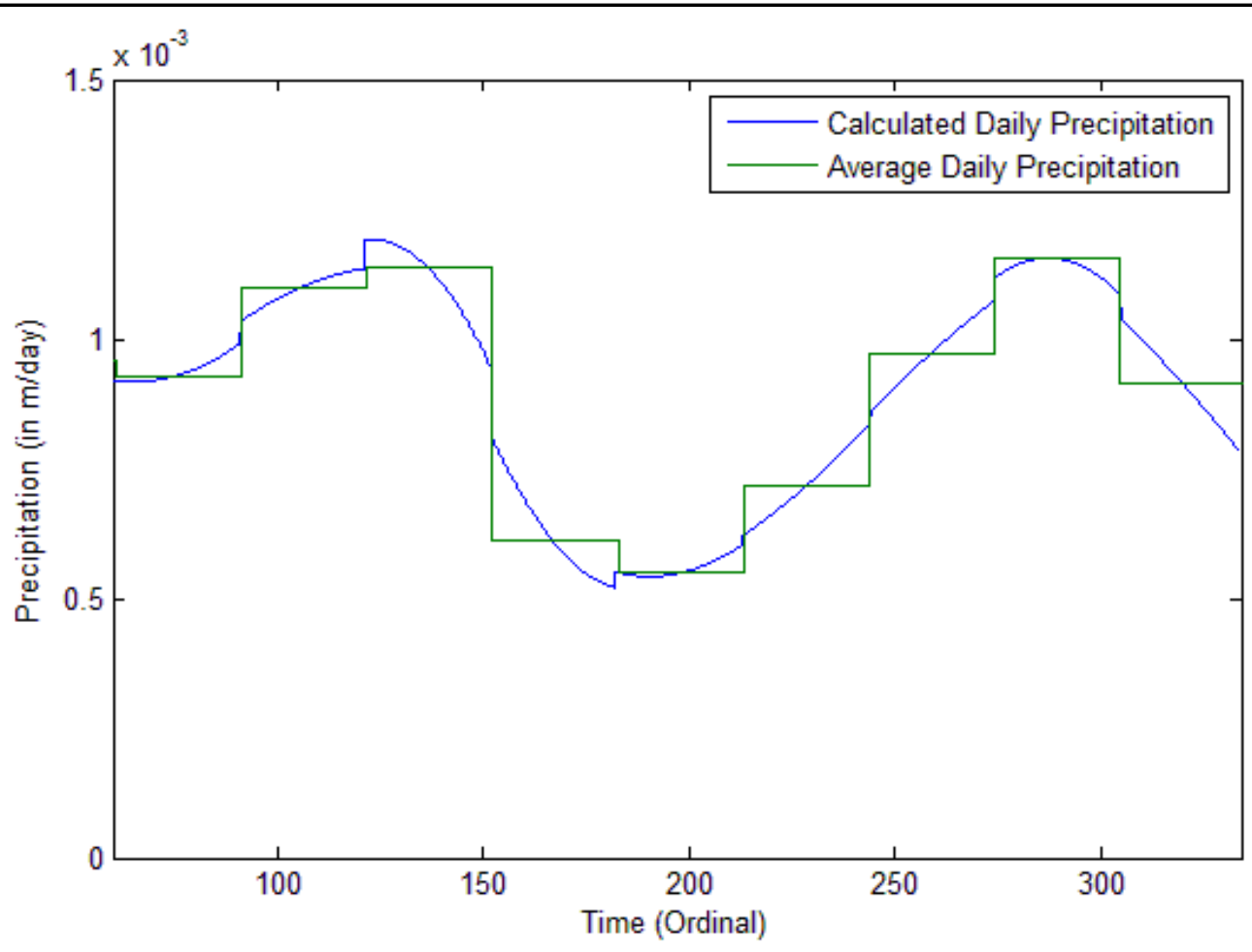

Figure 7.12 Interpolated rainfall values and average monthly values.

\subsubsection{Solar Radiation}

As mentioned in Sections 5.2.4 and 6.2.2, CWR-ELCOM includes two types of radiation in its simulations: short wave and long wave. The user is required to input short wave radiation values, either from direct measurement or using a radiation model. The long wave radiation values can either be input by the user or automatically calculated by CWR-ELCOM using the values for cloud cover, air temperature, and relative humidity. No radiation measurements were taken for the Utah Lake model, so a radiation model was used to produce the short wave radiation values. The long wave radiation values were computed by CWR-ELCOM as described above.

Hourly solar radiation values were obtained using the equations found in Martin and McCutcheon [36]. The model calculates incident short wave radiation based on the 
day of the year and the longitude and longitude of the region. It also accounts for the effect of dust particles in the air, diffusion of radiation into the atmosphere due to cloud cover, and the reflection of radiation off the surface of the earch.

To calculate the amount of short wave radiation reaching the surface, the method first calculates the total short wave radiation reaching the earth's atmosphere $H_{0}$ using the following equation:

$$
H_{0}=\frac{H_{s c}}{r^{2}}\left\{\begin{array}{c}
\sin \left(\frac{\pi \theta}{180}\right) \sin (\delta) \\
+\frac{12}{\pi} \cos \left(\frac{\pi \theta}{180}\right) \cos (\delta)\left[\sin \left(h_{e}\right)-\sin \left(h_{b}\right)\right]
\end{array}\right\} \Gamma
$$

where:

$$
\begin{aligned}
H_{0} & =\text { total short wave radiation reaching the earth's atmosphere }\left(\mathrm{W} / \mathrm{m}^{2}\right) \\
H_{s c} & =\text { solar constant }\left(1390 \mathrm{~W} \mathrm{~m}^{-2}=440 \mathrm{BTU} \mathrm{ft}^{-2} \mathrm{hr}^{-2}\right) \\
r & =\text { relative distance between the earth and sun } \\
\theta \quad= & \text { latitude (degrees) } \\
\delta \quad & \text { declination } \\
h_{e} \quad= & \text { solar hour angle (radians) at the end of the time period over which } H_{0} \\
& \text { is being calculated } \\
h_{b}= & \text { solar hour angle (radians) at the beginning of the time period over } \\
& \text { which } H_{0} \text { is being calculated } \\
\Gamma \quad & \text { correction factor for diurnal exposure to the radiation flux. }
\end{aligned}
$$

Next, the method calculates the amount of short wave radiation $H_{s w}$ that actually reaches the earth's surface after account for reflection due to dust particles and cloud cover:

$$
H_{s w}=H_{0} a_{t}\left(1-R_{s}\right) C_{a}
$$


where:

$$
\begin{aligned}
& a_{t} \quad=\text { atmospheric transmission term } \\
& R_{s} \quad=\text { albedo or reflection coefficient } \\
& C_{a} \quad=\text { fraction of solar radiation not absorbed by clouds }
\end{aligned}
$$

Further information on each of the terms in the above equations, including their definitions and how to calculate them, can be found in Martin and McCutcheon [36].

A subroutine was coded in Mathcad ${ }^{\circledR}$ based on these equations that used the cloud cover values calculated as described in Section 7.4.4 to determine the short wave radiation for each time in the data file.

\subsubsection{Wind Speed and Direction}

Wind data for the Utah Lake region was taken from the MesoWest system maintained by the University of Utah in Salt Lake City [34]. Only data from the year 2005 was available. The data showed the average wind velocity and direction at periodic intervals. This data was converted to an acceptable CWR-ELCOM format as described in Section 7.4.8 and used as a boundary condition file for the simulations.

\subsubsection{Initial Conditions}

Sufficient data to generate an initial temperature and velocity profile for the lake was not available. It was instead assumed that in early March, soon after all of the remaining ice on the lake melted, the water temperature was near freezing throughout the entire lake and very few, if any, currents were present. As a result, all simulations had a beginning date of March 8, 2007. The effect of the initialization temperature on the 
velocities and temperature distributions was included in the parametric study; the results are discussed in Section 9.2.3.

\subsubsection{Creating the Meteorological Data File}

CWR-ELCOM required that the meteorological data be placed in one or more formatted files, with each column containing a particular type of data (e.g. wind speed, cloud cover, etc.). An identifier for the data at the top of each column allowed the CWRELCOM simulation engine to properly utilize the data in the simulation.

Because the parametric study that formed such an integral part of the Utah Lake modeling effort focused on the influence of variations in individual parameters on the temperature distribution and flow field of Utah Lake, it was desirable to have a method to quickly and easily create various meteorological data files. A Matlab ${ }^{\circledR}$ code was written that performed the following functions:

- Allowed the user to specify separate percentages by which to vary the river inflow/outflow rates, river temperatures, air temperature, wind speed, precipitation, relative humidity, cloud cover, and solar radiation. In addition, the user could specify an angle by which to change the wind direction.

- Read in the MesoWest wind data, modified the wind speeds by the userdefined percentage and the wind direction by the user-defined angle, and wrote the file back out in a CWR-ELCOM acceptable format.

- Created an array of dates at user-specified intervals and interpolated to find river flow rate, river temperature, air temperature, relative humidity, and 
precipitation values for each time. The program also modified each type of value according to the user-defined percentages.

- Calculated cloud cover values for each interpolated relative humidity value, and modified them according to the user-defined percentage.

- Calculated solar radiation values for each cloud cover value, and modified them according to the user-defined percentage.

- Wrote the river flow rate values to a formatted file.

- Wrote the river temperature values to a formatted file.

- Wrote the air temperature, relative humidity, solar radiation, atmospheric pressure, precipitation, and cloud cover values to a formatted file.

- In each formatted file, the program included in the header section a list of the relevant user-defined percentages by which the data in that file had been modified.

Once this program was created, the requisite input files could quickly and easily be created for each simulation in the parametric study. In addition, the usage of the interpolation schemes enhanced the accuracy of the simulations. CWR-ELCOM's default method to obtain data values for each time step is linear interpolation between the two nearest data values. When only monthly data values are given, it must interpolate between data points that are far apart in time. Utilizing second-order interpolation between the monthly values and limiting CWR-ELCOM to linear interpolation between two closely spaced data points increased the accuracy of the input values and, by consequence, the overall accuracy of the simulation. 


\subsection{Boundary Conditions}

After the successful creation of a mesh representing the physical domain of Utah Lake, the rivers and streams that are the major tributaries of the lake could be located for inclusion in the simulation. The principal inflows for Utah Lake are the Provo River, Spanish Fork River, and Hobble Creek, while the principal outflow is the Jordan River.

\subsubsection{River Locations}

CWR-ELCOM requires that the user specify the river locations in a boundary condition file for use in the simulation. The user must specify the individual cell(s) in the mesh where the rivers join the lake system, as well as the face(s) of the cell through which water flows. The image of the Fish-n-Map Co.'s Utah Lake map was once again loaded into the digitizing software XYit, and approximate coordinates of the river openings around the edge of the lake were taken with respect to the image frame and saved in data files.

A linear interpolation scheme was used to locate the rivers inside the mesh. The approximate $i$ - and $j$-indices of the rivers were calculated according to the following equations:

$$
\begin{aligned}
& i^{*}=n_{x}\left(\frac{x_{v a l}}{L_{x}}\right) \\
& j^{*}=n_{y}\left(\frac{y_{v a l}}{L_{y}}\right)
\end{aligned}
$$

where:

$$
\begin{aligned}
& i^{*} \quad=\text { approximate } i \text {-index of the river in the mesh } \\
& j^{*} \quad=\text { approximate } j \text {-index of the river in the mesh }
\end{aligned}
$$




$$
\begin{aligned}
& n_{x} \quad=\text { total number of cells in the } x \text {-direction } \\
& n_{y} \quad=\text { total number of cells in the } y \text {-direction } \\
& x_{\text {val }} \quad=x \text {-coordinate of river found using digitizing software } \\
& y_{\text {val }} \quad=y \text {-coordinate of river found using digitizing software } \\
& L_{x} \quad=\text { length of digitizing image frame in } x \text {-direction } \\
& L_{y} \quad=\text { length of digitizing image frame in } y \text {-direction }
\end{aligned}
$$

Because the river indices must be integer values, $i^{*}$ and $j^{*}$ were rounded to the nearest whole numbers. However, because these were merely approximate indices for the rivers, the depth of the lake at point $\left(i^{*}, j^{*}\right)$ and at the surrounding cells was then checked automatically by an algorithm to ensure that $\left(i^{*}, j^{*}\right)$ was, in fact, the edge of the lake, and not a point in the land surrounding the lake or a cell surrounded by other water cells. If the algorithm discovered that the value was a land cell, it would "nudge" the river location by incrementing one of the indices for the river by one and rechecking the depths. If the location $\left(i^{*}, j^{*}\right)$ had previously been a "dry" land cell but was now, after relocation by the algorithm, a "wet" cell, the river was on the edge of the lake and the cell indices were stored as the location for that river in the mesh. Similarly, if the location $\left(i^{*}, j^{*}\right)$ had been a wet cell surrounded by other wet cells but now had a neighboring dry cell, the new indices of the location would be stored as the river indices.

Rather than allowing the algorithm to blindly search for the edge of the lake, however, it was told in what direction(s) to increment the indices for each of the rivers. For example, if a dry cell were discovered for the Jordan River, which is located in the northwest corner of Utah Lake, the algorithm would nudge its location alternately east 
and then south until water was encountered. Conversely, if a wet cell were discovered, the algorithm would nudge the river location alternately west and then north until land was encountered.

While the Jordan River, Provo River, and Hobble Creek could be represented by an influx of water through a single face of a wet cell because their entrance angles were fairly aligned with the mesh, the Spanish Fork River presented a unique challenge. It enters the lake at approximately a $45^{\circ}$ angle, so the algorithm was written to search for the nearest wet cell which had land on both its eastern and southern sides. Influx of water through both of these sides was specified to simulate the entrance angle.

After properly locating each river inside the mesh and identifying the cell faces through which the water would flow, the code containing the river locating algorithm would plot the locations of each river, as shown in Figure 7.13, write out the formatted boundary condition file required by CWR-ELCOM, and terminate.

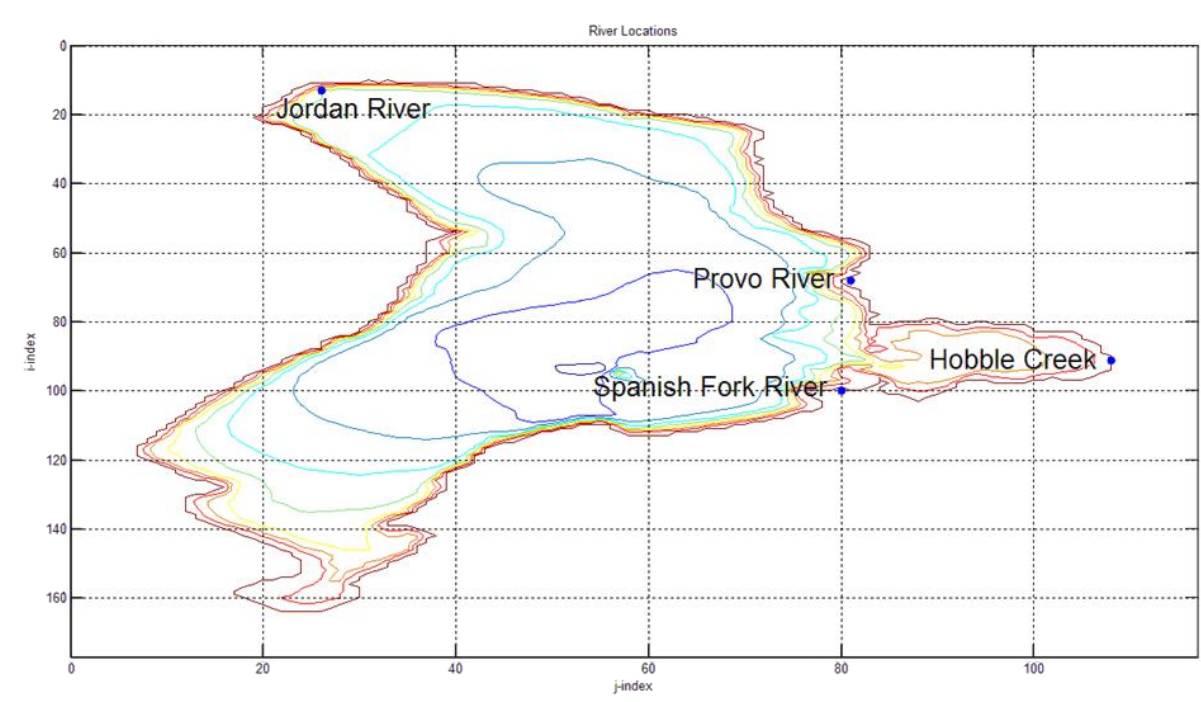

Figure 7.13 River locations in a 250-meter grid. 
Varying grid sizes were used as part of the parametric study. A line was added to the mesh generation script that "called" the code containing the river locating algorithm so as to generate the correct river indices within each new mesh. As a result, the user could specify the grid spacing, execute the code, and simultaneously produce both the bathymetry and boundary condition files for the simulation.

\subsubsection{River Flow Volumes}

Data on the volumetric flow rates as a function of time for Provo River, Hobble Creek, Spanish Fork River, and Jordan River was taken from water gauges maintained by the United States Geological Society (USGS) in each tributary. Table 7.3 has a list of the USGS gauge numbers from which the data was taken for each tributary, as well as the range of dates that the data spanned.

As can be seen, a substantial amount of historical data was available for Provo River, Hobble Creek, and Spanish Fork River. However, only about a year of data was available for the Jordan River. Because it was unknown whether or not 1986 was a typical flow year for the Jordan River, using these values would have increased the uncertainty in the simulation. The Jordan River is the only major outlet of the system, so it was assumed that its outflow would be approximately equivalent to the sum of the

Table 7.3 Sources of River Flow Data

\begin{tabular}{|l|c|c|}
\hline \multicolumn{1}{|c|}{ Tributary } & USGS Gauge Number & Data Period \\
\hline Jordan River & 10166605 & Oct. 1985 - Feb. 1987 \\
\hline Hobble Creek & 10152500 & Oct. 1908 - Sep. 1974 \\
\hline Provo River & 10163000 & Oct. 1903 - Sep. 2007 \\
\hline Spanish Fork River & 10152001 & Mar. 1975 - Apr. 1982 \\
\hline
\end{tabular}


inflows through the Provo River, Hobble Creek, and Spanish Fork River. The presence of underwater springs in Utah Lake (see Section 7.5.4) helps account for the losses due to evaporation and makes this approximation reasonable.

Average monthly flow values were extracted from the historical data of the USGS gauges and, using the second-order Lagrange interpolating polynomials in Eq. 7.3 and 7.4, flow values were found for individual dates according to user-specifications (see Section 7.4.8). The results were then written into a formatted file for use in CWRELCOM. Figure 7.14 depicts the river flow values obtained in this fashion at 20-minute intervals.

\subsubsection{River Water Temperatures}

Temperature data for Provo River, Hobble Creek, and Spanish Fork River were

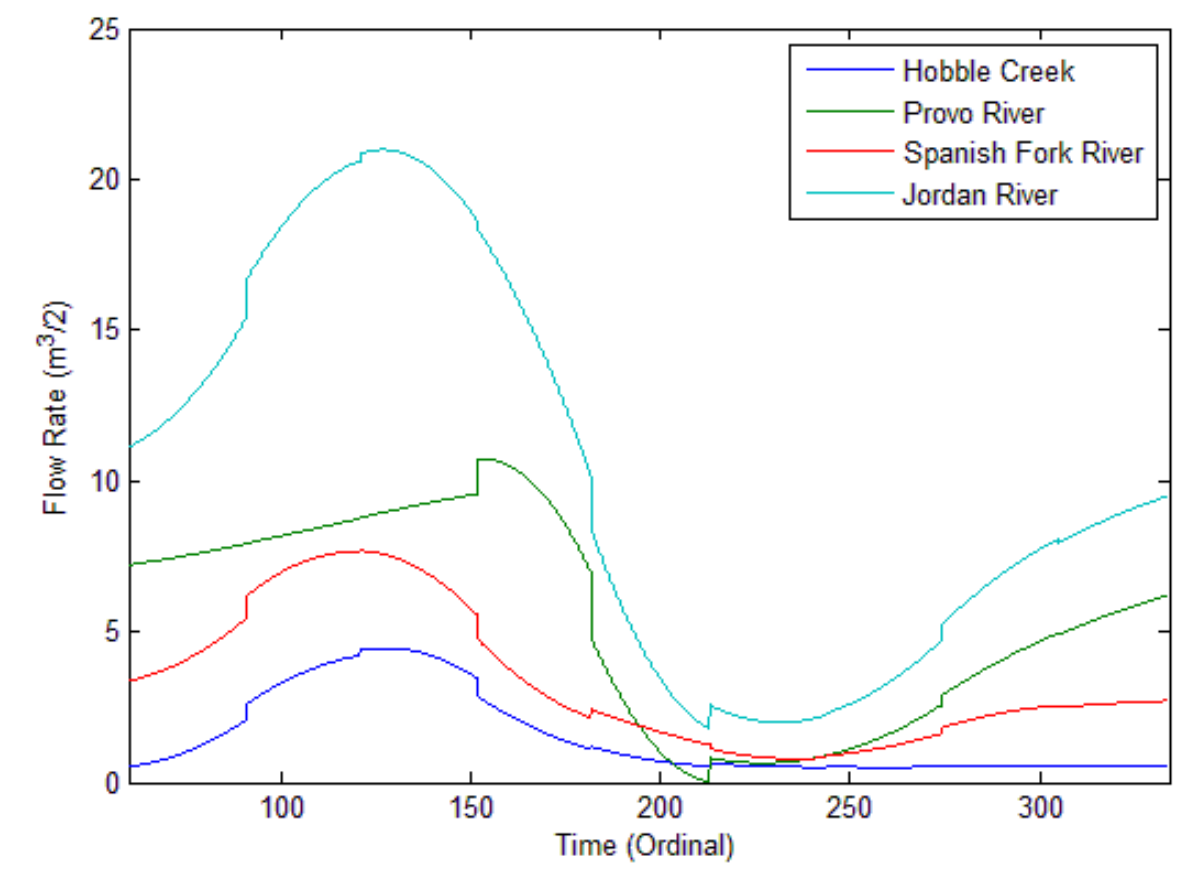

Figure 7.14 Interpolated volumetric flow rates for Utah Lake tributaries. 
not available. However, a USGS gauge (\#10133800) is located at East Canyon Creek to the northwest of Park City, Utah. The water in East Canyon Creek flows out of East Canyon Reservoir, located about 25 miles northwest of the Jordanelle Reservoir which feeds the Provo River. Because of the strong similarity between East Canyon Creek and the Provo River, the temperatures recorded in East Canyon Creek were applied to Provo River, Spanish Fork River, and Hobble Creek.

A separate USGS gauge (\#10171000) located in Salt Lake City recorded temperature information for the Jordan River from 1980 to 2002. While it would have been desirable to find a gauge closer to the source of the Jordan River to have more accurate data, such a gauge was not available. The monthly averages from the gauge in Salt Lake City were used as the basis for the Jordan River water temperature values.

Second-order Lagrange interpolating polynomials were used to convert the monthly average temperatures for all of the rivers to values at individual dates as specified by the user (see Section 7.4.8). The results were written to a formatted file for use in CWR-ELCOM. Figure 7.15 shows the interpolated temperatures plotted at 20minute intervals.

\subsubsection{Underwater Springs}

Several springs and seeps are found on the floor of Utah Lake, but the amount of inflow due to these groundwater sources is difficult to measure given their inaccessibility. Attempts have been made to estimate the inflow using a salt balance analysis in which concentrations of key dissolved ions in surface tributaries, fresh water springs, mineralized springs, and lake water was compared [37]. Using these methods, it was 


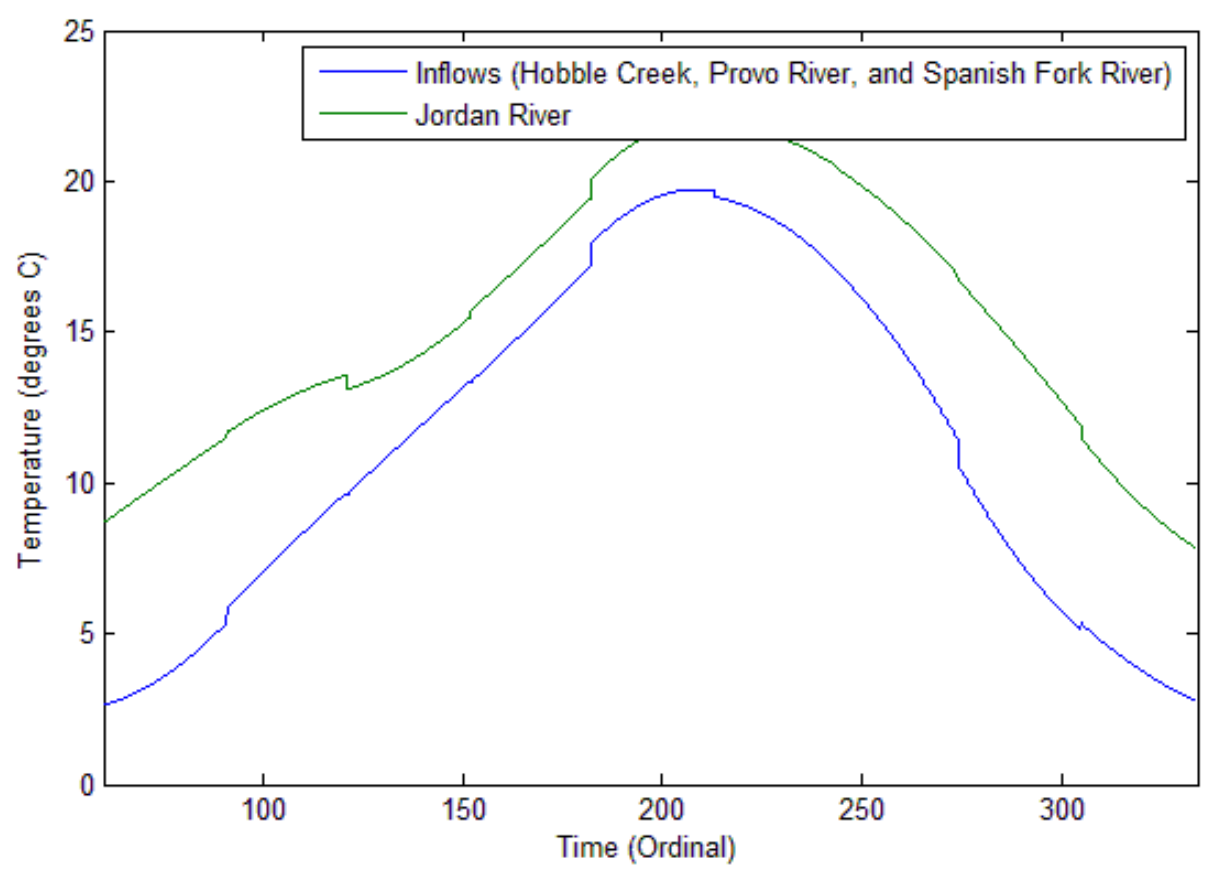

Figure 7.15 River water temperature values.

estimated that 114,000 acre-feet of total groundwater flows into the lake through the springs and seeps each year. Merritt [38] refined these methods and estimated that 77,000 acre-feet/year (12\% of total inflow) of the groundwater inflow is from freshwater springs and diffuse groundwater, while 26,000 acre-feet/year (4\% of total inflow) comes from mineral springs.

Although CWR-ELCOM has the capability to include springs and seeps along the lakebed, the lack of detailed information on spring and seep locations and flow rates as well as the level of difficulty associated with positioning each spring or seep within the mesh precluded their inclusion in this model. However, as mentioned in Section 7.5.2, the rate of outflow through the Jordan River was adjusted to compensate, in part, for the exclusion of the springs and seeps in the Utah Lake model. 


\subsection{Post-Processing CWR-ELCOM Output Files}

When the simulation engine, the second of CWR-ELCOM's three codes, completed a full simulation, it wrote out several files. The third CWR-ELCOM code was then used to convert these files to a format that could be processed using traditional data manipulation programs.

\subsubsection{Output File Format: netCDF}

The post-processing CWR-ELCOM code converted the results of each simulation to the network Common Data Format (netCDF) file format. The netCDF format was

developed by Glenn Davis, Russ Rew, Steve Emmerson, John Caron, Harvey Davies, and Ed Hartnett at the Unidata Program Center in Boulder, Colorado. According to the Unidata Program Center website, it has the following attributes:

- Self-Describing. A netCDF file includes information about the data it contains.

- Portable. A netCDF file can be accessed by computers with different ways of storing integers, characters, and floating-point numbers.

- Direct-access. A small subset of a large dataset may be accessed efficiently, without first reading through all the preceding data.

- Appendable. Data may be appended to a properly structured netCDF file without copying the dataset or redefining its structure.

- Sharable. One writer and multiple readers may simultaneously access the same netCDF file.

- Archivable. Access to all earlier forms of netCDF data will be supported by current and future versions of the software. [39]

As a result of these positive characteristics, the netCDF format was well-suited to the CWR-ELCOM application and was chosen as the default output file format for simulation results. 


\subsubsection{Matlab ${ }^{\circledR}$ Scripts}

The netCDF files were read into Matlab ${ }^{\circledR}$ using a script created by Paul Spencer that was found on the support site for Matlab ${ }^{\circledR}[40]$. Additional scripts were written in Matlab $^{\circledR}$ that would allow the user to extract the data from the netCDF file and plot temperatures and velocities at individual locations in the lake over time, create contour plots of the temperature profile at specified times, create vector plots of the velocity field at specified times, create videos of the temperature contours and velocity vector plots using the time-dependent values, and plot the free drifting path for fish larvae entering the lake through one of its tributaries.

\subsection{Grid Resolution}

While decreasing the size of the mesh does, in general, lead to a greater resolution in the results obtained, it also requires longer computational time. As described in Section 7.3, the programs that were written in Matlab $^{\circledR}$ allowed the user to define the size of the mesh for each simulation. Experimentation showed that simulations on 250-meter grids required approximately a day for completion. Coarsening the mesh to 500 meters reduced the required time to about four and a half hours, and 1000-meter mesh simulations could be solved in about an hour. Because of the large number of simulations to be performed as part of the parametric study, it was desirable to use as coarse of a mesh as possible while still maintaining model accuracy in order to reduce the total computational time required.

To determine the maximum mesh size allowable for accurate and resolved results, simulations with identical parameters were performed using 250-, 500-, and 1000-meter 
meshes. Because the sensor locations represented a good set of sampling locations, the temperature values and $u$ - and $v$-velocity components were plotted at each sensor location to determine the variations between the simulations performed on different grid sizes.

\subsubsection{Mesh Size and Temperature Resolution}

The majority of the plots showed very little difference between the temperatures calculated in the simulations with each grid size. However, at the "Jordan" sensor, the conditions produced a more significant difference in the plots for the 250-, 500-, and 1000-meter grids. Figures 7.16, 7.17, and 7.18 show plots of the temperature values over time at this sensor location. From these figures it can be seen that the results of the 1000$\mathrm{m}$ grid showed significant differences from those obtained using the more refined $250-\mathrm{m}$ grid. By contrast, however, the 500-m grid produced nearly the same results as the $250-\mathrm{m}$

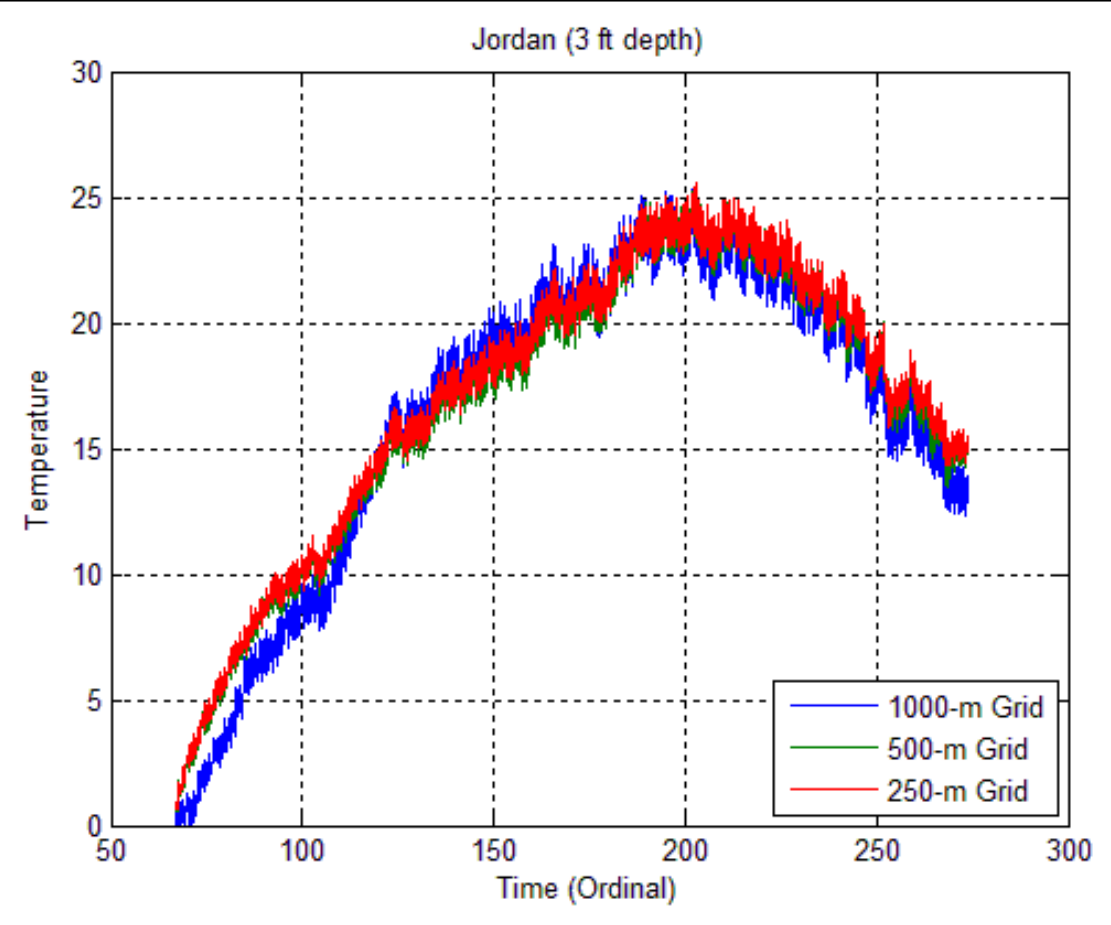

Figure 7.16 Simulation temperature results at Jordan sensor location: entire simulation grid comparison. 


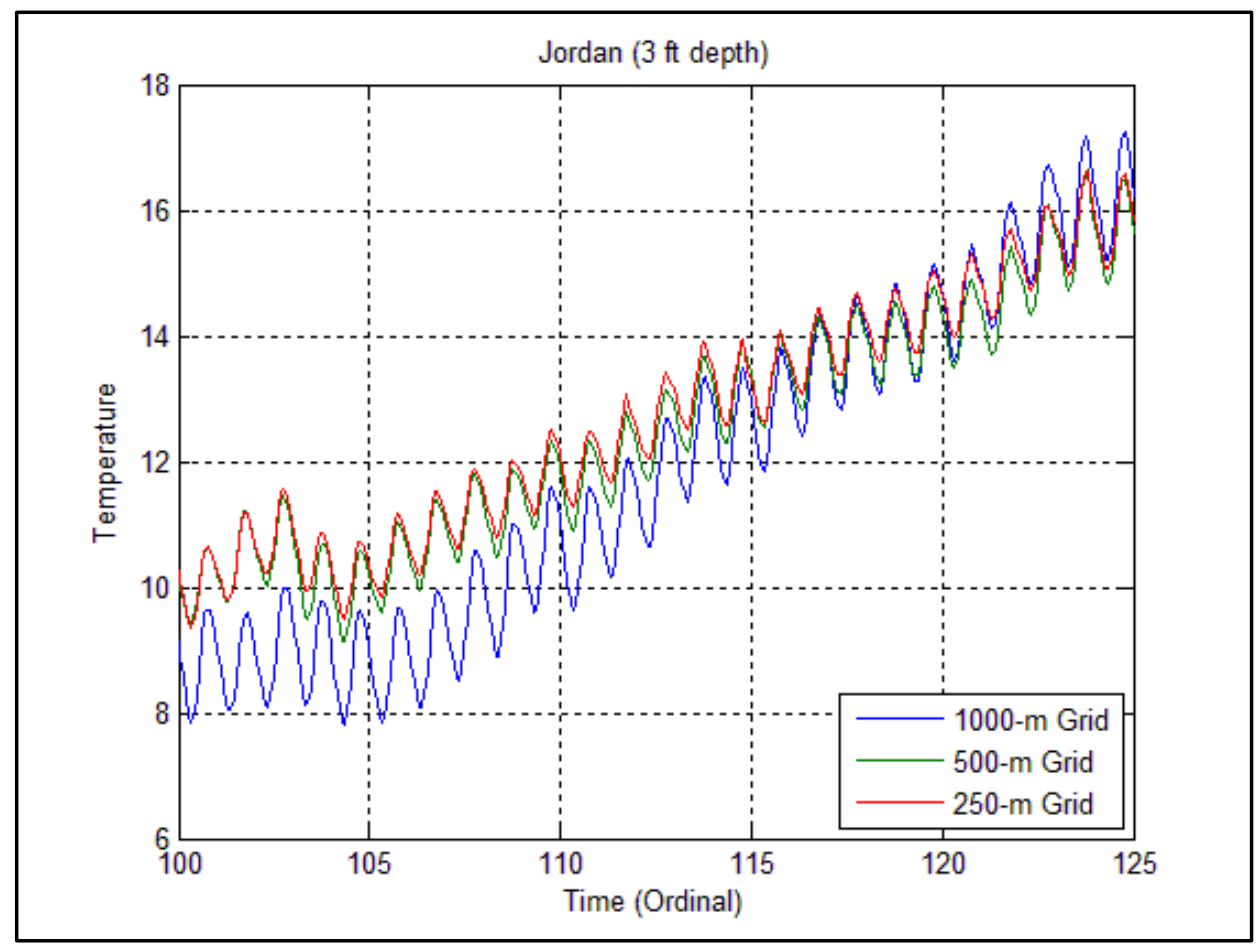

Figure 7.18 Simulation temperature results at Jordan sensor location: magnified view 1.

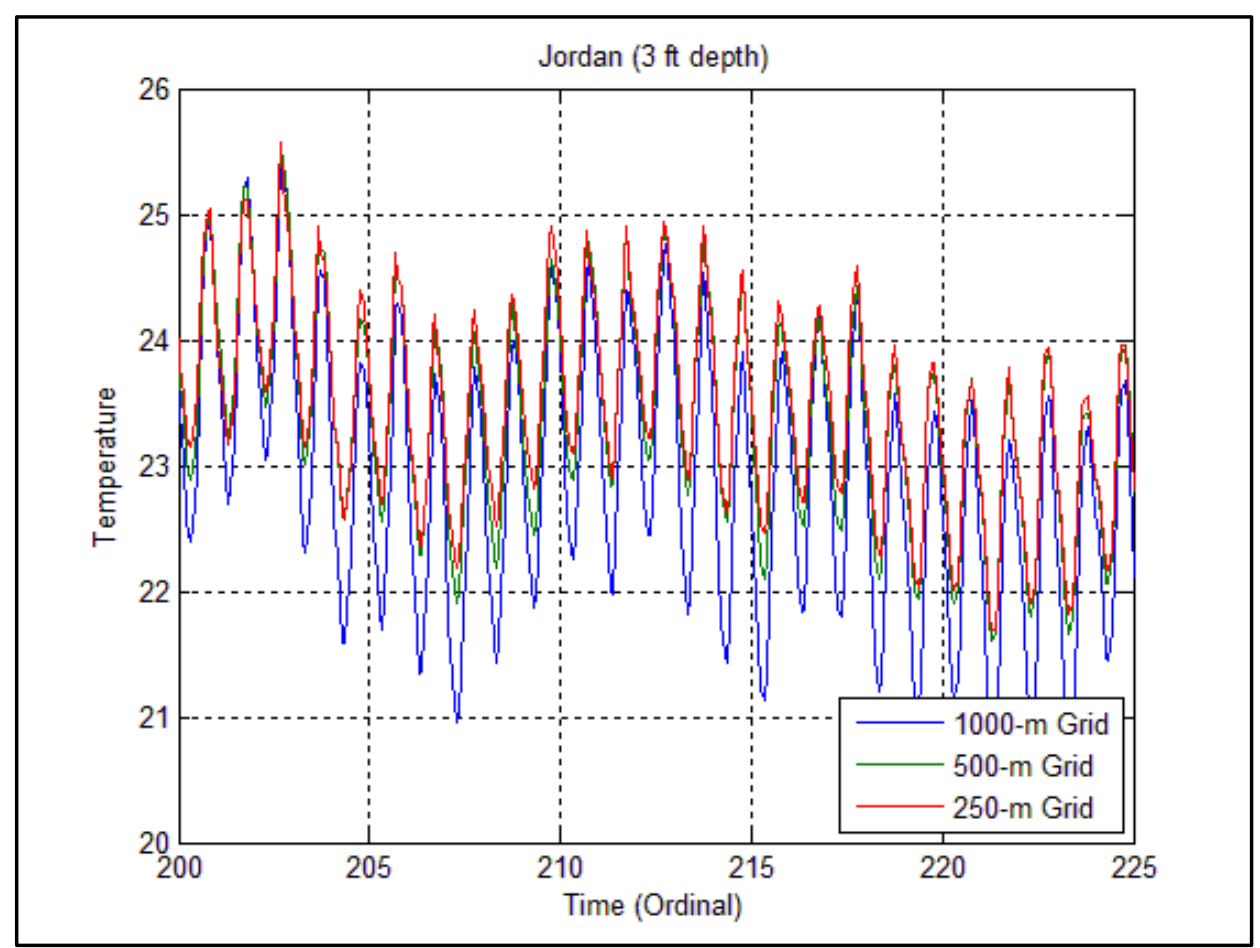

Figure 7.17 Simulation temperature results at Jordan sensor location: magnified view 2. 
grid. As a result, it was decided that, for the parametric study, the largest allowable grid size in order to still produce accurate temperature data would be 500 meters.

\subsubsection{Mesh Size and Velocity Component Resolution}

The $u$ - and $v$-velocity components from each grid size were plotted separately as functions of time for each of the sensor locations discussed in Section 7.8. Figures 7.19, 7.20, and 7.21 show sample plots created for the $u$-velocity components at some of the sensor locations, and Figures 7.21, 7.22, and 7.23 show sample plots for the $v$-velocity components. The 1000-m grid results deviated significantly from those obtained using the 250-m grid, while the 500-m grid produced very similar results. As with the grid resolution study for the temperature values, it was determined that the maximum allowable grid size to retain velocity component resolution would be 500 meters.

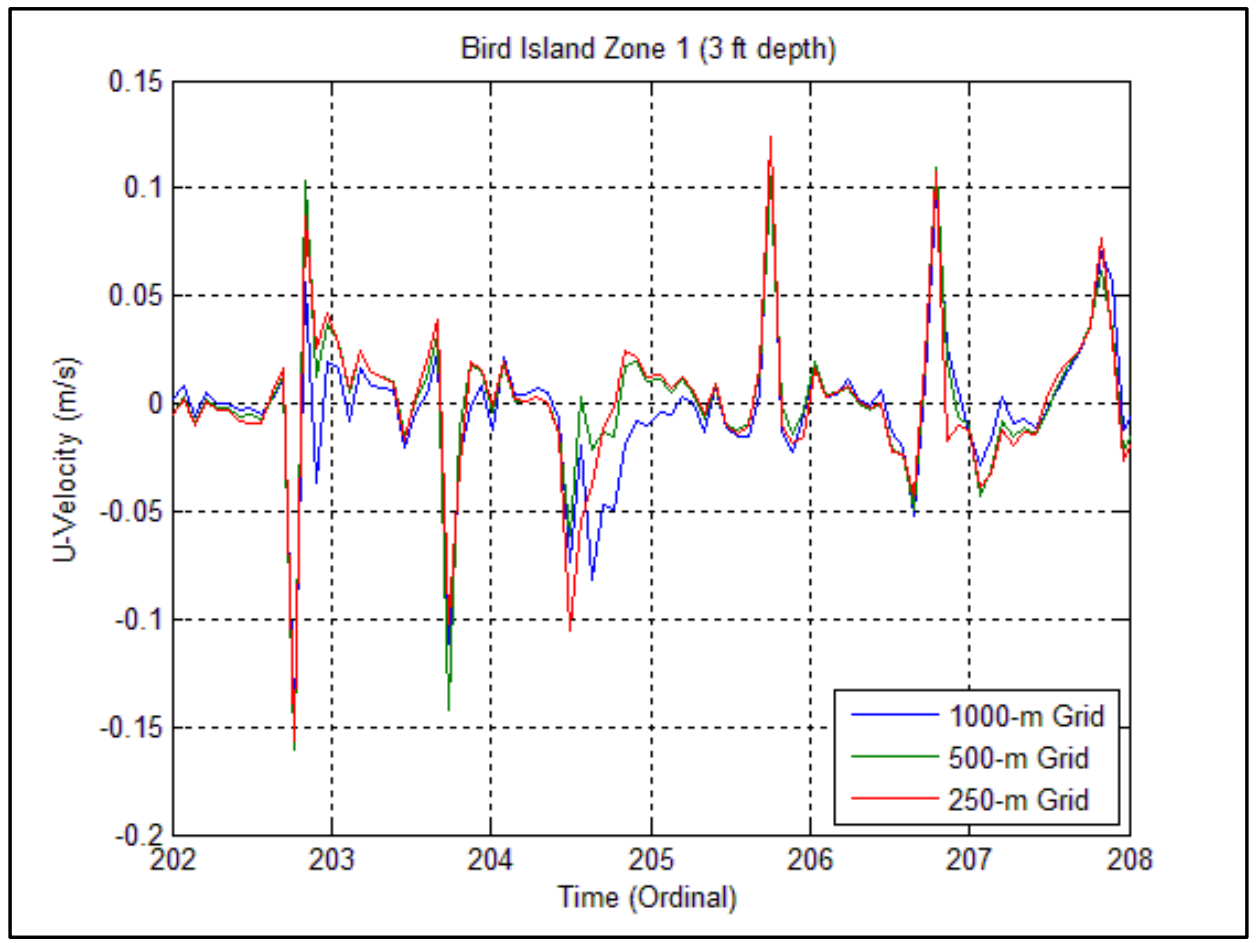

Figure 7.19U-velocity components at Bird Island sensor location. 


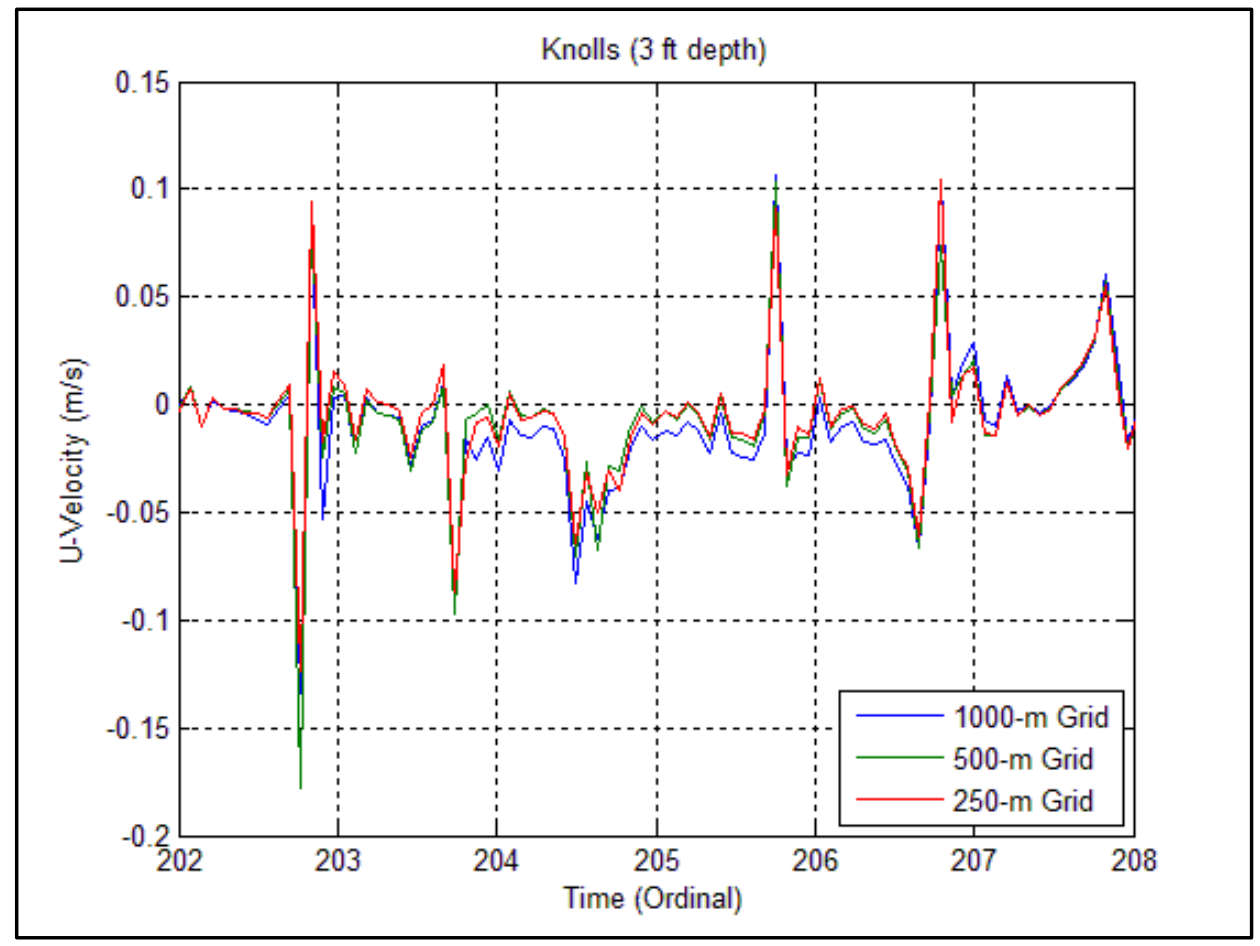

Figure 7.21 $U$-velocity components at Knolls sensor location.

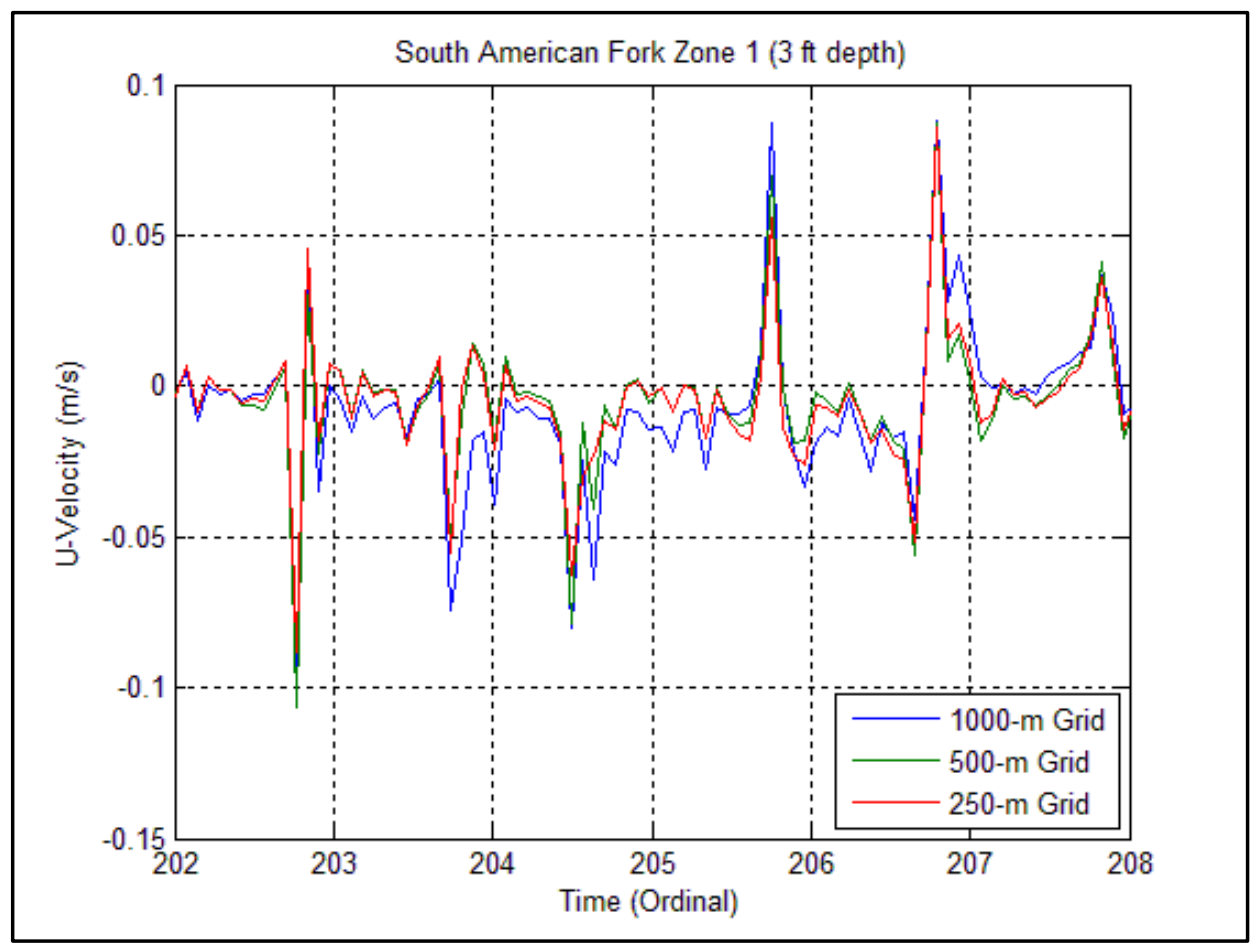

Figure 7.20 U-velocity components at South American Fork sensor location. 


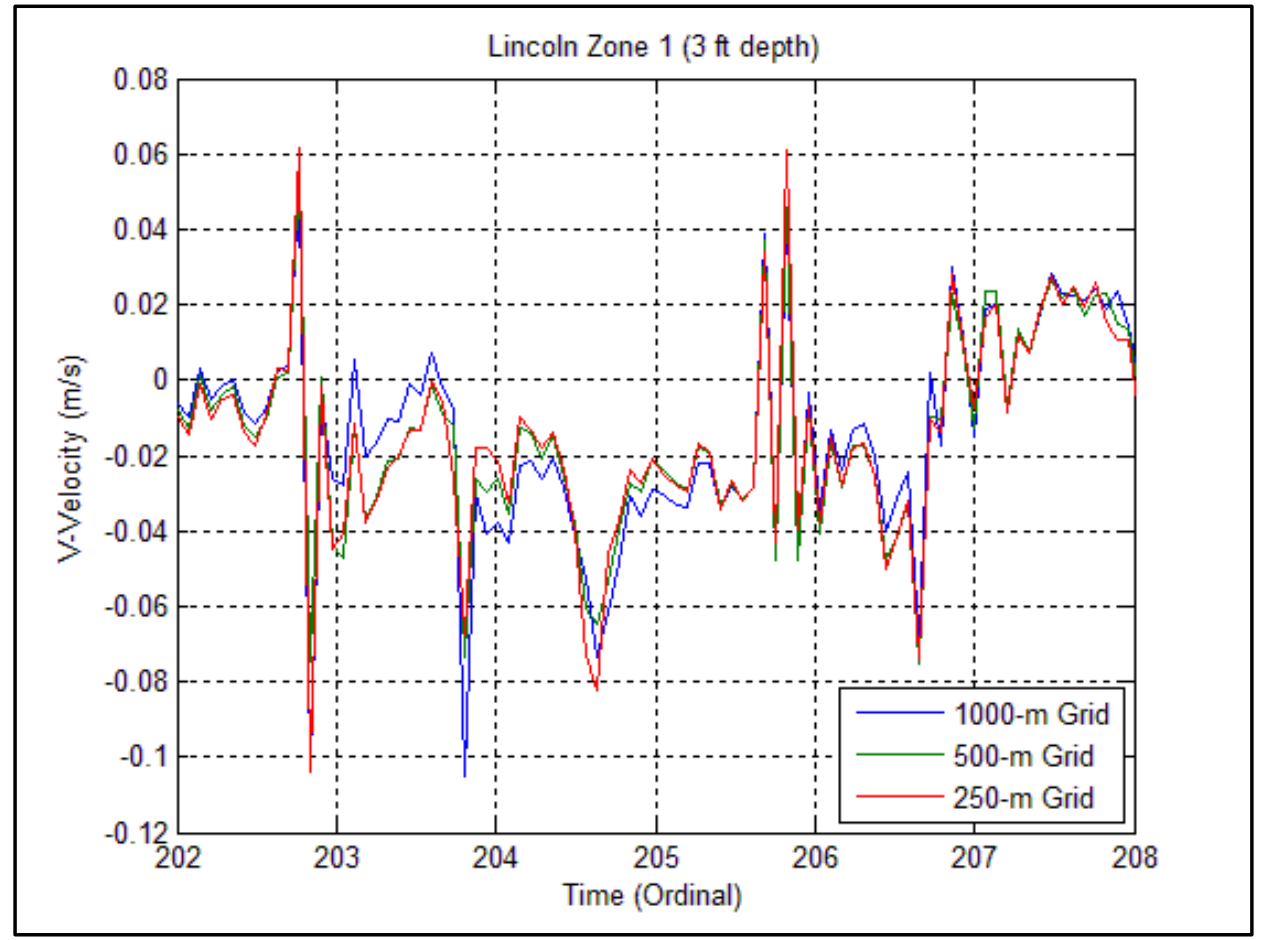

Figure 7.22 V-velocity components at Lincoln sensor location.

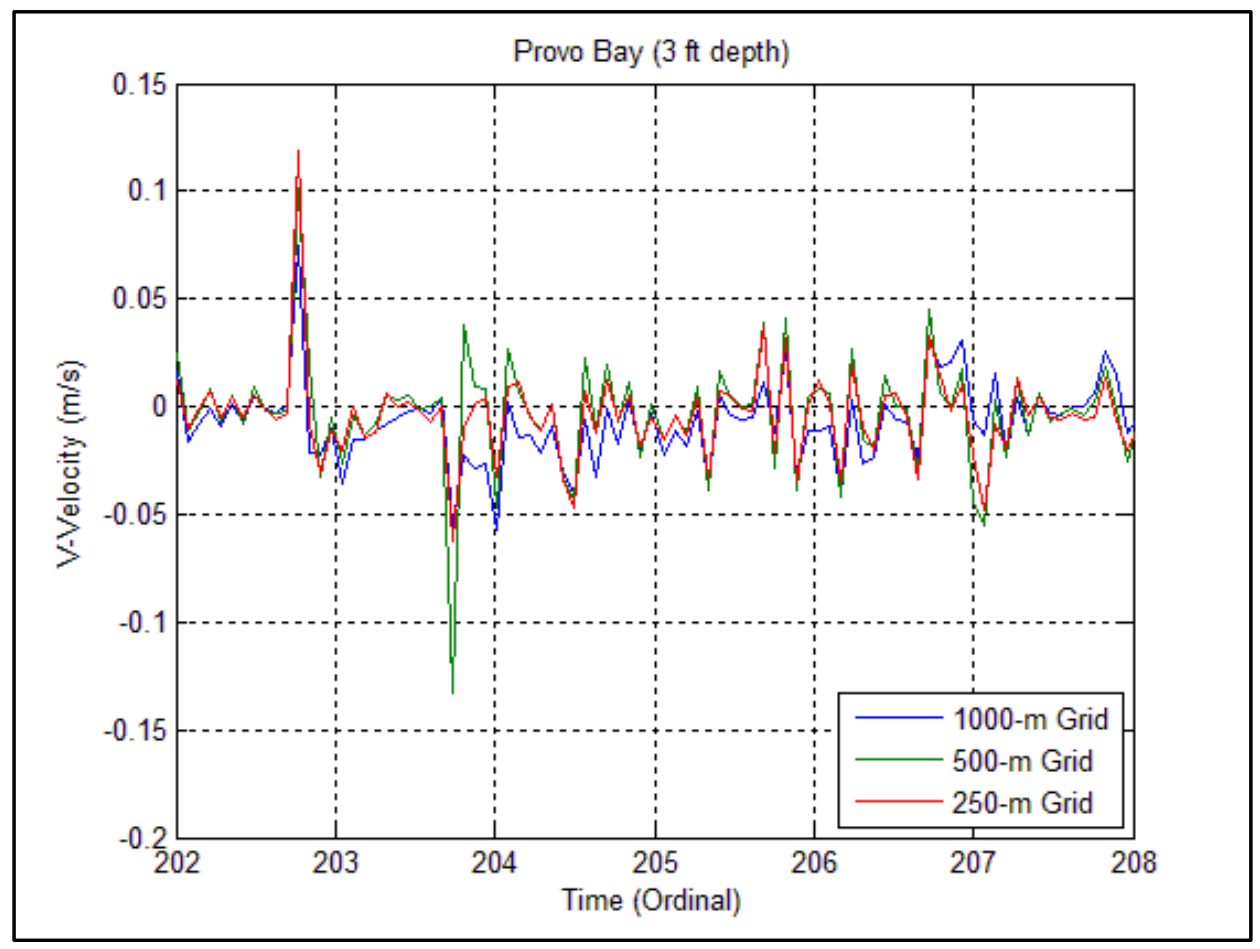

Figure 7.23 V-velocity components at Provo Bay sensor location. 


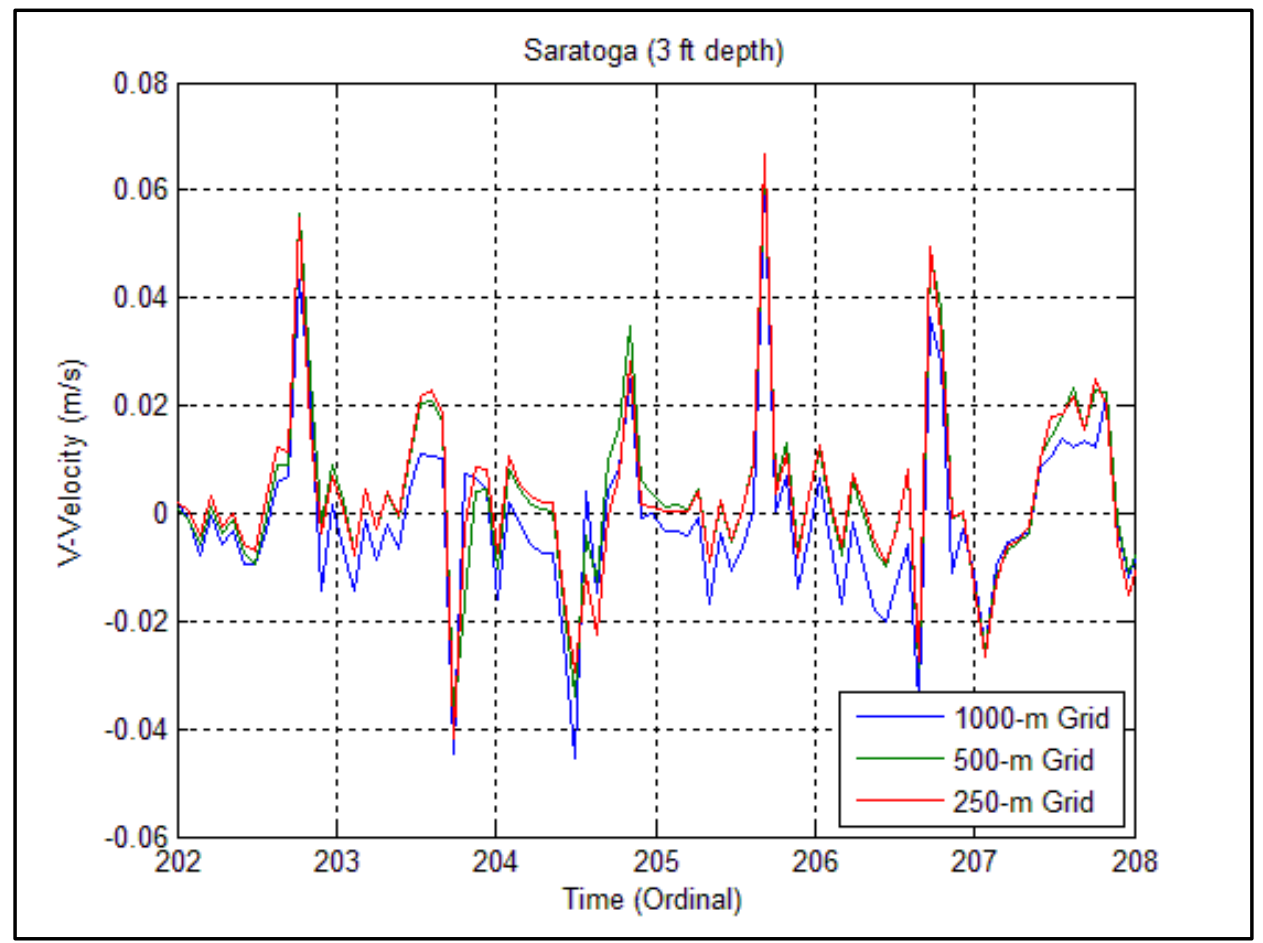

Figure 7.24 $V$-velocity components at Saratoga sensor location.

\subsection{Model Validation}

Several assumptions were made in the development of the Utah Lake model with regard to the input values. As a way to fine-tune these values and make any adjustments, if necessary, to make the model as accurate as possible, it was desirable to have a basis to which the simulation results could be compared. A set of 18 temperature sensors took temperature data at various locations in Utah Lake during the summer of 2007. Each chain had temperature sensors spaced at three-meter (9.84-foot) intervals along their length. The data from the sensors was recorded by a $\mathrm{HOBO}^{\circledR}$ Pendant Temperature/Light Data Logger that had a reported accuracy of about $\pm 0.5^{\circ} \mathrm{C}$ and a resolution of $0.10^{\circ} \mathrm{C}$. The results from the simulations were plotted against the measured data as a way to gauge the validity of the model. 


\subsubsection{Temperature Sensor Locations}

The approximate locations of the sensors were marked on a copy of the Fish-nMap Co.'s Utah Lake map by Brandon Wilson, one of the Utah State University students charged with maintaining the temperature sensors during the summer of 2007 . The image of this map was digitized using the XYit software to extract the coordinates for each temperature sensor. The indices for each sensor were then found using an interpolation system similar to the one described in Section 7.5.1 that was used to determine the river indices. Like the river indices algorithm, the algorithm for the temperature sensors also verified that each location was a wet cell and "nudged" the indices for each chain as necessary to ensure that each was in a wet cell. In general, the only situations for which the calculated indices had to be adjusted were when coarse grids were used. Because of the interpolations used in creating the mesh, temperature sensors located close to shore would appear to be in dry cells for large horizontal spacing. The locations of the temperature sensors in a 500-meter (1640-foot) mesh are shown in Figure 7.25.

\subsubsection{Plots of Actual vs. Simulated Temperatures}

Once the simulations were completed, the numerical results could be compared to the actual temperature data recorded by the temperature sensors to determine the approximate accuracy of the model. As mentioned in Section 2.2, unexpected natural phenomenon preclude the model from being able to predict the exact temperature and flow conditions at any point in the simulation time, but instead give average values for each. 


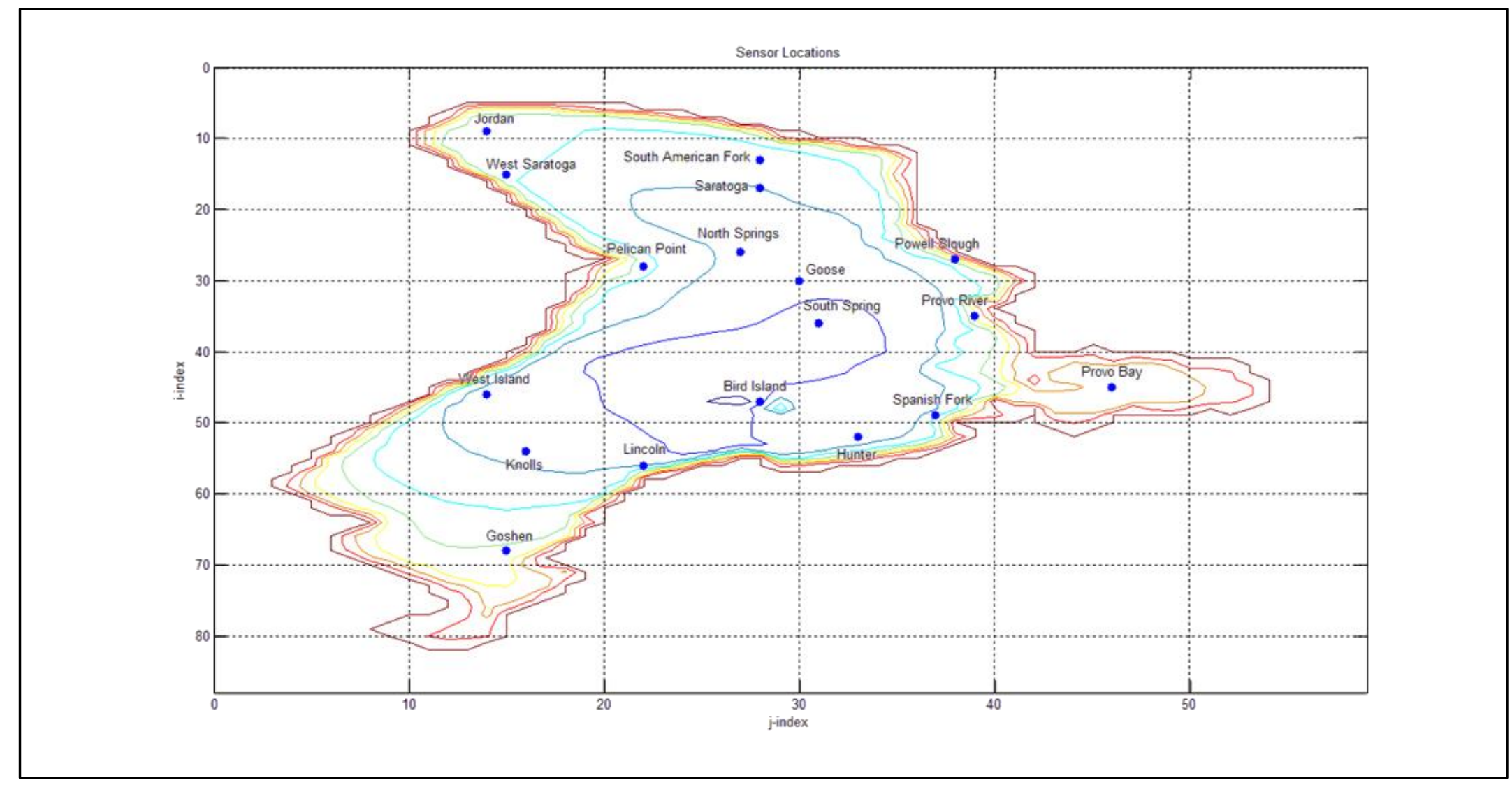

Figure 7.25 Temperature sensor locations in a 500-meter grid. 
Figures 7.26, 7.27, and 7.28 depict selected plots of the actual and simulation temperature values at three of the temperature sensor locations. The simulation manages to approximate the actual temperature values to within a few degrees at these three locations over the range of the simulated time. Close examination of the plots, however, reveals that the simulation slightly underpredicts the temperatures for the year 2007. It is unknown whether the discrepancy is attributable to measurement errors in the meteorological data or whether it is due to an error in the temperature measurements.

Analysis of the temperature sensor data revealed that several of the locations had unrealistic temperature values over a portion of the time in which they were taking measurements. For example, Figure 7.28 depicted the actual and simulation temperatures at the Saratoga temperature sensor location after day 165 (June $\left.14^{\text {th }}\right)$. The complete data

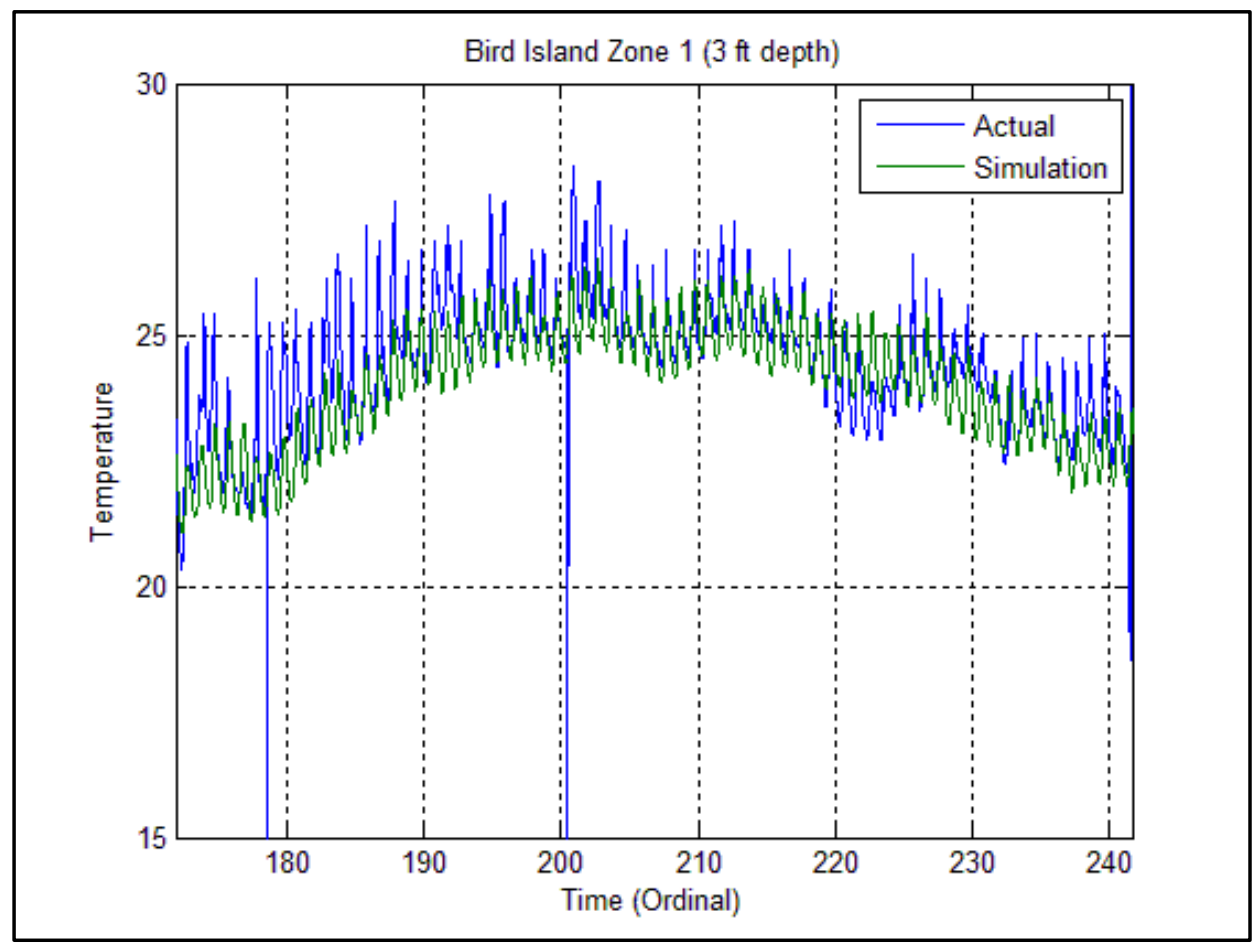

Figure 7.26 Actual vs. simulation temperatures at Bird Island sensor location. 


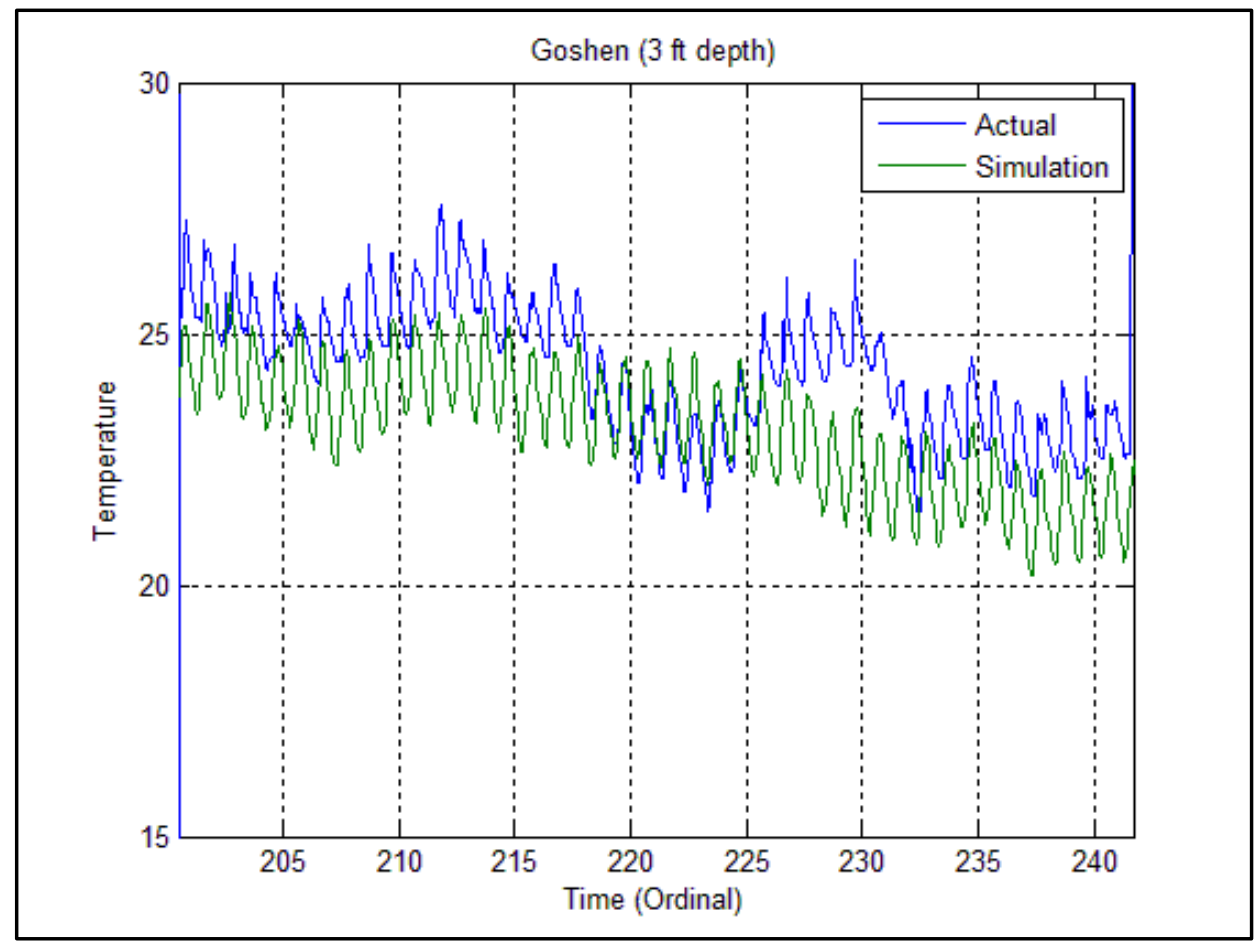

Figure 7.28 Actual vs. simulation temperatures at Goshen sensor location.

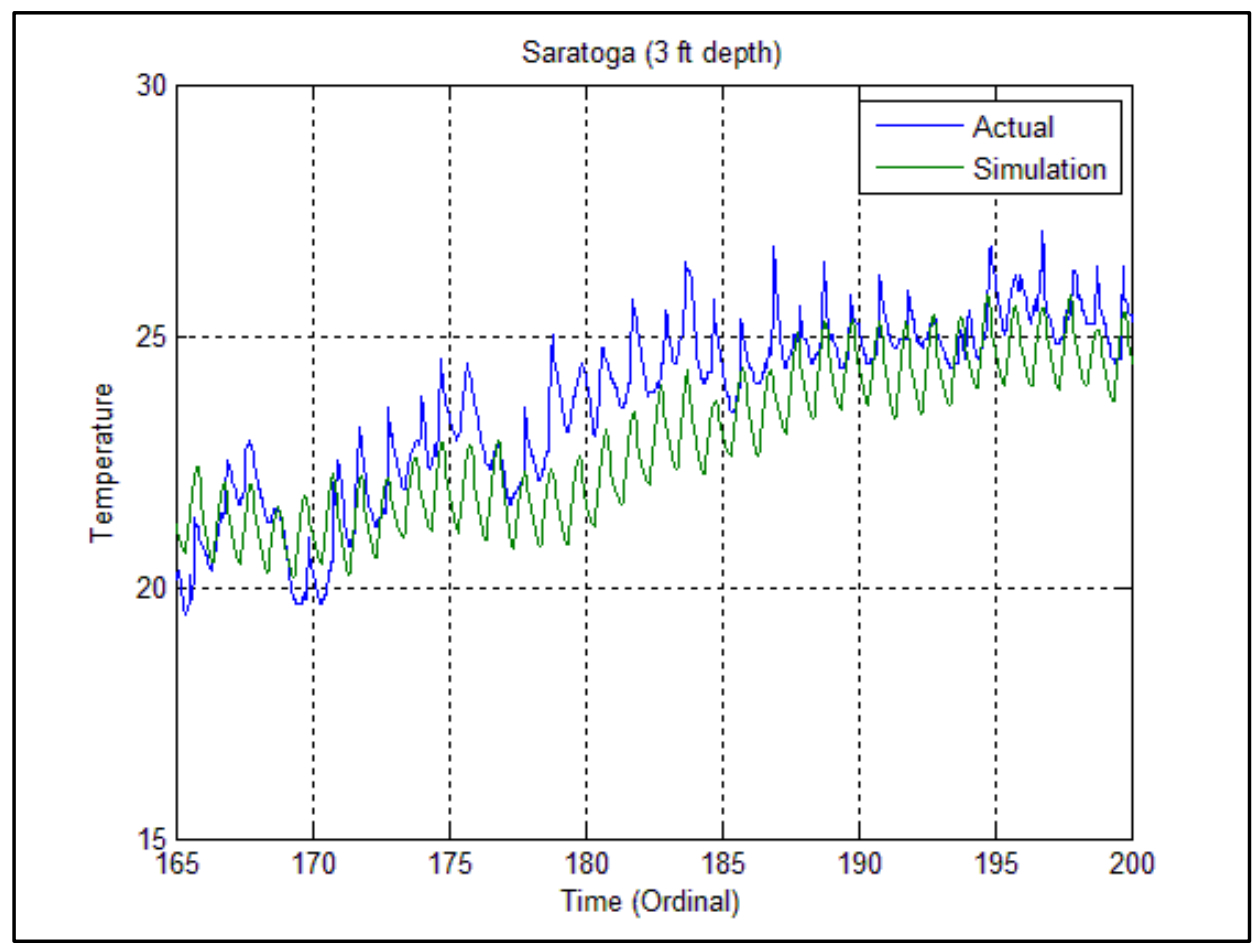

Figure 7.27 Actual vs. simulation temperatures at Saratoga sensor location. 
set from the temperature sensor is shown in Figure 7.29. A large amount of invalid data is found at the beginning of the data set, as evidenced by the large fluctuations in daily temperature values.

Approximately half of the eighteen temperature sensors had accidentally been turned on and left in the back of a pickup truck for three weeks before being placed in the identified locations in Utah Lake. As a result, the data logs from those chains show the large daily fluctuations in temperature evident in plots like Figure 7.29. From the time that the chains were placed in the lake forward, it appears that the temperature sensors were producing data representative of the temperature fluctuation. It is unknown whether the temperature sensors' accuracy was damaged by the time they spent in the back of the pickup truck.

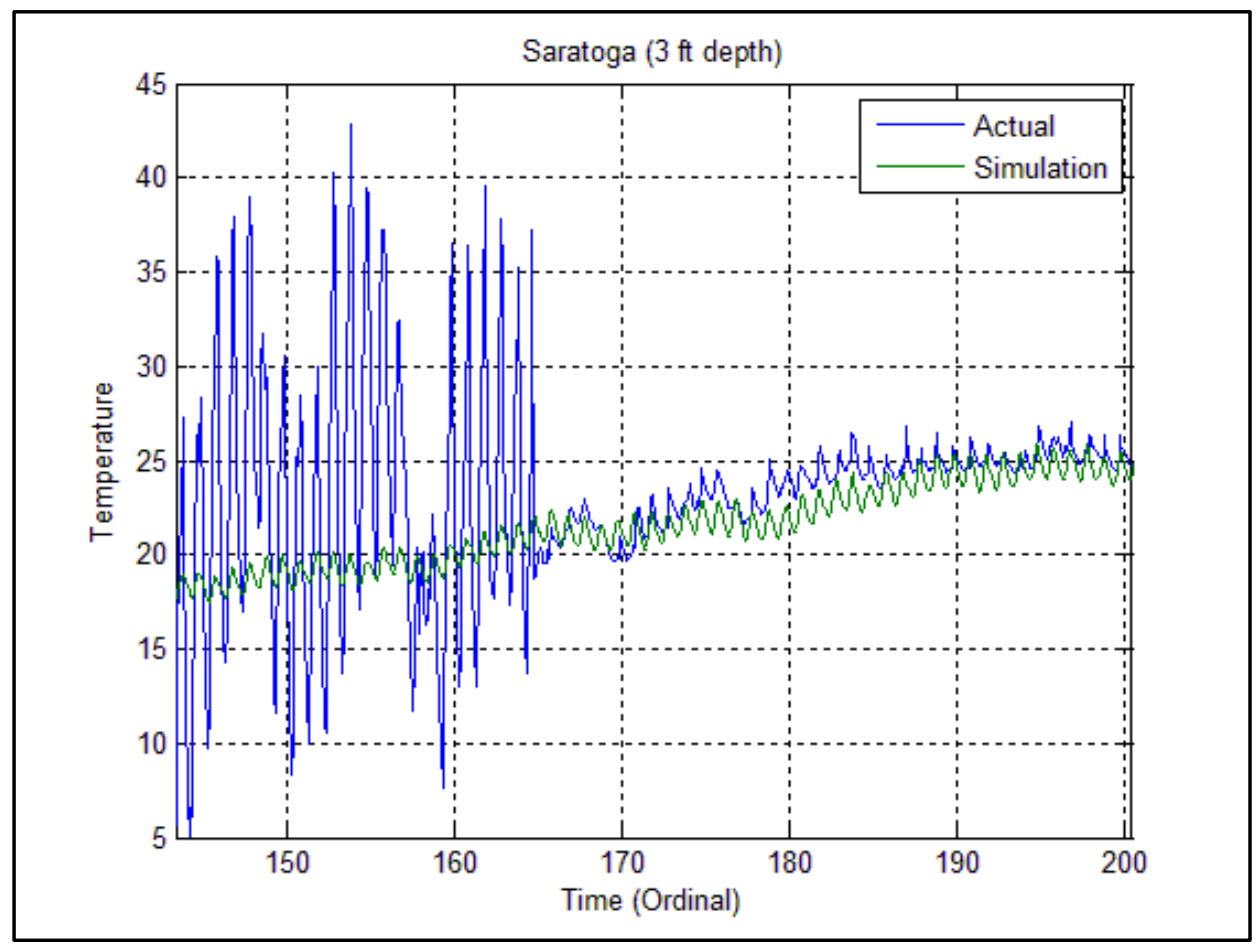

Figure 7.29 Complete data set for temperature sensor at Saratoga location. 
By assuming that the data sets from the temperature sensors were fairly accurate, however, the plotted results from the simulation at the same locations appeared to be fairly consistent with the actual measured data. The differences in the data sets could easily be attributed to errors in the forcing data (see Section 7.9) and not to problems with the model itself. The results of these simulations were accepted as validation of the modeling approach.

\subsection{Identified Sources of Error in Simulations}

The Utah Lake model has several sources by which error was introduced into the model. However, it is much easier to identify the sources of error than to quantify the magnitude of error in the model due to each source; the majority of the error was introduced from data sources with an unreported amount of error in the measurement results. The major sources of error and the anticipated impact of these errors can be discussed qualitatively, however.

One source that is inherent in every simulation comes because of the assumptions and numerical methods used to translate the governing equations into the computational algorithms that compose CWR-ELCOM. However, usage of CWR-ELCOM in other applications has shown that the magnitude of the errors thus introduced should be fairly small when compared to other possible sources.

The largest sources of error are the uncertainties in the data used as inputs for every simulation. While the simulations assumed that the forcing functions were evenly applied across the surface of the lake, the various sensors used to generate the data were actually located at ground stations around the lake. Because of the influence the lake 
exerts on the air above it, a certain amount of error was introduced through the use of this data.

In addition, the bulk of the meteorological data is derived from many individual, discrete measurements. For each type of data, the values were averaged over time to produce approximately "normal" values for each type of data. The "normalness" of any one set, however, depends strongly on how many years of data were taken. In some cases, the measurements extended over many years of data while, in others, the measurements represent only a few years. If significantly unique weather patterns or other phenomenon occurred during one of those years, the resulting data sets may have had significant errors in them.

Furthermore, the individual measurements themselves had a certain amount of error inherent because of equipment sensitivity and calibration. However, due to the averaging process used to produce the final data sets, the effects of the error in each measurement mostly canceled each other out and were small when compared to the errors due to strong natural phenomena.

Other data sets that served as inputs to the Utah Lake model were derived from mathematical models of natural phenomena. Specifically, cloud cover was calculated from the interpolated relative humidity values using a rough model found in the literature [35], and the solar radiation values were then calculated using the cloud cover values by a model that had been proposed by Martin and McCutcheon [36]. Because of their dependence on the accuracy of the relative humidity values and the models upon which they were based, additional error was introduced into the model through these data sets. 
As a result of these possibly large sources of error, the simulations are not expected to agree exactly with actual measurements taken from the lake itself. Error on the order of $10-15 \%$ is expected; the model can be considered highly successful if it can reproduce the actual temperatures and velocities within that margin of error. 


\section{CHAPTER 8}

\section{UTAH LAKE FLOW FIELD AND TEMPERATURE PATTERNS}

\subsection{Flow Field Velocities and Currents}

One of the principle objectives in the Utah Lake modeling effort was to obtain general information on the direction and magnitude of the currents and how they vary over time. Once the simulations had been validated, it was possible to create representative plots of the flow from the results that could be used to describe in general terms the most significant patterns in the water currents' variations over time.

\subsubsection{Graphical Analysis Tools for Velocities and Currents}

In addition to the analysis tools used previously to plot the temperature results as a function of time, a Matlab ${ }^{\circledR}$ script was written that created a movie that graphically showed how the velocities change over time. The velocity field at an instant in time was plotted using vectors at each cell center aligned with the flow direction at that location. The size of each vector was dependent on the magnitude of the flow, with larger vectors corresponding to larger magnitudes. The date and time for a particular vector plot were listed at the top of the image. The code successively created the vector plots, converted them to individual frames, and stitched them together to form a movie. Inputs were given so the user could choose both the resolution of the individual frames and the number of frames played per second.

Attempts to create a movie from the results of the 500-m grid simulation resulted in plots with individual vectors that were too small and too poorly resolved to make the 
movie useful. Consequently, the results of the 1000-m grid simulation were used, even though the accuracy of the individual velocity components was slightly poorer. The resulting video showed clearly resolved velocity vectors that were useful in determining the direction of flow at any one time in the lake.

\subsubsection{Visible Features in Flow Field}

One of the prevailing features in the video of the velocity plots was the swift changes in flow direction during a single day. The erratic nature of many of the currents observed in the video was most likely attributable to the strong dependence of the flow on the wind. This relationship was determined with more exactness in the parametric study (see Sections 9.2.10 and 9.2.11).

In general, strong currents in the southeast or northwest directions were observed in the central, open areas of the lake during the afternoon and evening hours. Figure 8.1 shows a vector plot of this phenomenon from the afternoon of July $22^{\text {nd }}$. Figures 8.2 and 8.3 show the plots of the $u$ - and $v$-velocity components for the $250-, 500-$, and $1000-\mathrm{m}$ grids from July $19^{\text {th }}$ to August $13^{\text {th }}$ from the South Spring sensor location. The strong afternoon velocity components each afternoon are clearly visible. The lake was relatively calm during most of the night and part of the early morning, as evidenced by the relatively small currents during these time periods in Figures 8.2 and 8.3.

The water in the horn at the southern end of the lake just north of Goshen Bay was relatively unaffected by the presence of strong currents in the main body of the lake, 


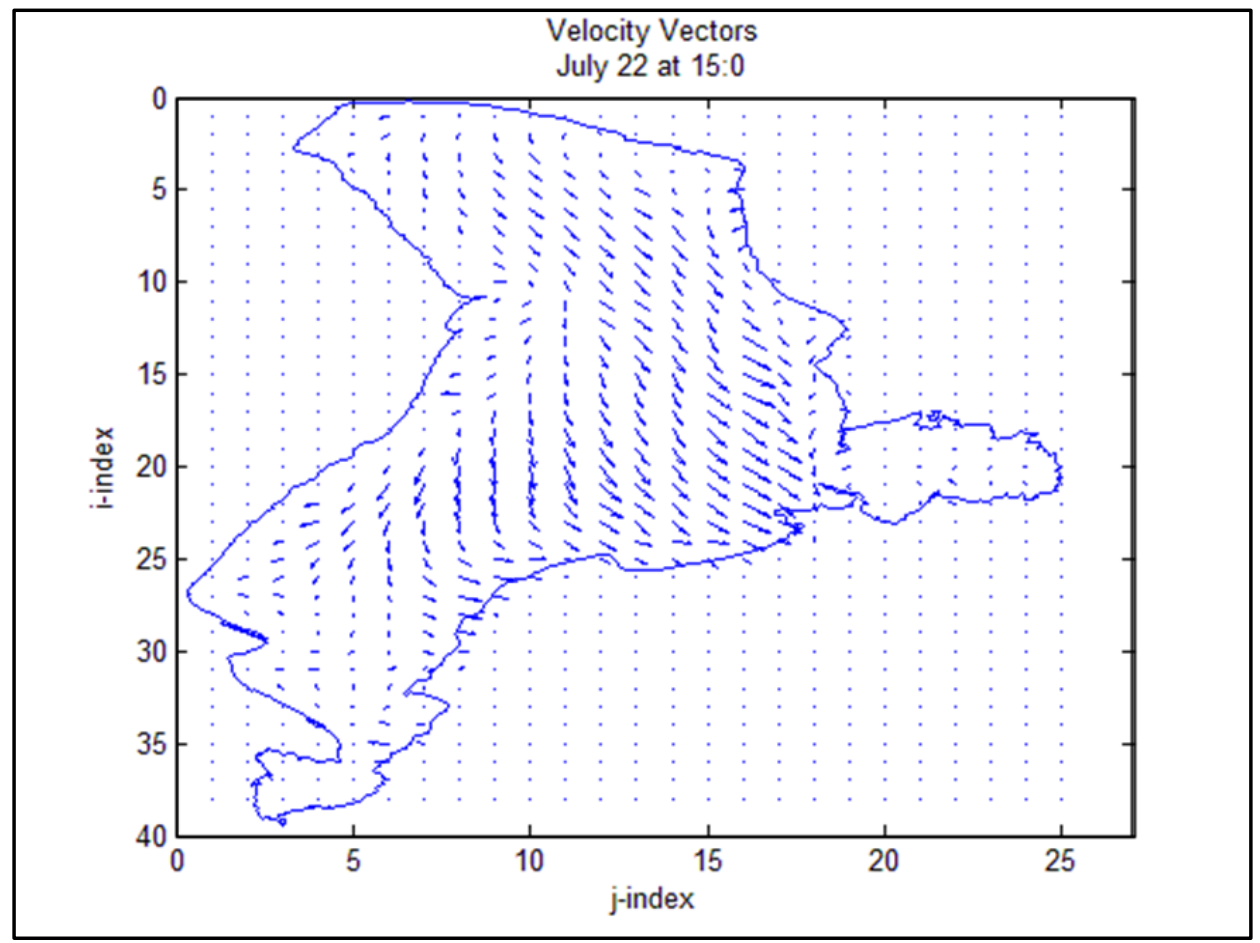

Figure 8.1 Velocity vector plot on July $22^{\text {nd }}$ at 5:00 p.m.

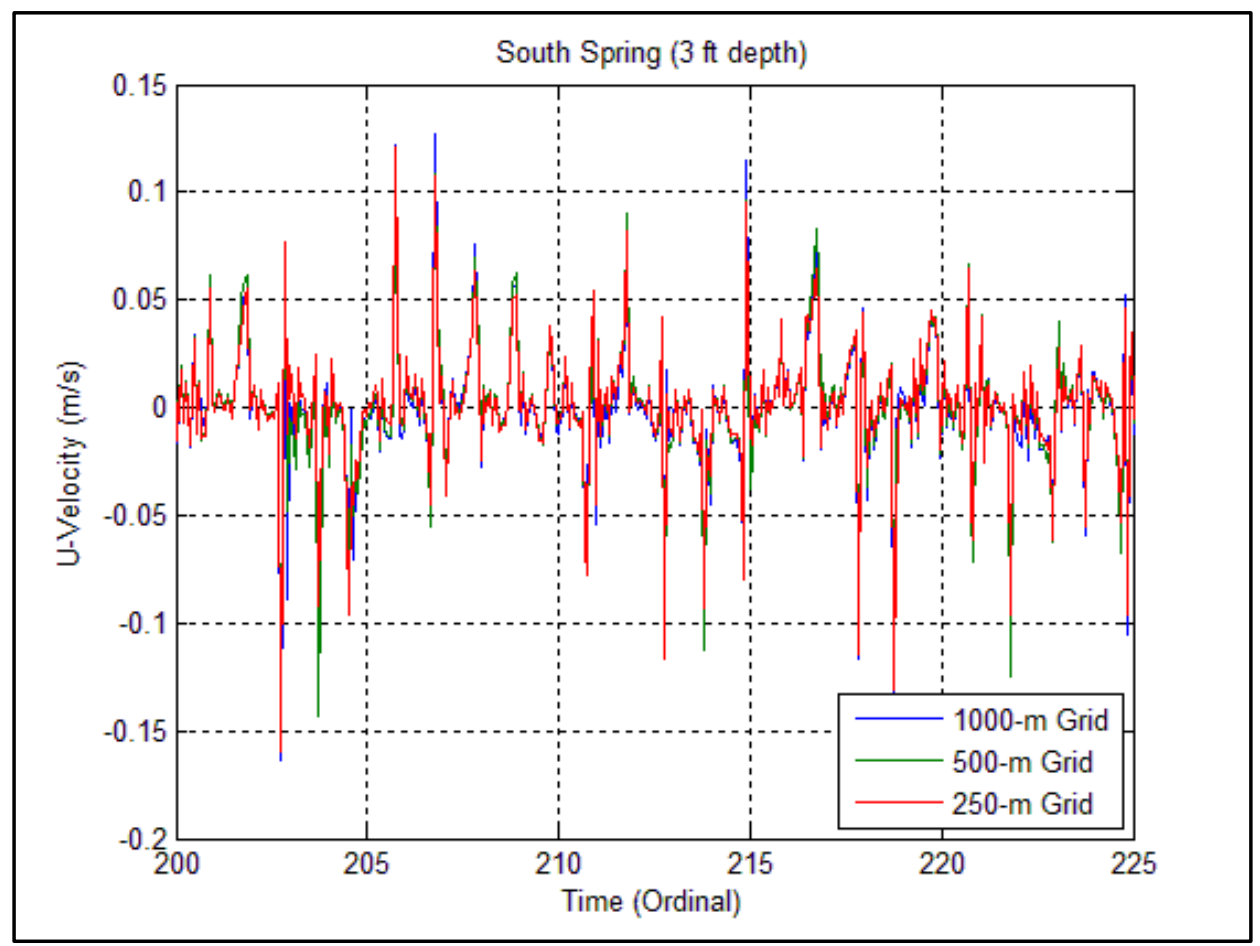

Figure $8.2 U$-velocity component at South Spring sensor location. 


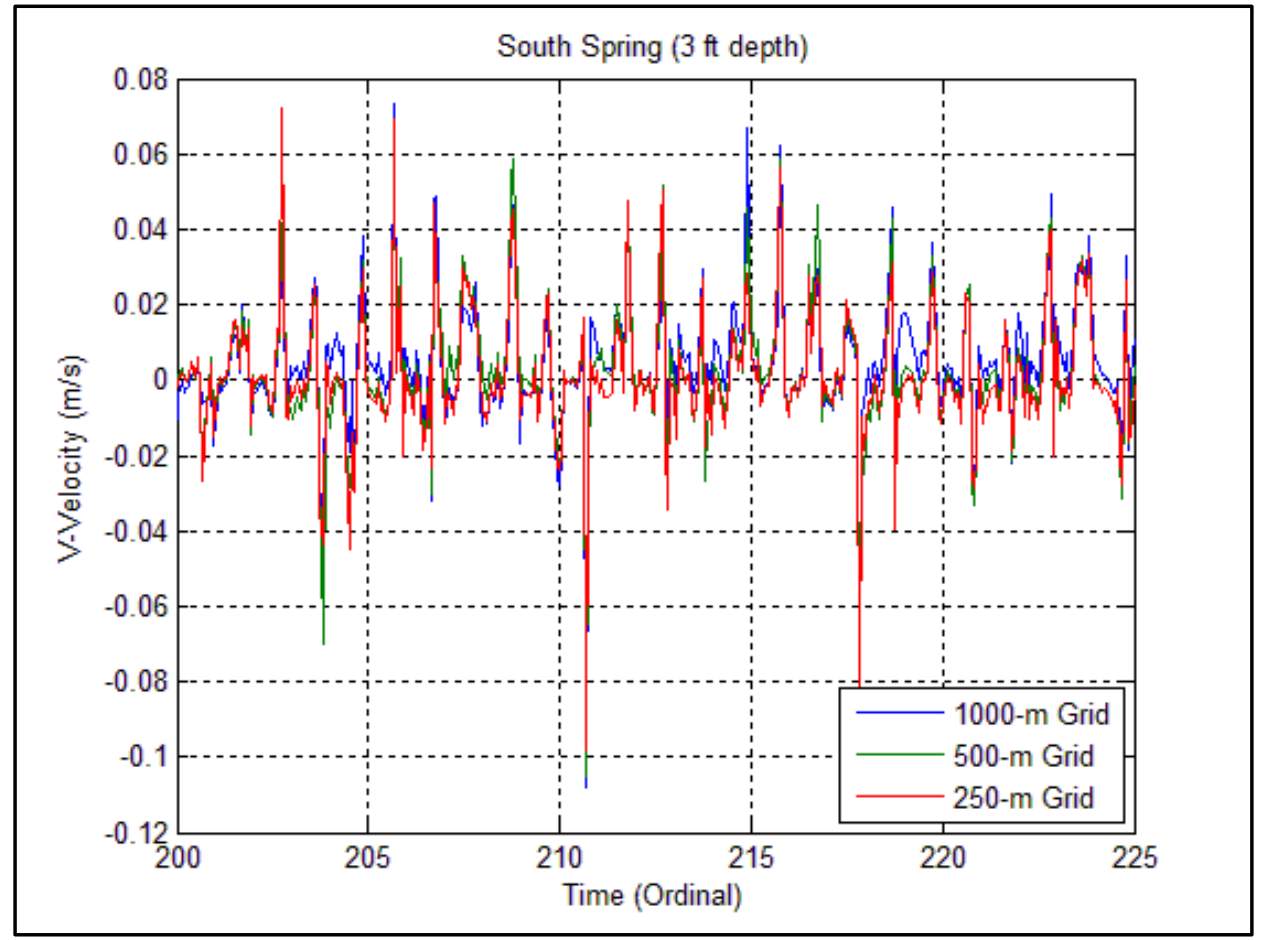

Figure $8.3 V$-velocity component at South Spring sensor socation.

as shown in Figure 8.4, and mostly oscillated between flowing almost directly east and west. This is probably due in part to the fact that no major rivers enter or leave the lake in the vicinity of the horn.

The water in Provo Bay was generally unaffected by the currents in the main body of Utah Lake. It was often seen that the currents there flowed in the opposite direction from those found in the rest of the lake, as shown in Figure 8.5. In general, however, the currents in Provo Bay were stronger along the south shore, as seen in Figures 8.4 and 8.5.

Several instances were observed where the currents along the east side of Utah Lake appeared to diverge from a central dividing line. It was theorized that this was due largely to an upwelling of deeper water as it converted its horizontal momentum into vertical motion. Quite often this feature was observed in tandem with similar features on 


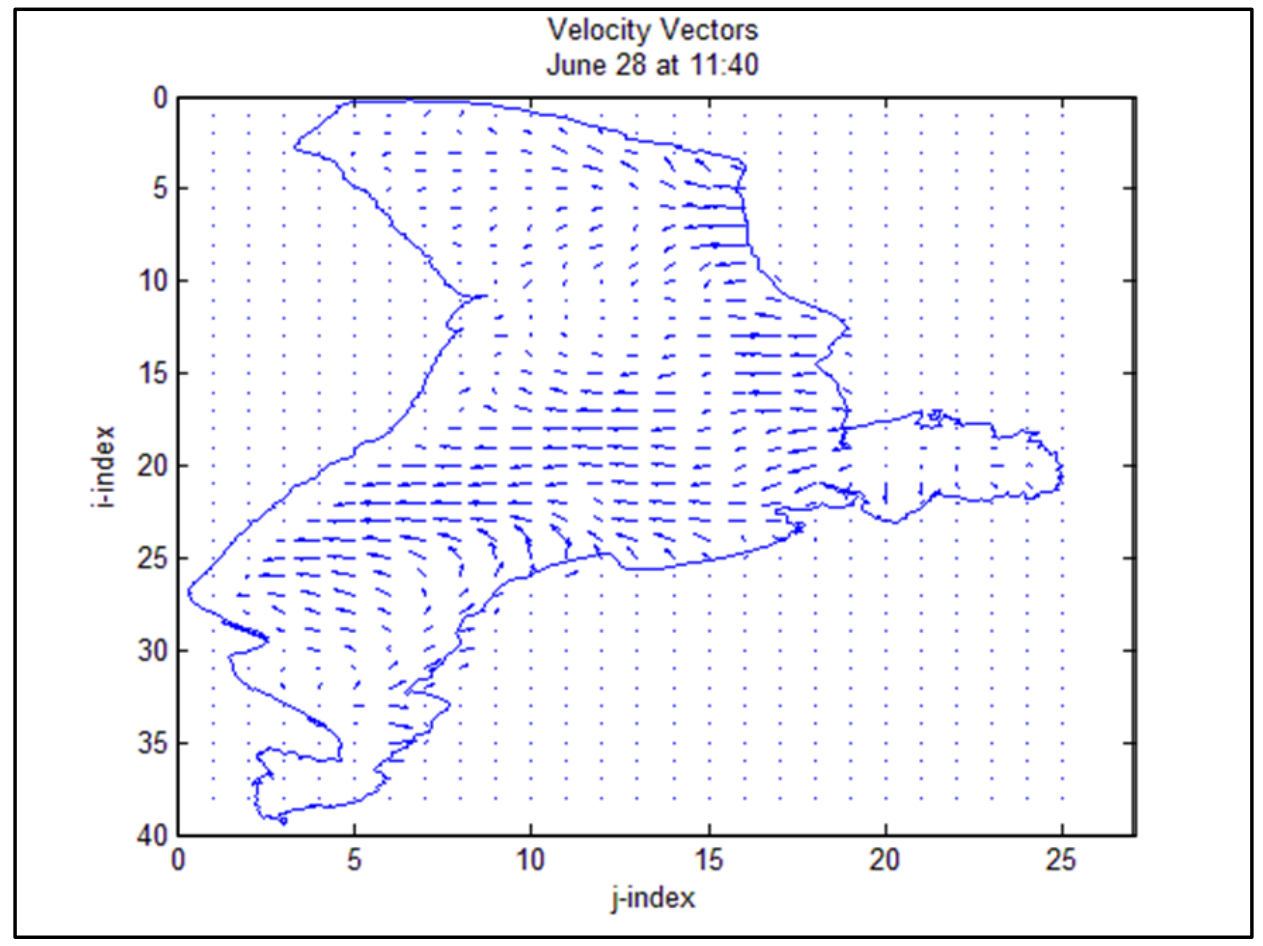

Figure 8.4 Primarily horizontal flow in southern horn of Utah Lake.

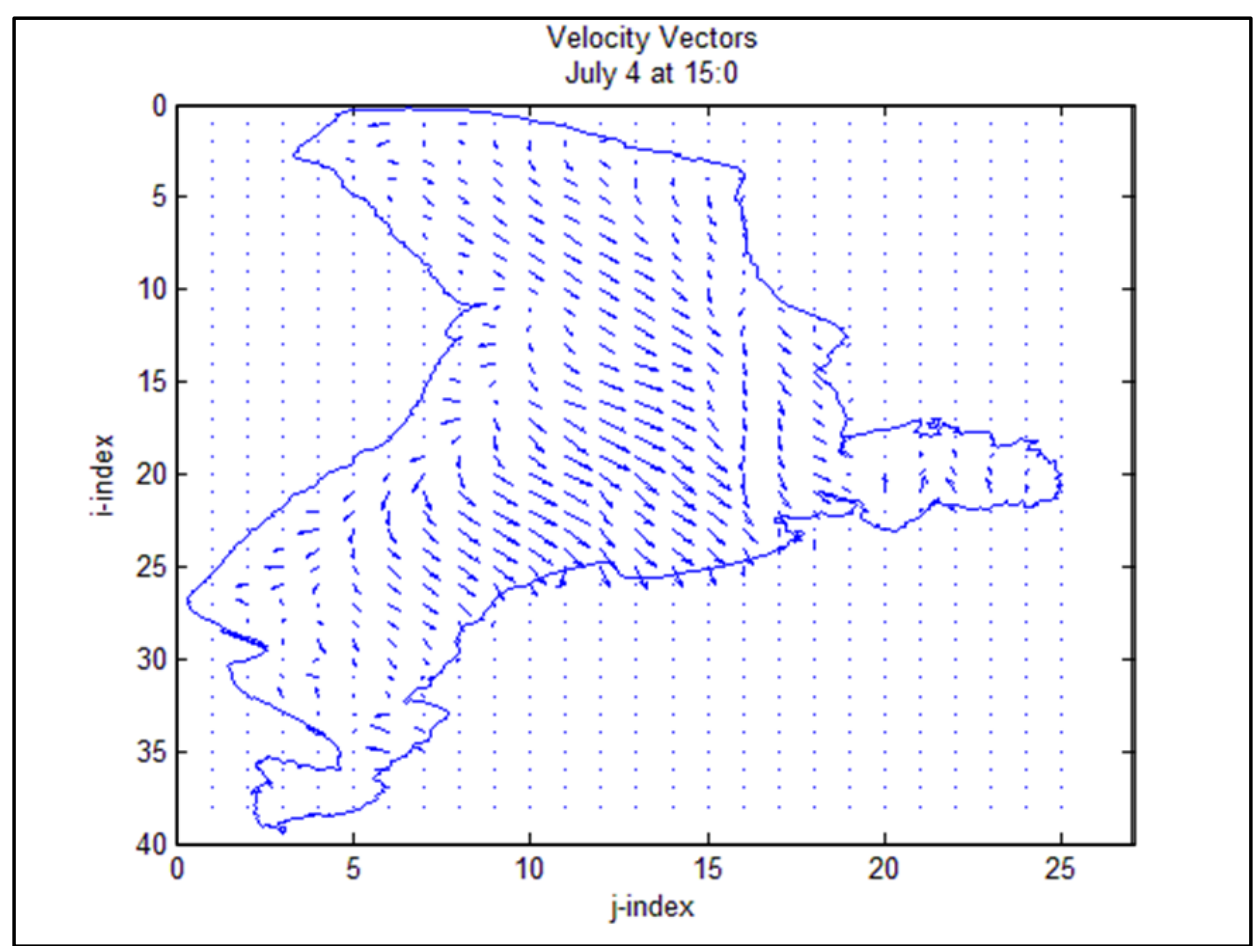

Figure 8.5 Independence of Provo Bay currents from lake currents. 
the west side of Bird Island. An example of this is shown in Figure 8.6.

\subsection{Flow Field Temperature Variations and Distribution}

In addition to characterizing the flow field, another important objective in the Utah Lake modeling effort was to determine how the water temperatures change over time and to identify any salient features in the distribution of those temperatures.

\subsubsection{Graphical Analysis Tools for Water Temperature}

Matlab ${ }^{\circledR}$ scripts had already been created to generate plots of the water temperature versus time at specific locations in the lake as part of the grid resolution study. An additional script was written to create contour plots of the water temperatures with the date and time for the data used in the image appearing at the top of the frame. A

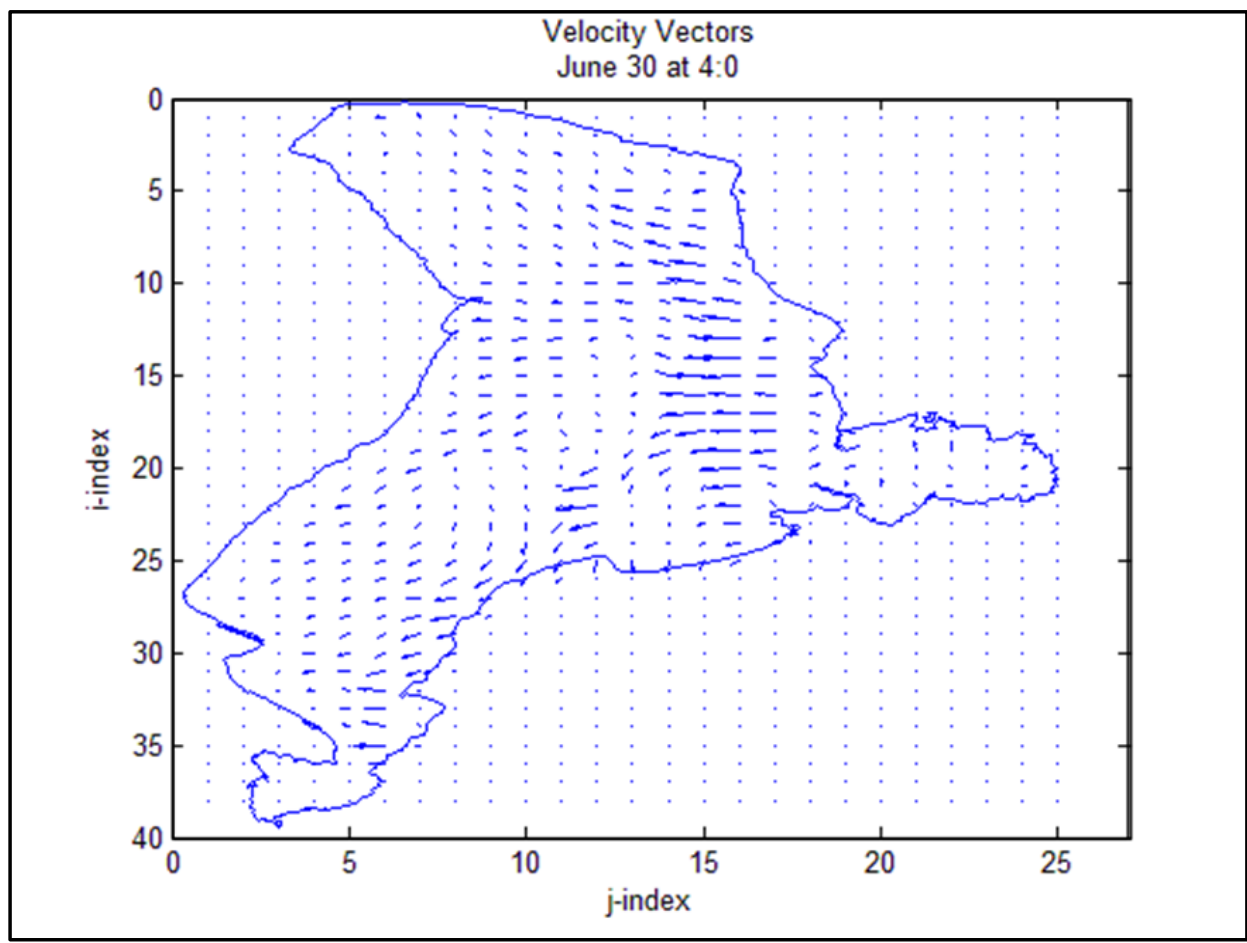

Figure 8.6 Diverging currents on east side of Utah Lake. 
third script took successive images of the contour plots and converted them into frames in a movie to graphically show the variations in temperature over the simulation time.

Because of their accuracy, results from the 250-m grid simulation were used to create the movie and contour plots.

\subsubsection{Notable Temperature Characteristics}

Both Provo and Goshen Bays are relatively shallow areas of Utah Lake when compared to the main body. As such, it was expected that the water in those areas would be strongly influenced by air temperature and incident solar radiation and would, as a result, experience the highest water temperatures. Surprisingly, however, this was not found to be the case in the simulation results. Instead, the warmer areas were in the central portion of the main body of the lake, with the highest temperatures centered around Bird Island, as shown in Figure 8.7, a representative contour plot for the temperatures on July $21^{\text {st }}$ at 11:40 a.m. Close analysis of the actual temperature data showed a similar trend; temperatures at the three foot depth indicated that the water temperatures in shallow areas were equal to or slightly less than the temperatures in deep areas.

All of the temperature plots at the sensor locations had the characteristic shape shown in Figure 8.8. The highest water temperatures typically occurred at about day 202, or July $21^{\text {st }}$. This was true in both the simulation results and actual data, as shown in Figure 8.9. Daily water temperature variations were typically less than $2^{\circ} \mathrm{C}$ in areas where the water was over 3.04 meters (10 feet) deep, between $2-3^{\circ} \mathrm{C}$ for water between 1.83 and 3.04 meters ( 6 to 10 feet) deep, and $3-5^{\circ} \mathrm{C}$ for water less than 1.83 meters $(6$ 


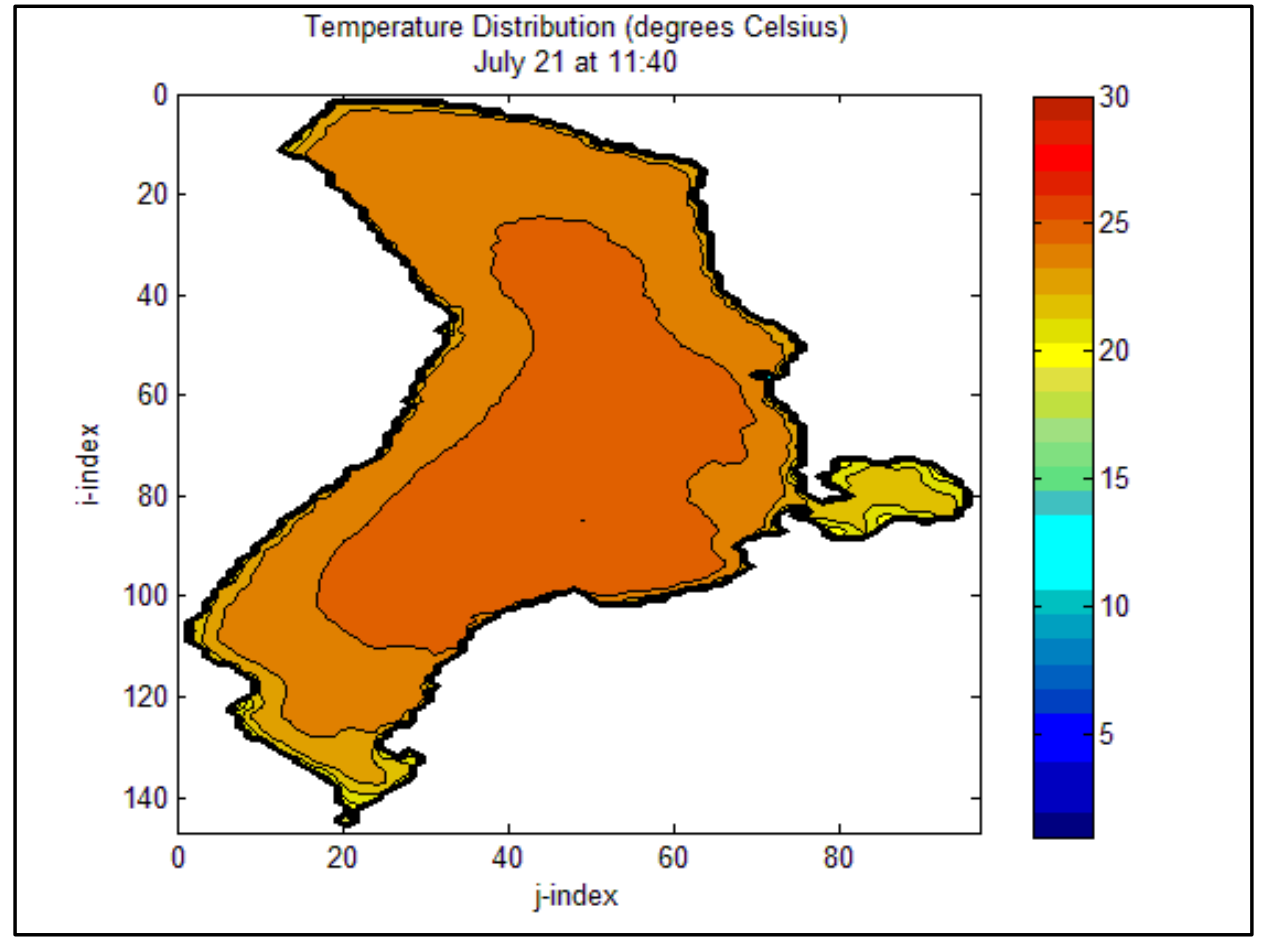

Figure 8.7 Water temperature contours on July $21^{\text {st }}$.

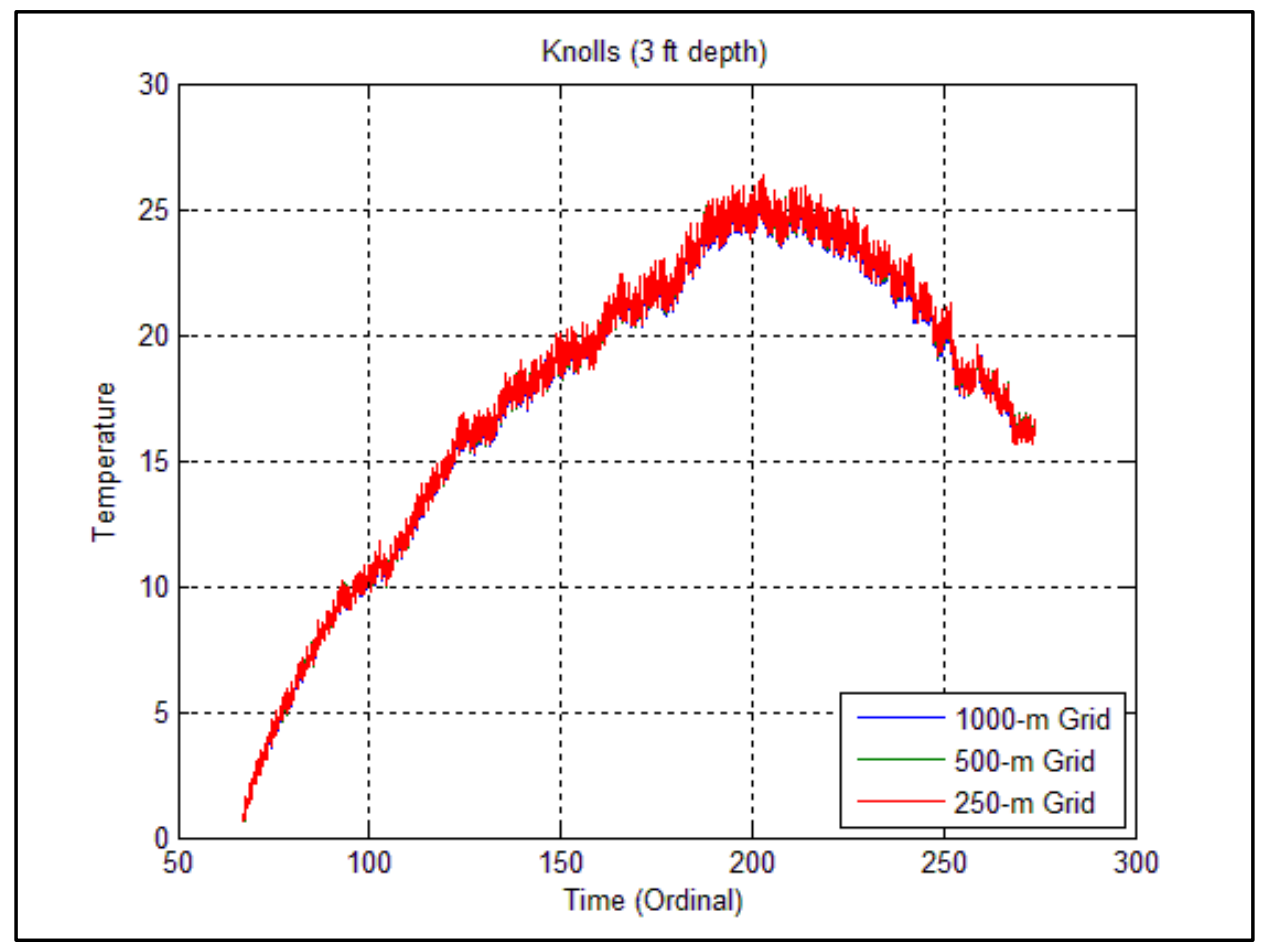

Figure 8.8 Representative plot of temperature vs. time. 


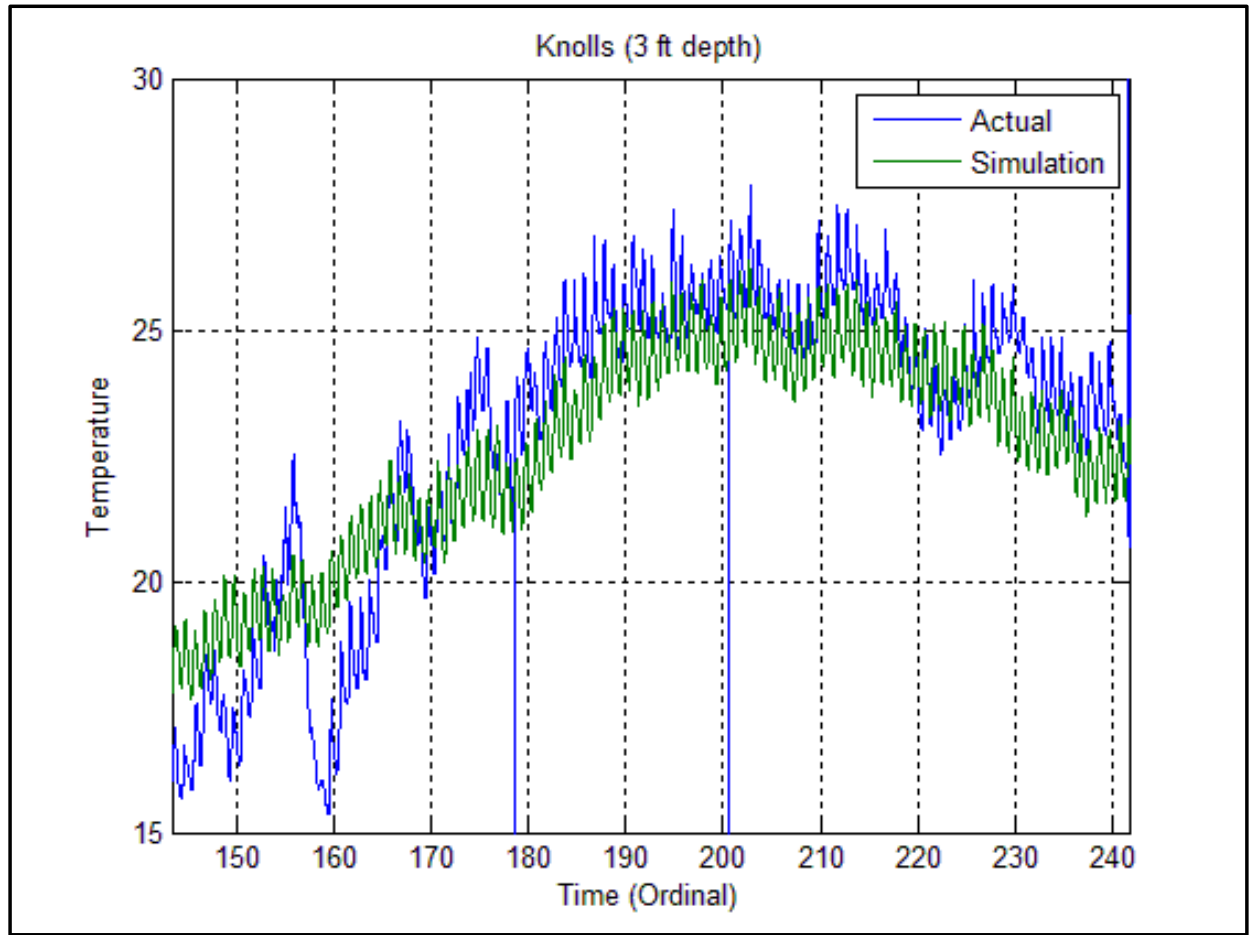

Figure 8.9 Peak temperatures occurred on July $21^{\text {st }}$ (day 202).

feet) deep. Figure 8.10 shows the temperature fluctuations at the Bird Island sensor location, which had a depth of about 4.27 meters (14 feet). Figure 8.11 shows the temperature data at the Provo Bay sensor location, which had a depth of about 1.22 meters (4 feet) of water. 


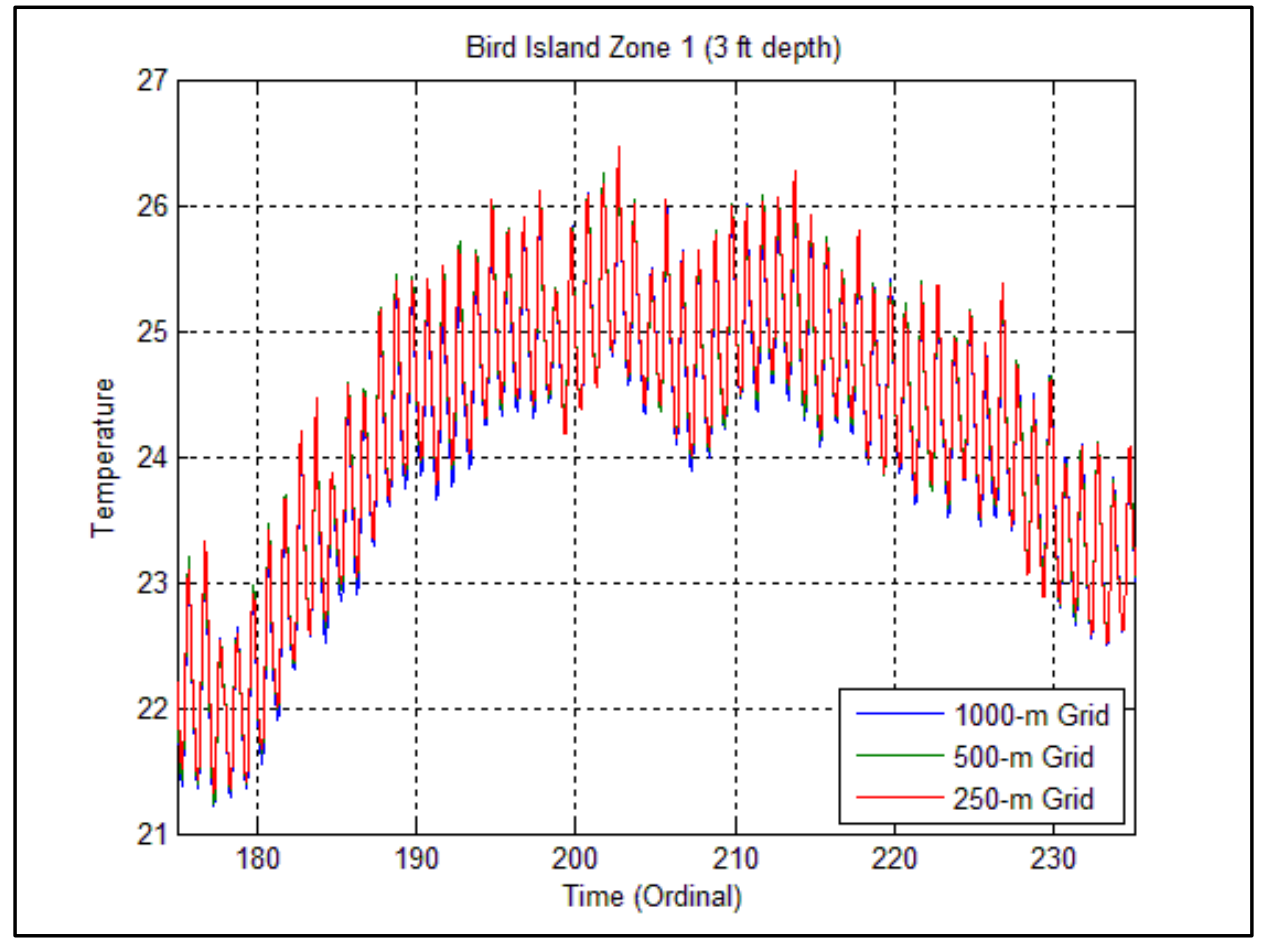

Figure 8.10 Plot of temperature vs. time at Bird Island sensor location.

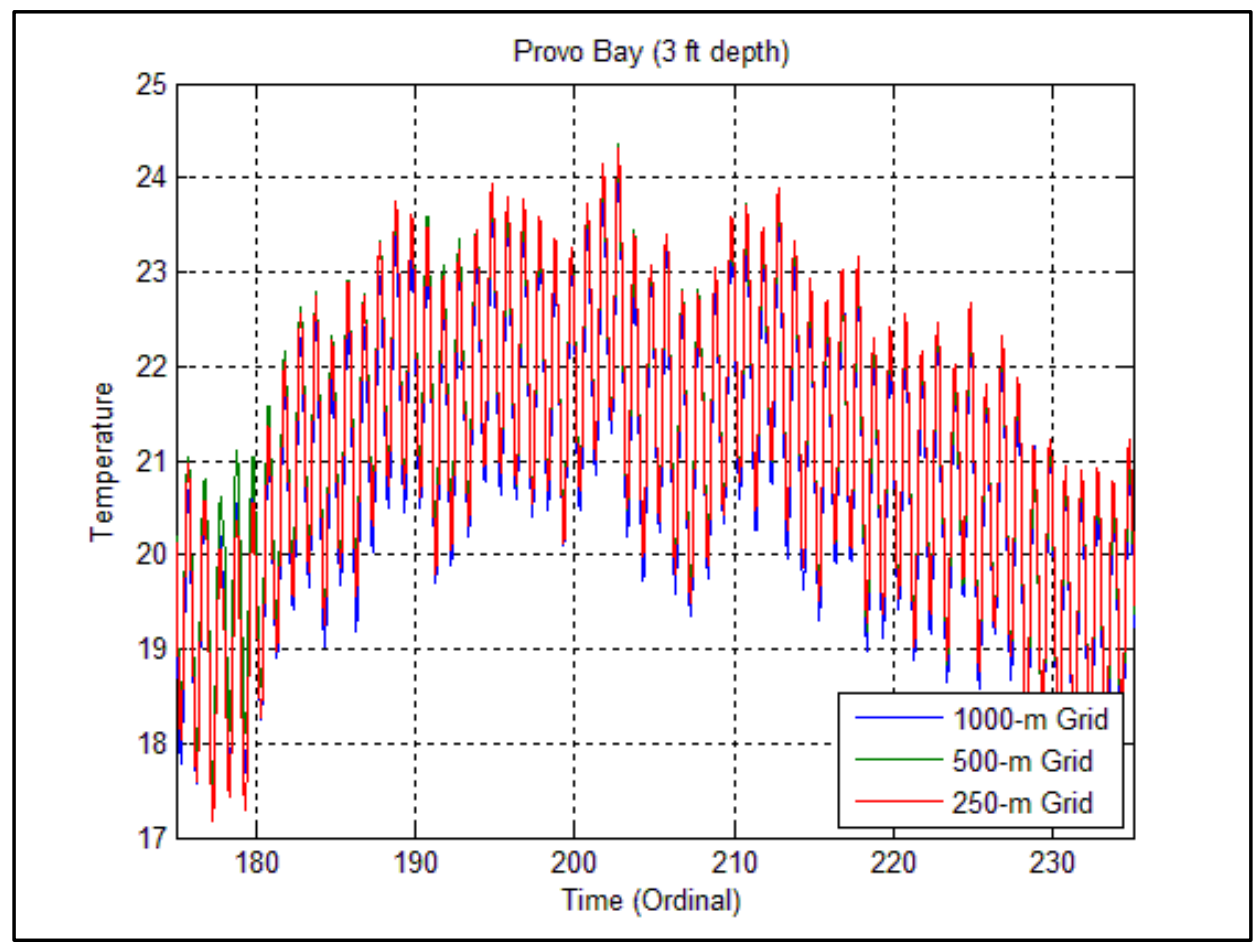

Figure 8.11 Plot of temperature vs. time at Provo Bay sensor location. 


\section{CHAPTER 9}

\section{PARAMETRIC STUDY AND ANALYSIS}

\subsection{Simulation Variations}

As stated in Section 2.1, the principal objectives of the Utah Lake modeling effort were to predict how water circulation patterns and temperature distributions vary over time, determine the amount of influence each of the controlling parameters exerts over the water conditions, and predict the free drifting path taken by June sucker larvae. A parametric study was undertaken to determine the influence of each individual parameter on the overall lake flow and water temperatures, and the results are discussed below. Chapter 10 discusses the problem of predicting the free drifting path of June sucker larvae, including the simulation preparation, special considerations, and the results.

Several steps were taken in order to conduct a parametric study for Utah Lake. First, all relevant forcing functions were identified. Second, each forcing function, or parameter, was placed into one of two categories: negligible or non-negligible. Those parameters that were considered non-negligible were required to be reasonably capable of affecting the flow field and temperature distribution of the water in the lake. Third, a systematic method for varying the parameters and observing the effects was developed, and a simulation matrix was created. Lastly, after the simulations were performed the results were plotted to determine what deviations existed, if any, because of the variations in the parameter. 


\subsubsection{Model Parameters}

The following quantities were considered as possible parameters for the Utah Lake model:

- Air Temperature

- Atmospheric Pressure

- Cloud Cover

- Initial Conditions

- Relative Humidity

- Solar Radiation

- Precipitation

- River Inflow Rates

- River Outflow Rates

- River Inflow Temperatures

- Wind Direction

- Wind Speed

Of those parameters listed above, the only one whose variations were considered as having a negligible influence on the water conditions was the atmospheric pressure. The changes in atmospheric pressure over time would have relatively little effect on any thermodynamic and momentum transfer processes that occur at the surface of the lake, especially when compared to the effects exerted by the other parameters. As a result, variations in atmospheric pressure were not considered as part of the parametric study. 
The remaining non-negligible parameters which are listed above were included in the study.

\subsubsection{Simulation Matrices}

Listed below are the simulation matrices for the parametric study that detail exactly which simulations were done. Simulations were performed on both 500- and 1000 -m grids as a way to correlate the results and discover any significant variations due to grid size.

Table 9.1 lists the simulations that were performed with variations in the air temperature, including the grid size for each simulation and the constant factor by which each air temperature value was multiplied before being writing into the input file for CWR-ELCOM.

Table 9.2 lists the simulations performed with variations in the cloud cover values. Because the solar radiation values were calculated based on the amount of cloud cover present, variations in cloud cover were considered non-negligible.

The simulations that were performed with variations in the initial conditions are listed in Table 9.3. As mentioned in Section 7.2.2, CWR-ELCOM allows the user to specify a scalar value or create an initial temperature profile with which to initialize the

Table 9.1 Air Temperature Simulation Matrix

\begin{tabular}{|c|c|c|c|c|c|c|c|c|}
\hline Grid Size (m) & 500 & 1000 & 500 & 1000 & 500 & 1000 & 500 & 1000 \\
\hline Factor & 0.90 & 0.90 & 0.95 & 0.95 & 1.05 & 1.05 & 1.10 & 1.10 \\
\hline
\end{tabular}

Table 9.2 Cloud Cover Simulation Matrix

\begin{tabular}{|c|c|c|c|c|c|c|c|c|}
\hline Grid Size (m) & 500 & 1000 & 500 & 1000 & 500 & 1000 & 500 & 1000 \\
\hline Factor & 0.90 & 0.90 & 0.95 & 0.95 & 1.05 & 1.05 & 1.10 & 1.10 \\
\hline
\end{tabular}


Table 9.3 Initial Conditions Simulation Matrix

\begin{tabular}{|c|c|c|c|c|c|c|c|c|c|c|}
\hline $\begin{array}{c}\text { Grid Size } \\
(\mathbf{m})\end{array}$ & 500 & 1000 & 500 & 1000 & 500 & 1000 & 500 & 1000 & 500 & 1000 \\
\hline $\begin{array}{c}\text { Initial } \\
\text { Temperature } \\
\left({ }^{\circ} \mathbf{C}\right)\end{array}$ & 1.00 & 1.00 & 5.00 & 5.00 & 10.00 & 10.00 & 15.00 & 15.00 & $\begin{array}{c}\text { Variable, } \\
1-9\end{array}$ & $\begin{array}{c}\text { Variable, } \\
1-9\end{array}$ \\
\hline
\end{tabular}

model. For the "variable" initial condition, an initial profile was defined in which the temperature was assumed to vary linearly with depth from $9^{\circ} \mathrm{C}$ at the surface to $1^{\circ} \mathrm{C}$ at the lakebed. All simulations had a starting date of March 8, 2007, in accordance with the assumptions listed in Section 7.4.8.

Table 9.4 lists the variations in relative humidity for the simulations. Because relative humidity served as the basis for the cloud cover model, which in turn was used to calculate the solar radiation values (see Sections 7.4.4 and 7.4.6), it was considered a non-negligible parameter.

The simulation matrix for solar radiation is found in Table 9.5. It was assumed that the solar radiation values would strongly impact surface water temperatures, so it was considered a non-negligible parameter.

Variations in the precipitation level were also included in the parametric study. Although it would appear that the amount of rain received during the simulation period might have little impact on the overall results, it could not be ruled out with absolute certainty and was thus included in the parametric study. The simulation matrix for precipitation levels is found in Table 9.6.

The river flow rates could conceivably have a large impact on the lake, so the simulations matrices for the river inflow and outflow rates are shown in Tables 9.7 and 
9.9, respectively. Table 9.8 is the simulation matrix for the temperature of the water

flowing into the lake.

Wind is a parameter that can be highly variable from day to day and is difficult to characterize fully. Because the data taken from MesoWest [34] was not averaged over time, it was desirable to consider the effects of both the wind direction and wind speed on the resulting temperature and flow results. The corresponding simulations for the wind direction and speed are shown in Tables 9.10 and 9.11, respectively.

Table 9.4 Relative Humidity Simulation Matrix

\begin{tabular}{|c|c|c|c|c|c|c|c|c|}
\hline Grid Size (m) & 500 & 1000 & 500 & 1000 & 500 & 1000 & 500 & 1000 \\
\hline Factor & 0.90 & 0.90 & 0.95 & 0.95 & 1.05 & 1.05 & 1.10 & 1.10 \\
\hline
\end{tabular}

Table 9.5 Solar Radiation Simulation Matrix

\begin{tabular}{|c|c|c|c|c|c|c|c|c|}
\hline Grid Size (m) & 500 & 1000 & 500 & 1000 & 500 & 1000 & 500 & 1000 \\
\hline Factor & 0.90 & 0.90 & 0.95 & 0.95 & 1.05 & 1.05 & 1.10 & 1.10 \\
\hline
\end{tabular}

Table 9.6 Precipitation Simulation Matrix

\begin{tabular}{|c|c|c|c|c|c|c|c|c|}
\hline Grid Size (m) & 500 & 1000 & 500 & 1000 & 500 & 1000 & 500 & 1000 \\
\hline Factor & 0.90 & 0.90 & 0.95 & 0.95 & 1.05 & 1.05 & 1.10 & 1.10 \\
\hline
\end{tabular}

Table 9.7 River Inflow Rates Simulation Matrix

\begin{tabular}{|c|c|c|c|c|c|c|c|c|}
\hline Grid Size (m) & 500 & 1000 & 500 & 1000 & 500 & 1000 & 500 & 1000 \\
\hline Factor & 0.90 & 0.90 & 0.95 & 0.95 & 1.05 & 1.05 & 1.10 & 1.10 \\
\hline
\end{tabular}

Table 9.8 River Outflow Rates Simulation Matrix

\begin{tabular}{|c|c|c|c|c|c|c|c|c|}
\hline Grid Size (m) & 500 & 1000 & 500 & 1000 & 500 & 1000 & 500 & 1000 \\
\hline Factor & 0.90 & 0.90 & 0.95 & 0.95 & 1.05 & 1.05 & 1.10 & 1.10 \\
\hline
\end{tabular}

Table 9.9 River Inflow Temperatures Simulation Matrix

\begin{tabular}{|c|c|c|c|c|c|c|c|c|}
\hline Grid Size (m) & 500 & 1000 & 500 & 1000 & 500 & 1000 & 500 & 1000 \\
\hline Factor & 0.90 & 0.90 & 0.95 & 0.95 & 1.05 & 1.05 & 1.10 & 1.10 \\
\hline
\end{tabular}


Table 9.10 Wind Direction Simulation Matrix

\begin{tabular}{|c|c|c|c|c|c|c|c|c|c|c|c|c|}
\hline $\begin{array}{c}\text { Grid Size } \\
(\mathbf{m})\end{array}$ & 500 & 1000 & 500 & 1000 & 500 & 1000 & 500 & 1000 & 500 & 1000 & 500 & 1000 \\
\hline Angle & $30^{\circ}$ & $30^{\circ}$ & $45^{\circ}$ & $45^{\circ}$ & $60^{\circ}$ & $60^{\circ}$ & $90^{\circ}$ & $90^{\circ}$ & $135^{\circ}$ & $135^{\circ}$ & $180^{\circ}$ & $180^{\circ}$ \\
\hline
\end{tabular}

Table 9.11 Wind Speed Simulation Matrix

\begin{tabular}{|c|c|c|c|c|c|c|c|c|}
\hline Grid Size (m) & 500 & 1000 & 500 & 1000 & 500 & 1000 & 500 & 1000 \\
\hline Factor & 0.90 & 0.90 & 0.95 & 0.95 & 1.05 & 1.05 & 1.10 & 1.10 \\
\hline
\end{tabular}

\subsection{Results of Parametric Study}

Each of the simulations listed in the matrices of Section 9.1.2 were performed in CWR-ELCOM. The results were then analyzed to determine the influence of each parameter on the overall flow conditions and the temperature distribution of the water in Utah Lake. Because the temperature sensor locations represent a fairly representative set of sampling locations, the values were plotted at those locations. Representative plots from the 500-m grid simulations are shown for each parameter.

\subsubsection{Air Temperature}

The temperature of the water at any given time is strongly influenced by the air temperature. Figure 9.1 shows the plots of the temperatures at the Goose temperature sensor location as a function of time for each multiplication factor that was used. The large differences between each plot clearly show that variations in the air temperature result in significant variations in the resulting water temperature.

The air temperature exerts a very weak influence on the water currents, though. Figures 9.2 and 9.3 show the plots of the u- and v-velocity components at the Goose temperature sensor location. Only negligible difference can be observed for the different multiplication factors that were used. 


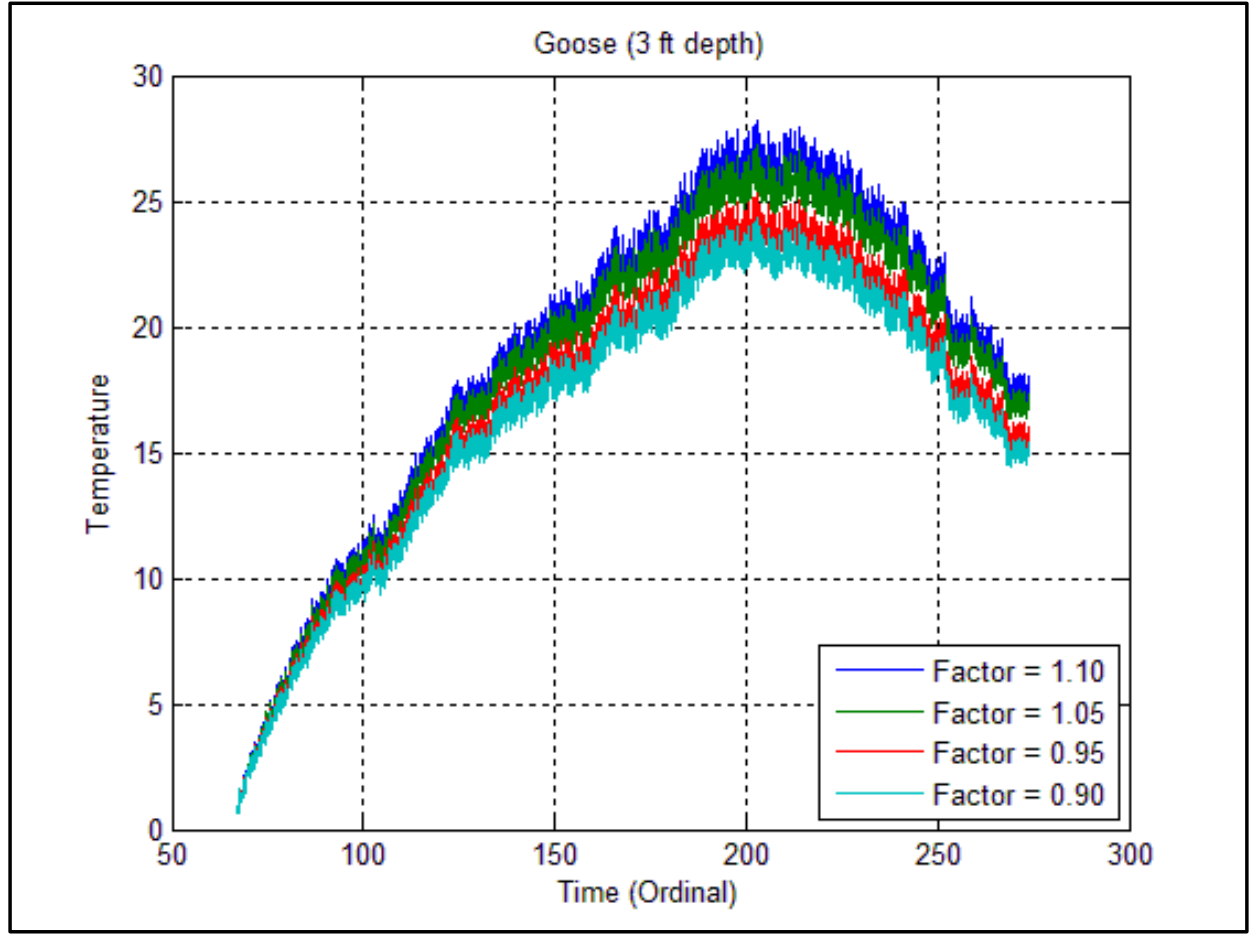

Figure 9.1 Effect of air temperature variations on water temperature.

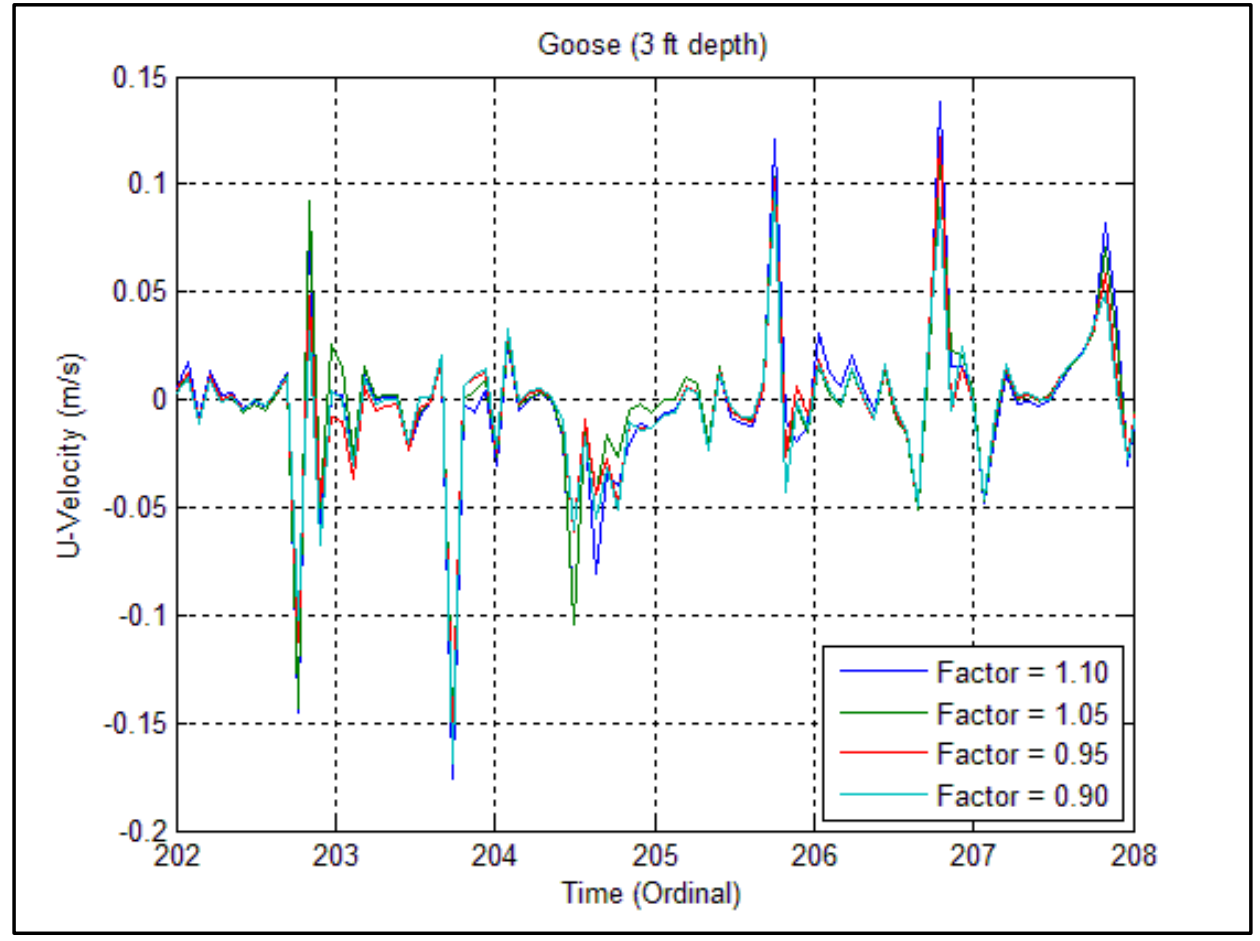

Figure 9.2 Effect of air temperature variations on $u$-velocity component. 


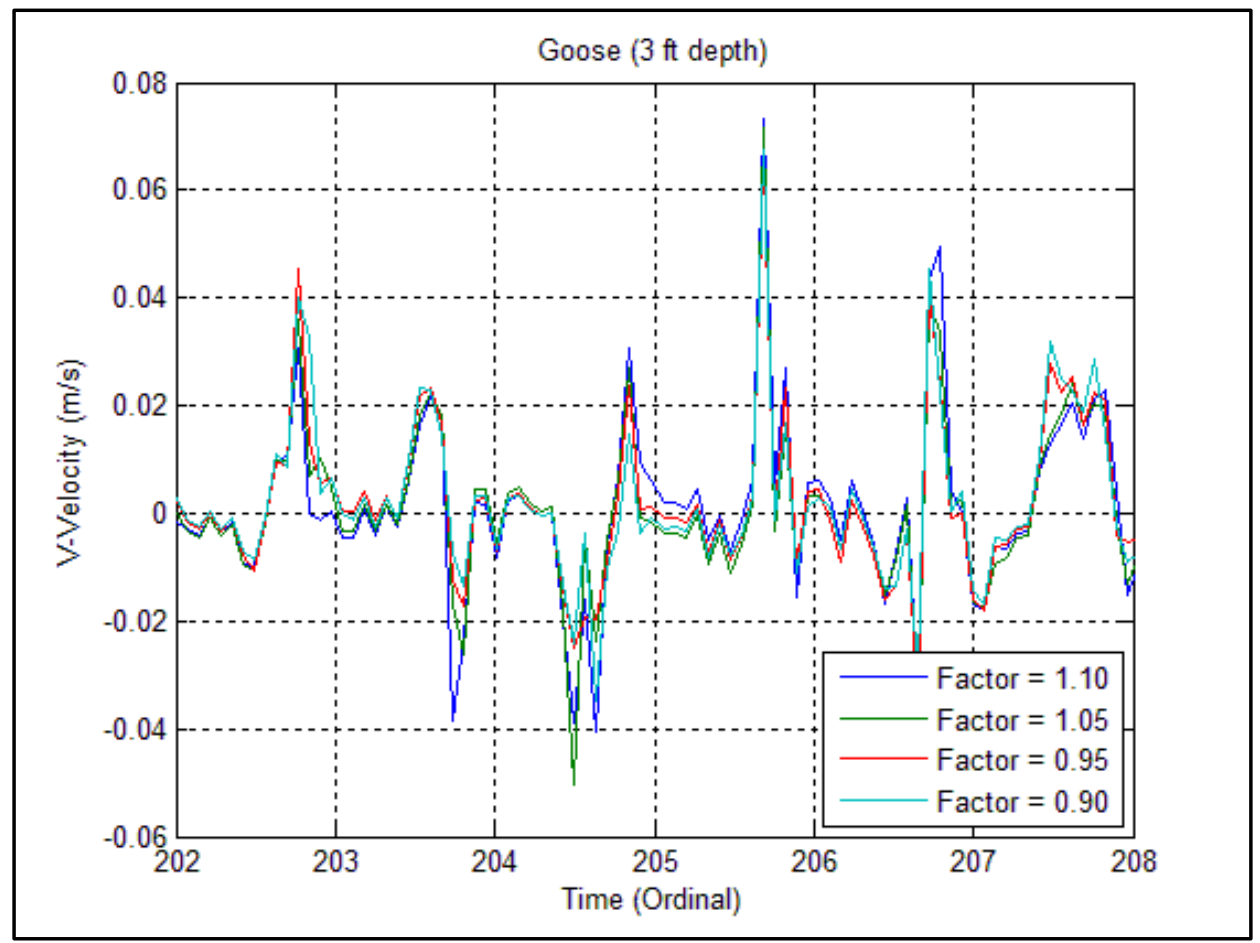

Figure 9.3 Effect of air temperature variations on $v$-velocity component.

\subsubsection{Cloud Cover}

Variations in cloud cover had a small but perceptible effect on the water temperatures, as shown in Figure 9.4. This was most likely a result of the dependence of solar radiation values on the amount of cloud cover present. Cloud cover variations had virtually no impact on the $u$ - and $v$-velocity components, as shown in Figures 9.5 and 9.6.

\subsubsection{Initial Conditions}

The water temperature plots for each initial condition simulation varied at the start of the simulation time according to the defined values, but quickly converged. After approximately 30 days, the plots were no longer distinguishable, as shown in Figure 9.7. It was concluded that the effects of the initial conditions on the water temperature were negligible compared to other factors once the initially transient was overcome. 


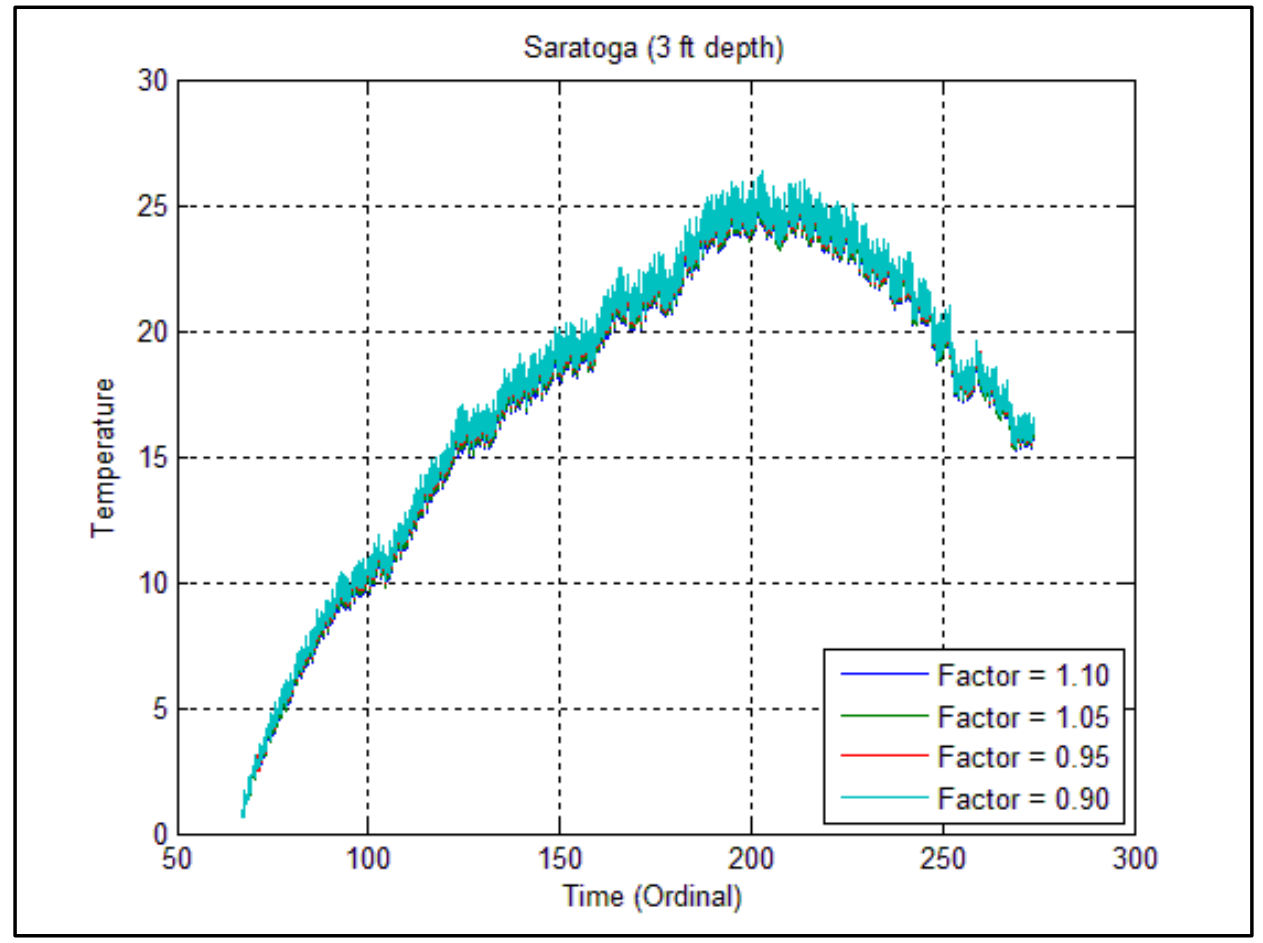

Figure 9.4 Effect of cloud cover on water temperature.

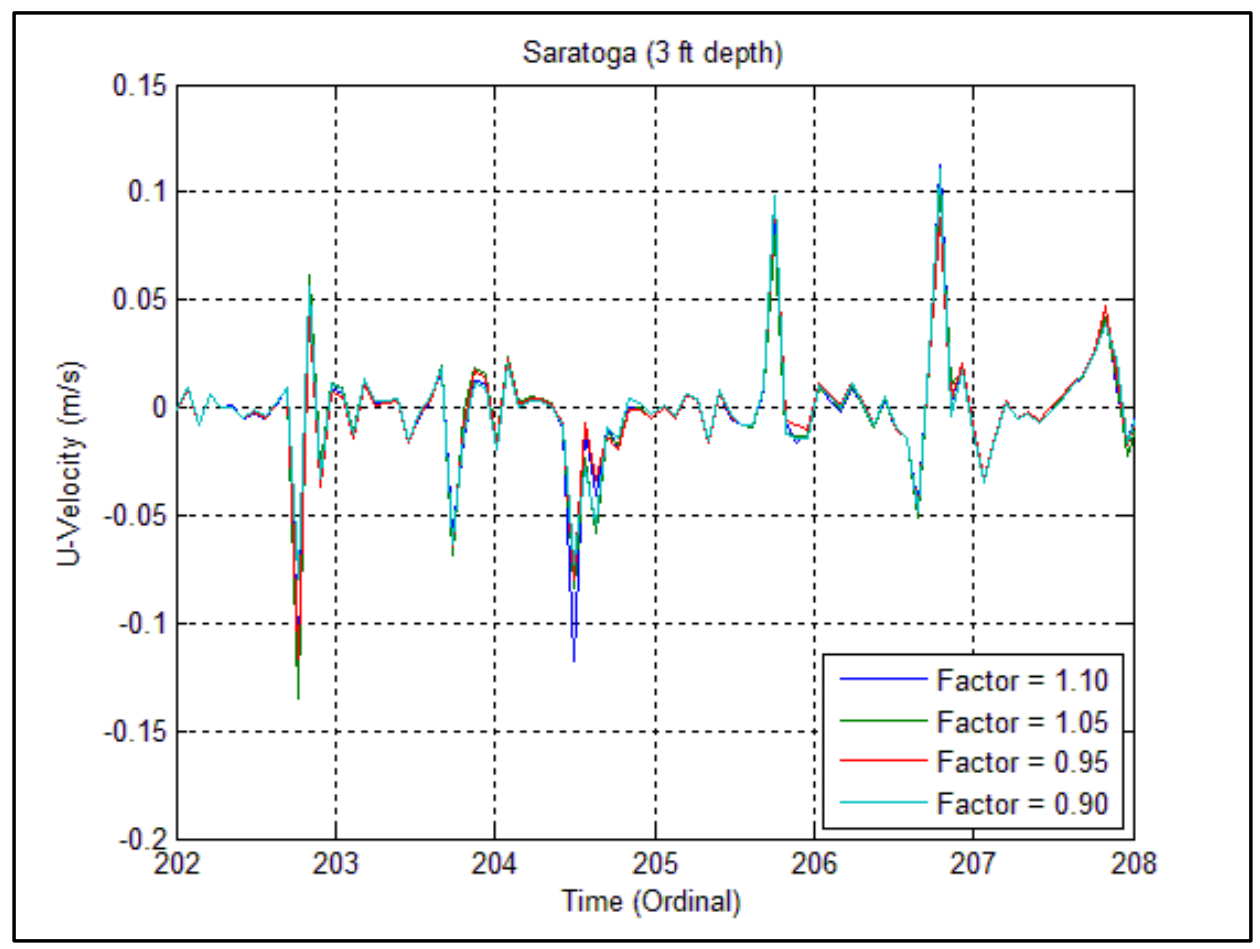

Figure 9.5 Effect of cloud cover on $u$-velocity component. 


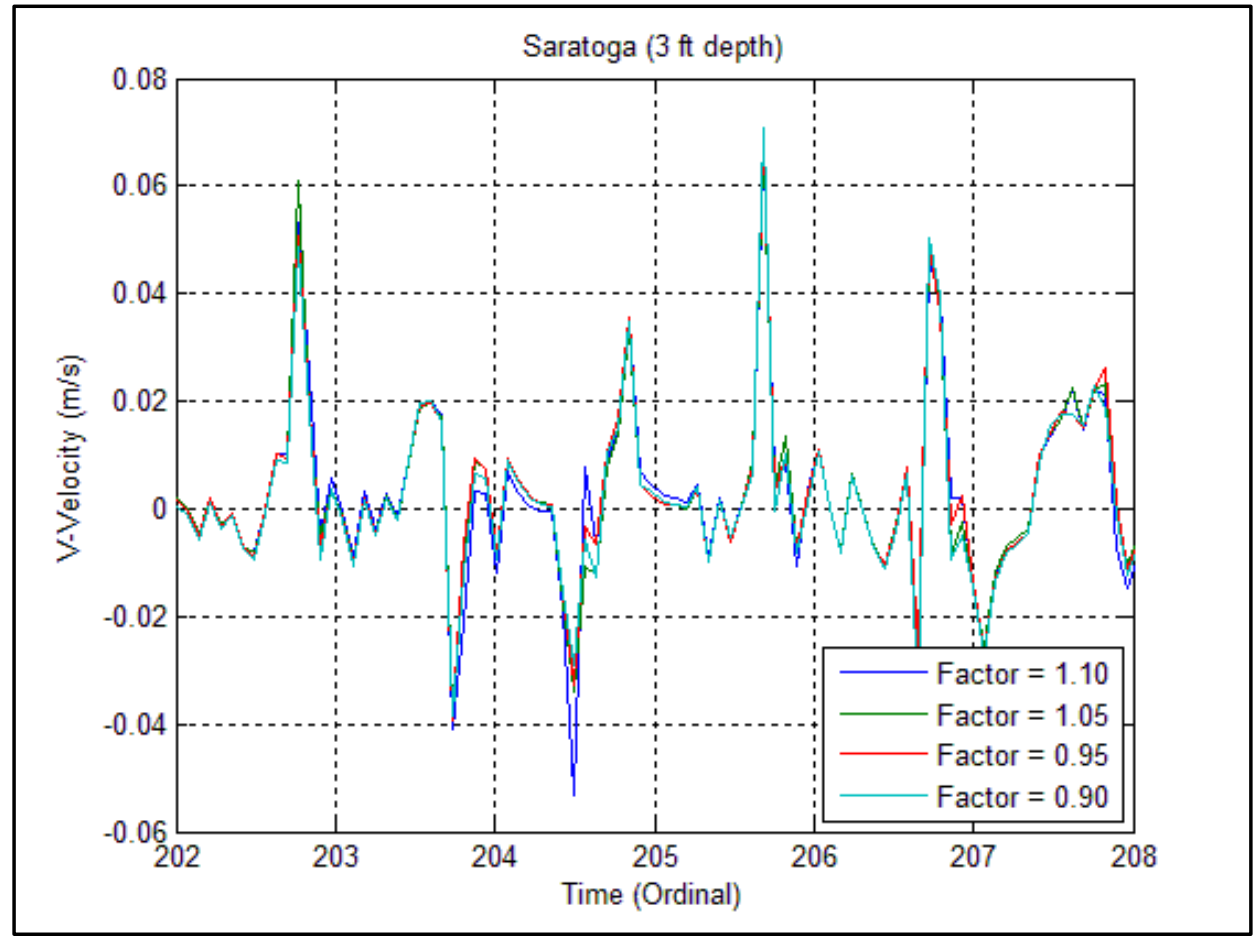

Figure 9.6 Effect of cloud cover on $v$-velocity component.

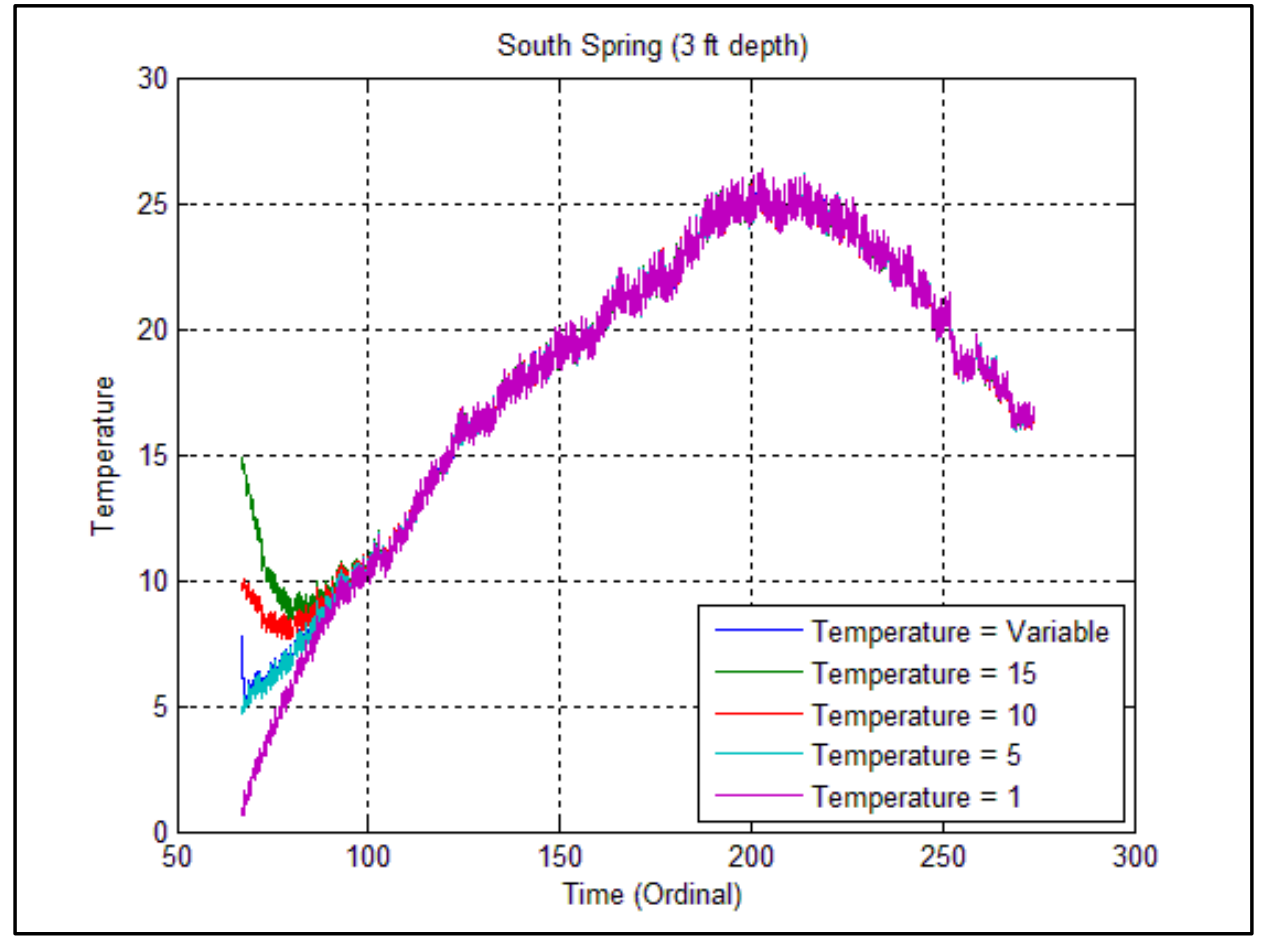

Figure 9.7 Effect of initial conditions on temperature. 
Plots of the $u$ - and $v$-velocity components for the different initial conditions revealed similar results. Once the effect of the initial transient was gone, the results were virtually indistinguishable, as shown in Figures 9.8 and 9.9.

\subsubsection{Relative Humidity}

The variations in the relative humidity had a very small influence on the water temperature, as shown in Figure 9.10. Not only did the humidity directly affected the rate of evaporative cooling, but, because it was used as the basis for calculating the cloud cover values which were used in the solar radiation model, it also indirectly affected the amount of incident solar radiation. However, the relative humidity had almost no effect on the $u$ - and $v$-velocity components, as shown in Figures 9.11 and 9.12.

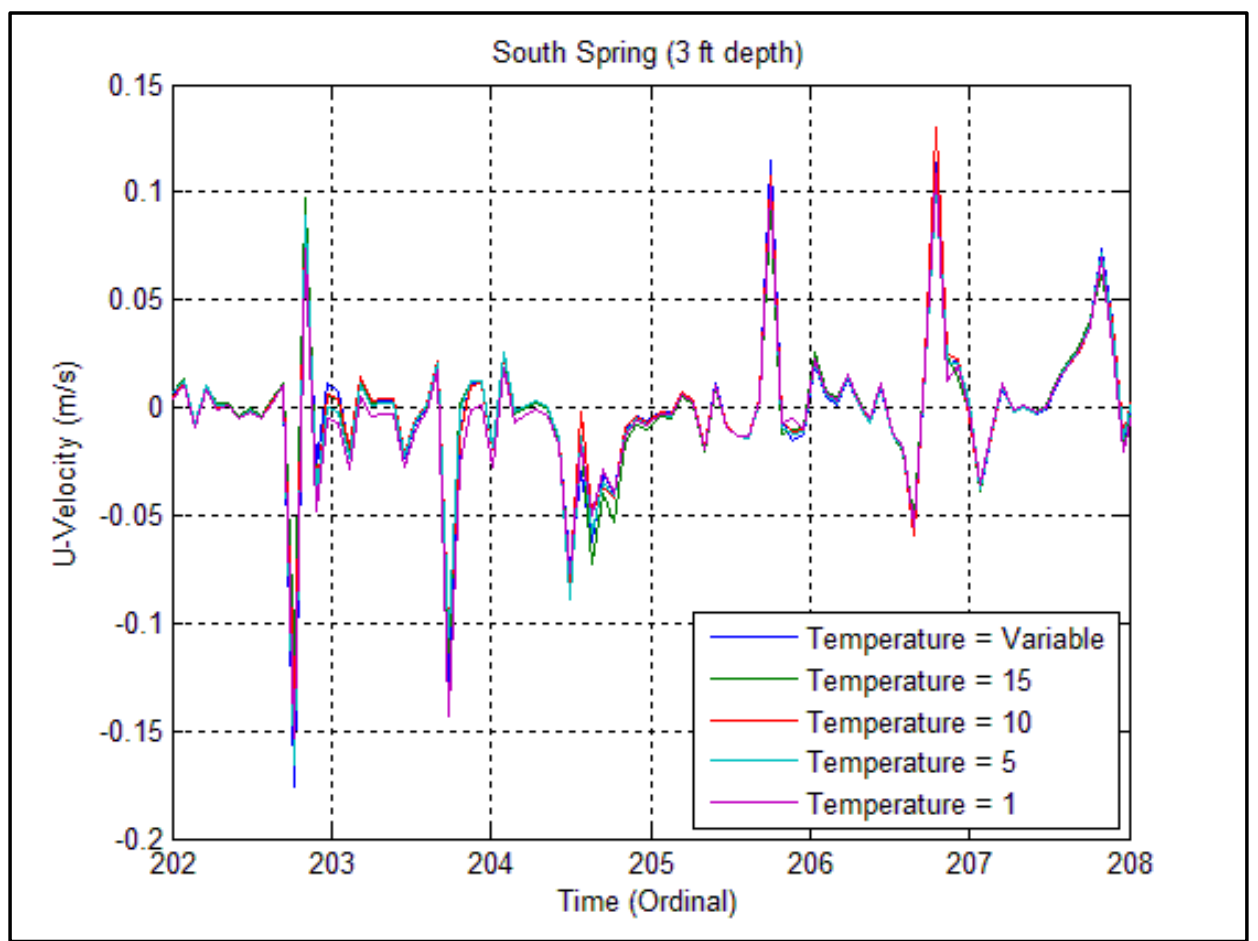

Figure 9.8 Effect of initial conditions on $u$-velocity component. 


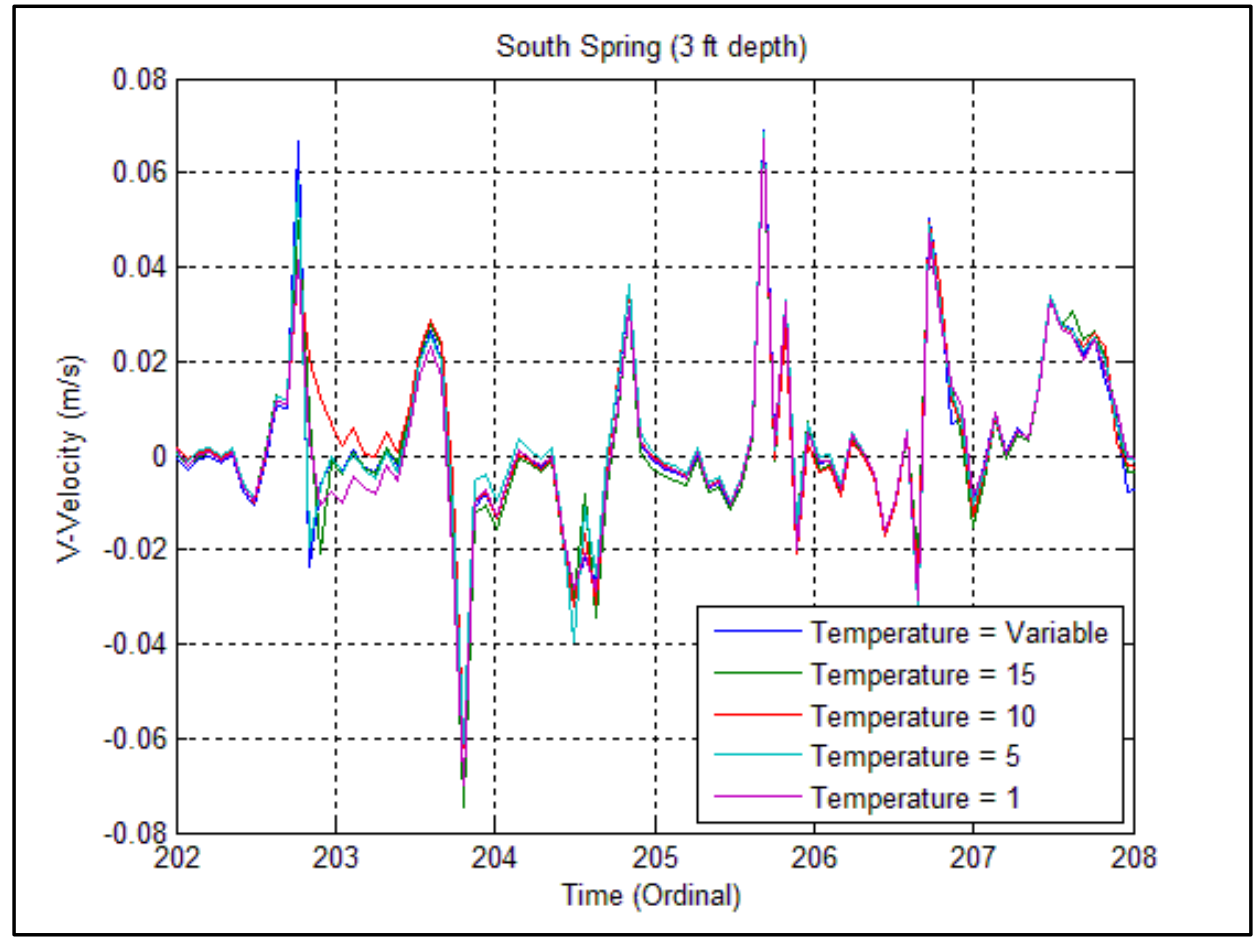

Figure 9.9 Effect of initial conditions on $v$-velocity component.

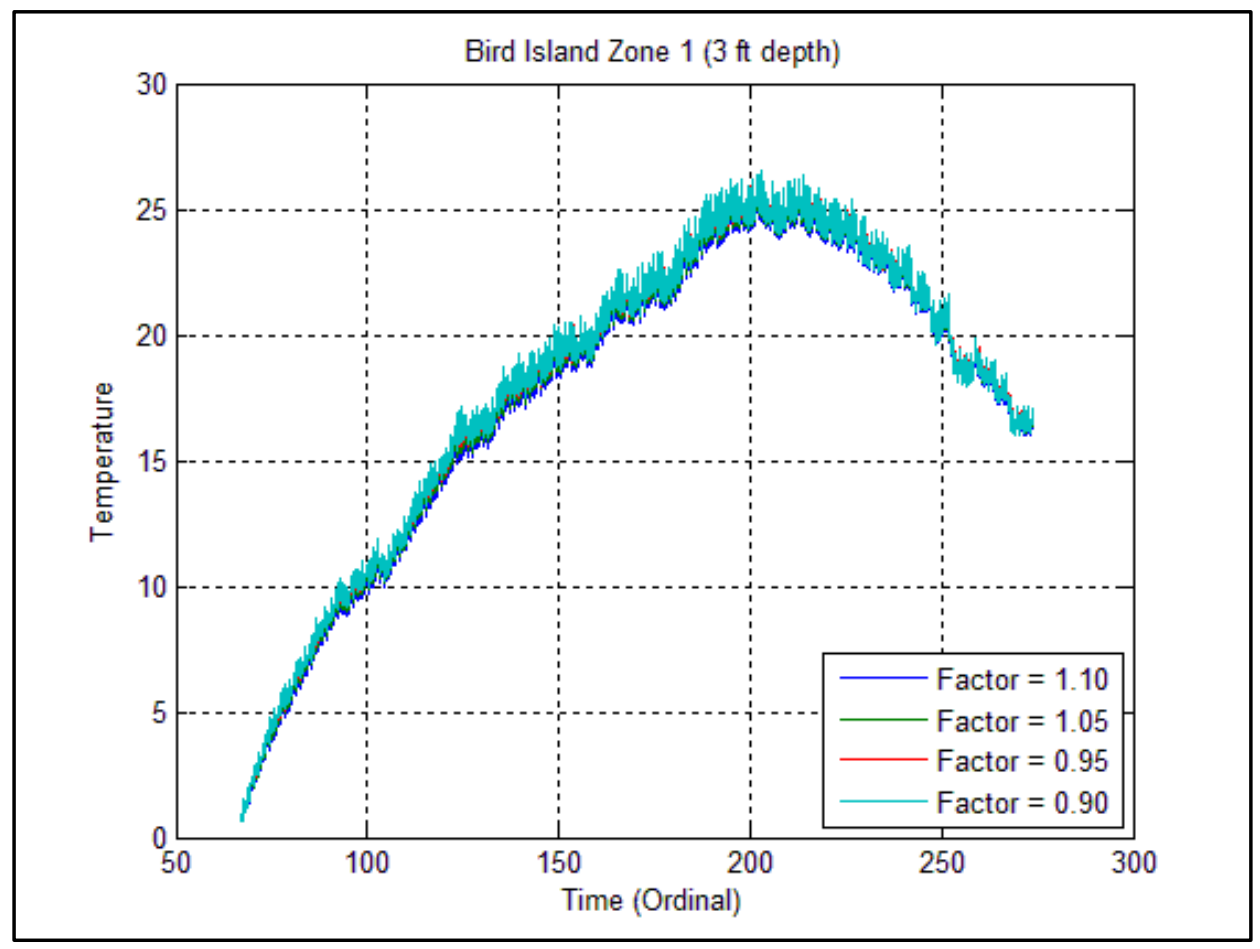

Figure 9.10 Effect of relative humidity on water temperature. 


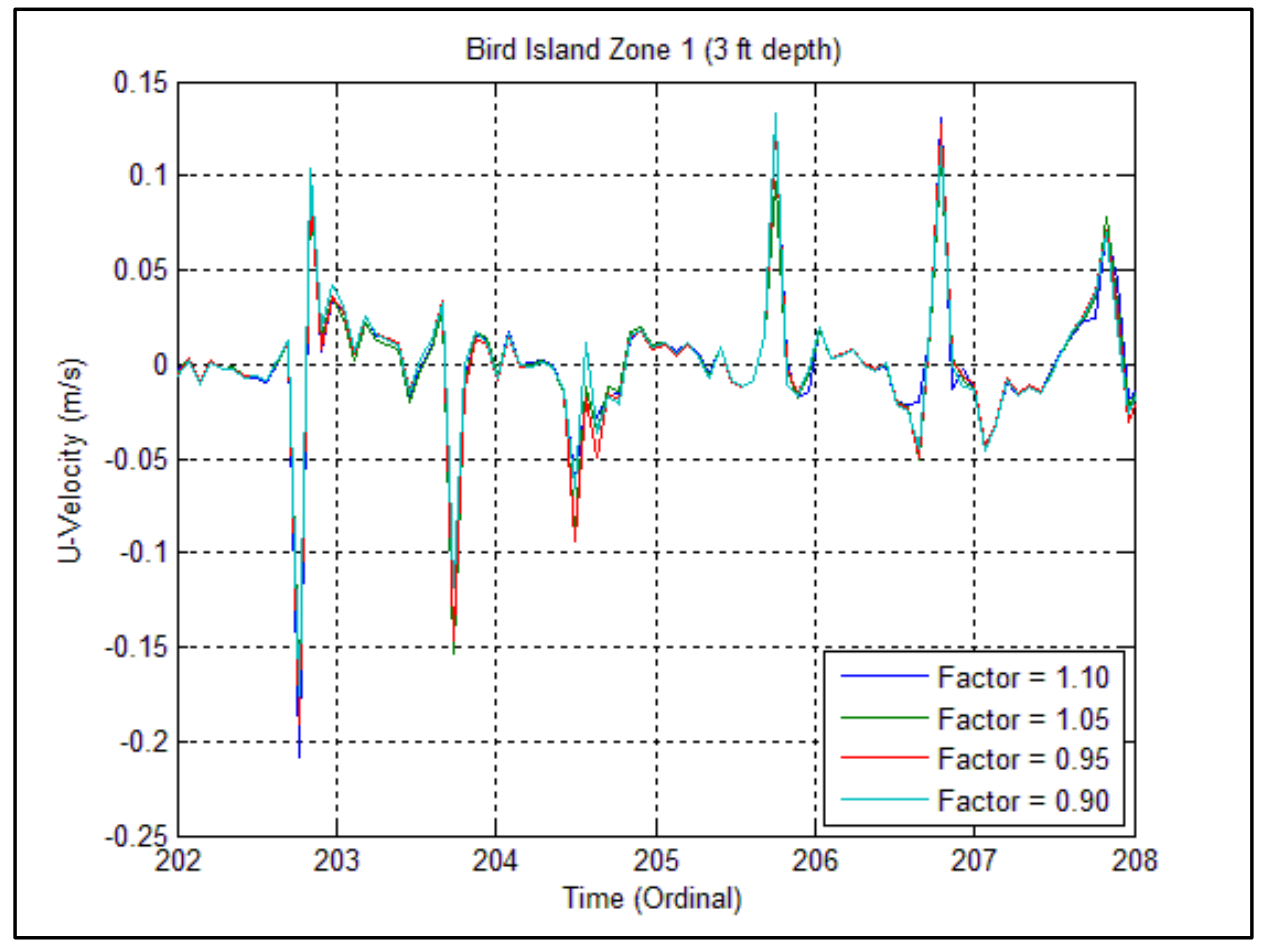

Figure 9.11 Effect of relative humidity on $u$-velocity component.

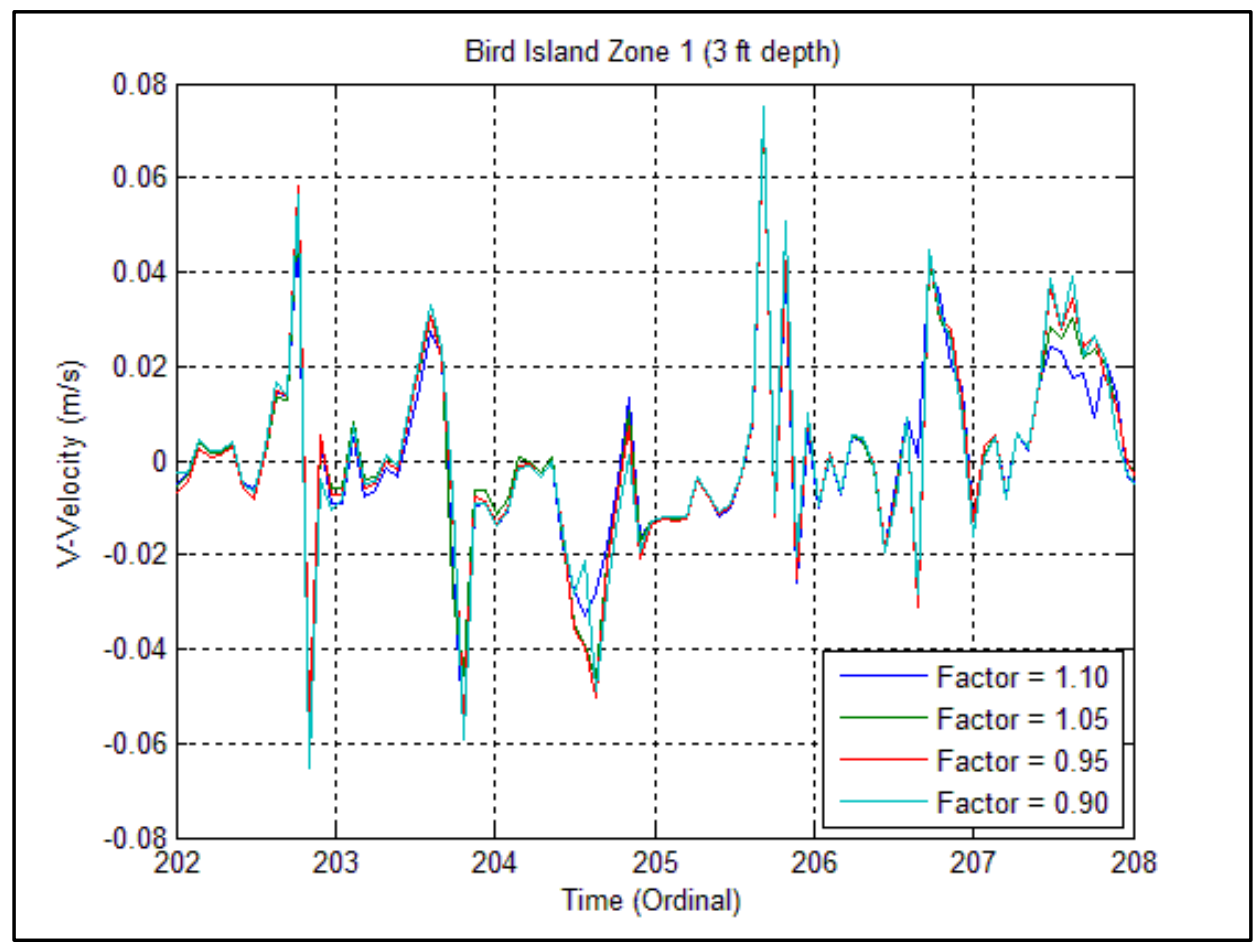

Figure 9.12 Effect of relative humidity on $v$-velocity component. 


\subsubsection{Solar Radiation}

Plots of the water temperature values for each variation in the incident short wave solar radiation showed significant differences in the results. The incident radiation not only manifested itself as heating in the initial mixed-layer but also penetrated into the water and warmed deeper layers. A plot of the water temperatures for different solar radiation multiplication factors is shown in Figure 9.13.

The solar radiation had little overall effect on the $u$ - and $v$-velocity components, as shown in Figures 9.14 and 9.15.

\subsubsection{Precipitation}

Because precipitation is assigned the surface water temperature upon contact with the surface, variations in the precipitation levels had no effect on the water temperature,

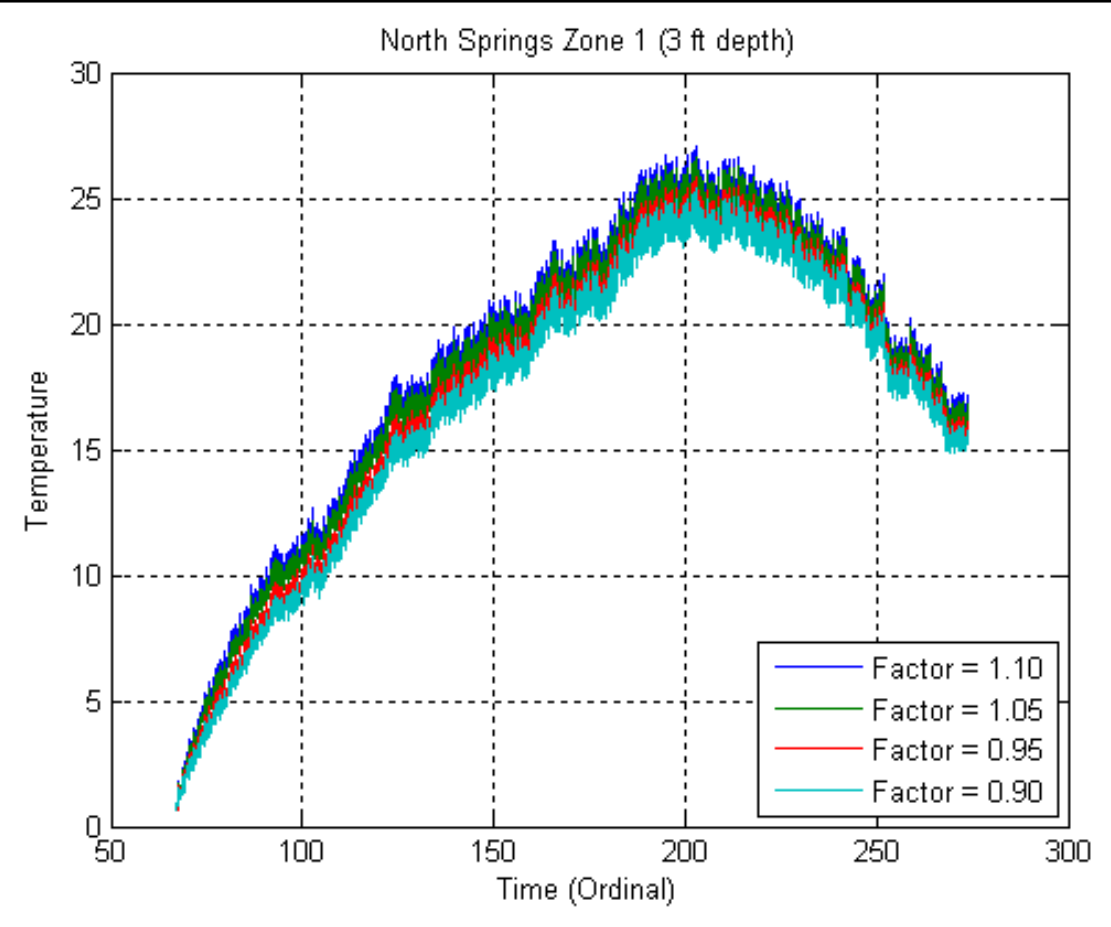

Figure 9.13 Effect of solar radiation on water temperature. 


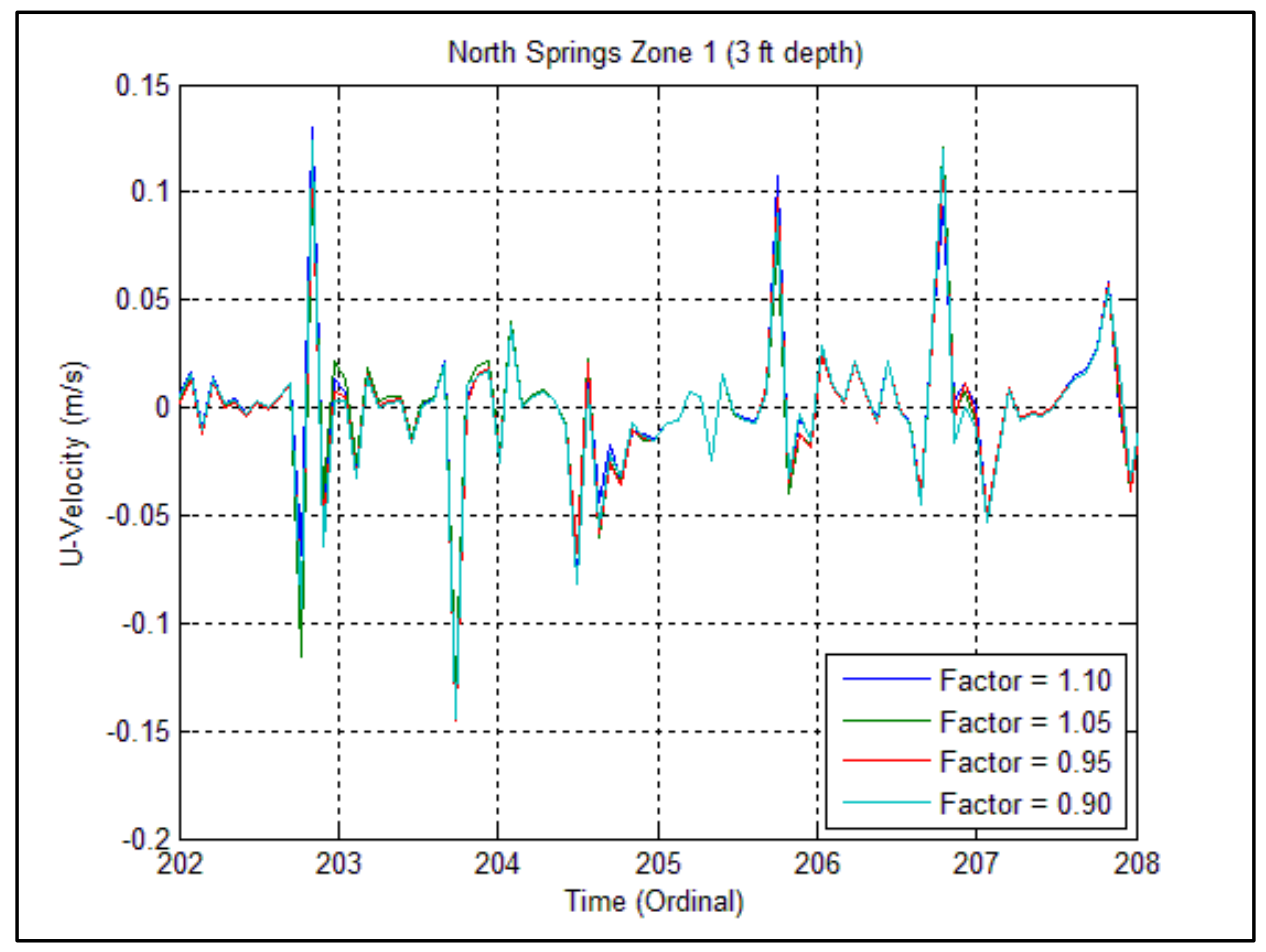

Figure 9.14 Effect of solar radiation on $u$-velocity component.

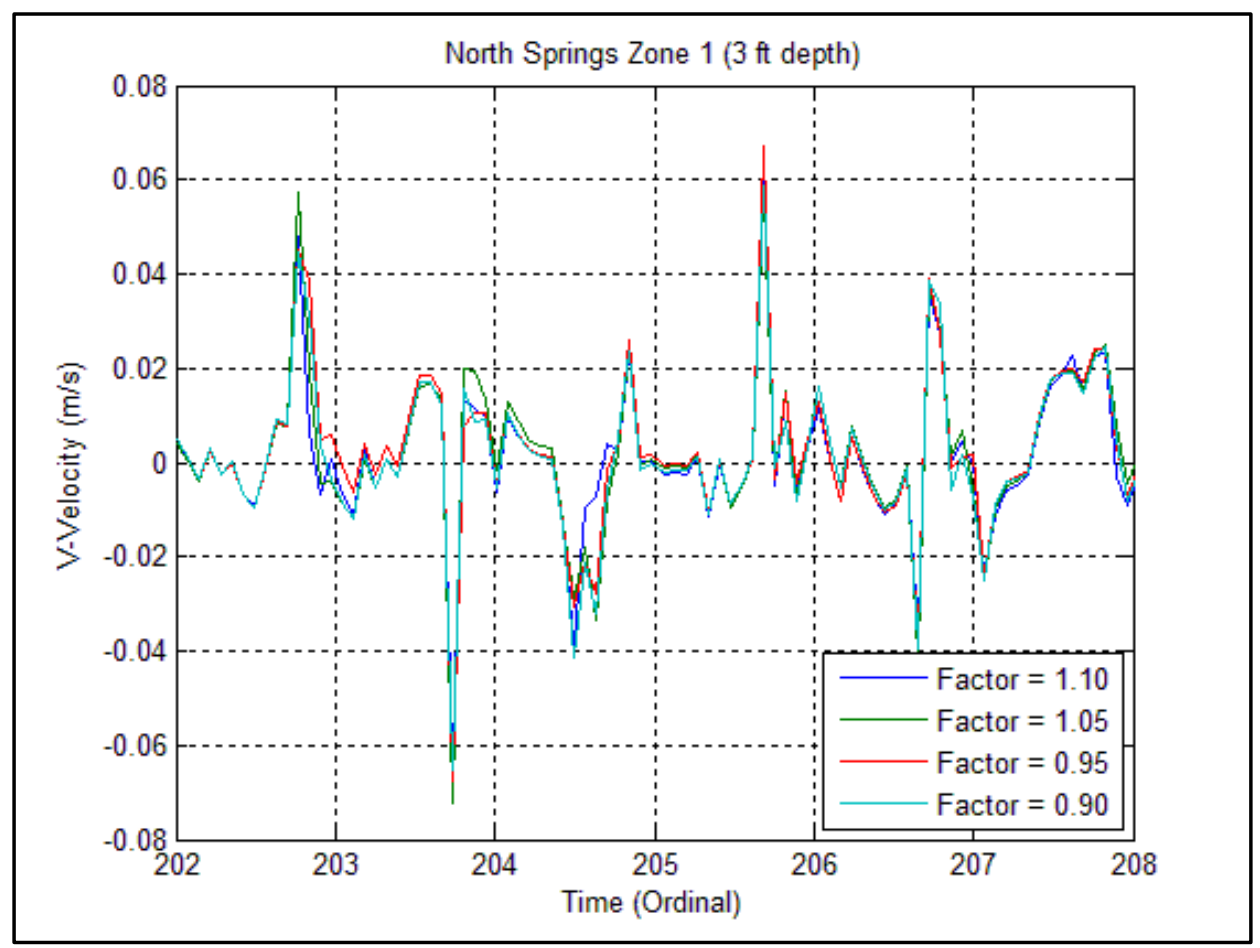

Figure 9.15 Effect of solar radiation on $v$-velocity component. 
as shown in Figure 9.16. Plots of the $u$ - and $v$-velocity components showed that the precipitation also had no effect on the flow direction, as shown in Figures 9.17 and 9.18.

\subsubsection{River Inflow Rates}

Plots of the water temperatures for various river inflow rates showed that small variations in the volume of water entering the lake had only a very small effect, as illustrated in Figure 9.19. The $u$ - and $v$-velocity components showed some small effects near the mouths of the rivers, but the majority of the lake showed no significant changes in the flow field, as shown in Figures 9.20 and 9.21.

\subsubsection{River Outflow Rates}

Variations in outflow rate through the Jordan River produced a small change in

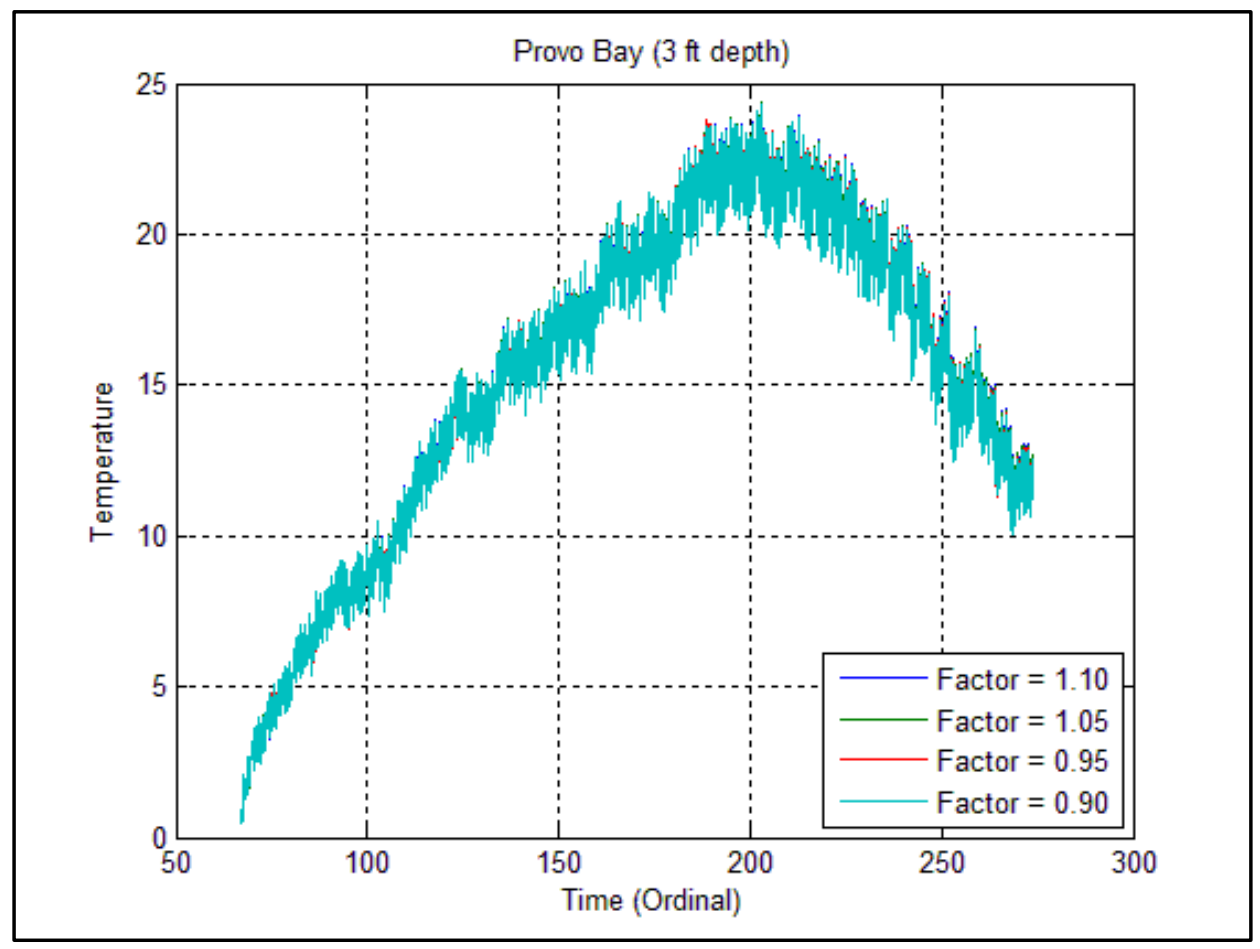

Figure 9.16 Effect of precipitation on water temperature. 


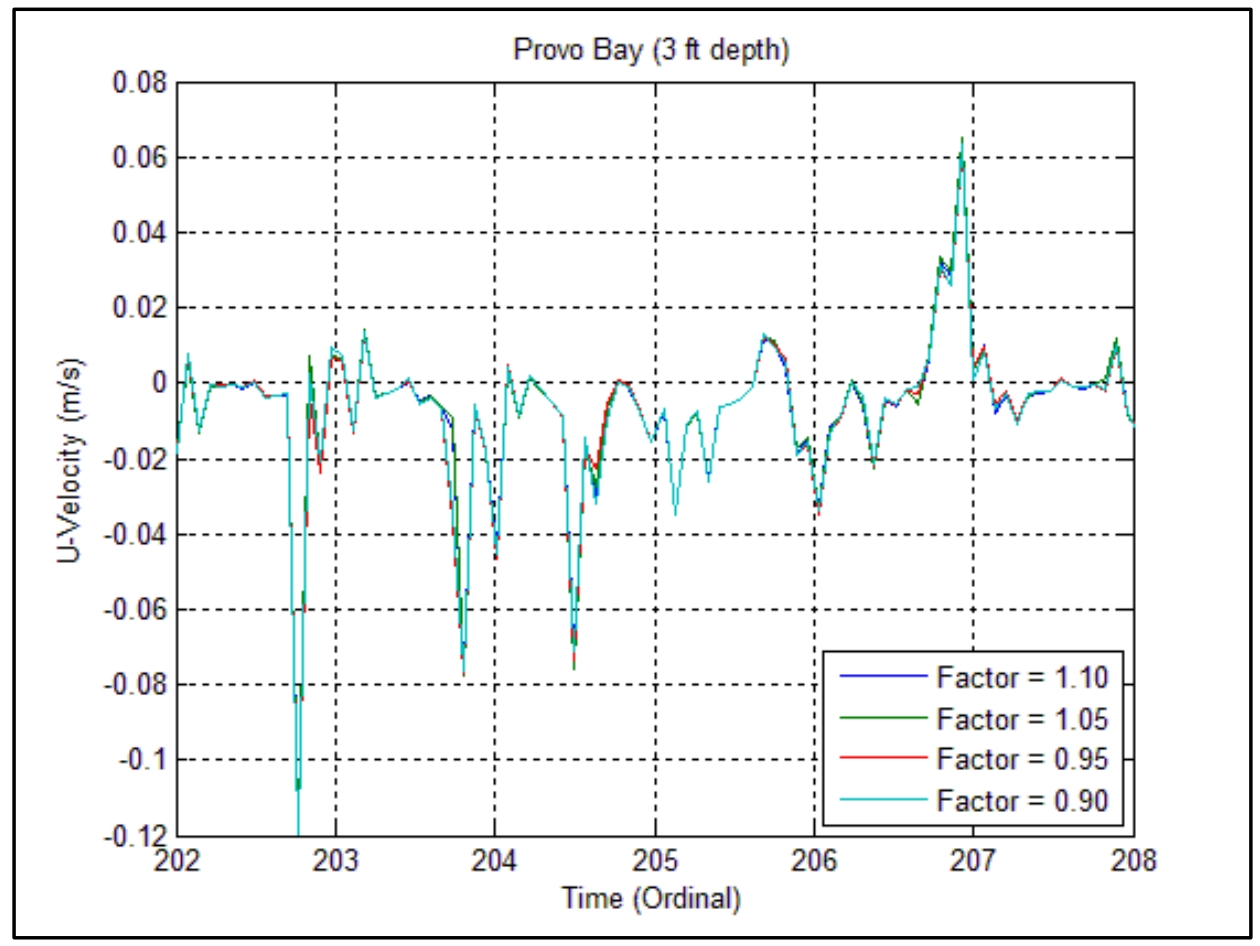

Figure 9.17 Effect of precipitation on $u$-velocity component.

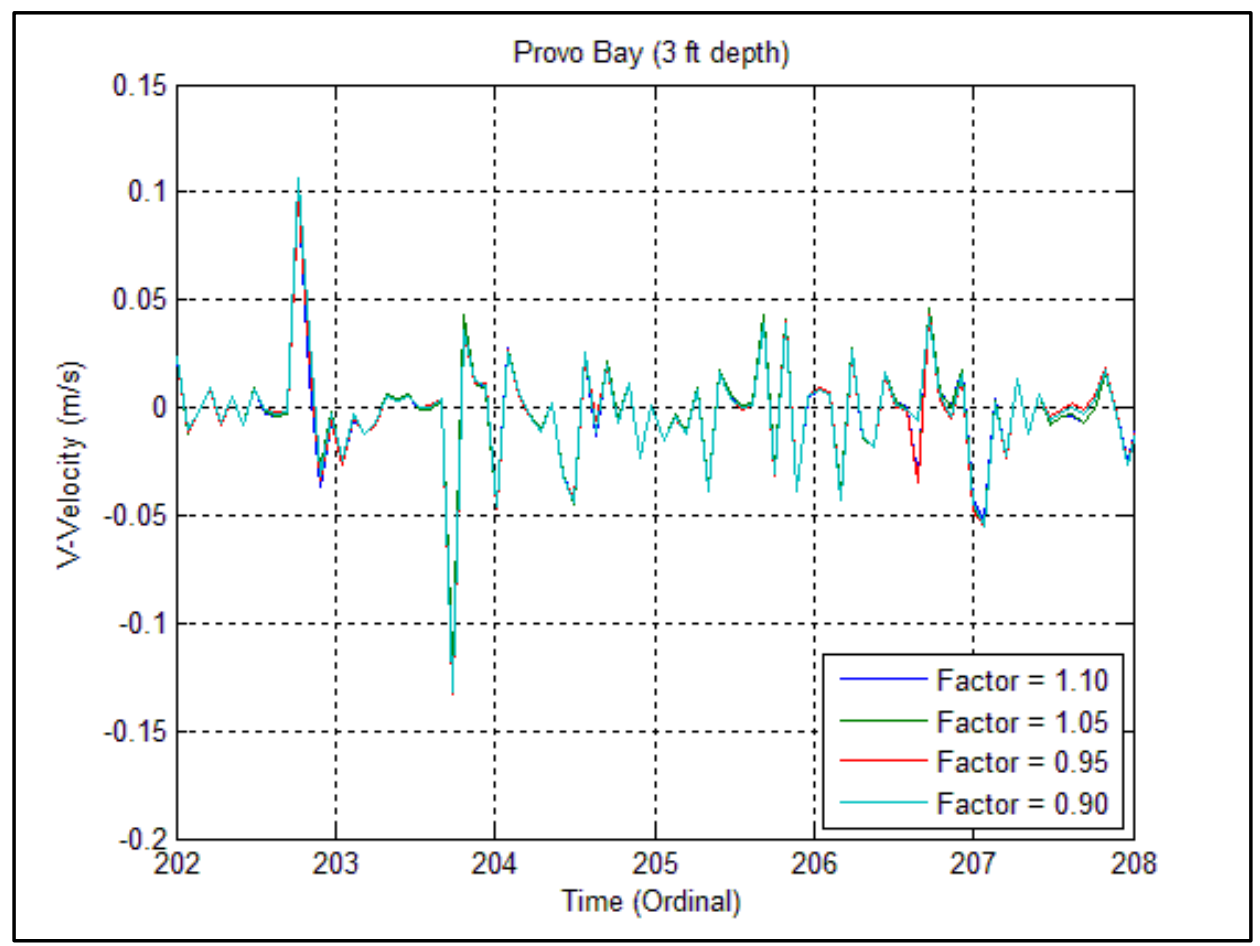

Figure 9.18 Effect of precipitation on $v$-velocity component. 


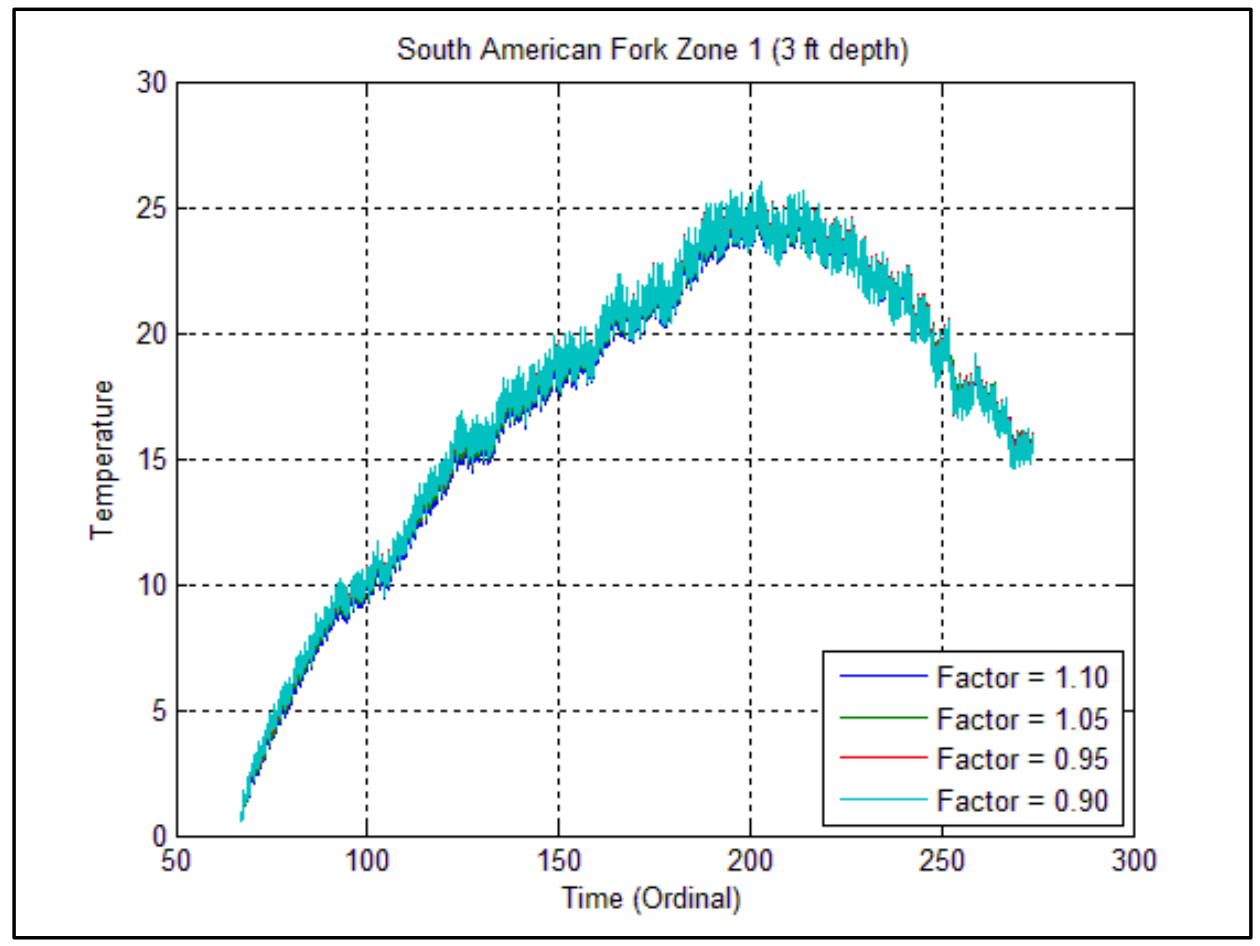

Figure 9.19 Effect of river inflow rate on water temperature.

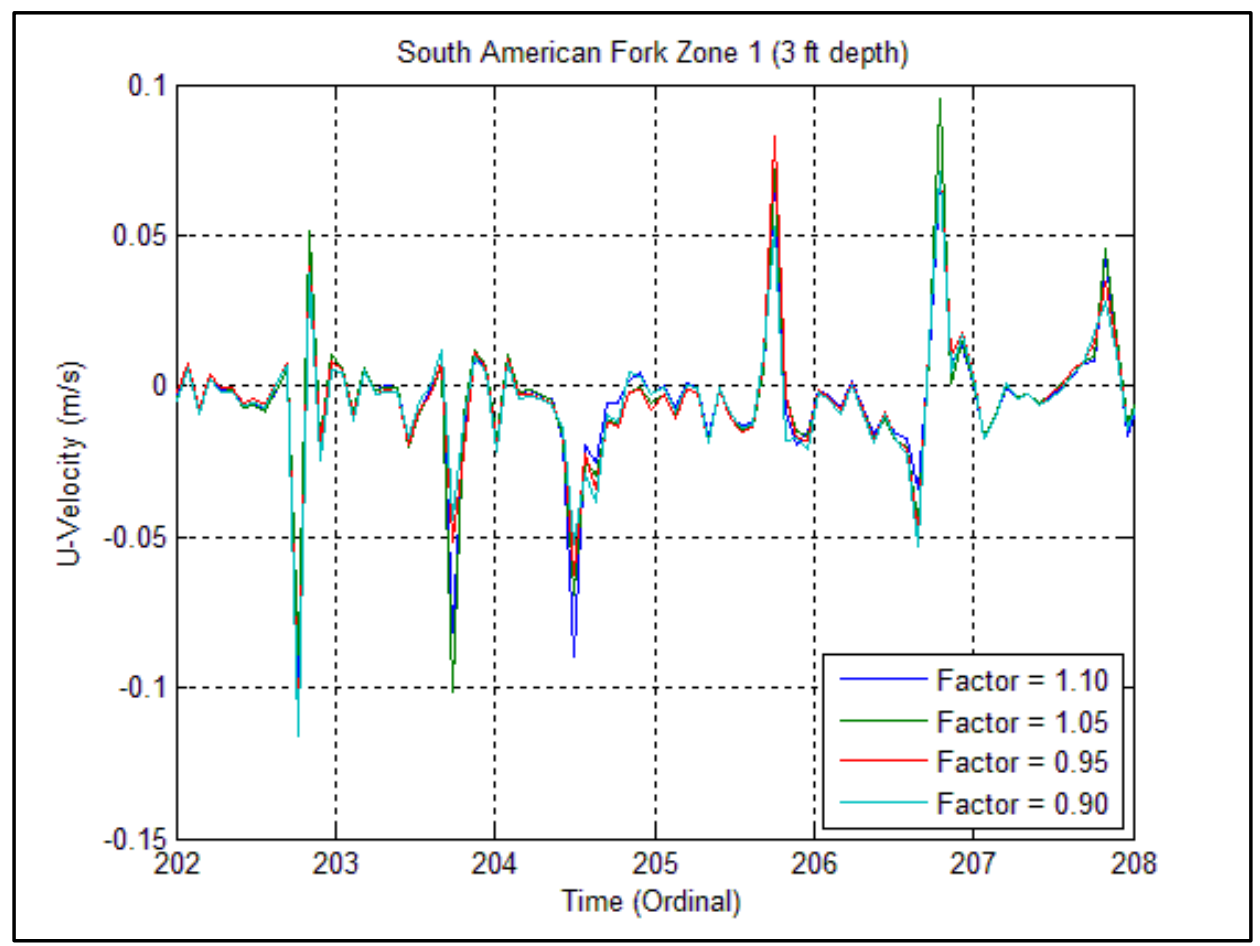

Figure 9.20 Effect of river inflow rate on $u$-velocity component. 


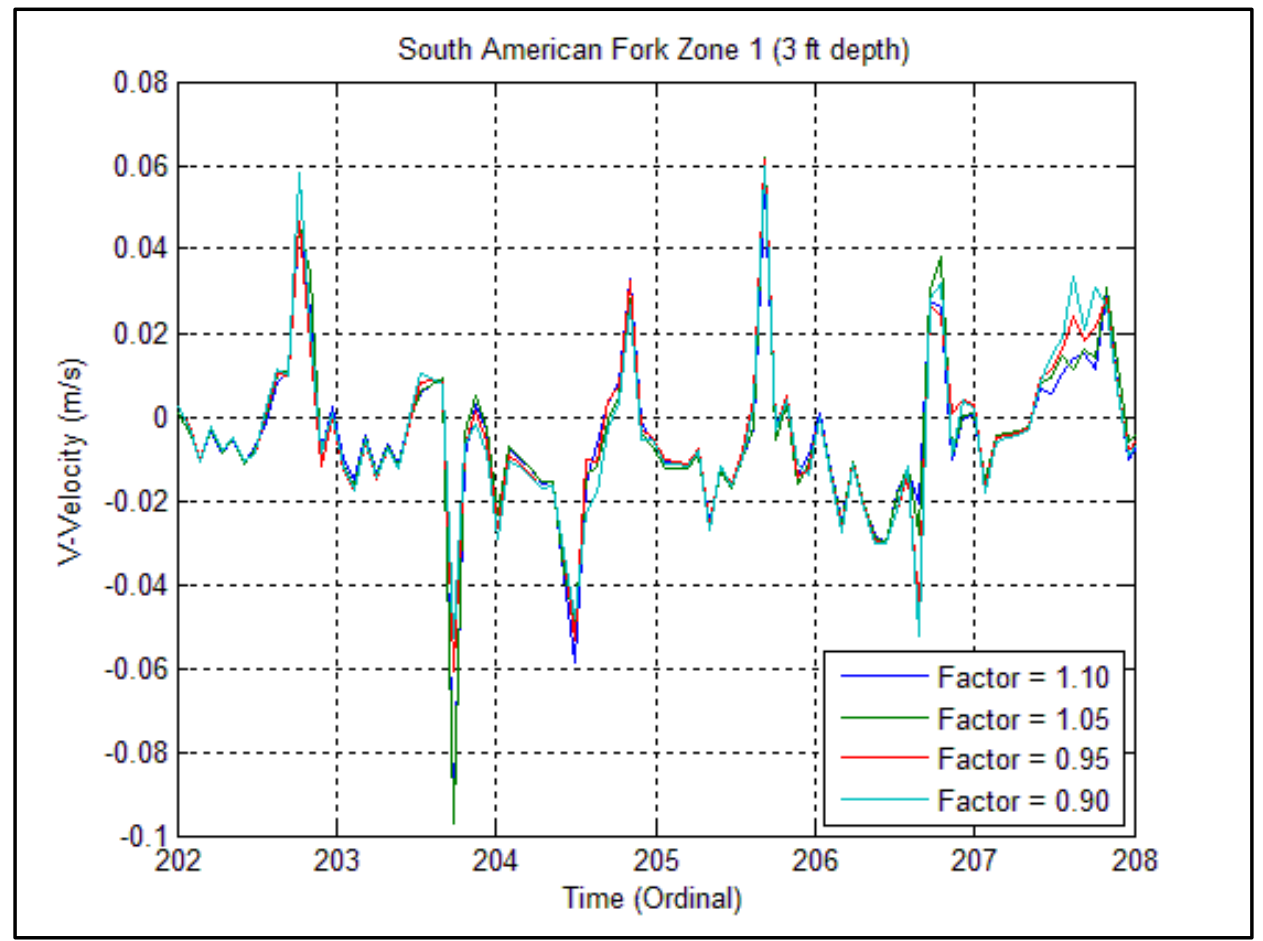

Figure 9.21 Effect of river inflow rate on $v$-velocity component.

water temperature values at all of the sensor locations, as shown in Figure 9.22. Lower outflow rates corresponded to slightly higher temperatures. Changes in the outflow rate had a negligible effect on the currents in the lake, as shown by the $u$ - and $v$-velocity component plots in Figures 9.23 and 9.24.

\subsubsection{River Inflow Temperatures}

Varying the temperature of the water flowing into Utah Lake had only a slight effect on the overall temperature, as shown in Figure 9.25. The $u$ - and $v$-velocity components were similarly unaffected, as shown in Figures 9.26 and 9.27.

\subsubsection{Wind Direction}

Plots of the temperature values for different wind directions revealed that those 


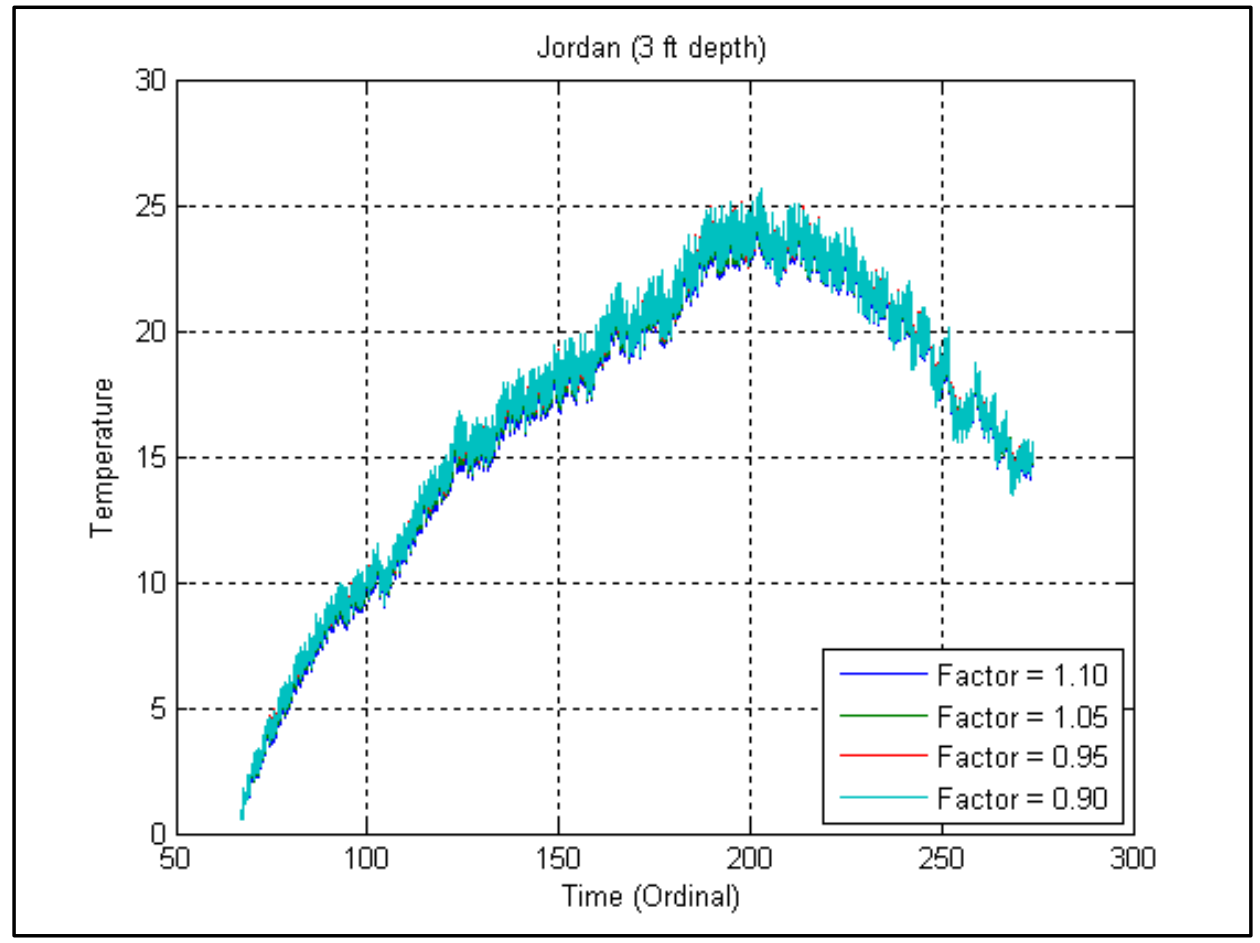

Figure 9.22 Effect of river outflow rate on water temperature.

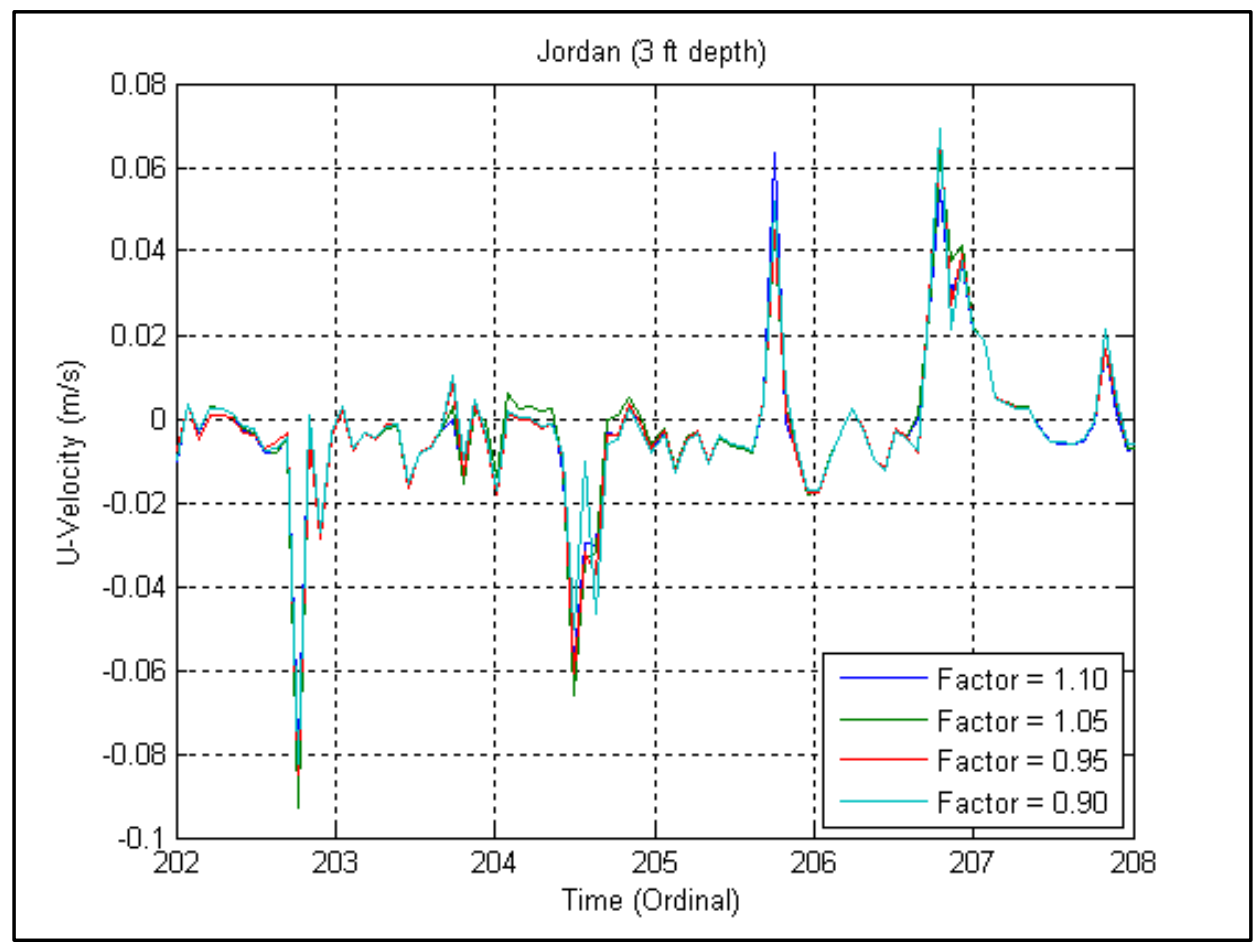

Figure 9.23 Effect of river outflow rate on $u$-velocity component. 


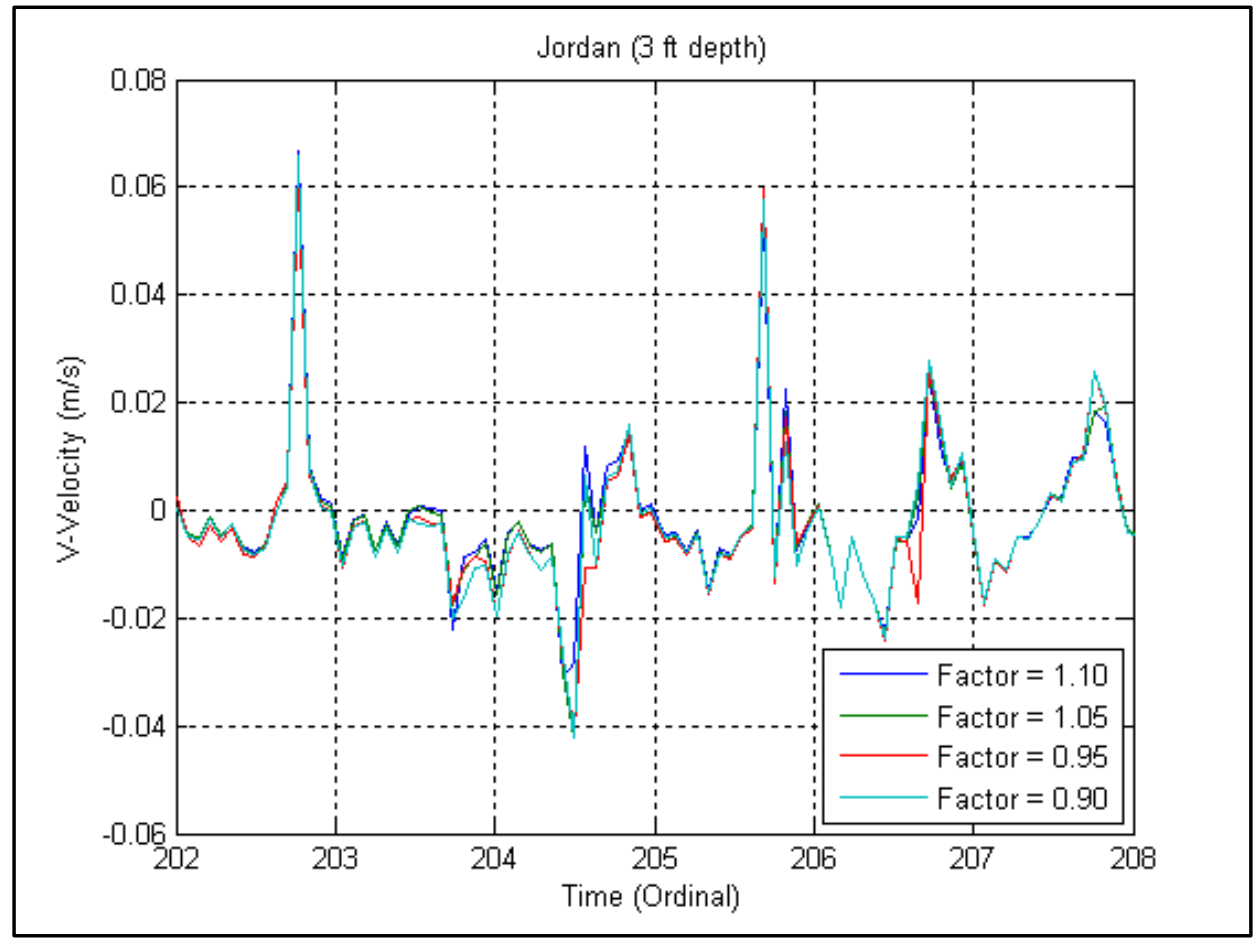

Figure 9.24 Effect of river outflow rate on $v$-velocity component.

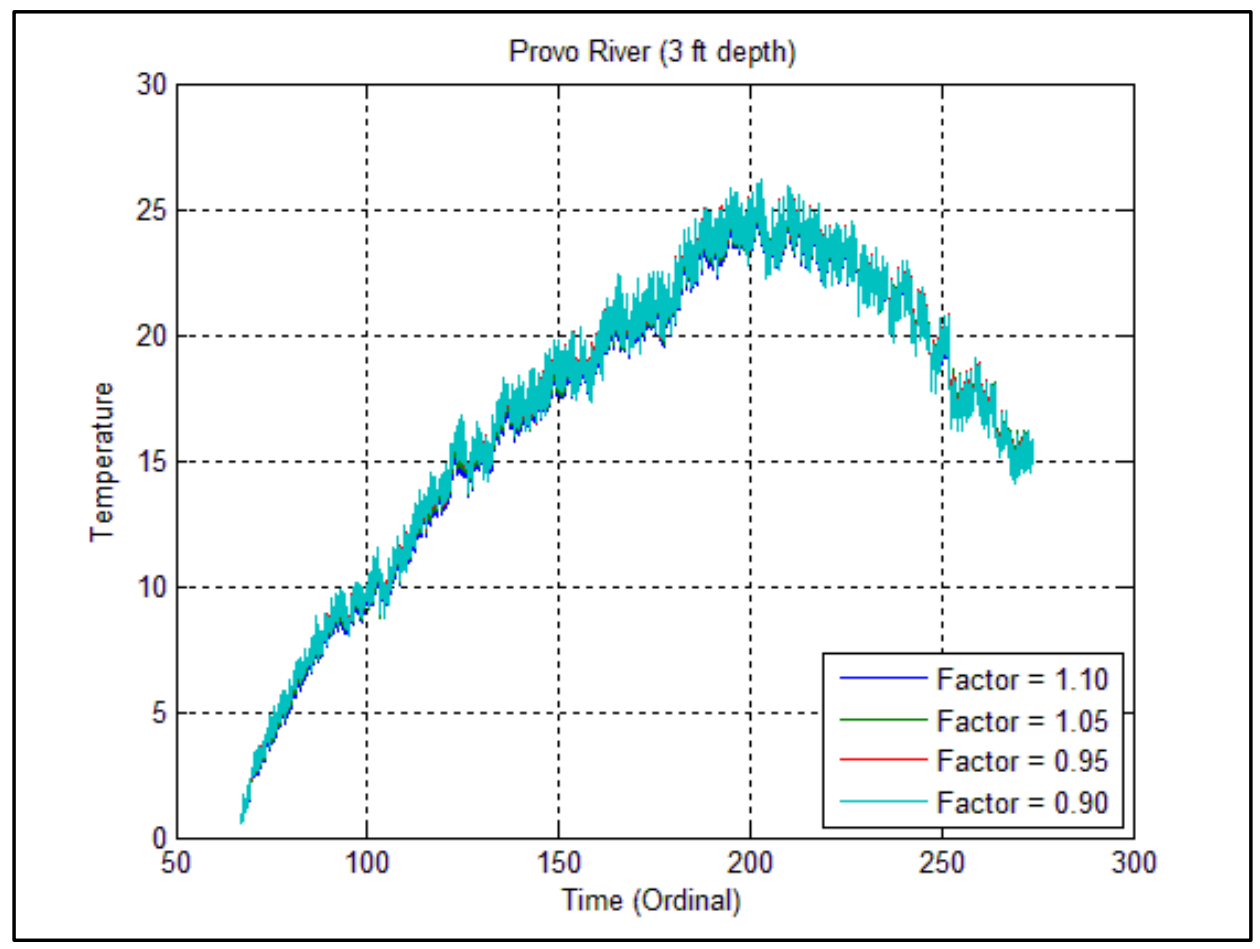

Figure 9.25 Effect of river inflow temperature on water temperature. 


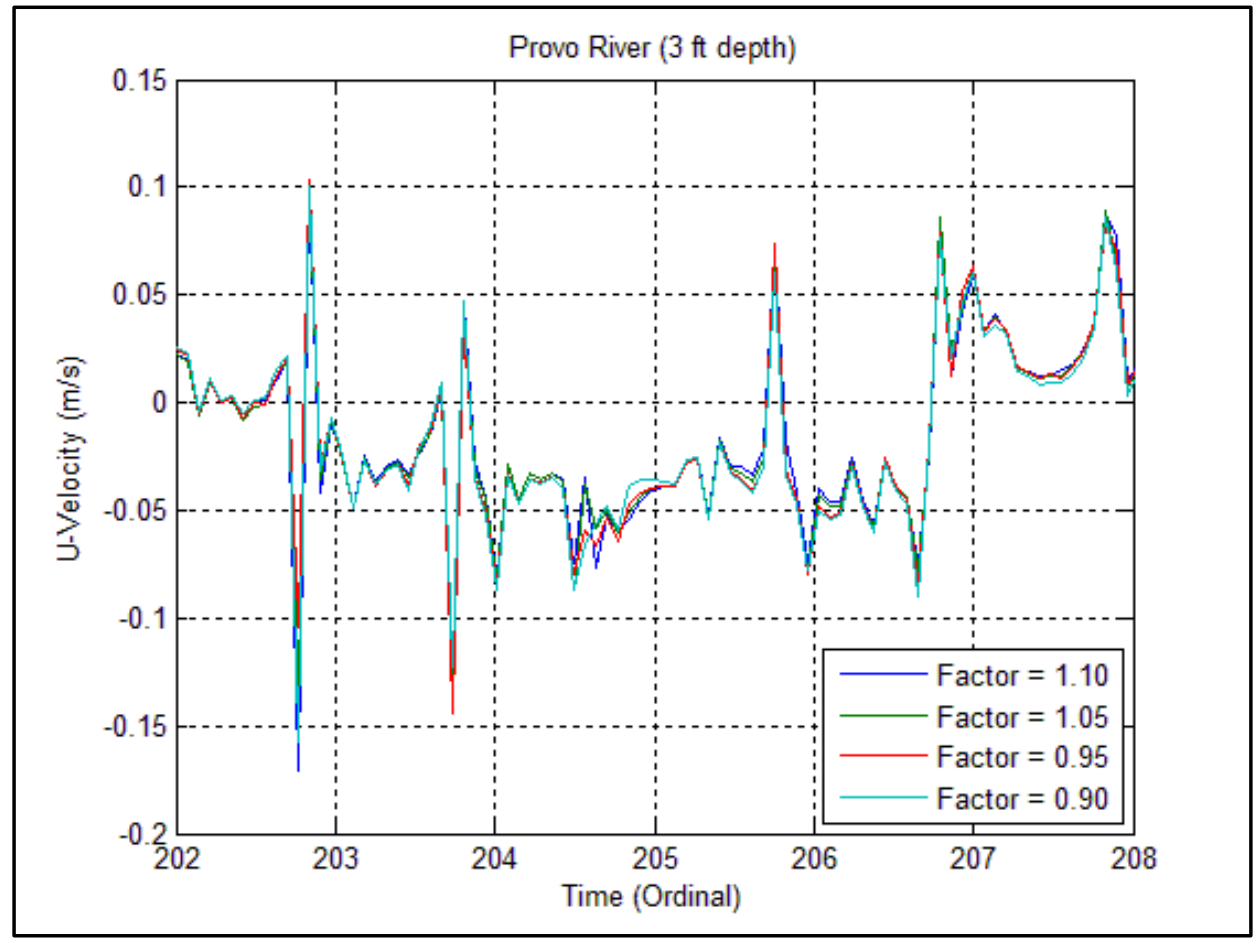

Figure 9.26 Effect of river inflow temperature on $u$-velocity component.

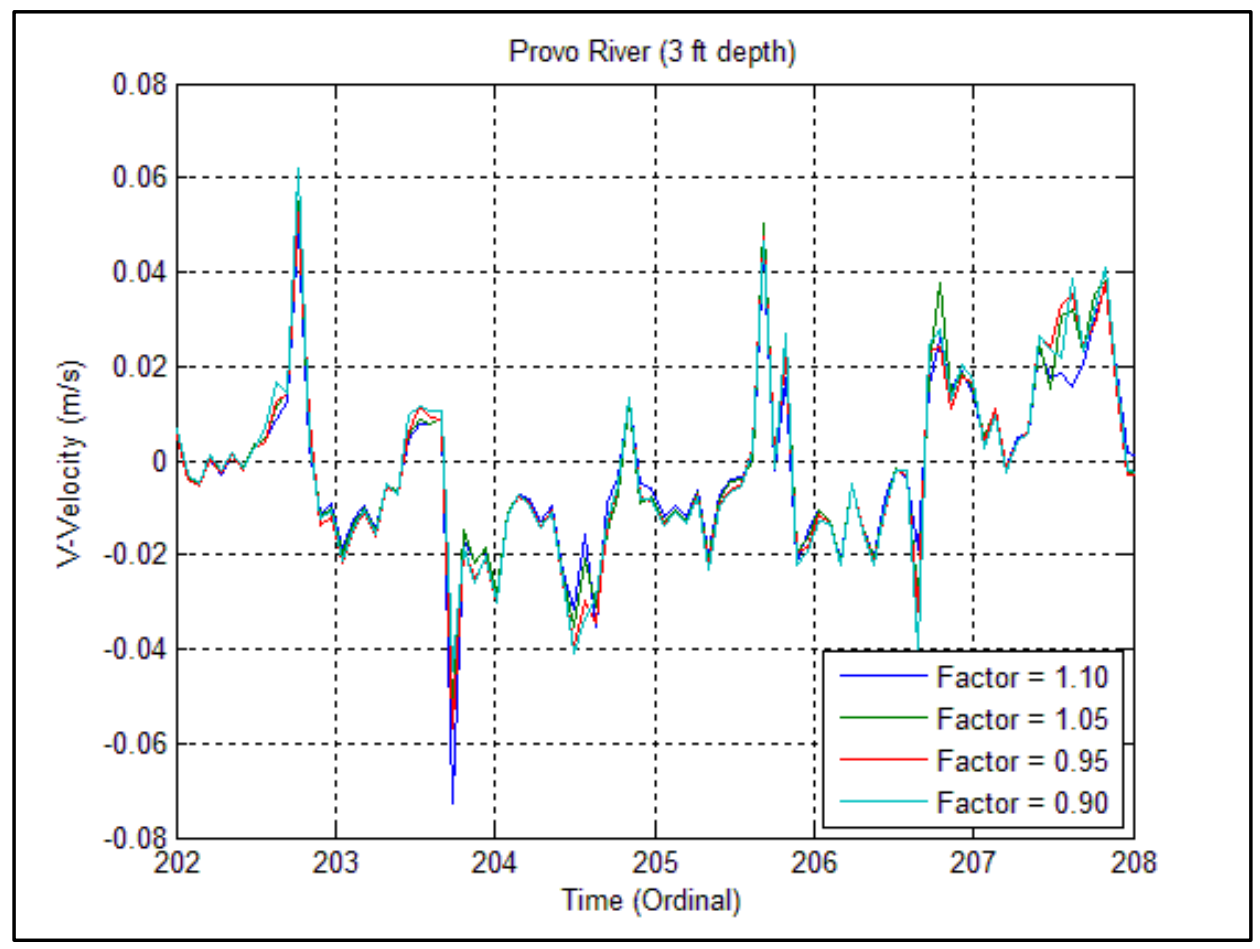

Figure 9.27 Effect of river inflow temperature on $v$-velocity component. 
locations close to the shore of the lake were strongly affected by the wind direction, while those in deeper water were relatively unaffected. Figure 9.28 shows the plot of the temperature history at the West Island location on the west side of the lake, while Figure 9.29 shows the temperatures at the Powell Slough location on the east shore of the lake.

In addition, the current direction and magnitude is most strongly influenced by the wind. Figures 9.30 and 9.31 show plots for the $u$ - and $v$-velocity components at the West Island location, while Figures 9.32 and 9.33 show the same plots for the Powell Slough location. It can be seen that changing the direction of the wind by $180^{\circ}$ made the current flow in the opposite direction. Similar graphs were produced for all of the other sensor locations, indicating that wind direction affects the direction of flow across the entire lake.

\subsubsection{Wind Speed}

Variations in the wind speed have a noticeable effect on the water temperature, as shown in Figure 9.34. Lower wind speeds correlate with higher water temperatures, probably as a result of reduced heat loss through evaporation and convective heat transfer. In addition, the wind speed variations have a small effect on the magnitude but not the direction of the $u$ - and $v$-velocity components, as shown by the plots in Figures 9.35 and 9.36 .

\subsubsection{Summary}

In order to determine the degree to which parameter controls the temperature and flow field in Utah Lake, each was varied individually while the others were held constant, 


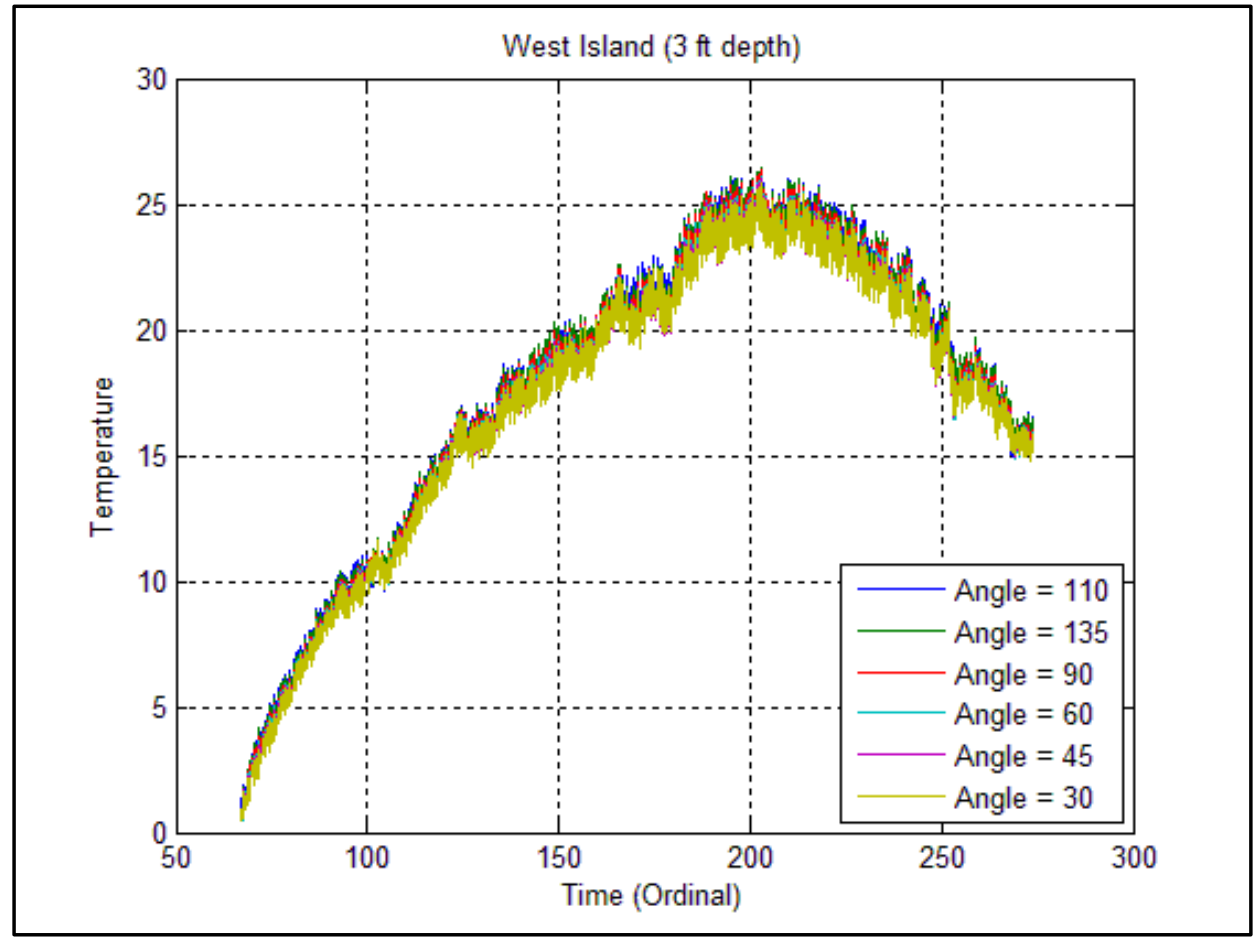

Figure 9.28 Effect of wind direction on water temperature: west shore.

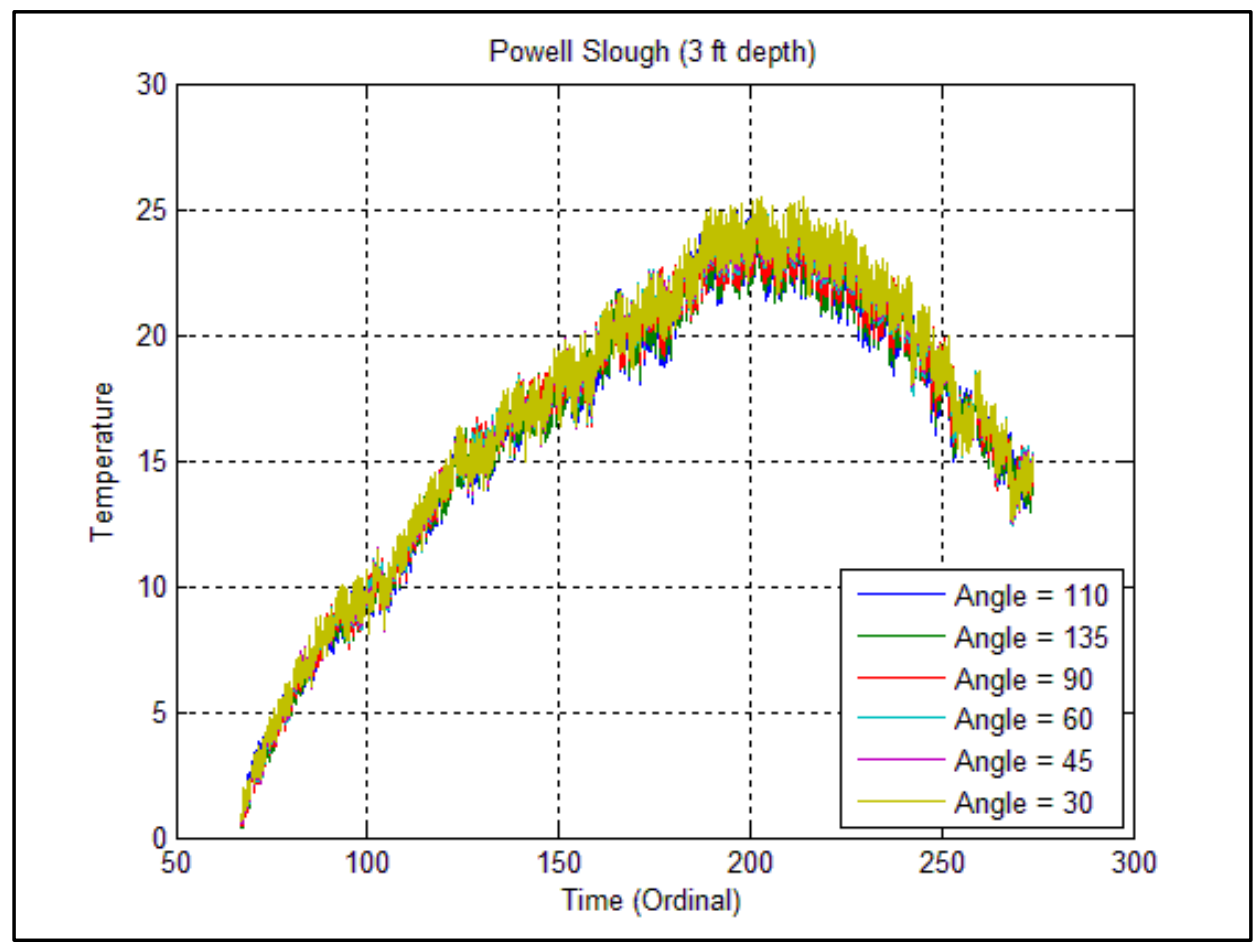

Figure 9.29 Effect of wind direction on water temperature: east shore. 


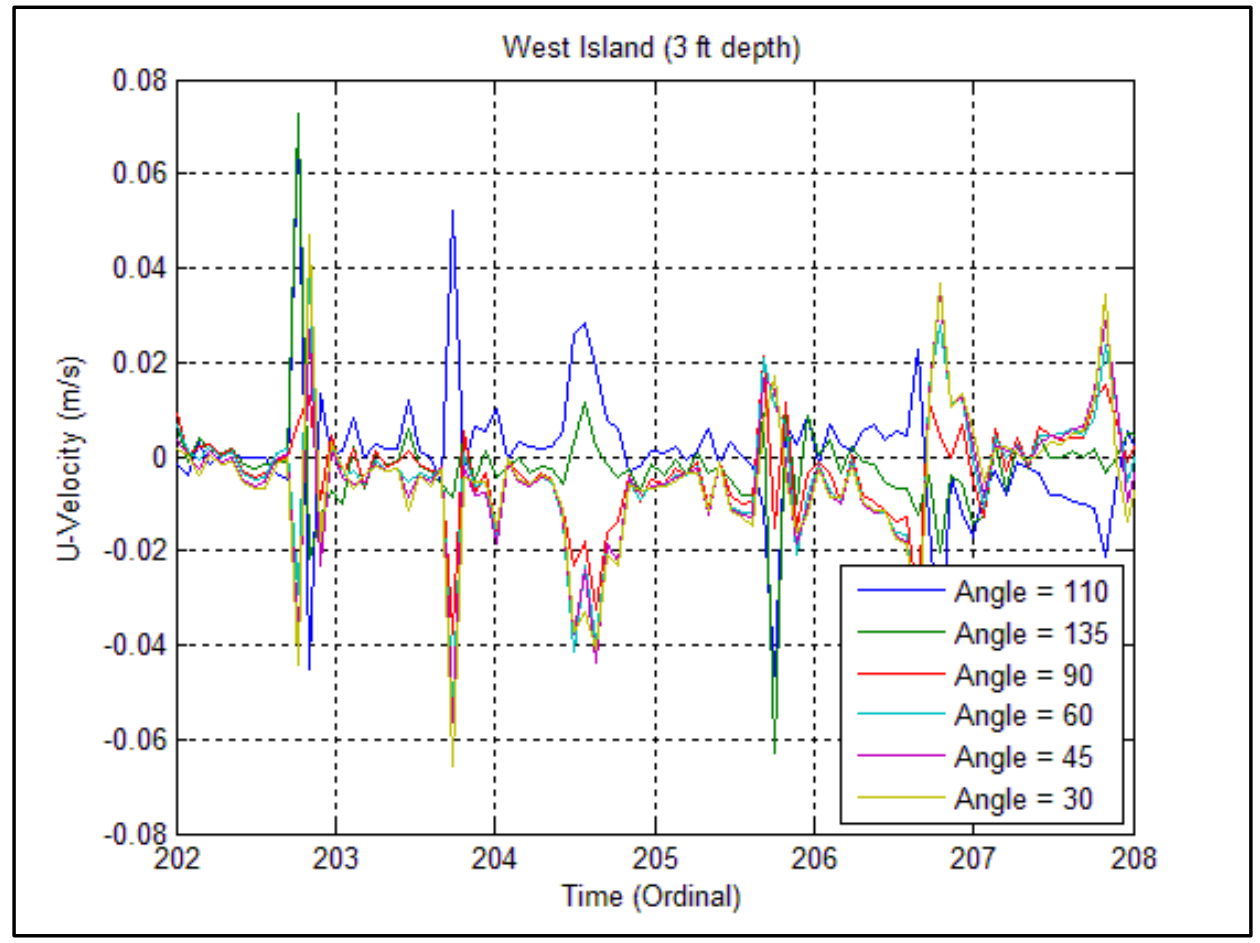

Figure 9.30 Effect of wind direction on $u$-velocity component: west shore.

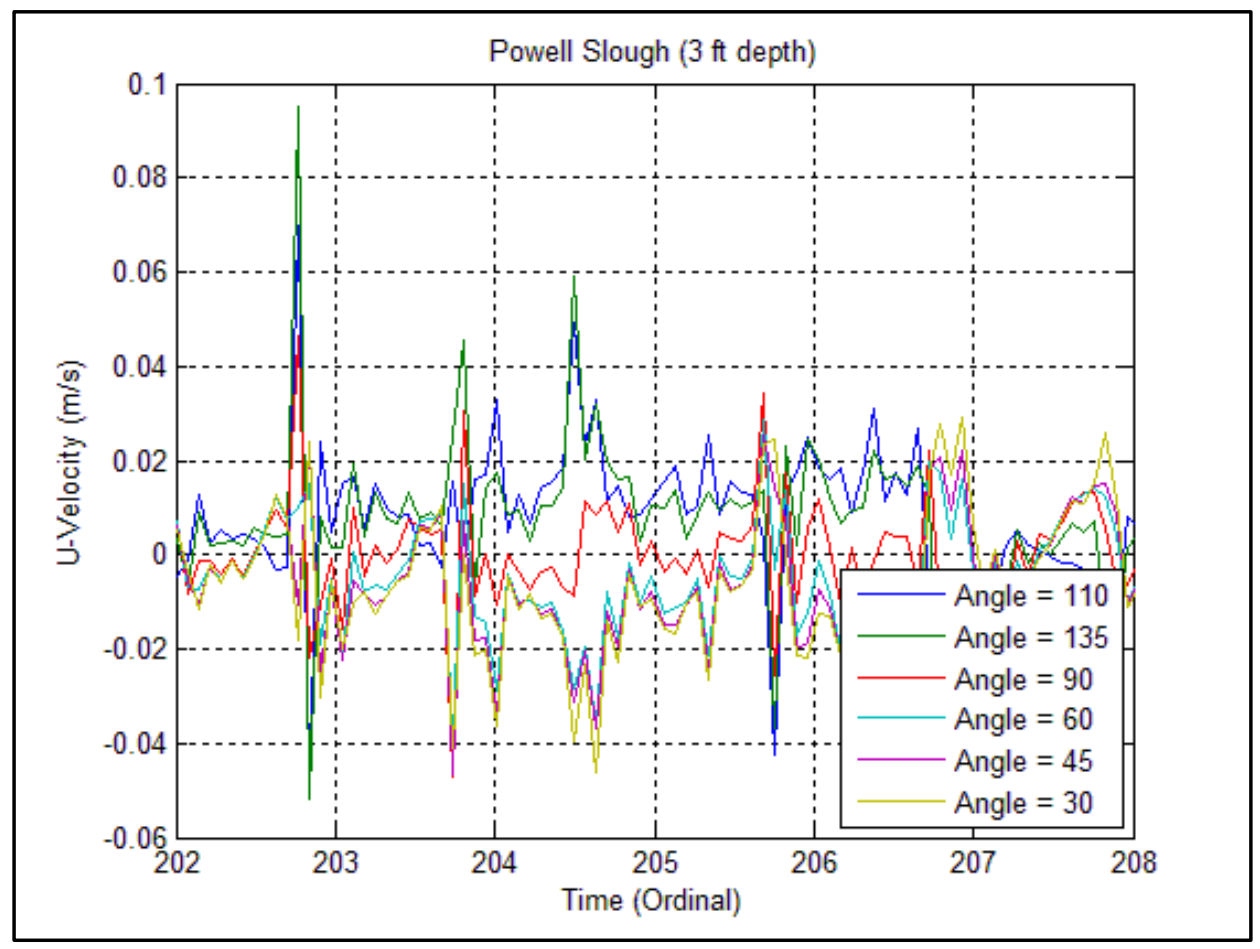

Figure 9.31 Effect of wind direction on $u$-velocity component: east shore. 


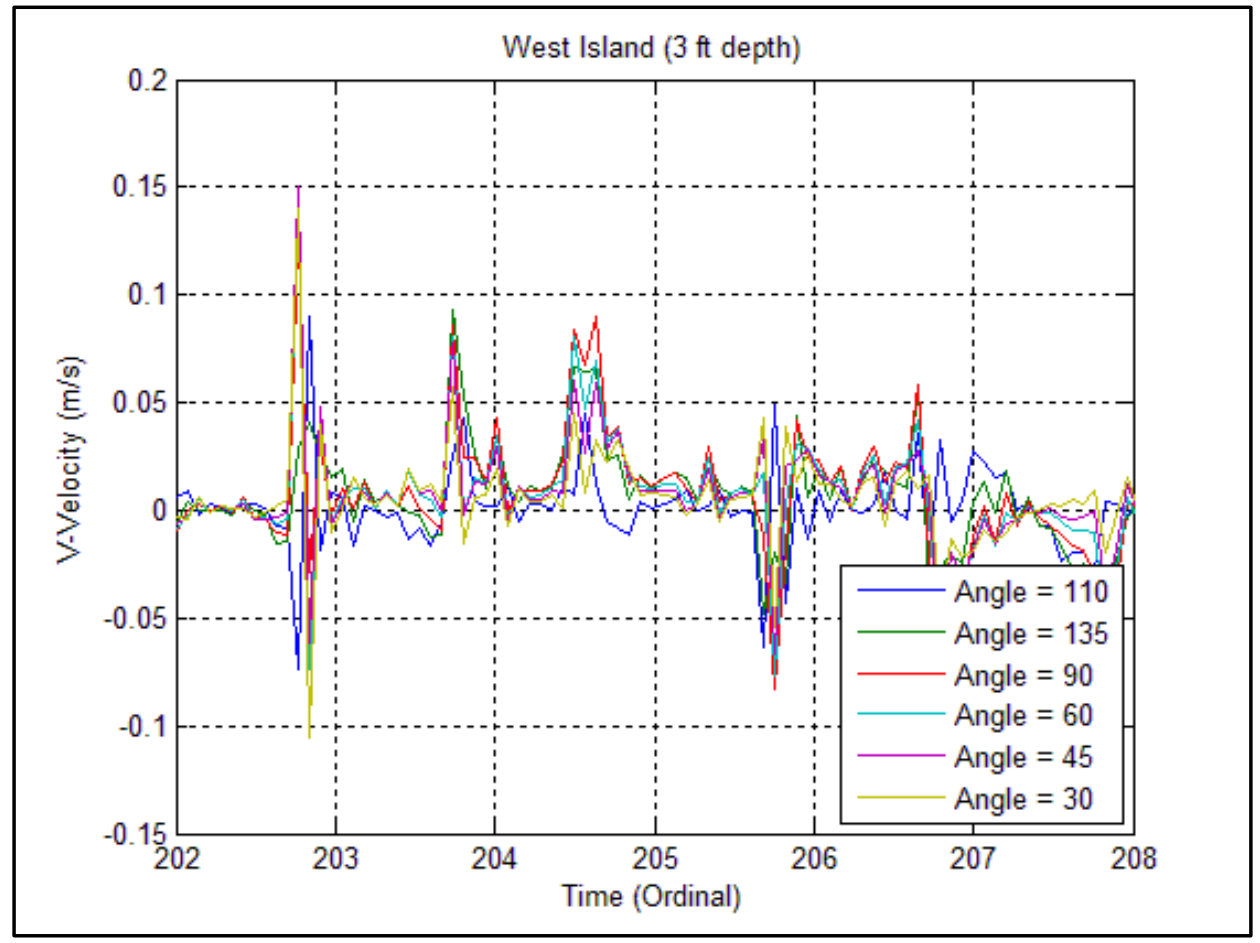

Figure 9.32 Effect of wind direction on $v$-velocity component: west shore.

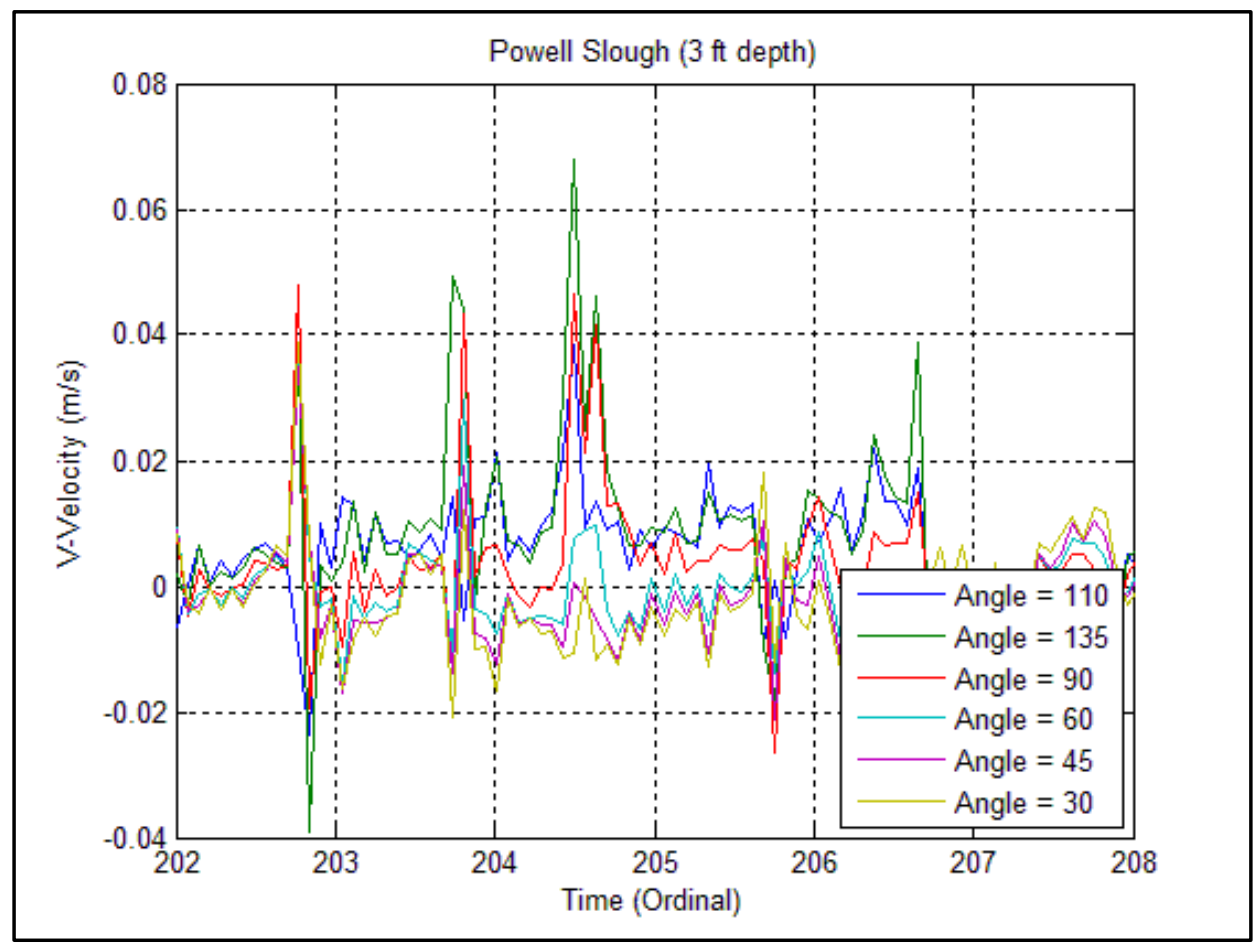

Figure 9.33 Effect of wind direction on $v$-velocity component: east shore. 


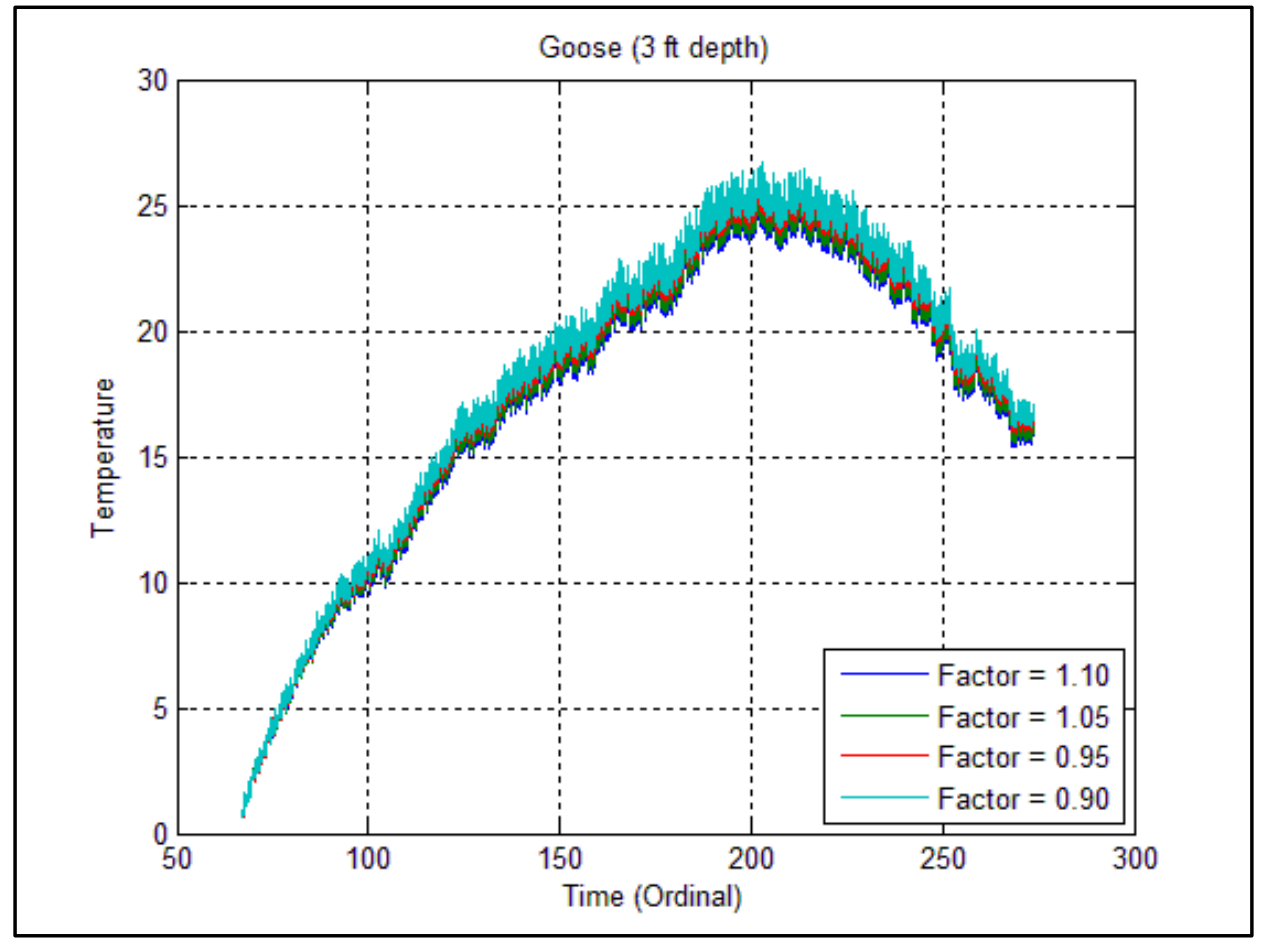

Figure 9.34 Effect of wind speed on water temperature.

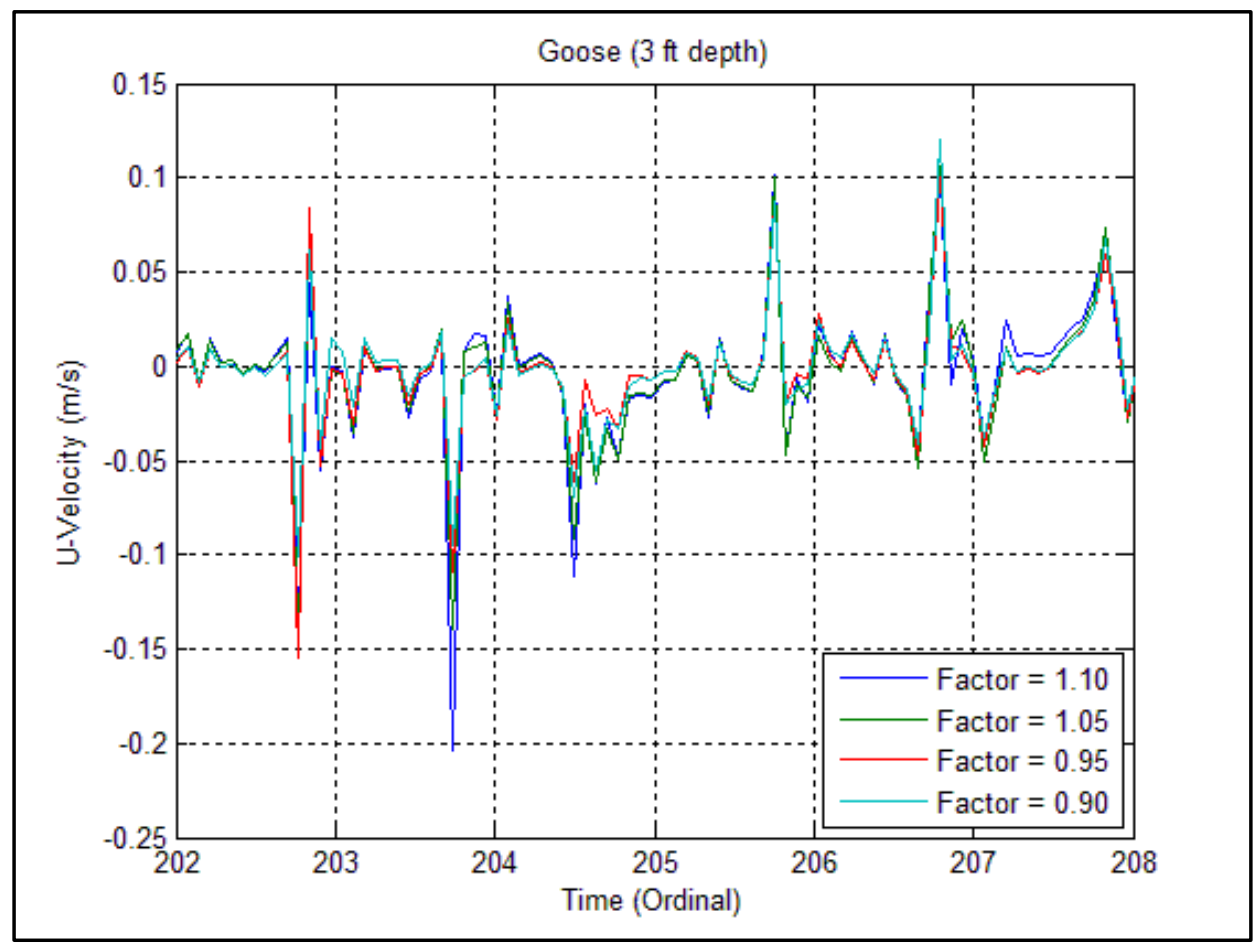

Figure 9.35 Effect of wind speed on $u$-velocity component. 


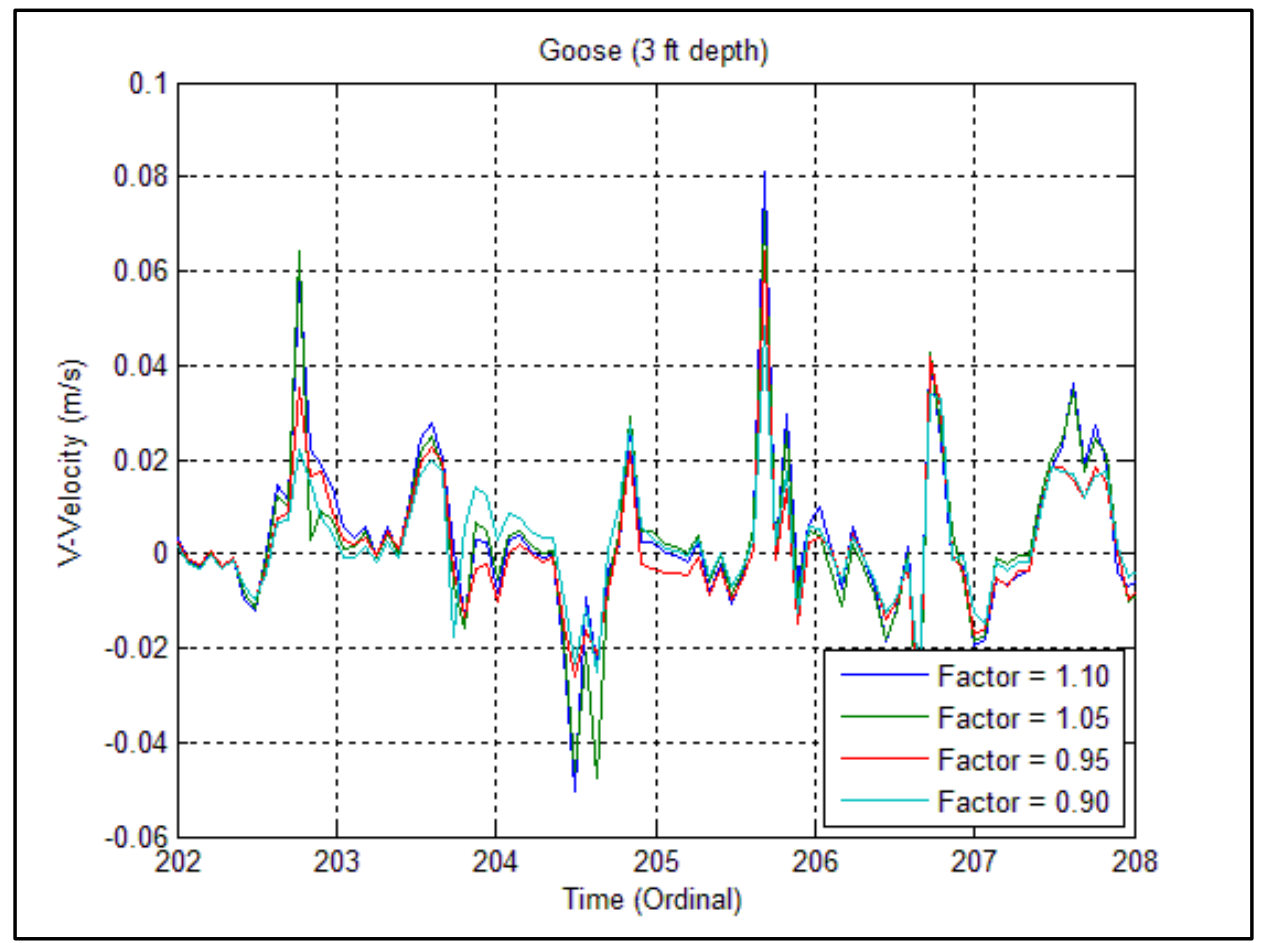

Figure 9.36 Effect of wind speed on $v$-velocity component.

and the results were plotted at the temperature sensor locations. From the plots, it was determined that those factors that most strongly influence the water temperatures are the air temperature, incident short wave radiation, wind speed, and wind direction, with relative humidity and cloud cover having a lesser degree of influence. The factors that have the greatest effect on the flow field are the wind direction and wind speed. 
CHAPTER 10

\section{LARVAE FLOW SIMULATIONS}

\subsection{June Sucker Spawning}

In addition to performing the parametric study to determine the major forcing parameters for Utah Lake, another key objective of the modeling effort was to ascertain the general free drifting path for June sucker larvae that enter the lake through the Provo River and Spanish Fork River.

Depending on yearly water conditions, adult June suckers enter the lower Provo River to spawn in April, May, and June. The spawning area is typically limited to the lower three miles of the river by an irrigation diversion, but during especially wet years adult suckers can pass beyond the irrigation diversion and spawn in an additional 3.0 kilometers ( 1.9 miles) of the river. The water in which the fish spawn is between 0.3 and 0.9 meters ( 1.0 to 3.0 feet) deep and flows at rates between 0.06 and 0.975 meters $(0.2$ and 3.2 feet) per second. The adult suckers return to Utah Lake soon after spawning [2]. The June sucker eggs hatch between four and ten days afterward, depending on the water temperature, the current in the river carries the larvae downstream to Utah Lake.

\subsection{Larvae Flow Inclusion in CWR-ELCOM}

In conjunction with its capacity to predict flow fields and temperatures, CWRELCOM also has the ability to "release" a free drifting particle at a specified location in a flow field and then track its theoretical path. This function was used to simulate the entry of June sucker larvae into the Utah Lake basin through the Provo and Spanish Fork 
Rivers and to track the resulting drifting paths. Table 10.1 shows the simulation matrix for the larvae drift simulations.

To specify that CWR-ELCOM use one or more drifting particles in a simulation, the user is required to prepare three additional input files with information on the particle(s). The first file, drifters_update.dat, designates the release locations of each "drifter" and the time step(s) at which the particles are to be released. The second file, drifters_in.dat, echoes the release locations and allows the user to control other options, such as whether or not the particles can get "stuck" when they run up against the lakebed and the type of solution scheme the program uses to track the particle. The third file, drifters_prop.dat, allows the user to specify additional properties of the drifter such as drag coefficient, density, etc.

In order to correctly generate the free drifting paths of the particles, simulations were initialized using all of the boundary conditions, initial conditions, and forcing data

Table 10.1 Larvae Drift Simulation Matrix

\begin{tabular}{|c|c|c|}
\cline { 2 - 3 } \multicolumn{1}{c|}{} & \multicolumn{2}{|c|}{ Grid Size (m) } \\
\cline { 2 - 3 } & 500 & 1000 \\
\cline { 2 - 3 } Release & 22-Apr & 22-Apr \\
\cline { 2 - 3 } Date & $29-\mathrm{Apr}$ & 29-Apr \\
\cline { 2 - 3 } & 6-May & 6-May \\
\cline { 2 - 3 } & 13-May & 13-May \\
\cline { 2 - 3 } & 20-May & 20-May \\
\cline { 2 - 3 } & 27-May & 27-May \\
\cline { 2 - 3 } & 3-Jun & 3-Jun \\
\cline { 2 - 3 } & 10-Jun & 10-Jun \\
\cline { 2 - 3 } & 17-Jun & 17-Jun \\
\cline { 2 - 3 } & 24-Jun & 24-Jun \\
\hline
\end{tabular}


used in other simulations. The simulations progressed normally until the time step when the drifters were to be released. At that time, the simulations stopped and saved all of the current flow field information in a designated restart. When the simulations were restarted, the drifters were released as specified in the input files and the programs continued running the simulations from where they had previously stopped while also tracking the paths of the particles.

Once the simulations terminated and the post-processing code had converted the results into a netCDF file, the $x$ - and $y$-coordinates of the particles were plotted over an outline of Utah Lake using Matlab ${ }^{\circledR}$ to graphically show the free drifting paths. The recorded $z$-coordinates (depths) for each particle were also plotted as a function of time. The range of the plots was the three weeks of data following the release date of each particle.

\subsection{Results and Analysis}

As seen in Table 10.1, 22 simulations with larvae particles were performed on 500- and 1000-m grids. Representative plots of the free drifting path for a larvae entering through the Provo River using the data from the 500-m grid simulations are found in Figures 10.1 and 10.2. The corresponding plots for a larvae entering Utah Lake through the Spanish Fork River are found in Figures 10.3 and 10.4. The remainder of the plots for larvae entering through the Provo and Spanish Fork Rivers can be found in Appendices A and $\mathrm{B}$, respectively.

Larvae entering through the Provo River generally flowed in a northwest direction into the lake, nearly parallel to the closest shoreline. However, after leaving the 


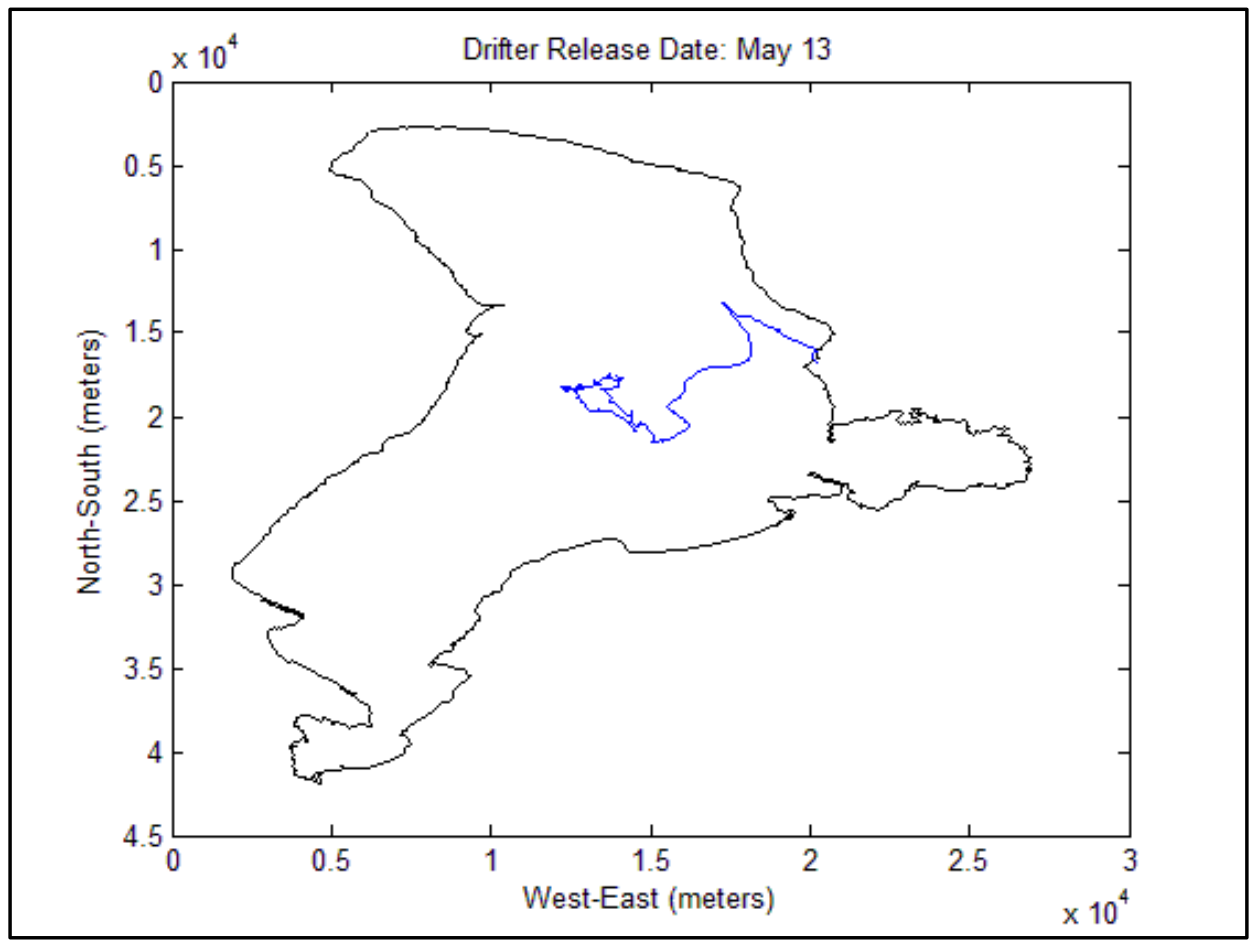

Figure 10.1 Free drifting path of a June sucker larvae entering Utah Lake through the Provo River on May 13.

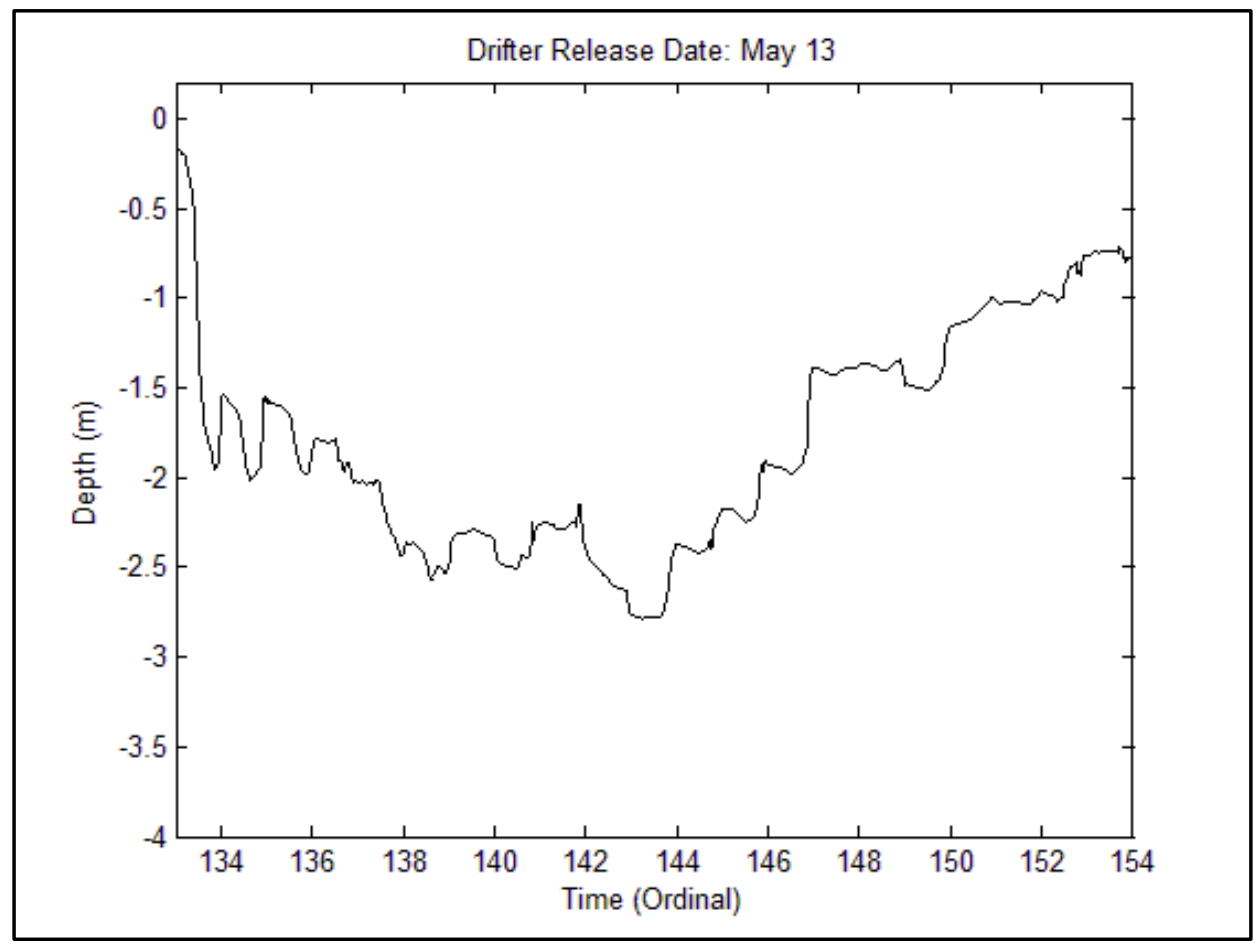

Figure 10.2 Plot of depth vs. time for a June sucker larvae entering Utah Lake through the Provo River on May 13. 


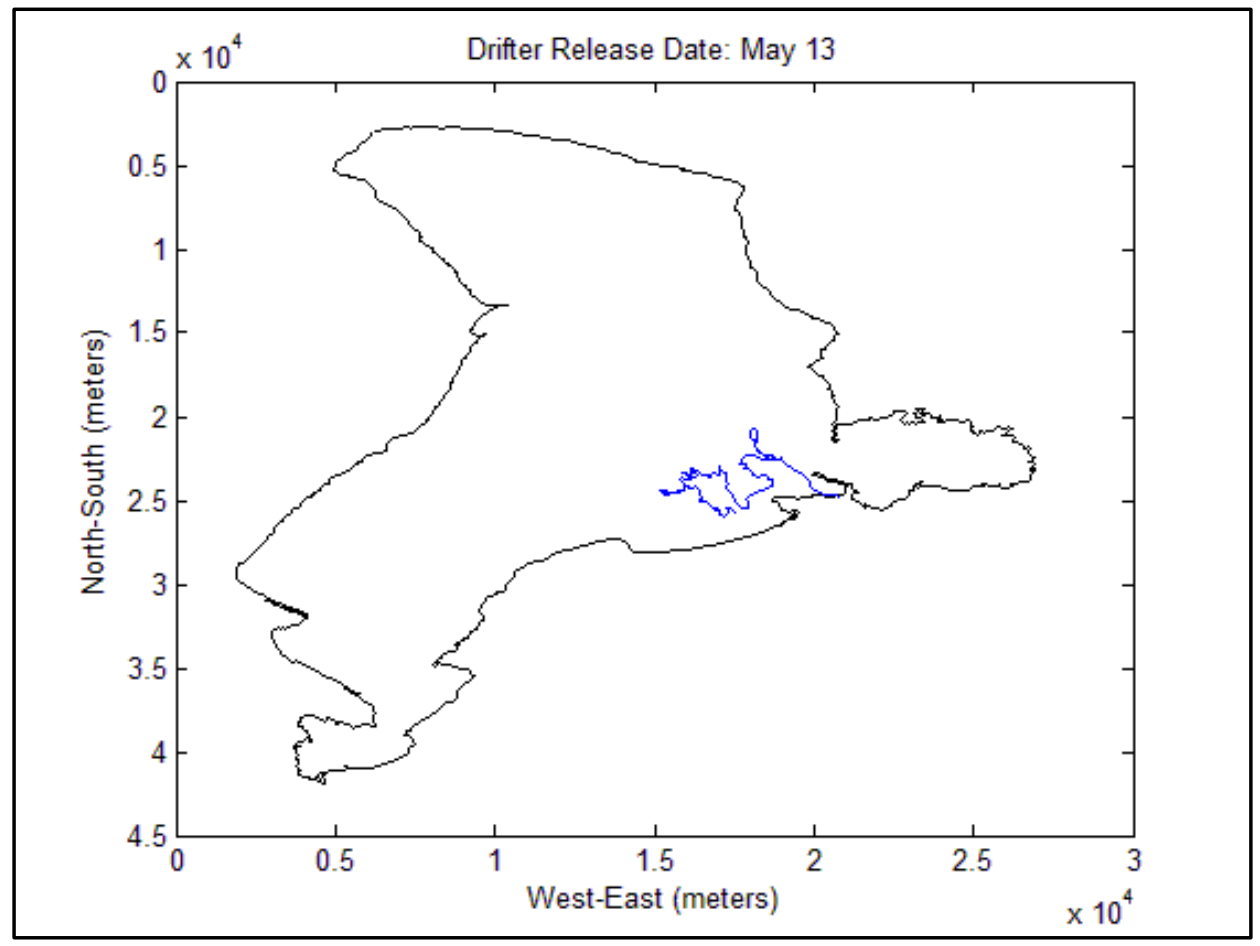

Figure 10.3 Free drifting path of a June sucker larvae entering Utah Lake through the Spanish Fork River on May 13.

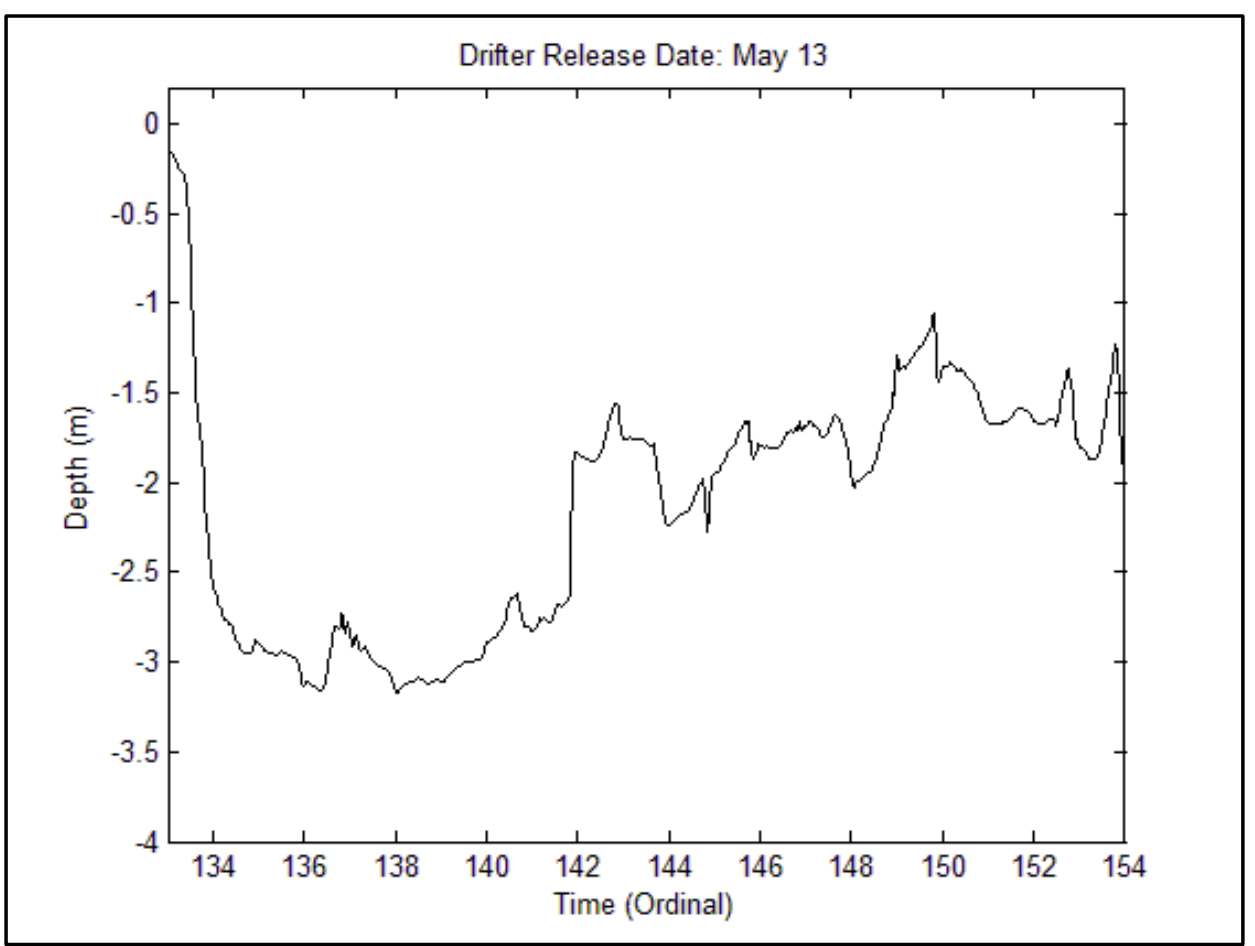

Figure 10.4 Plot of depth vs. time for a June sucker larvae entering Utah Lake through the Spanish Fork River on May 13. 
shoreline and entering the deeper water in the main body of the lake, different paths were taken depending on the release date of the drifter. Larvae released between mid-April and mid-May generally turned southward and terminated in the deep water northwest of Bird Island. Larvae released between mid-May and mid-June continued in a northwesterly direction upon leaving the shoreline and ended up in the deeper waters in the northern half of the lake. Between mid-June and early July, the larvae either flowed directly west or slowly circled near the edge of the deep water in the main body of the lake.

Larvae entering Utah Lake through the Spanish Fork River between mid-April and mid-May generally stayed close to the river inlet. Initial currents carried the larvae due north away from shore, but then circulating eddies drew the larvae back towards shore. After mid-May, however, if strong northern currents happened to be present at the time of the larvae release, some of the larvae could escape the pull of the eddies and flow north along the east shore of Utah Lake to where the Provo River inlet was located. Currents in that region then forced the larvae out into the main body of the lake, where their paths terminated. 


\section{CHAPTER 11}

\section{CONCLUSIONS}

The main objectives for the Utah Lake modeling effort were to characterize how the flow field and temperature distributions vary temporally and spatially, perform a parametric study to determine what parameters had the greatest overall influence on the lake, and predict the free drifting path of June sucker larvae that flow into Utah Lake through the Provo and Spanish Fork Rivers. CWR-ELCOM, an established CFD program with a history of success in modeling lakes, was used to accomplish these objectives. Numerous Matlab ${ }^{\circledR}$ scripts were written to aid in the management of forcing data, creation of the necessary input files, and processing of the simulation results.

The Utah Lake model relied heavily on meteorological data for its accuracy. Because the data consisted mostly of time-averaged values of natural processes, a fairly substantial amount of error was, of necessity, introduced into the model. However, comparisons between the simulation results and actual water temperature data taken using temperature sensors during the summer of 2007 showed good agreement and served to validate the model.

The water temperature at a given location in the lake was found to be a strong function of the air temperature, incident short wave radiation, wind speed, and wind direction. It was also influenced to a lesser degree by relative humidity and cloud cover. The direction and speed of the water currents were most influenced by wind direction and wind speed. 
June Sucker larvae entering Utah Lake through the Provo River traveled in a northwest direction parallel to the shore before diverting into the deeper water in the center of the lake. In mid-April to mid-May, the larvae flowed into the southern half of the lake. Between mid-May and mid-June, however, the larvae flowed into the northern half of the lake. After mid-June, the larvae circulated in the deeper water southeast of the Provo River inlet. Larvae entering the lake through the Spanish Fork River in mid-April to mid-May were generally captured by large eddies and remained close to the shoreline west of the river inlet. When strong northern currents were present after about mid-May, however, some larvae escaped the eddies and traveled north along the east shore of the lake until currents in the vicinity of the Provo River inlet carried them west into the main body of the lake.

In the future, the Utah Lake model could be improved in a few key ways. First, sufficient measurements of temperature and water velocities to initialize the model would help reduce any transient effects that may have influenced the free drifting paths of the June sucker larvae. Second, a greater characterization of the springs and seeps along the lakebed floor and their inclusion in the model would eliminate some approximations that were made and would, consequently, enhance the model's accuracy. Third, increasing the data library for the wind in the region to more than one year would help substantiate the currents found using the Utah Lake model. Finally, accurate data on the temperatures of the water flowing into Utah Lake through would help resolve the flow fields and temperature distributions in the critical areas around the Provo and Spanish Fork River inlets. 


\section{REFERENCES}

[1] Horns, D., "Utah Lake Comprehensive Management Plan Resource Document," Department of Earth Science, Utah Valley State College, Orem, Utah, 2005.

[2] June Sucker Recovery Implementation Program (JSRIP), Salt Lake City, Utah, 2007. [http://www.junesuckerrecovery.org. Accessed 11/19/07.]

[3] Heckmann, R.A., Thompson, C.W., and White, D.A., "Fishes of Utah Lake," Great Basin Naturalist Memoirs Number 5, Utah Lake Monograph, Brigham Young University, Provo, Utah, 1981, pp. 107-127.

[4] Cook, A.G., "A review of the comparative morphology and systematics of Utah Lake suckers (Catostomidae)", Journal of Zoology, Vol. 254, Issue 3, 2001, pp. 293-308.

[5] Popov, B.J., "The introduced species, game birds and furbearing mammals of Utah,” Unpublished thesis, Utah State University, Logan, Utah, 1949.

[6] Central Utah Water Conservancy District, "Utah Lake Drainage Basin Water Delivery System Environmental Impact Statement: Draft Aquatic Resources Technical Report," U.S. Department of the Interior, Orem, Utah, 2004, p. 165.

[7] Baum, S., "Ocean/Atmosphere Circulation Modeling Projects," Department of Oceanography, Texas A\&M University, College Station, Texas, May 2004. [http://stommel.tamu.edu/ baum/ocean_models.html. Accessed 2/29/08.]

[8] Centre for Water Research (CWR), Crawley, Western Australia, 2006. [http://www.cwr.uwa.edu.au. Accessed 2/27/08.]

[9] Hodges, B.R., “ELCOM,” Department of Civil, Architectural, and Environmental Engineering, University of Texas at Austin, Austin, Texas, July 2005. [http://www.ce.utexas.edu/prof/hodges/site2006/elcom.htm. Accessed 3/17/08.]

[10] Hodges, B.R., Imberger, J., Saggio, A., and Winters, K.B., "Modeling Basinscale Internal Waves in a Stratified Lake," Limnology and Oceanography, Vol. 45, 2000, pp. 1603-1620.

[11] Lemckert, C.J., and Imberger, J., "Turbulent Benthic Boundary Layer Mixing Events in Fresh Water Lakes," Physical Processes in Lakes and Oceans, Vol. 54, 1998, pp. 503-516. 
[12] Appt, J., Imberger, J., and Kobus, H., "Basin-scale Motion in Stratified Upper Lake Constance,” Limnology and Oceanography, Vol. 49, 2004, pp. 919-933.

[13] León, L.F., Lam, D.C.L., Schertzer, W.M., Swayne, D.A., and Imberger, J., "Towards Coupling a 3D Hydrodynamic Lake Model with the Canadian Regional Climate Model: Simulation on Great Slave Lake," Environmental Modelling \& Software, Vol. 22, 2007, pp. 787-796.

[14] Schertzer, W.M., Rouse, W.R., Blanken, P.D., and Walker, A.E., “Over-Lake Meteorology and Estimated Bulk Heat Exchange of Great Slave Lake in 1998 and 1999," Journal of Hydrometeorology, Vol. 4, 2003, pp. 649-659.

[15] Hodges, B.R., and Dallimore, C., "Estuary, Lake and Coastal Ocean Model: ELCOM v2.2 Science Manual," Centre for Water Research, University of Western Australia, Nedlands, Western Australia, 2006.

[16] Hodges, B.R., "Numerical Techniques in CWR-ELCOM (code release v.1)," Centre for Water Research, University of Western Australia, Nedlands, Western Australia, 2000.

[17] Kowalik, Z., and Murty, T.S., Numerical Modeling of Ocean Dynamics, World Scientific, River Edge, NJ, 1993.

[18] Casulli, V., and Cheng, R.T., "Semi-implicit Finite Difference Methods for Three-dimensional Shallow Water Flow," International Journal for Numerical Methods in Fluids, Vol. 15, 1992, pp. 629-648.

[19] Casulli, V., and Cattani, E., "Stability, Accuracy and Efficiency of a Semiimplicit Method for Three-dimensional Shallow Water Flow," Computers and Mathematics with Applications, Vol. 27, 1994, pp. 99-112.

[20] Casulli, V., "Numerical Simulation of Three-dimensional Free Surface Flow in Isopycnal Co-ordinates," International Journal for Numerical Methods in Fluids, Vol. 25, 1997, pp. 645-658.

[21] Gross, E.S., Casulli, V., Bonaventura, L., and Koseff, J.R., "A Semi-implicit Method for Vertical Transport in Multidimensional Models," International Journal for Numerical Methods in Fluids, Vol. 28, 1998, pp. 157-186.

[22] Gross, E.S., Koseff, J.R., and Monismith, S.G., "Evaluation of Advective Schemes for Estuarine Salinity Simulations," Journal of Hydraulic Engineering, Vol. 125, 1999, pp. 32-46. 
[23] Amorocho, J.J., and DeVries, J., "A New Evaluation of the Wind Stress Coefficient over Water Surfaces," Journal of Geophysical Research, Vol. 85, 1980, pp. 433-442.

[24] Imberger, J., and Patterson, J.C., "A Dynamic Reservoir Simulation Model DYRESM 5," Transport Models for Inland and Coastal Waters, Academic Press, San Diego, CA, 1981, pp. 310-361.

[25] Jacquet, J.M., "Simulation of the Thermal Regime of Rivers," Mathematical Modeling of Water Quality: Streams, Lakes and Reservoirs, WileyInterscience, New York, NY, 1983, pp. 150-176.

[26] Hodges, B.R., "Heat Budget and Thermodynamics at a Free Surface," Centre for Water Research, ED 1300 BH, University of Western Australia, Nedlands, Western Australia, 2000.

[27] Spigel, R.H., Imberger, J., and Rayner, K.N., "Modeling the Diurnal Mixed Layer," Limnology and Oceanography, Vol. 31, 1986, pp. 533-556.

[28] Imberger, J., and Patterson, J.C., "Physical Limnology," Advances in Applied Mechanics, Vol. 27, 1990, pp. 303-475.

[29] Martin, P.J., "Simulation of the Mixed Layer at OWS November and Papa with Several Models," Journal of Geophysical Research, Vol. 90, 1985, pp. 903-916.

[30] Staniforth, A.N., and Côté, J., "Semi-Lagrangian Integration Schemes for Atmospheric Models - a Review," Monthly Weather Review, Vol. 119, 1991, pp. 2206-2223.

[31] Hodges, B.R., and Dallimore, C., "Estuary, Lake and Coastal Ocean Model: ELCOM v2.2 User Manual," Centre for Water Research, University of Western Australia, Nedlands, Western Australia, 2007.

[32] NCDC, "Monthly Station Normals of Temperature, Precipitation, and Heating and Cooling Degree Days, 1971-2000," NOAA, Climatography of the United States No. 81, 2002.

[33] Kroo, I., "Standard Atmosphere Computations," Aircraft Aerodynamics and Design Group, Stanford University, Stanford, California, April 1997. [http://aero.stanford.edu/StdAtm.html. Accessed 12/12/07.]

[34] MesoWest, Department of Meteorology, University of Utah, Salt Lake City, Utah, 2007. [http://www.met.utah.edu/mesowest/. Accessed 9/15/07] 
[35] Walcek, C.J., "Factors Influencing Regional-Scale Cloud Cover: Investigations Using Satellite-Derived Cloud Cover and Standard Meteorological Observations," Third Atmospheric Radiation Measurement (ARM) Science Meeting, Norman, Oklahoma, March, 1993, pp. 119-122.

[36] Martin, J.L., and McCutcheon, S.C., "Stratification and Heat Transfer in Lakes and Reservoirs," Hydrodynamics and Transport for Water Quality Modeling, 1st ed., CRC Press, Boca Raton, Florida, 1999, pp. 335-384.

[37] Fuhriman, D.K., Merritt, L.B., Miller, A.W., and Stock, H.S., "Hydrology and Water Quality of Utah Lake," Great Basin Naturalist Memoirs Number 5, Utah Lake Monograph, Brigham Young University, Provo, Utah, 1981, pp. 43-67.

[38] Merritt, L.B., "Utah Lake Nutrient Loading,” Unpublished letter, 2004.

[39] Rew, R.K., “NetCDF FAQ," Unidata Program Center, Colorado, April 2008. [http://www.unidata.ucar.edu/software/netcdf/docs/faq.html\#whatisit. Accessed 4/8/08.]

[40] Spencer, P., "NetCDF Reader," The Mathworks, Inc., Natick, Massachusetts, December 2007.

[http://www.mathworks.com/matlabcentral/files/15177/netcdf.m. Accessed $12 / 27 / 07$. 
APPENDICES 


\section{Appendix A: Provo River Larvae Drifting Paths}
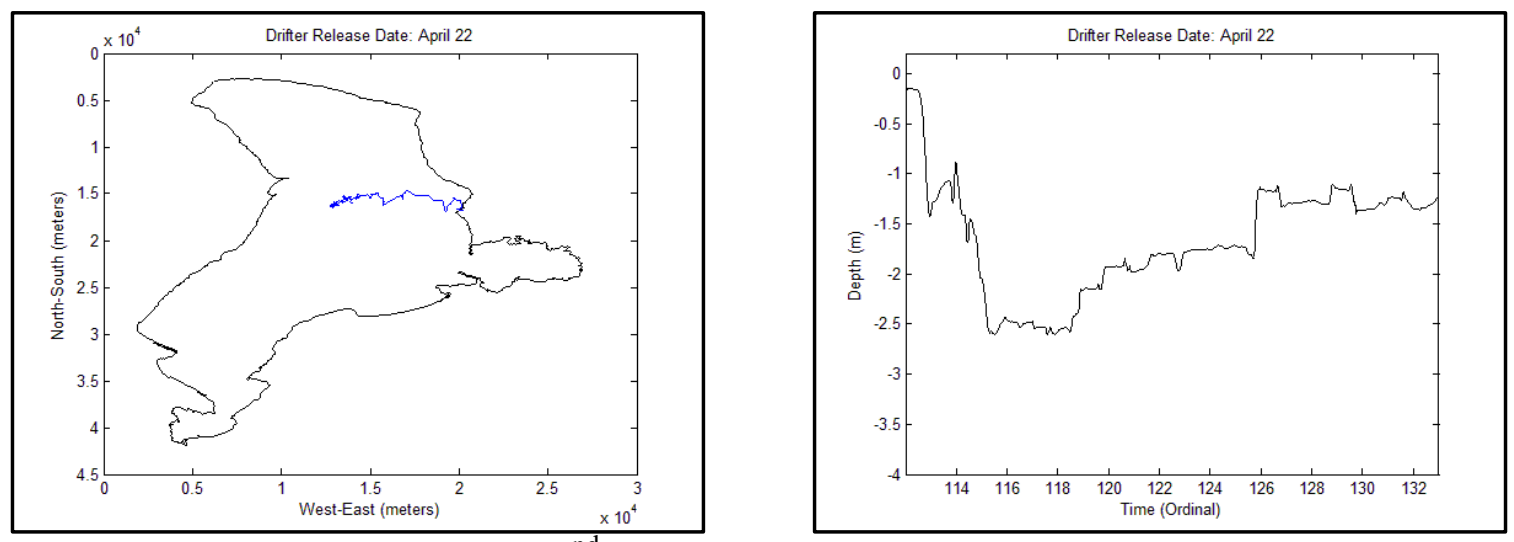

Figure A.1 Release date: April 22 ${ }^{\text {nd }}$.
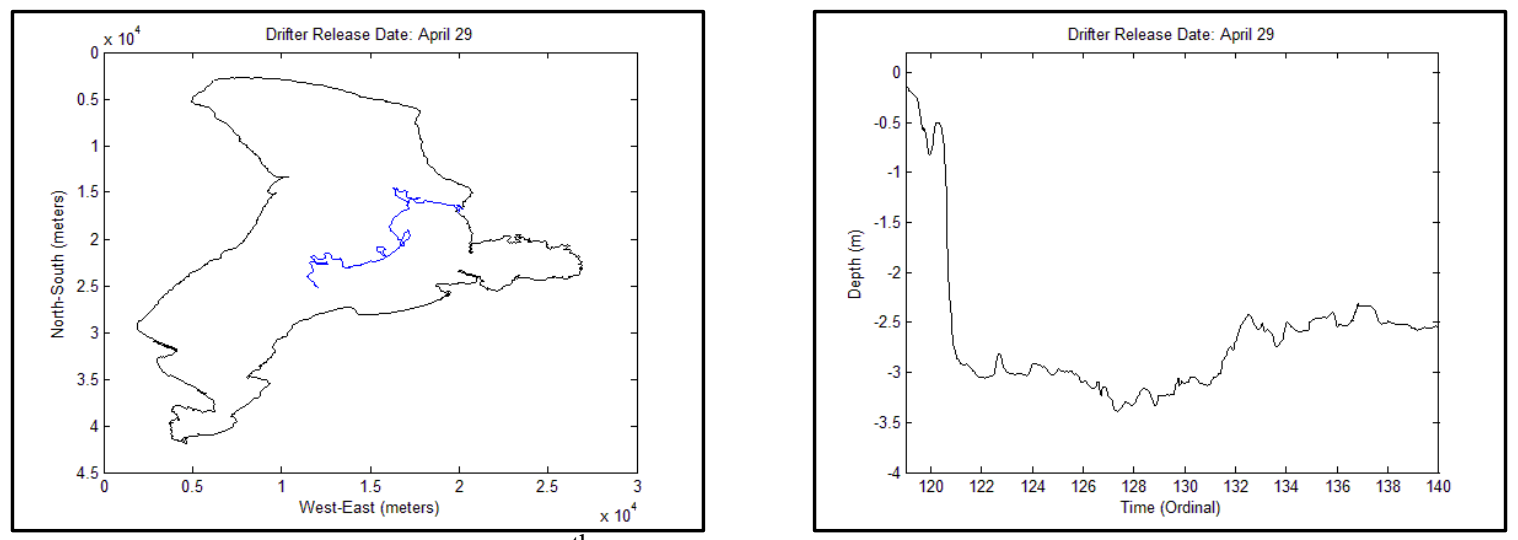

Figure A.2 Release date: April $29^{\text {th }}$.
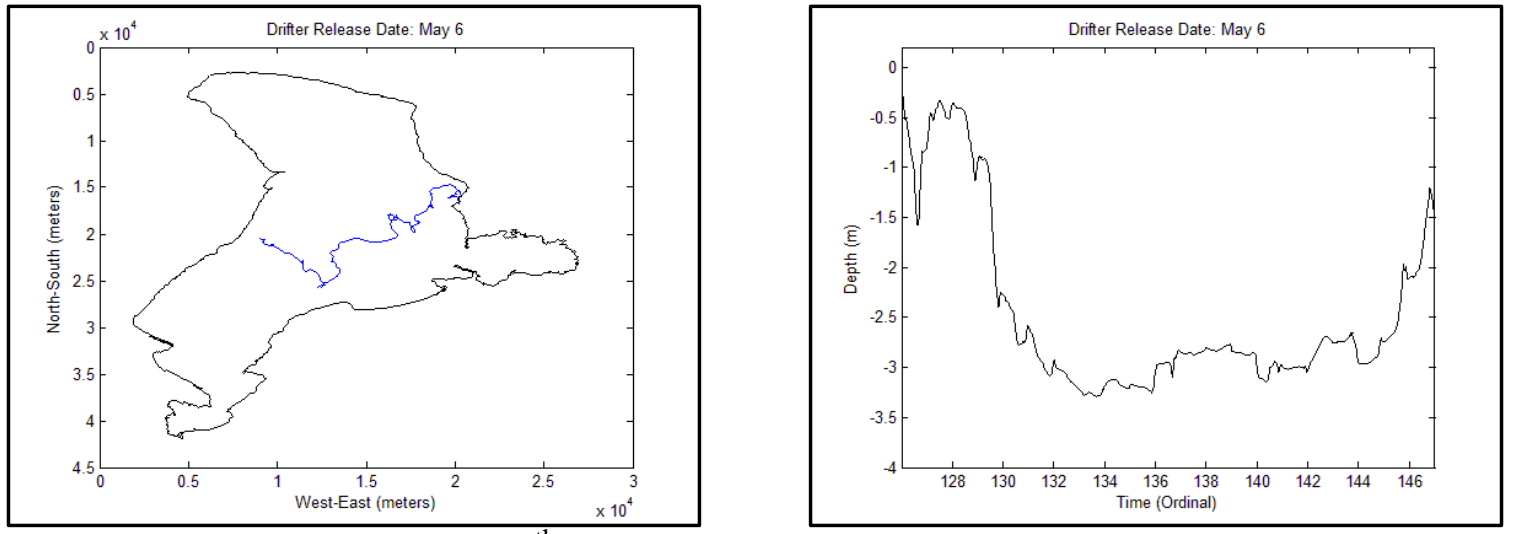

Figure A.3 Release date: May $6^{\text {th }}$. 

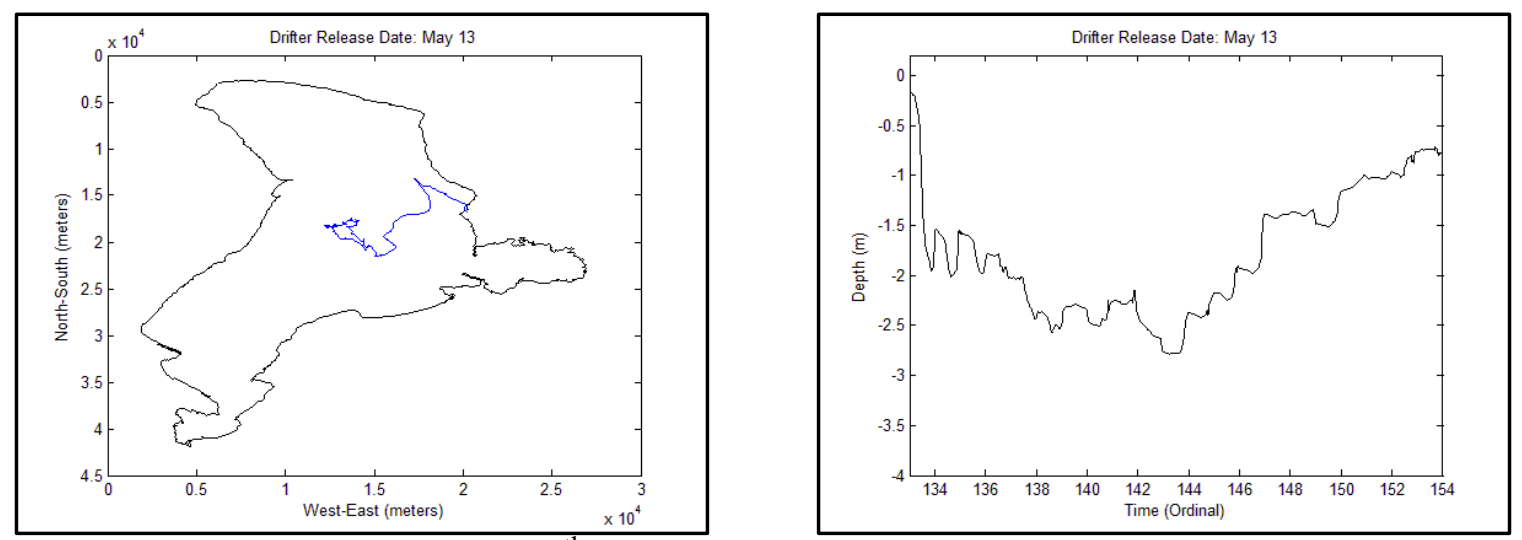

Figure A.4 Release date: May $13^{\text {th }}$.
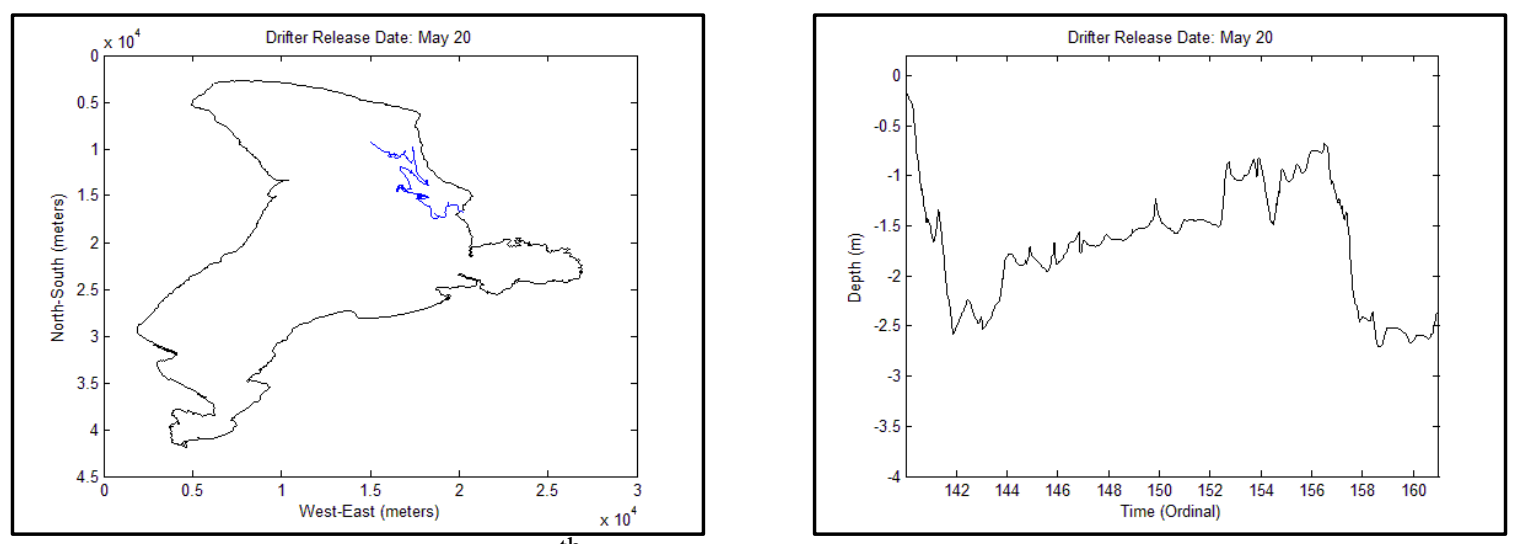

Figure A.5 Release date: May $20^{\text {th }}$.
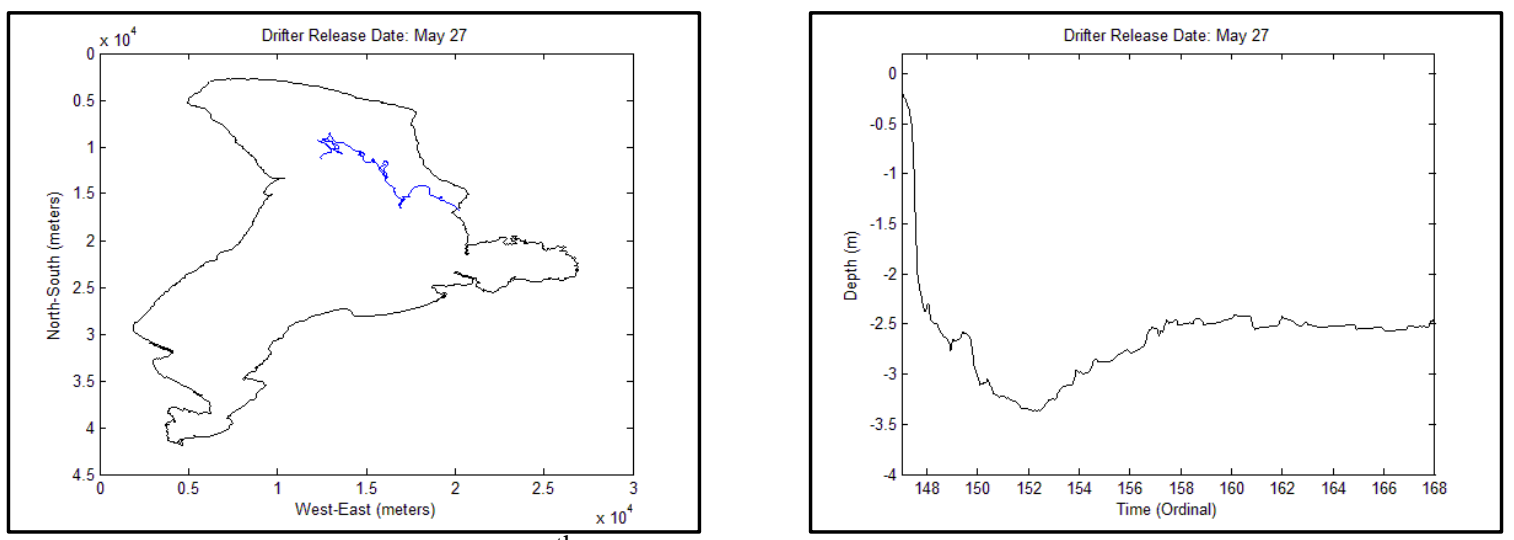

Figure A.6 Release date: May $27^{\text {th }}$. 

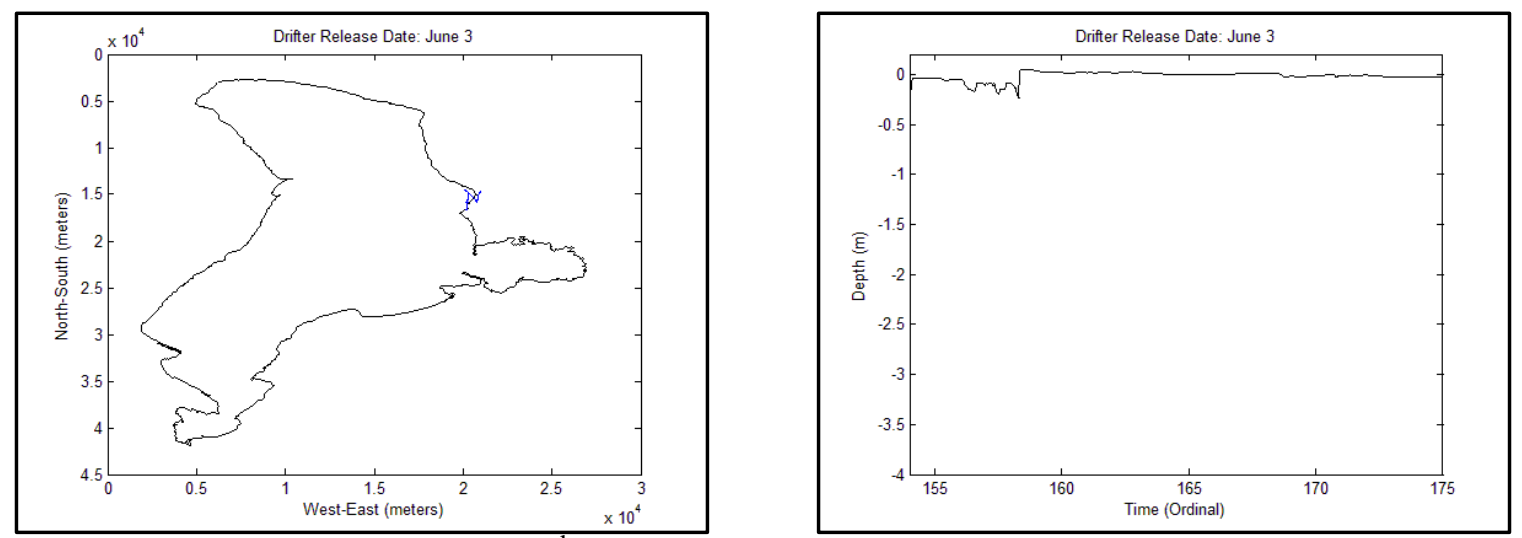

Figure A.7 Release date: June $3^{\text {rd }}$.
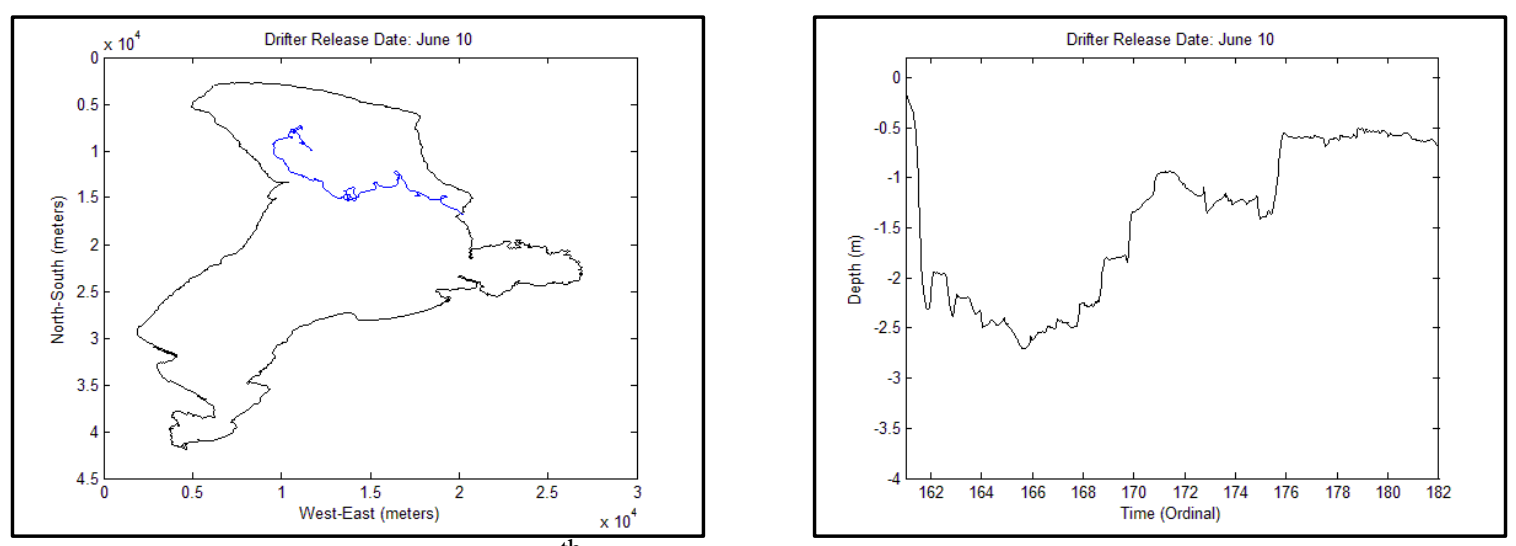

Figure A. 8 Release date: June $10^{\text {th }}$.
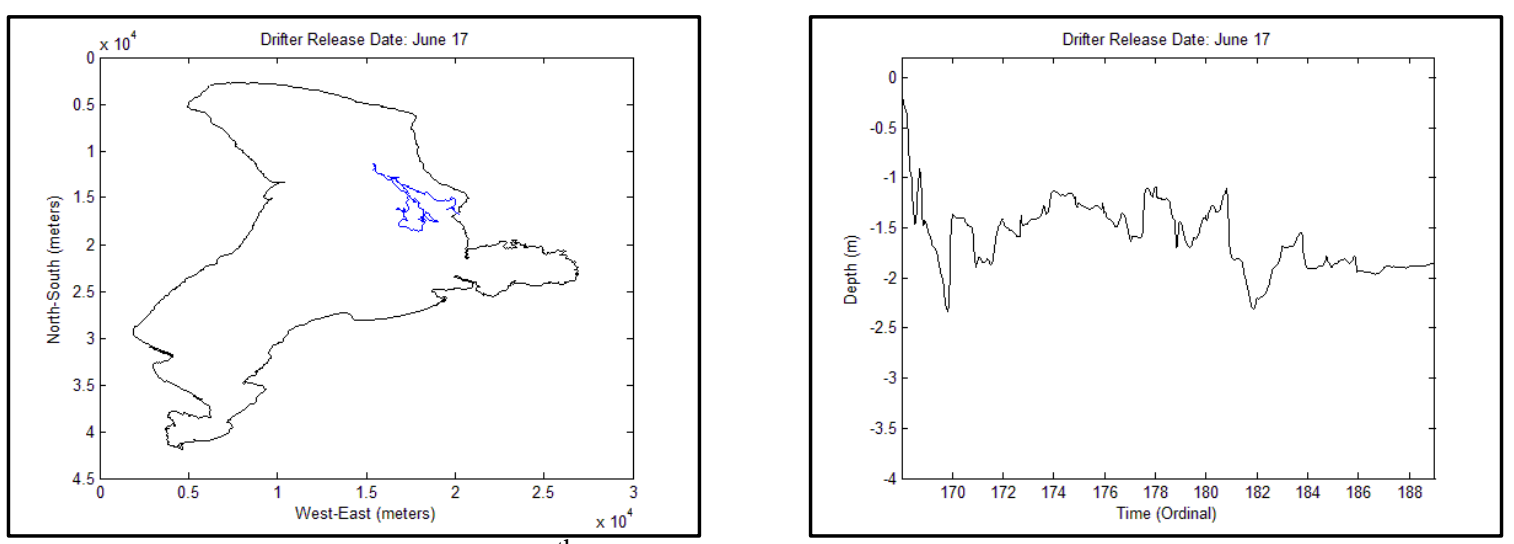

Figure A.9 Release date: June $17^{\text {th }}$. 

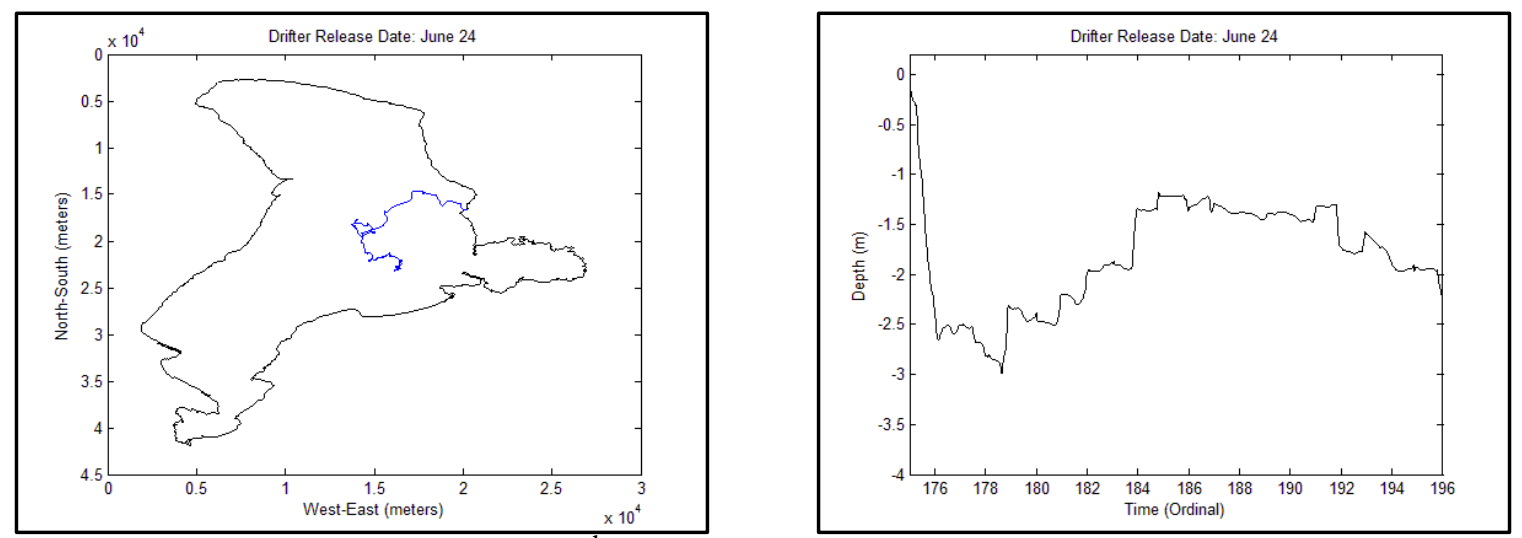

Figure A.10 Release date: June $24^{\text {th }}$.
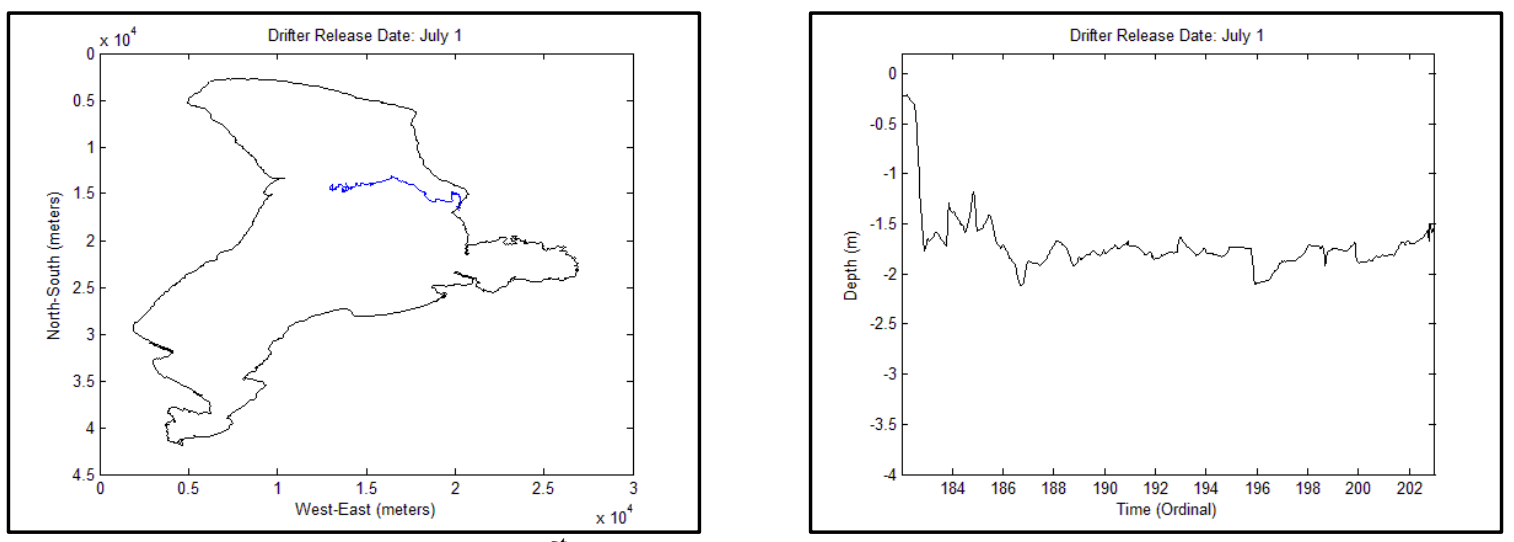

Figure A.11 Release date: July $1^{\text {st }}$. 


\section{Appendix B: Spanish Fork River Larvae Drifting Paths}
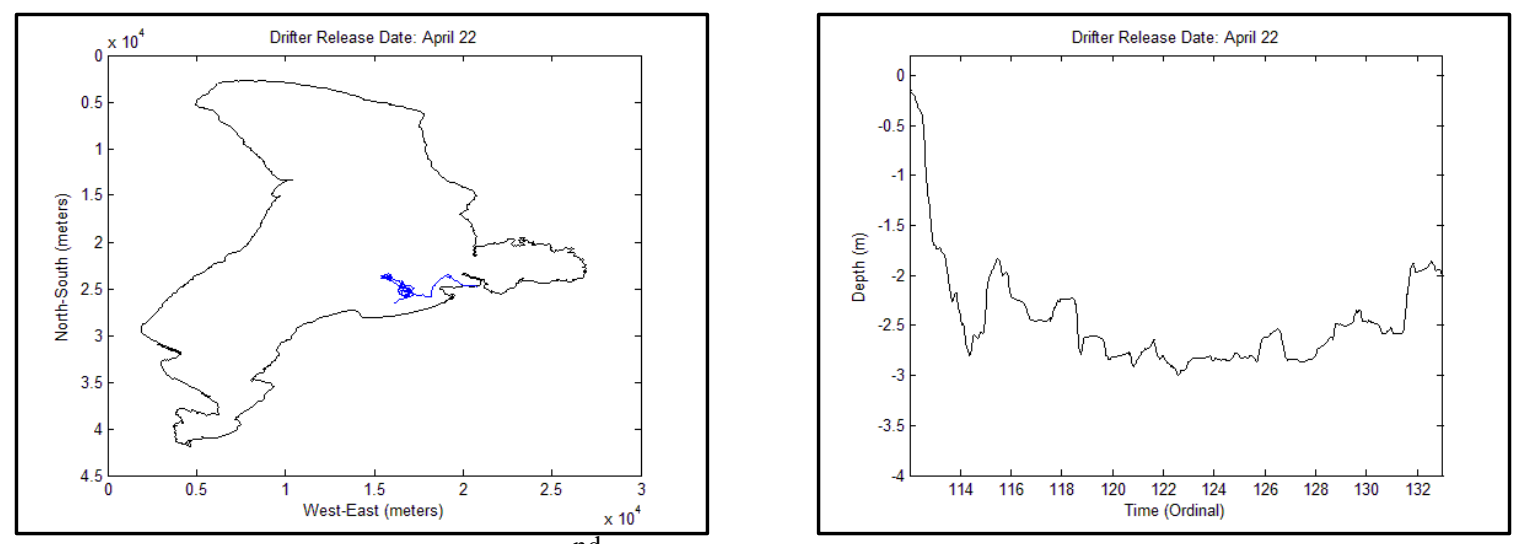

Figure B.1 Release date: April 22 ${ }^{\text {nd }}$.
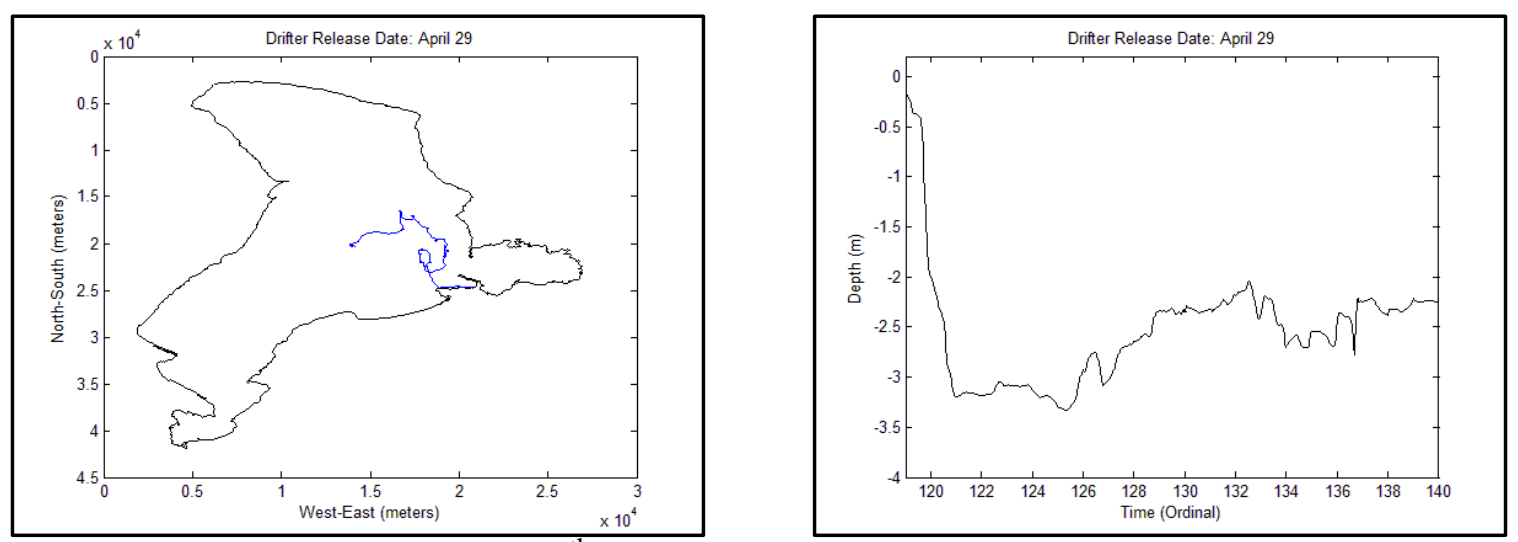

Figure B.2 Release date: April $29^{\text {th }}$.
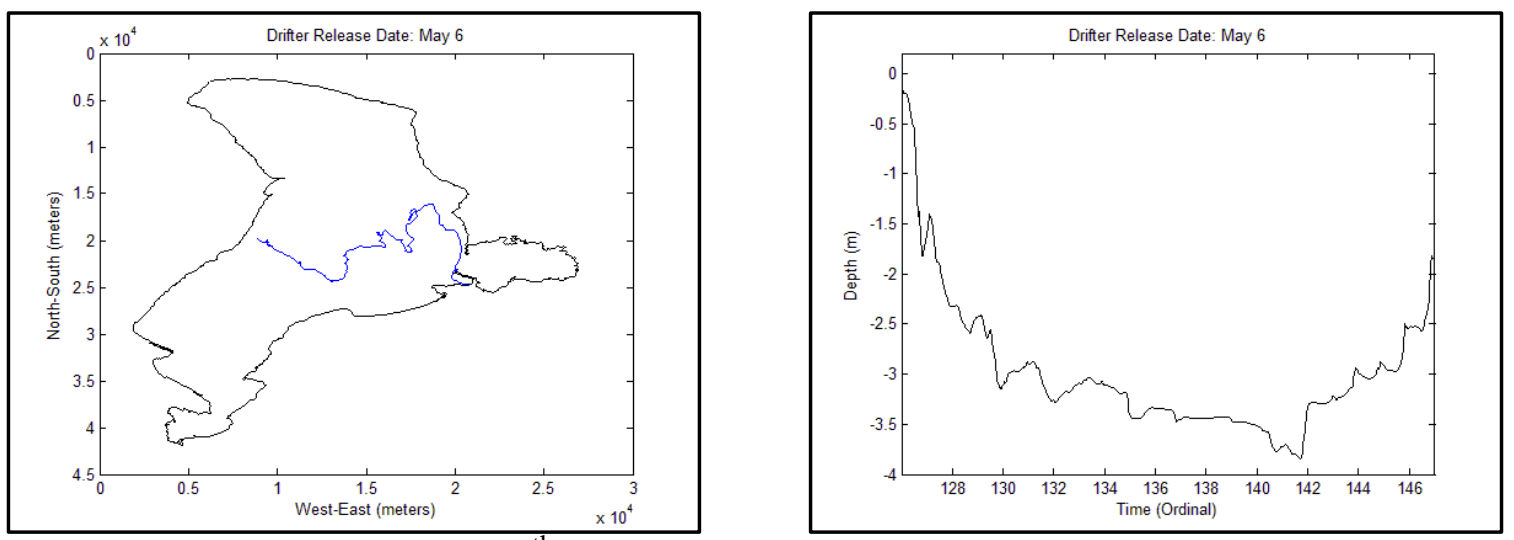

Figure B.3 Release date: May $6^{\text {th }}$. 

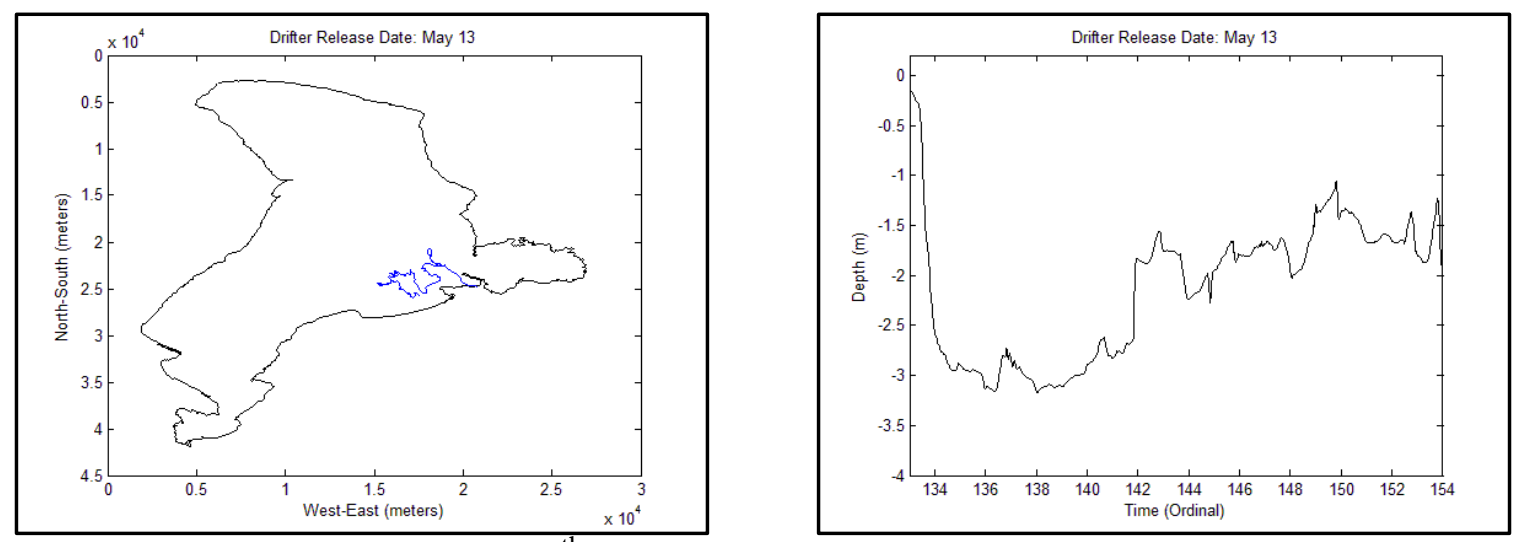

Figure B.4 Release date: May $13^{\text {th }}$.
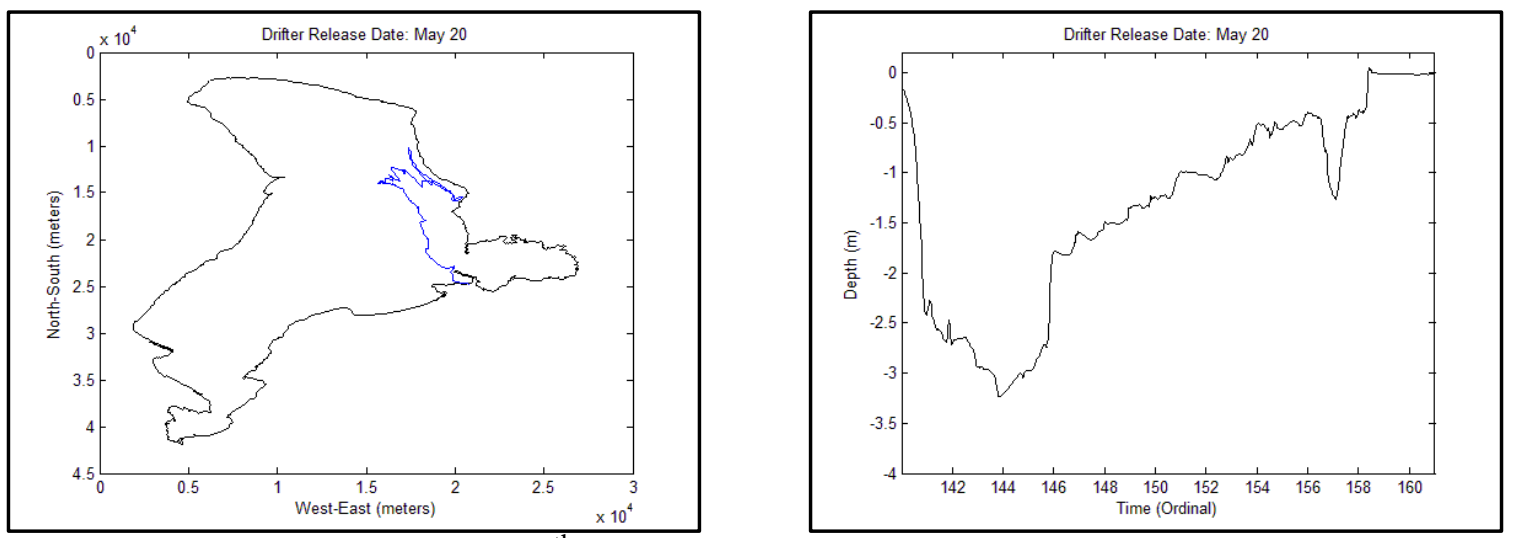

Figure B.5 Release date: May 20 ${ }^{\text {th }}$.
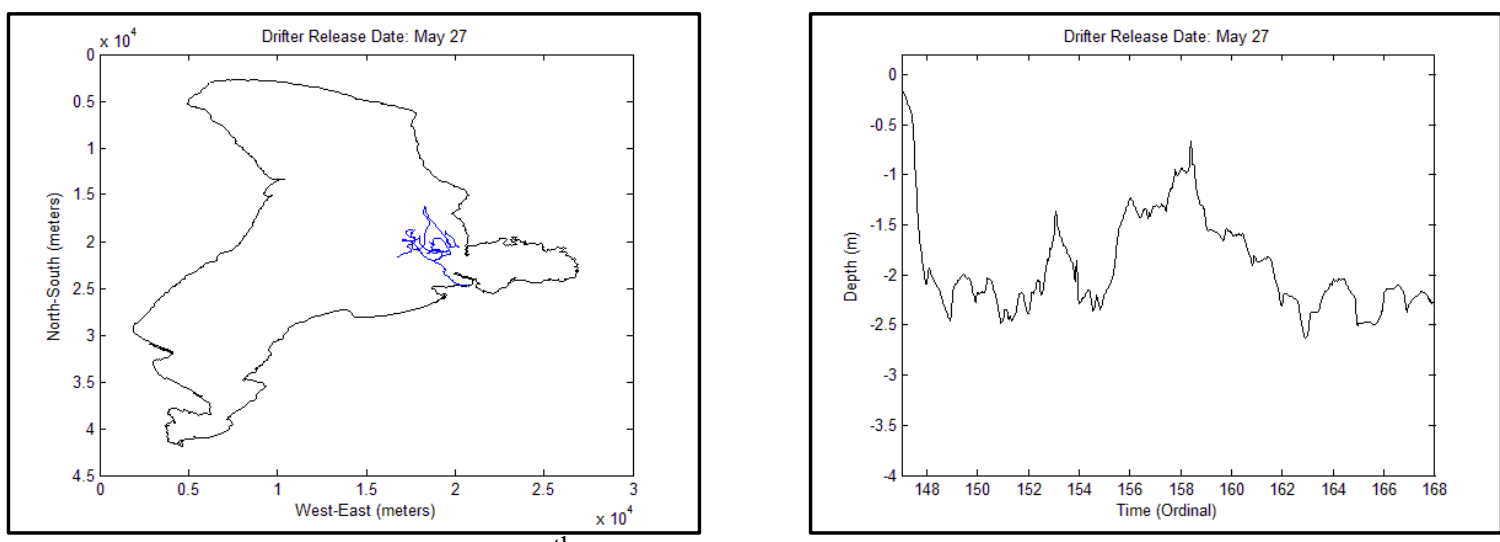

Figure B.6 Release date: May $27^{\text {th }}$. 

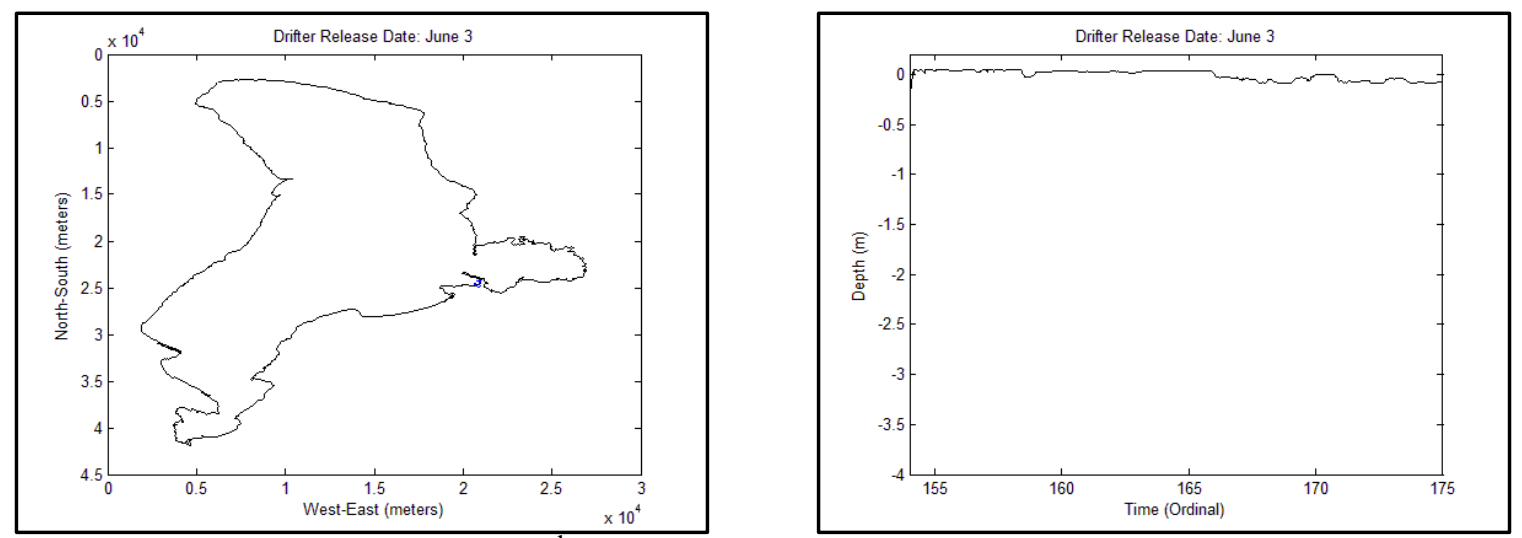

Figure B.7 Release date: June $3^{\text {rd }}$.
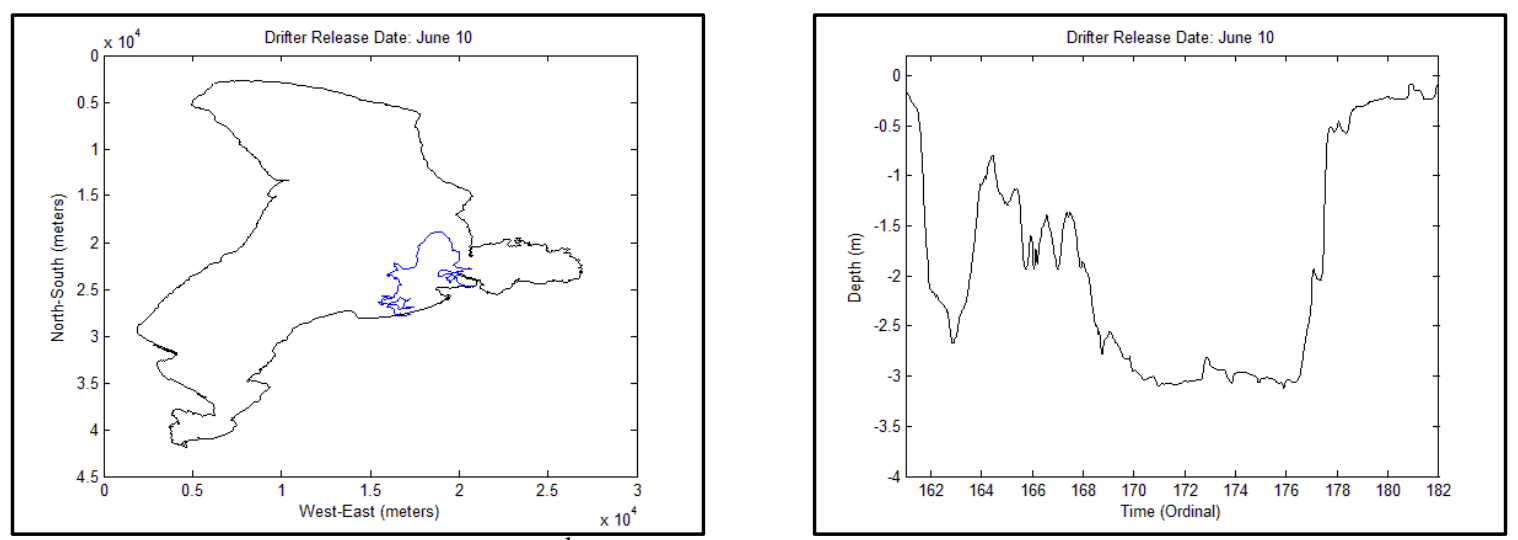

Figure B.8 Release date: June $10^{\text {th }}$.
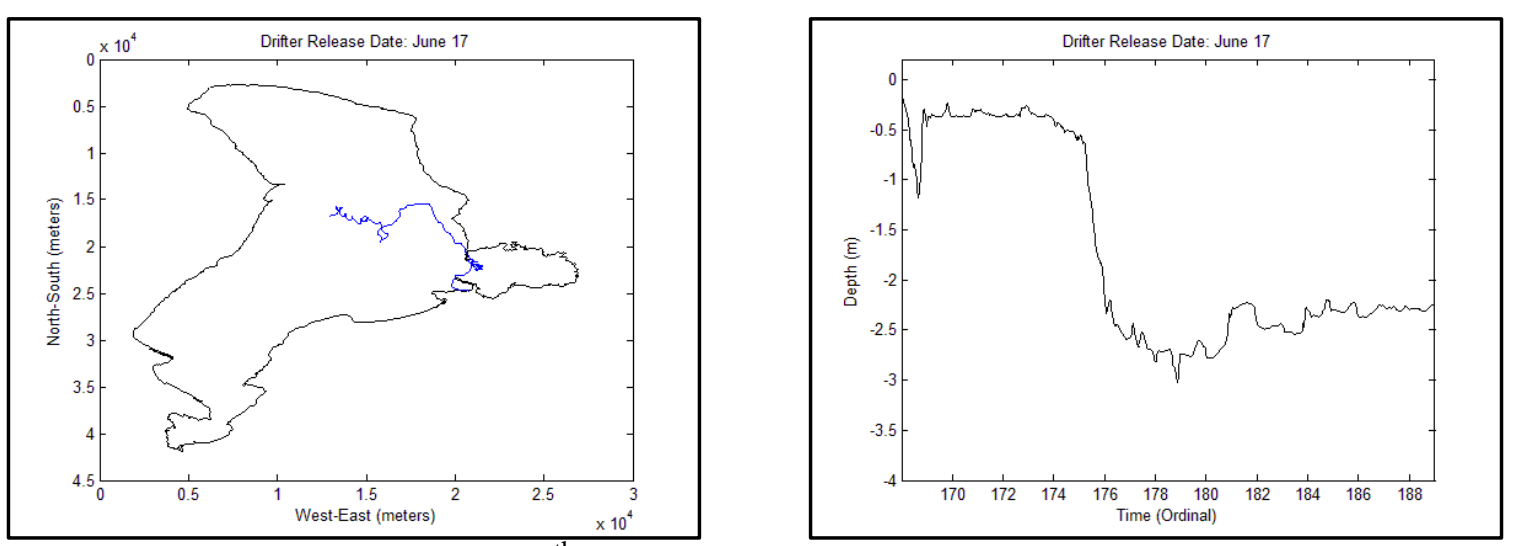

Figure B.9 Release date: June $17^{\text {th }}$. 

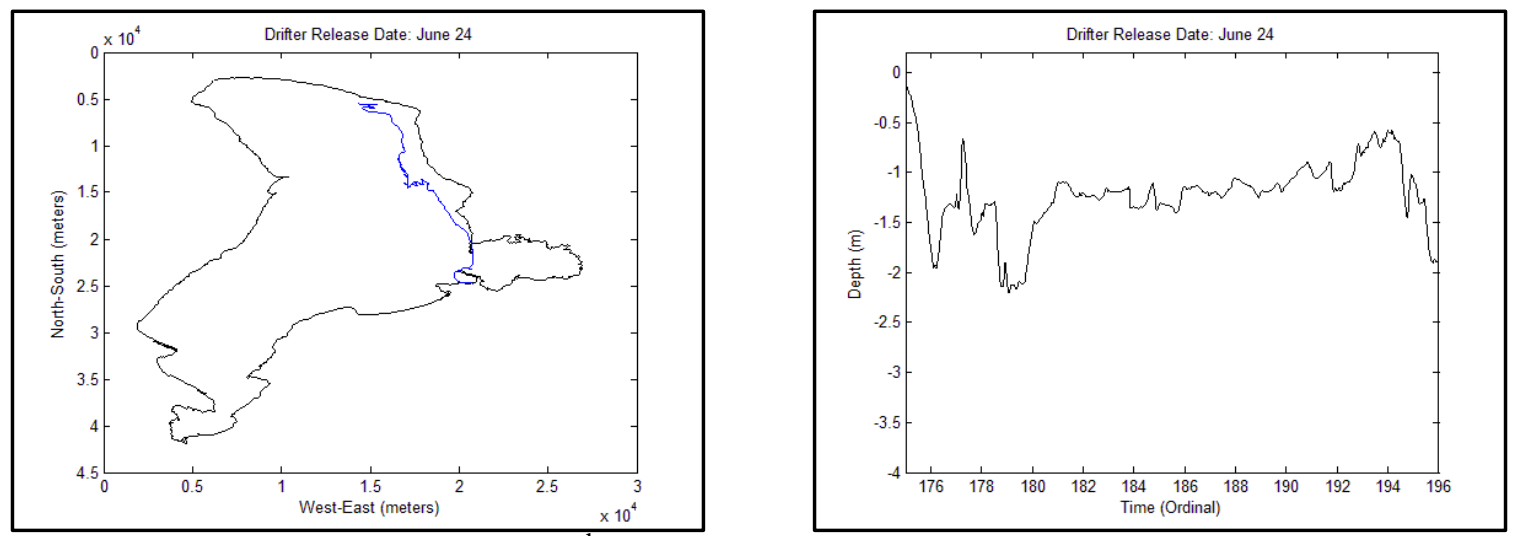

Figure B.10 Release date: June $24^{\text {th }}$.
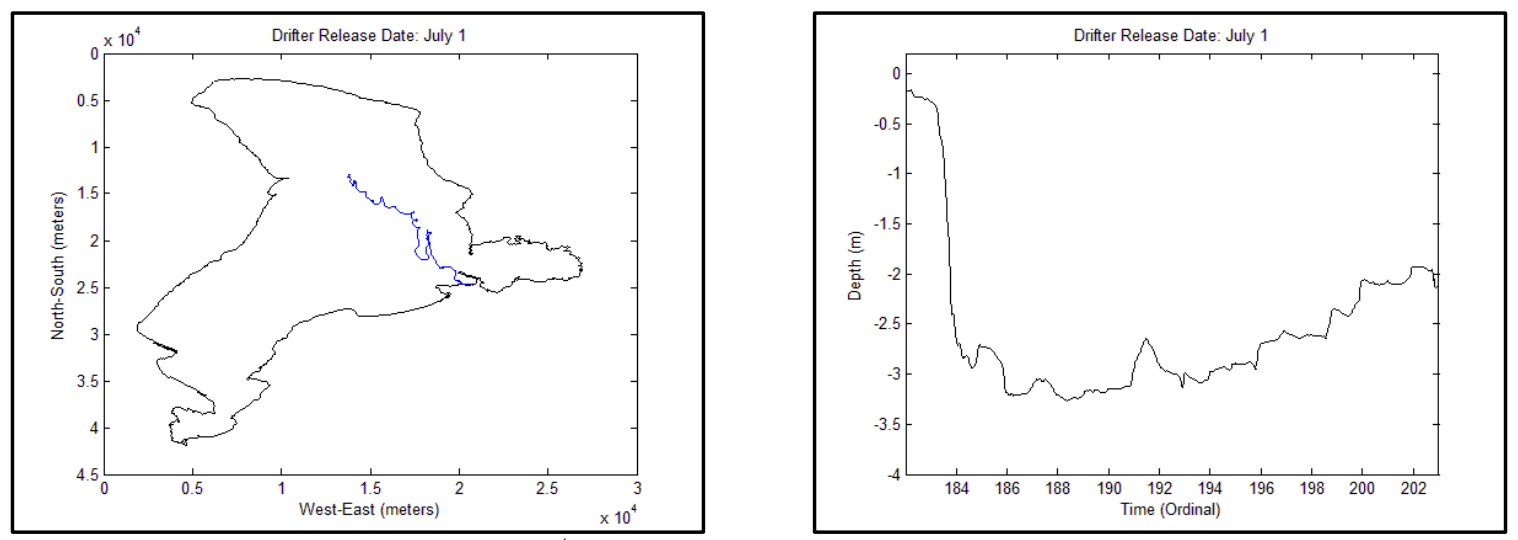

Figure B.11 Release date: July $1^{\text {st }}$. 